\title{
The Status of Women News Journalists in Lebanese Television: A Field-Gender Approach
}

by

Christy Mady

A thesis submitted to the Faculty of Graduate and Postdoctoral Affairs in partial fulfillment of the requirements for the degree of

Doctor of Philosophy

in

Communication

Carleton University

Ottawa, Ontario

(C) 2015

Christy Mady 


\section{Abstract \\ The Status of Women News Journalists in Lebanese Television: A Field-Gender Approach}

This dissertation examines the status of women in the Lebanese television newsroom using the field theory proposed by Bourdieu, gender theory in relation to journalism studies and the concept of the glass ceiling. Women's newsroom positions, field accomplishments, social and educational capitals, as well as the obstacles they face, are studied alongside the effect of their religious and political affiliation and their strategies of struggle. Utilizing a qualitative research design, individual in-depth interviews were conducted in the fall of 2014. Respondents included 27 newsroom workers, 18 of whom were females and 9 of whom were males chosen from Lebanon's nine official television stations, thereby comprising 2 females and 1 male from each television station. The gendered distribution of the respondents ensured the inclusion of both the male and female perspectives of the newsroom environment. The findings were thematically divided under cultural and social capitals, gendered news division, age and appearance, the glass ceiling, obstacles and advancement strategies. The findings revealed the Lebanese television newsroom as a field that juggles inter-state and intra-state rivalries which are part of the television's politico-sectarian identity. Journalists in this field deal with its politico-sectarian complexities as well as inter-newsroom gendered interaction, subject to socio-cultural influences. This study showed that respondents' career paths are affected in fluid ways by a number of characteristics that intersect with the politicosectarian nature of the Lebanese television and gender. These characteristics, which include age, appearance, parenthood, political and religious affiliations, shape the respondents' experiences and offer them ways to comply with or resist the dominant 
newsroom culture. Women, who seem to bear the weight of these characteristics more than men, have managed to prove themselves in the Lebanese television newsroom. They occupy senior management positions and have established parity in pay and in news coverage. Though they are still a minority in top management positions and in governance, women have re-shaped the newsroom environment inviting us to reconceptualize established gendered news divisions and forms of gendered interaction and struggle. Yet women in the Lebanese television newsroom have a long way to go- their reach into the upper echelons of media management is conditioned by their political participation in a country where the media are an extension of the politico-sectarian governing body, in which women are still a minority. 


\section{Acknowledgements}

I launched myself on an adventure and luckily, I did not travel alone. This fabulous adventure of the mind was a true challenge that kept me wondering about my internal capacities and my ability to make the best out of every moment. I am happy I did it. I have completed my dissertation and I am very grateful for all those who supported me along the way.

I was blessed with an exceptional supervisory committee - my heartfelt thanks to all of them. My gratitude goes first to my supervisor Dr. Karim H. Karim for his continuous support, patience and guidance throughout my doctoral study. I am indebted to Dr. Mahmoud Eid for his valuable feedback and for challenging me into unleashing the study's full potential. I also thank Dr. Barbara Freeman whose insightful comments and observations guided me through new ways of seeing.

I am truly grateful to my external examiner, Dr. Naomi Sakr, whose suggestions push the boundaries of the thesis into a bigger and greater work. It was an honor having a prominent scholar on Arab media assess my dissertation and question me about my work. Thanks also goes to the internal examiner, Dr. Doris Buss for her useful feedback and contribution to the thesis.

My family and friends have been instrumental throughout what proved to be a wonderfully tedious and enjoyable journey. I am very thankful to my husband, Gilbert, for being highly supportive and encouraging- for reading, editing, and discussing my work, with me tirelessly. Thank you for not letting me give-up and for being there every step of the way. I am thankful to my children, Halle and Sean, who lovingly understood that I had to work on my $\mathrm{PhD}$ and constantly pushed me into completing it with their 
never ending question - "Mommy, when will you finish your studies?" You have always been and will always be my inspiration and joy. I love you always "avelo" and I am so blessed with your presence, your beauty and your love. Thanks to my sister, Carol, for her last minute reads and uplifting words and for my brothers and father for their moral support. But mostly thanks to my mother, Rose, who has always pushed me into doing more than I thought I could do.

I feel fortunate to be surrounded by many friends whose constant encouragement and understanding kept me determined. You know yourselves - thanks to all of you! And Johnny, you make me feel especially blessed- thank you for your smart words and for seeing me through my crazy moments, for your sound advice and for having more confidence in me than I had in myself. I am just too lucky and too loved!

I dedicate this thesis to you, Dr. Boulos Sarru' - wish you were here to read it! 


\section{Table of Contents}

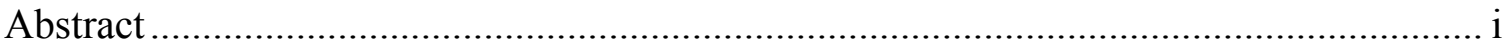

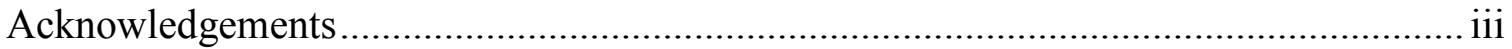

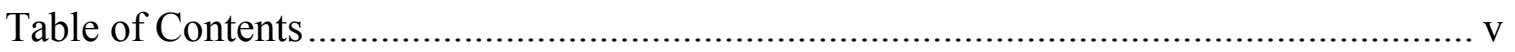

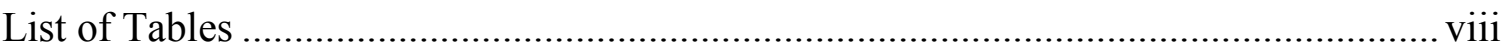

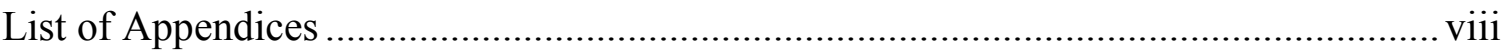

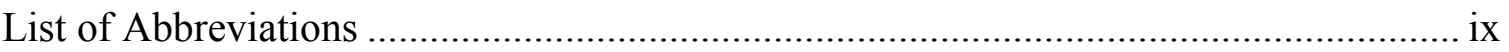

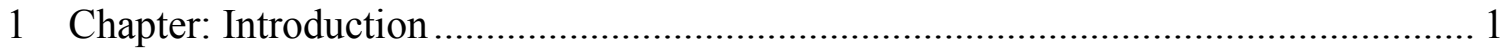

$1.1 \quad$ Status of Women News Journalists.............................................................. 3

1.2 Research Problematic and Purpose …………............................................... 7

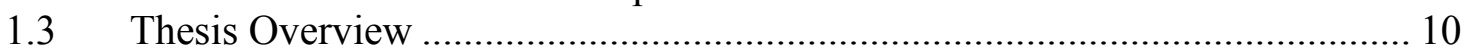

2 Chapter: The Lebanese Media Scene.................................................................. 13

2.1 Lebanon: Confessional Democracy, Confessional Media ................................. 13

2.2 The Lebanese Media System: Categorization and Financing ........................... 23

2.3 Media Regulation: Law and Violations ......................................................... 30

2.4 Press and Broadcast Journalists: Bodies and Representation .......................... 34

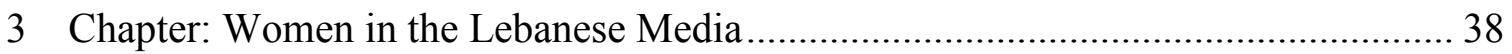

3.1 The Media Workplace: Competencies and Constraints ...................................... 41

3.2 Women, Labor Policy and Media Policy ………………………………....... 53

3.3 Images of Women in the Media: Empowerment and Disempowerment .......... 58

3.4 Lebanese Television: Male Dominated but Women Populated?........................ 66

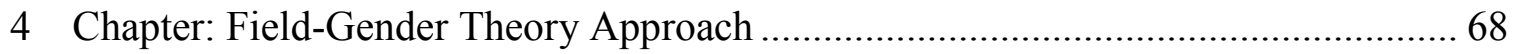

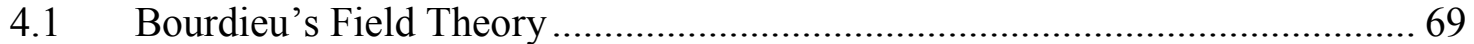

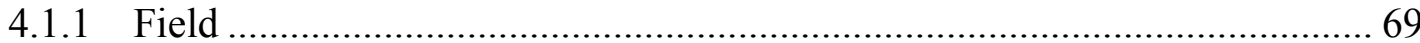

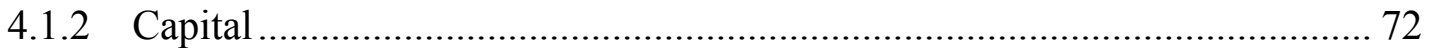

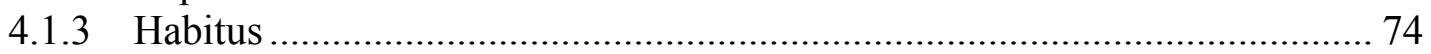

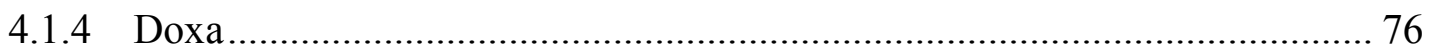

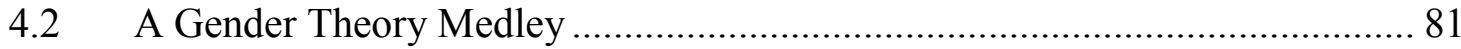

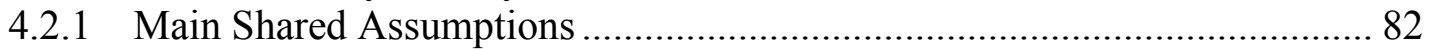

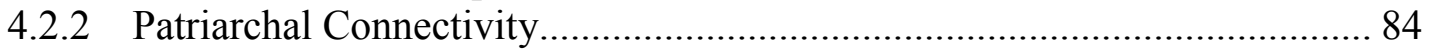

4.3 Women in the Newsroom: Scholars Shared Findings .................................... 88

4.3.1 Gender: Soft and Hard News .................................................................. 89

4.3.2 Minding the Context ............................................................................... 91

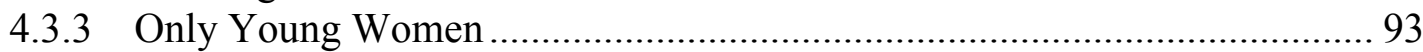

4.3.4 Women Journalists: Critical Mass and Content........................................... 94

4.3.5 The Newsroom: Sexual Harassment and Old Boys' Club ............................. 97

4.3.6 Women's Newsroom Strategies................................................................ 98

4.4 The Concept of the Glass Ceiling ……….................................................. 100

4.5 Bringing It All Together: Bourdieu's Logic of Practice and Gender .............. 101

5 Chapter: Research Methodology........................................................................ 104 


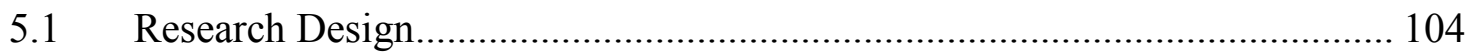

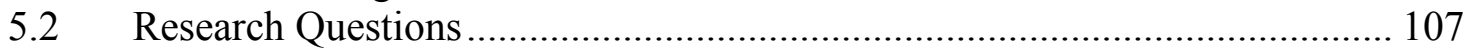

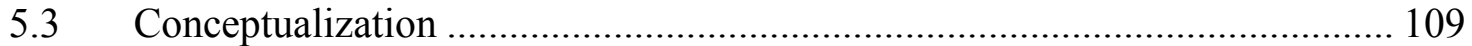

5.3.1 Field, Cultural Capital and Social Capital ................................................ 109

5.3.2 Religious Beliefs and Political Affiliation ................................................. 110

5.3.3 Gender Contextualized....................................................................... 111

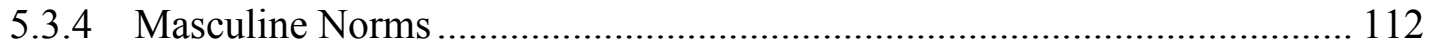

5.3.5 Sexual Harassment and Old Boys' Club..................................................... 113

5.3.6 Newsroom Strategies .............................................................................. 114

5.3.7 Progression and Management Positions ……………………………....... 115

5.4 Context and Composition of Lebanese Television Stations ……………........ 116

5.5 Data Collection and Analysis................................................................ 123

5.5.1 Research Method: In-depth Interviews ..................................................... 123

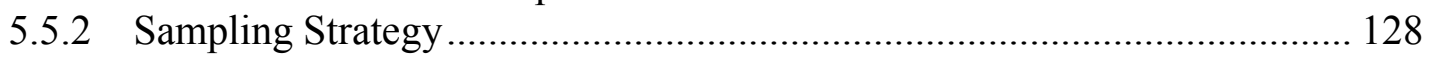

5.5.3 Approaching the Research Participants ................................................... 131

5.5.4 Interview Process and Challenges .......................................................... 134

5.5.5 The Researcher - Participant Relationship ……….................................... 138

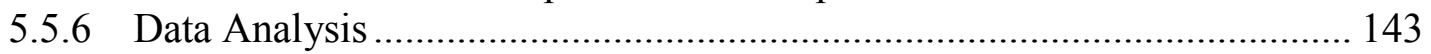

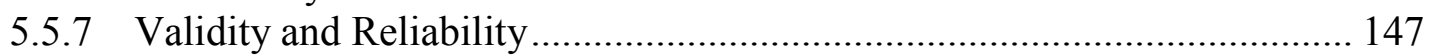

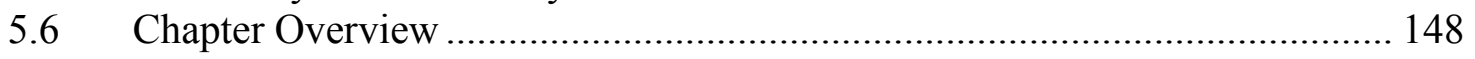

6 Chapter: Uncovering the In-Depth Interviews: Ties, Coverage and Appearance .... 150

6.1 The Significance of Cultural Capital ………………...................................... 151

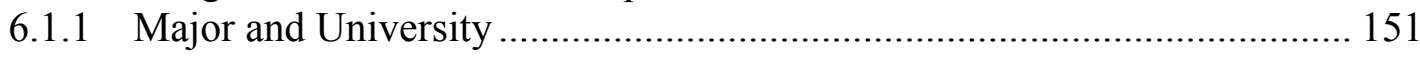

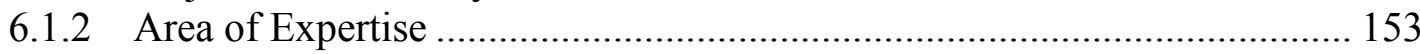

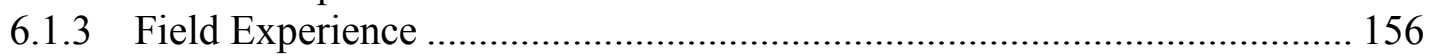

6.2 Social Ties and Patriarchal Connectivity ..................................................... 159

6.2.1 Social and Familial Ties (12 respondents- 3Ms \& 9Fs) ............................. 160

6.2.2 Social and Familial Ties as Effective (9 respondents -2Ms \& 7Fs) ........... 161

6.2.3 Social and Familial Ties as Inconsequential ............................................... 162

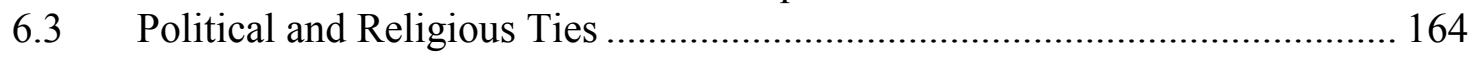

6.3.1 Political Affiliation as Inconsequential...................................................... 164

6.3.2 Political Affiliation as Effective ............................................................ 167

6.3.3 Religious Affiliation as Inconsequential.................................................. 169

6.3.4 Religious Affiliation as Effective ……………..................................... 172

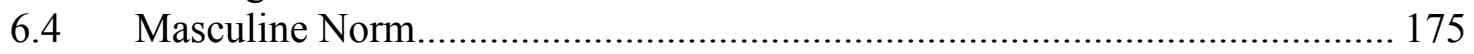

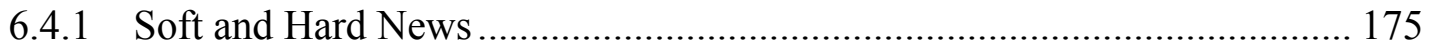

6.4.2 Appreciation of Professional Women ........................................................ 180

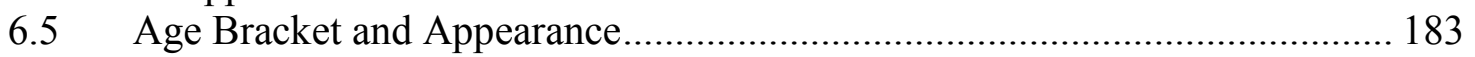

6.5.1 Newsroom Age Bracket Gender Sensitive ……………............................. 184

6.5.2 Age Limit for Female Anchors ............................................................. 186

6.5.3 Age Limit for Male Anchors................................................................... 189

6.5.4 Dissatisfaction with Age Limit .............................................................. 190

6.5.5 Appearance: A Gender Sensitive Issue ..................................................... 192

7 Chapter: Findings from In-Depth Interviews: Management, Obstacles and

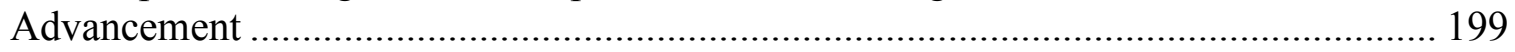

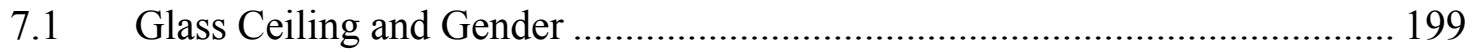




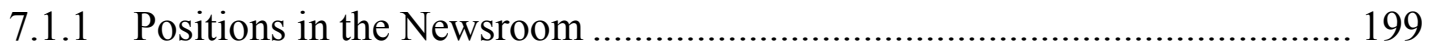

7.1.2 Management Opportunities for Women ..................................................... 201

7.1.3 Women's Presence in Management......................................................... 203

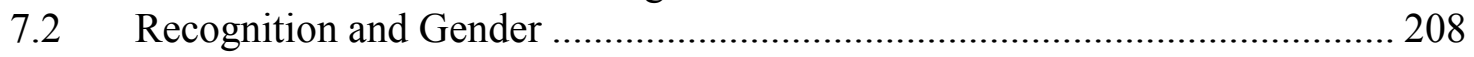

7.2.1 Moral and Financial Recognition........................................................... 208

7.2.2 Gender and Financial Recognition.......................................................... 210

7.3 Obstacles and Advancement Strategies ...................................................... 212

7.3.1 Obstacles to Women's Advancement (10 obstacles) ................................. 213

7.3.2 Compromises and Advancement ........................................................... 223

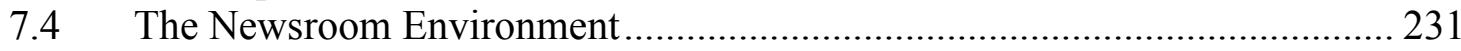

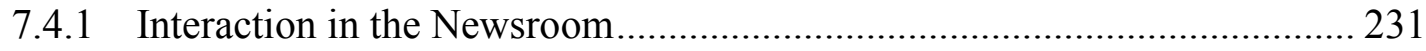

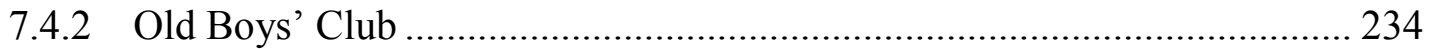

7.4.3 Dominant Presence of Women in the Newsroom...................................... 237

8 Chapter: In-Depth Analysis of the Lebanese Television Newsroom.......................... 244

8.1 Cultural Capital: Education and Experience ……………………………....... 244

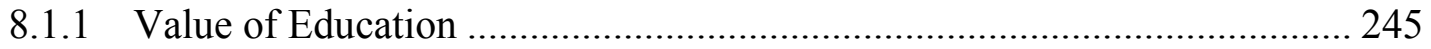

8.1.2 Value of Experience.............................................................................. 248

8.2 Social Capital: Familial/Social, Political, and Religious Connections ............ 252

8.2.1 Social Connections as Capital............................................................... 252

8.2.2 Political Affiliation as Capital ............................................................ 254

8.2.3 Religious Affiliation as Capital ........................................................... 256

8.3 Gender Divisions: Coverage, Age and Appearance ……………………...... 259

8.3.1 No More Hard or Soft News ................................................................ 260

8.3.2 Age for Men and Women Journalists ....................................................... 263

8.3.3 Appearance for Men and Women Journalists ............................................. 267

8.4 Glass Ceiling: Management, Recognition and Progression.............................. 271

8.4.1 Women in Newsroom Positions and Management.................................... 272

8.4.2 Parity in Insufficient Pay ........................................................................ 279

8.4.3 Impediments to Women's Advancement...................................................... 281

8.4.4 Compromise and Advancement ............................................................. 286

8.5 Newsroom Interaction: A Site for Negotiation .......................................... 288

8.5.1 New Boys' and Girls' Club.................................................................. 289

8.5.2 Culturally Bound Interaction ................................................................... 292

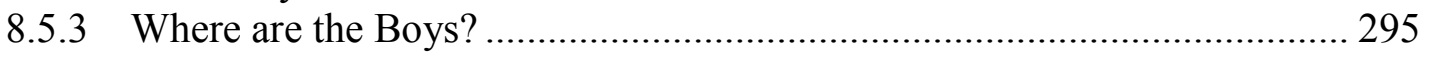

9 Chapter: Concluding Insights into the Lebanese Television Newsroom................... 297

9.1 Conceptual and Practical Reconsideration..................................................... 297

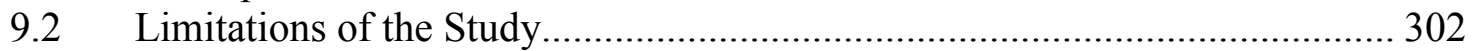

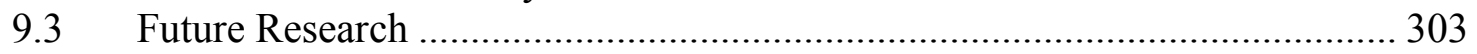

$9.4 \quad$ Brave Female Journalists .......................................................................... 305

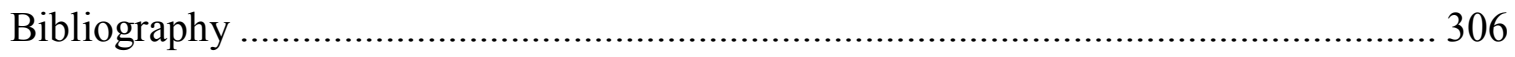

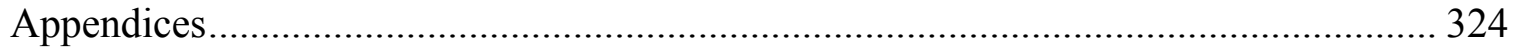




\section{List of Tables}

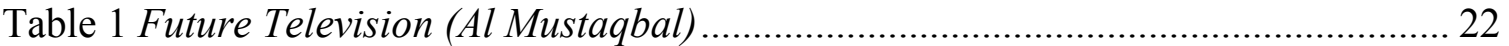

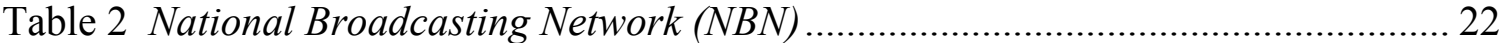

Table 3 Media Studies Students in Lebanon by Gender from 2001 to 2007.................... 42

Table 4 Gender-Related News Company Policies in Lebanon ....................................... 56

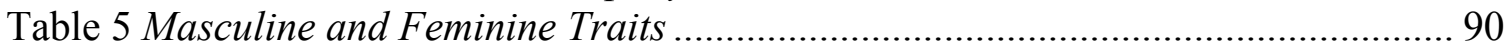

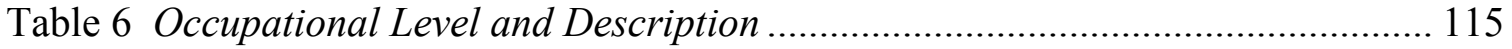

Table 7 Breakdown of Stations by Political Affiliation ............................................... 122

Table 8 Gender Distribution of Respondents............................................................. 129

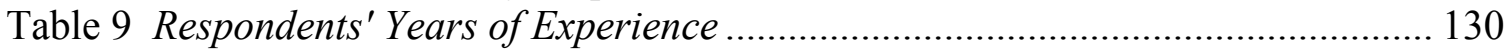

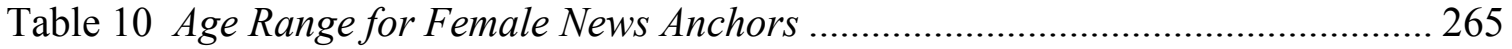

Table 11 Age Range for Male News Anchors ........................................................... 265

Table 12 Editor- in-Chiefs by Gender ....................................................................... 325

\section{List of Appendices}

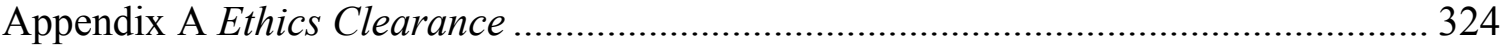

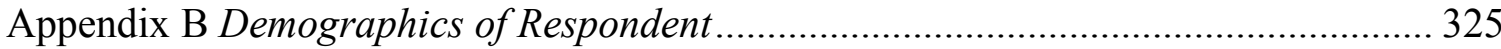

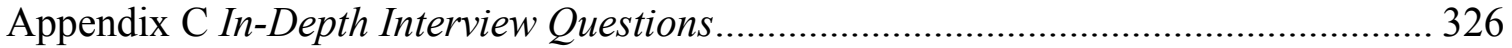

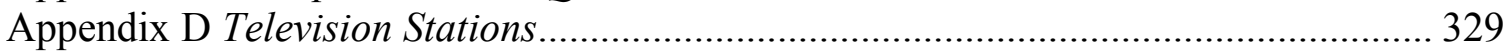




\section{List of Abbreviations}

$\begin{array}{ll}\text { ABC } & \text { American Broadcasting Corporation } \\ \text { ACHPR } & \text { African Commission on Human and Peoples' Rights and Social } \\ & \text { Commission for Western Asia } \\ \text { AUB } & \text { American University of Beirut } \\ \text { AVML } & \text { Audio Visual Media Law } \\ \text { CAQDAS } & \text { Computer Assisted Qualitative Data Analysis Software } \\ \text { CEDAW } & \text { Convention on the Elimination of All Types of Discrimination against } \\ & \text { Women } \\ \text { CEO } & \text { Chief Executive Officer } \\ \text { CFO } & \text { Chief Financial Officer } \\ \text { CLT } & \text { Compagnie Libanaise de Television } \\ \text { CNN } & \text { Cable News Network } \\ \text { DG } & \text { Director General } \\ \text { ESCWA } & \text { United Nations Economic and Social Commission for Western Asia } \\ \text { FPM } & \text { Free Patriotic Movement } \\ \text { FTV } & \text { Future Television } \\ \text { GMMP } & \text { Global Media Monitoring Project } \\ \text { HRW } & \text { Human Rights Watch } \\ \text { ICAN } & \text { International Civil Society Action Network } \\ \text { ISIL } & \text { Islamic State of Iraq and the Levant } \\ \text { IWMF } & \text { International Women's Media Foundation } \\ \text { LAU } & \text { Lebanese American University } \\ \text { LBCI } & \text { Lebanese Broadcasting Corporation International } \\ \text { LF } & \text { Lebanese Forces } \\ \text { LU } & \text { Lebanese University } \\ \text { LJU } & \text { Lebanese Journalists' Union } \\ \text { MDG } & \text { Millennium Development Goals } \\ \text { MP } & \text { Member of Parliament } \\ \text { MSI } & \text { Media Sustainability Index } \\ \text { MTV } & \text { Murr Television } \\ \text { NAC } & \text { National Council for Audiovisual Media } \\ \text { NBN } & \text { National Broadcasting Network } \\ \text { NDU } & \text { Notre Dame University - Louaize } \\ \text { NOW } & \text { National Organization of Women } \\ \text { OAS } & \text { Organizational of American States } \\ \text { OSCE } & \text { Organization for Security and Cooperation in Europe } \\ \text { OTV } & \text { Orange Television } \\ \text { POGAR } & \text { Program on Governance in the Arab Region } \\ \text { QSR } & \text { QSR International } \\ \text { TL } & \text { Tele Liban } \\ \text { USEK } & \text { Universite Saint Esprit de Kaslik } \\ & \\ & \end{array}$




\section{Chapter: Introduction}

Lebanon boasts one of the most free media systems in the Arab world (Freedom House, 2012). But it is also one of the most sophisticated. Lying at the intersection of political and sectarian forces, Lebanon's media are part of challenging interlinks that affect and are affected by inter-state and intrastate rivalries (Fandy, 2007). It is within this intricately interweaved media system that women must find their place while battling the prejudices of patriarchy and the particularities of a liberally conservative society where religion and politics are part and parcel of an individual's everyday identity.

Fortunately, there is no scarcity of women in media studies in Lebanon. In fact, they form the majority of media studies graduates (Melki, 2009). They also form around half of the staff of Lebanese television stations (Internews, 2009; Dabbous-Sensenig, 2000). Yet, despite their presence in the media in considerable numbers, the role they play in the Lebanese television newsrooms and in the decision making process in those newsrooms has been hardly examined. While competence gained through education and experience is a vital factor for career progression, it seems that it is not enough for women who often face a glass ceiling through confronting barriers that prevent them from advancing upwards in management (Bollinger \& O’Neill, 2008). This phenomenon is by no means unique to Lebanon. Scholarly studies document the underrepresentation of female journalists and news workers in top level management and policy setting positions in Western news organizations (Gallagher, 1995; Van Zoonen, 1998; De Bruin \& Ross, 2004; Mahtani, 2005; Meehan \& Riordan, 2002; Byerly \& Ross, 2004; Byerly \& Ross, 2006; Creedon \& Cramer, 2007; Bollinger \& O’Neill, 2008). Studies on Arab and Lebanese media mainly reveal that men outnumber women in news and the disparity 
rises when it comes to top level management positions (Byerly, 2011; Sakr, 2004; Abu Fadil, 2004 \& 2007; Melki, 2009; Haidar, 2007; Dabbous-Sensenig, 2000; Internews, 2009).

This dissertation provides a more in-depth look, not at the Lebanese media in general, but at the status of women in the Lebanese television newsroom, the complexities that govern their presence within the medium and the challenges they face within and outside the newsroom. Choosing Lebanon for this study on women is not without merit. Lebanon's liberal culture compared to nearby Gulf countries and its relatively free media landscape formulate an empowering environment for women. Women in Lebanon actively strive for their legal and civil rights. In 2001, for instance, women gained equal rights in terms of retirement and dismissal procedures and in 2002 equal insurance treatment under the National Social Security bylaws (Haidar, 2007). Women's rights movement and civil society groups recently managed to pass several laws including honor crime (Human Rights Watch, 2011) and domestic violence laws (Number 293) (HRW, 2014) and are advocating for an anti- sexual harassment law. Add to that, Lebanon's Labor Law (Number 267) was amended on April 15, 2014 to increase women's maternity leave from seven weeks to ten weeks (Article 28) during which women receive full pay and cannot be dismissed (Article 29). In effect, Lebanon's privileged liberality invites the supposition that it would be the one to guide steps towards equitable gender practices thus forming a well-warranted context for this study.

While there is a dearth of academic studies on women in Arab media, there is no paucity of research on women in news in other contexts. This chapter therefore starts with an overview of the status of female journalists in the news in the American states, 
Africa, Europe and Asia. It then provides a synopsis of the studies on women in the Arab media and the Lebanese media. The chapter explicitly states the research problematic and purpose and ends with an overview of the thesis.

\subsection{Status of Women News Journalists}

Surveying 522 news companies in 60 countries located in Asia, Australia, Europe and the Americas, through a 12-page questionnaire conducted and analyzed over a twoyear period, a 2011 global report on the Status of Women in News Media revealed that men occupy the majority of management jobs and news gathering positions. Women, according to the report, remain underrepresented not only in the news media but where they fit in the "decision-making or ownership structures of their companies" (International Women's Media Foundation, 2011, p. 11). The report uncovered that gender segregation in newsrooms persists in most countries surveyed especially in management and governance positions (IWMF, 2011).

Well aware of women's situation in the news room, international media organizations consider bolstering women's professional status in news journalism and more specifically in the decision-making positions as one of their main aims as they identify the cultural, organizational and economic factors that hinder women's progress while emphasizing the importance of women's agency in producing content (International Women's Media Foundation, 2011; Global Media Monitoring Project, 2010; Economic and Social Commission for Western Asia, 2011; United Nations Educational, Scientific and Cultural Organization, 2009).

Ever since it produced its first report in 1995, the Global Media Monitoring Project (GMMP), “the world's largest and longest-running longitudinal research and 
action initiative on gender in the news media" (GMMP, 2010, p.1), noticed a systematic exclusion of women's voices not only across different kinds of media, such as newspapers, television and radio, but also across the 180 countries that were part of the most recent study in 2011. By monitoring the news media for gender indicators over one single day (November 10, 2009), the report, written by Margaret Gallagher, an independent media researcher who investigates gender patterns, attributed women's exclusions to the "distinct economic and social relations of women and men, the gender relations that both determine and result from such positions and the gender-specific priorities that arise from these positions and relations" (Gallagher, cited in GMMP, 2010, p.iii).

Gender Links organization, based in Johannesburg, conducted two main gender studies on 14 South African countries --the first, on the status of women in the southern African region newsroom in 2005 and the second, a comprehensive quantitative audit of men and women in 126 media houses in 2008-- to conclude that women, who were outnumbered by men, often faced a glass ceiling when it came to senior management positions (Made\& Morna, 2010; Gender Links, 2009). The United Nations Special Rapporteur on Freedom of Opinion and Expression, including the Organization for Security and Cooperation in Europe (OSCE), the Organization of American States (OAS), and the African Commission on Human and Peoples' Rights (ACHPR) identify, in their 2010 declaration, the underrepresentation of historically marginalized groups, including women, among mainstream media workers and their unequal access to information and power as obstacles that impede the freedom of expression (LaRue, Haraszti, Botero \& Tlakula, 2010). 
In general, studies in the West have systematically documented the phenomenon of the male dominated media and the underrepresentation of women in upper media positions (Gallagher, 1995; Van Zoonen, 1998; De Bruin \& Ross, 2004; Mahtani, 2005; Meehan \& Riordan, 2002; Byerly \& Ross, 2004; Byerly \& Ross, 2006; Creedon \& Cramer, 2007; Bollinger \& O’Neill, 2008). Bollinger and O’Neill (2008) investigate the positions held by women in the major media conglomerates to emphasize that the phenomenon of the glass ceiling is still in place and it is taking women time to overcome the barriers to advance (p.8). The authors relied on employment data from the Bureau of Labor Statistics, the Equal Employment Opportunity Commission and the top Fortune 500 media companies to examine women's careers in newspapers, book publishing, magazines, television, radio and movies. In their book Gender and Newsroom Cultures, De Bruin and Ross (2004) emphasize that their edited volume does not deal with the number of women in the newsroom, but bring a feminist analysis to examine the changing dialectics of gender and newsroom culture. Their main concern is the interpretation of the behavior of the male and female journalist "in a culture where gender is a major "given"” (p.viii). Djerf-Pierre and Lofgren-Nilsson (2004) study the gender patterns of Swedish news organizations at three analytical levels: the structural or sextyping task distribution, the symbolic or gender notions and symbols and the relational in terms of the relation between men and women within the news organization. Their research, based on historical analysis of women reporters in television and a quantitative analysis of 7,700 news stories collected from 4 television stations from 1958 to 2000, shows an increase in the number of female reporters and editors, but the space for women in news during the 1990 s and 2000 remained at 30\%. Interestingly Djerf-Pierre and 
Lofgren-Nilsson (2004) condemn media studies as being too media-centric and invite them to study status, prestige and power in society to fully understand the gendered nature of the news. Examining the status of women in journalism and mass communication professions in the United States, Pamela Creedon documented female exclusion from the news and decision making positions in three book editions written by global media and gender scholars (Creedon, 1989; Creedon, 1993; Creedon \& Cramer, 2007). All 24 scholars writing on the last volume agreed that "transformative change has not happened. Where change had taken place, it had occurred in baby steps" (Creedon \& Cramer, 2007, p.6).

The reports and studies issued for the American states, Europe and Africa echo, more or less, the same concerns that women have in Asia. While many studies on women and media are done in Europe and the United States, "the same cannot be said for the developing world" (Sakr 2004, p.6). Yet two studies initiated by the United Nations will help draw a clear picture of women's status in Arab media. The United Nations Committee on Women of the Economic and Social Commission for Western Asia (ESCWA) in its fifth session held in Beirut in December 2011 emphasized the importance of increasing women's participation in decision making in all areas of public life. Countries attending the session included Bahrain, Egypt, Iraq, Jordan, Kuwait, Lebanon, Morocco, Oman, Palestine, Qatar, Saudi, Sudan, Syria and Yemen (not a member of ESCWA). Put together by the United Nations Development Program, the Arab Human Rights Development Report 2005 entitled Towards the Rise of Women in the Arab World documents the increase in the number of women employed by the broadcast and print media but mentions that "women play no role in planning media 
policy or making media decisions." The report questions the extent to which the presence of Arab women in the media positively influences the programming and women's images.

\subsection{Research Problematic and Purpose}

Although Lebanon boasts one of the most free and most sophisticated media landscapes in the Arab region (Freedom House, 2012; Pies, Madanat \& El Saeber, 2011; Abu Fadil, 2007; International Press Institute, 2006), women in Lebanese media are still minorities in the higher echelons of power and, more importantly for this study in the male-dominated news room. Research on journalists and statistical data in Lebanon is not readily available and updated. Lebanon does not have a central organization that regularly gathers and updates information on journalists or media personnel. Nonetheless, women's presence in the media newsroom is somewhat documented. A 2009 Internews report, developed by the European Journalism Center, revealed that among the 55 Lebanese media institutions surveyed, women formed over half of the staff in $45 \%$ of all media institutions, especially broadcast media. Yet, few women were admitted or given access to the area of political journalism, which remains male-dominated. Studying the status of female journalists in seven Lebanese news companies, the IWMF 2011 report revealed that men outnumbered women by a ratio of more than 2:1. "Particularly noticeable," the report revealed, "is women's severe under-representation in governance and top-level management levels.” Magda Abu Fadil (2007), Director of Journalism Training Program at the American University of Beirut, and a prominent news journalist, laments the fact that Lebanese "women journalists remain trapped under the corporate glass ceiling of their media institutions." According to Abu Fadil (2007), women have 
only been able to overcome the glass ceiling through familial or kinship relationships but essentially remain a minority in senior managerial and editorial positions.

The under-representation of women in power positions in the Arab media is also a recurring topic in academic discourse (Sakr, 2004; Abu Fadil, 2004 \& 2007; Melki, 2009; Haidar, 2007; Dabbous-Sensenig, 2000; Internews, 2009). However, the majority of these studies concentrate either on general statistical data regarding women in power positions in television stations, or on very specific cases dealing with biographical profiles of individual female journalists. Neither approach, establishes a connection between media organizations' existent organizational cultures and women's advancement. In fact, no empirical studies exist on women's place in the Lebanese television newsroom; nor are there studies that systematically describe the relationship of men and women within Lebanese media institutions. More importantly, the studies do not discuss whether women's career progression is contingent upon, or affected by, their religious and political affiliations in a media environment defined by politico-sectarian divisions. In effect, none of these studies investigate whether women remain under-represented across all management positions, particularly in the Lebanese television newsroom.

This dissertation attempts to bridge these gaps in the scholarly literature through an in-depth analysis of the Lebanese media environment and the potential it bears for women's career advancement by examining the status of women in the Lebanese television newsroom using Bourdieu's field theory, gender theory in relation to field of journalism and the concept of the glass ceiling.

The first aim of the thesis is to identify how the different forms of cultural and social capital affect female journalists' employment and progression in the Lebanese 
television newsroom which exists within and is affected by the politico-sectarian divisions of the country. Capital, which Bourdieu (1984) defines as the set of usable sources and powers, determines the positions that journalists occupy in the field. Cultural capital will be explored through education and experience, while social capital will be explored through social, religious and political connections. Social capital is strongly tied to the theoretical concept of connectivity, which is proposed by Suad Joseph (1999), to identify how kinship and social ties in Middle Eastern society function as short cuts into various entitlements including employment and advancement.

The second aim is to explore female journalists' positions within the Lebanese television newsroom. The newsroom is an arena of continued power struggle where male and female journalists vie for the different forms of capital. In this arena, status is largely determined by the internal workings of the newsroom and the external cultural, political, social and religious influences. It is ever changing and continuously subject to negotiation. The focus of this study is not only on women's presence or lack thereof in top management positions; this study looks at the other positions that women occupy in the newsroom and the extent to which women have progressed in terms of these positions, their decision making power and their pay. The status of women in the newsroom is also explored through the areas of news coverage, career longevity as well as advancement strategies and management roles, using Bourdieu's field lens and the concepts of gender theory.

To investigate the status of women in the Lebanese television newsroom, Lebanon's nine officially recognized television stations will be included in the study. Indepth interviews with 2 females and 1 male from every television station will be 
conducted. The total number of interviews is 27 . Taking the opinion of both males and females helped generate an idea of the newsroom environment from both perspectives. Limiting the study to the opinion of one gender would have been restrictive since males and females may have differing opinions with regards to the same situation.

\subsection{Thesis Overview}

The thesis examines the social, cultural, legal and media contexts of the Lebanese environment. Locating women newsroom workers within this environment is vital for a thorough and comprehensive understanding of their status in the Lebanese television newsroom. Guided by Bourdieu's field theory and the concept of the glass ceiling, the thesis also uses the concepts of a gender theory mix, combining Eastern and Western perspectives of gender. Effectively, concepts such as masculine norms and patriarchal

connectivity from gender theory find their continuity in Bourdieu's masculine-feminine divisions and social capital. As the two theories combine, a profound understanding of the workings of the Lebanese television newsroom is generated. The findings reveal a newsroom whose politico-sectarian adaptive measures have infiltrated the professional identities of its journalists. Women equipped with the necessary academic qualifications and field expertise, learn and master the newsroom game to cover all types of news, reach senior management positions and compete in what has been dubbed as a male terrain. Juggling home duties, the dictates of patriarchy and socio-cultural standard of appearance and aging, women carry a heavier burden than men in the field. The parity in pay and duties that women news workers have established with men are advancement strides that invite us to question the reasons behind men's minority status in the Lebanese television newsroom and whether the newsroom and the media field, in general, has become too 
feminine for men. Women's strides in the Lebanese newsroom are not to be undermined. Though the women maintain a shy presence in top management positions, their involvement in the day to day decisions of the television newsroom and their occupation of senior management positions is a proof of their resilience and their capabilities, not simply to endure, but also to advance.

The thesis is structured in consistence with the above mentioned aims. It is divided into nine chapters. The introduction provides an overview of the status of women in the news in Western, African, and Arab countries. It identifies the purpose as well as the structure of the thesis.

The second and third chapters entitled the Lebanese Media Scene and Women in Lebanese Media delve into details about the Lebanese socio-political, legal and media contexts to locate women journalists within those contexts. The chapters also survey the relevant research dealing with women in the area of news journalism in Western and Arab studies as well as studies on Lebanon. The scholarly findings in the field of Lebanese news provide a platform of conceptual foundations that can be negotiated through the current study.

The study of women in the Lebanese television newsroom is done through the theoretical lens of Bourdieu's field theory as well as gender theory, both of which are discussed in chapter four. The main concepts from both theories are used to explore women's status in the Lebanese television newsroom. The concept of glass ceiling uncovers whether or not women suffer from obstacles to career advancement and the advancement points at which their career reaches a standstill. 
Chapter five discusses the research methodology detailing the research design, research questions, conceptualization, as well as methods of data collection and data analysis.

Chapters six and seven discuss the findings gathered from the in-depth interviews. The main concepts generated from the theoretical frameworks and discussed in the methodology chapter form the themes uncovered in the two findings chapters. Chapter six relates and engages the themes of cultural and social ties, news coverage and appearance. Chapter seven discusses the themes of glass ceiling, financial recognition, advancement and the newsroom environment.

An analysis of the findings is presented in chapter eight, where the research threads are pulled together in thematic discussions. The analysis situates the results in relation to the current research uncovered in chapters two and three. It also explores the findings within the conceptual foundations of the theoretical frameworks discussed in chapter four. The newsroom becomes a site of negotiation of the many capitals that interact within it and outside it. Female journalists seem to be faring better in today's newsroom where the prospects of the advancement are more promising.

The ninth chapter briefly engages the important contributions of the study extending an invitation for the reconsideration of a number of theoretical foundations negated by the findings. The study's limitations are described opening the leeway for an exploration of future research opportunities and endeavors. 


\section{Chapter: The Lebanese Media Scene}

Lebanon is home to nine national television stations including the one public broadcaster, Tele Liban. The commercial television stations are the Lebanese Broadcasting Corporation International (LBCI), Future Television (FTV), Al-Manar, Al Jadeed (or New TV), the National Broadcasting Network (NBN), Orange Television (OTV), and Murr Television (MTV). Tele Lumiere, a Christian religious station, is not licensed yet it operates with tacit government approval.

Understanding the many factors that influence women's status within the Lebanese television entails an understanding of the context that governs those media organizations. The literature review chapter will therefore be divided into two sections: the first describes the Lebanese media scene and the second deals with a review of the scholarly literature on women in the media. The Lebanese media scene covers the historical development of the Lebanese television, its politico-sectarian nature, the implications of its ownership structure and the law governing audio-visual media in Lebanon. The second section describes women's participation in the Lebanese workforce and more specifically in media, the role women play in Lebanese television, and the gender policy in work and the ramifications it has on women working in the media.

\subsection{Lebanon: Confessional Democracy, Confessional Media}

Since its beginnings the Lebanese media have been swayed by the interplay of local and regional, political, religious and financial factors. They are a microcosm of the larger national, political, and often times regional, divides that are rooted in the political and religious factions of the country. 
The Republic of Lebanon is composed of a patchwork of communities residing together in a total area of 4,105 square miles or 10,450 square kilometers. The country was established as an administrative entity after the end of the World War I, upon the collapse of the Ottoman Empire (1516-1918). In 1918, it came under the French mandate which expanded the area of Mount Lebanon, mostly populated by Maronite Catholics and Druze, into Greater Lebanon to include a larger Muslim population. The first Lebanese constitution, passed in 1926, declared Lebanon a democracy but also adopted the Ottoman millet system whereby each religious community would continue to be governed by its own religious and communal structure. Seats in the first parliament, distributed on confessional basis, were mostly occupied by the Christian elite.

By 1943, when Lebanon gained its independence, confessionalism was fully developed. A National Pact distributed government positions according to the religious composition of the country as recorded in the 1932 census, the last official census taken in Lebanon. It was decreed that the President of the republic would be a Christian Maronite, the Prime Minister a Muslim Sunni and the Speaker of the House a Muslim Shiite. This confessional system extends to all political and parliamentary appointments, thereby guaranteeing a fixed number of seats to the 18 officially recognized religious sects of the country, 4 of which are Muslim, 12 are Christian, 1 is Druze and 1 is Jewish. The main branches of Islam practiced in Lebanon are the Shia and Sunni, followed by the minority Alawites and Ismai'li. The largest Christian group is the Maronite group, affiliated with the Catholic Church, followed by the Greek Orthodox and Greek Catholics. Other Christian groups include Armenian Orthodox (Gregorians), Armenian Catholics, Syriac Orthodox (Jacobites), Syriac Catholics, Assyrians (Nestorians), 
Chaldeans, Copts, Evangelicals (including Protestant groups such as the Baptists and Seventh-day Adventists), and Latins (Roman Catholic).

The mosaic of confessions that make up the political body of the country permeates the country's economic, social and media structures. Confessional communities control judiciary matters, as well, and personal status looms large in such affairs; they also often control schools, universities, youth groups, cultural and religious associations, and charities (Labaki, 1988). As we will see, they control the media too.

From its independence until 1975, Lebanon progressed well under the confessional system of government. Its political stability led to economic prosperity. Beirut became the banking and commercial center of the Middle East (Dajani, 1979). Samir Kassir (2010), a prominent Lebanese journalist, describes the importance of Beirut in the region then as a university seat, a medical center, a transit port and an airline hub and as the capital of Arab publishing and journalism. At that time, the peaceful existence of the diverse confessional groups led to the creation of a relatively free and independent press, as each religious and political group developed its own publications. Limited only by the laws of libel, the press offered a broad range of political opinions without fear of persecution or censorship. The press did not rely on advertising or circulation for their financial revenue, however, but on foreign, mainly Arab, sponsorship (Dajani, 1979; Kraidy, 1999; Rugh, 2004) - a trend that is still visible in the wide spectrum of Lebanese media today. The press laws adopted in 1948, 1952 and 1962 helped journalists develop unions and set professional standards (Internews, 2003). The Press Law of 1962, still in effect, guarantees the freedom of the press but prohibits the publication of news that endangers national security or attacks head of states (article 75), with sanctions that range 
from financial penalties to imprisonment. The restrictions were relatively mild and the Lebanese press interpreted the laws liberally (Dajani, 1979; Kraidy, 1998; Rugh, 2004). Broadcasting in Lebanon got off to a tenuous start with only one radio and one television station. In sharp contrast, before the outbreak of the civil war, there were around 99 licensed political publications, over 300 non-political publications (Dajani, 1979 ) as well as twenty weekly and twenty-five political daily newspapers (Kraidy, 1999). Lebanon's first radio station was established in 1938 under the French mandate. The station was transferred to the Lebanese government in 1946 (Dajani, 1979; Rugh, 2004). Radio Lebanon remained the country's sole radio station until the state monopoly of radio broadcasting came to an abrupt end with the start of the Lebanese Civil War in 1975 (Internews, 2003). Owned by two Lebanese entrepreneurs, with some French shares (Boyd, 1988; Rugh, 2004), Lebanon's first television station, La Compagnie Libanaise de Television (CLT), was the first private commercial television station in the Arab world. It started broadcasting in 1956. The second commercial television station, Compagnie de Television du Liban et du Proche-Orient (Tele Orient), started broadcasting in 1962. It was partially financed by the American Broadcasting Corporation (ABC) in the United States (Boyd, 1988; Kraidy, 1999). The government agreements with the first television stations prohibited programs that would "threaten public security, morals, religious groups or enhance the image of any political personality or party" (Dajani, 2001, p.2). All news programs and official bulletins were issued by the Ministry of Information. In 1976, one year into the Civil War, the stations were occupied by the warring Lebanese militias. The station in West Beirut, CLT, became the mouthpiece of the nationalist movement, mostly Muslim, while the one in East Beirut, Tele Orient, was in the hands of the 
Lebanese Forces, mostly Christian. "The split of the broadcast media also marked a serious escalation in the war. Broadcasting installations became targets for the warring groups" (Dajani, 2001, p.3) as they belonged and were in the hands of the opposing religious (Muslim vs. Christians) and political factions. Weakened by the war and grave reduction of advertising revenue, the stations called for government intervention and were merged by a government decree in 1977 to form Tele-Liban, a half private, half state-owned company (Dajani, 1979; Kraidy, 1999; Internews, 2003), with the private shares held by the Rizk brothers - wealthy Lebanese businessmen - and SOFIRAD, a French government corporation (Boyd, 1999). Tele-Liban was given a monopoly over television broadcasting in Lebanon until 2012.

During the early civil war years, Lebanese broadcast media came under government censorship (Dajani, 1979; Kraidy \& Khalil, 2009). The media were asked not to reflect the civil and inter-religious strife taking place in the country. Government censorship was also reinforced by the Arab Deterrent Force, which entered Lebanon in 1976 in hope of stabilizing the country (Rugh, 2004). The force was mostly composed of Syrian military units, which ended up staying until 2005. Their control over the country's politics and media remained visible throughout their stay in Lebanon.

The government's monopoly over broadcasting and news did not last long. It became ineffective as a plethora of television stations appeared on the Lebanese media scene during the Civil War between 1975 and 1990. The warring parties took advantage of the government's deteriorating power to operate their own media outlets. As a result, there were around 54 television stations operating in Lebanon, 17 of which aired their programs in the greater Beirut region (Boulos, 1995). Most of the stations were small 
and served limited geographical regions (Boulos, 1995). Only a few remained on the national scene. The first illegal television station, and the most important one, was the Lebanese Broadcasting Corporation (LBC), launched by the Lebanese Forces (LF), a Christian militia, in 1985. Al Mashrek Television was launched by nationalist parties, opposed to the Lebanese Forces and the Phalangist Party, in 1989. In 1990, New TV, which currently goes under the name of Al Jadeed, was established by the Lebanese Communist Party. The station was later bought by Sunni businessman Tahseen Khayyat. All the Lebanese channels currently have satellite counterparts. LBC-Sat and Future International Sat were the first to begin satellite transmission in 1996.

The Lebanese media landscape remained chaotic throughout the Civil War which ended with the 1989 Agreement of National Reconciliation. The agreement, also known as the Taif Accord, after the Saudi city where the accord was signed by members of the Lebanese parliament, maintained the confessional system in a revised form (Faour, 2007). It revised the constitution to re-assign the Christian-Muslim representation from 6:5 to 5:5 in the executive and legislative branches of government. While the accord's ultimate aim was to abolish sectarianism, it ended up solidifying its existence. It stripped the Christian Maronite President of most powers and re-distributed those powers between the Sunni Prime Minister and the Shiite head of Parliament. This redistribution of control is reflective of the power relations among religious communities. As a result, Lebanon became effectively governed by three presidents, commonly known as the governing of the troika. Changes to policy became measured in scores of "losses" or "gains" of the Maronite, Sunni and Shiite sectarian communities (Ofeish, 1999). The struggle for power was reflected in the assignment of executive position in the public sector, ranging from 
assignments of deans in the only public university, the Lebanese University (LU) to the granting of licenses to television stations.

The Taif Accord put an end to the Lebanese Civil War but not to the presence of foreign forces on Lebanese land. Israel and Syria remained part of the Lebanese political equation. Israel withdrew its forces from south Lebanon after its confrontation with Hezbollah (literally the Party of God), dubbed Lebanon's Resistance Forces, in 2000. The assassination of Prime Minister Rafik Harriri in 2005 created a number of reactionary movements that led to the withdrawal of the Syrian forces from Lebanon and to the creation of political strife between two confessional movements: the March 8 Coalition led by Hezbollah, with Syrian and Iranian backing, and the March 14 Coalition led by previous Prime Minister Fouad Al Saniora (leading Harriri’s Al Mustaqbal or Future Movement) with Western and Saudi Arabian backing. The movements marked a reshuffling of relationships within the Lebanese confessional associations, as the Christians became divided between the two movements. General Michel Aoun's Free Patriotic Movement (FPM) forged an alliance with March 8 while the Lebanese Forces (LF) and the Lebanese Phalanges (Phalangists or Lebanese Kataeb Party) joined March 14. The stand-off between the two movements threatened the country with another civil war, but this prospect was put to an end during a meeting in Qatar in which an agreement between the movements was negotiated. The agreement led to the formation of a national unity government and the election of President Michel Suleiman in May 2008. President Suleiman's six-year tenure ended in May 2014 and since then till the writing of this thesis Lebanon has been suffering from a presidential vacuum due to a lack of quorum. 
All of this political strife and the subsequent settlements from the Taif Accord onwards were directly reflected in the composition of the media. To regain state control of the media by the end of the Civil War, the government introduced the 1994 Audio Visual Media Law (AVML). The AVML, the first Arab legislation that incorporated privately owned radio and television, was a response to the call for media regulation in the Taif Accord. It revoked the monopoly of the state broadcaster, Tele Liban, and gave the Council of Ministers the power to issue licenses. In 1996, the first licenses were given to television stations owned by politicians who represented the major sectarian divisions of the country. Out of the dozens of applicants, exactly 63 applications in the initial round, licenses were granted to four television stations, each affiliated to a specific religious sect and a prominent political leader representing that sect and has representation in the government or is himself part of the government. The Lebanese Broadcasting Corporation (LBC and now LBCI), previously affiliated with the Lebanese Forces is Catholic Maronite, Future TV is affiliated with the Future Party presided over by the late Prime Minister Rafik Al Harrir and is Muslim Sunni, Murr Television (MTV) is affiliated with Michel Murr, then Minister of Interior, and is Greek Orthodox, while the National Broadcasting Network (NBN) is affiliated with Al Amal Party, presided over by head of parliament, Nabih Berri, and is Muslim Shiite. Other television stations that were eventually licensed include Al Manar (Shiite and affiliated with Hezbollah) in 1996, New TV (leftist- Sunni) in 1999, and Orange TV (Christian and affiliated with the Free Patriotic Movement) in 2007. Tele Lumiere, a Christian religious channel, operates, until this day, without a license and is seen to provide religious balance to Al Manar. 
The Audio-Visual Media Law also led to the creation of the National AudioVisual Media Council (article 17). The council consists of ten members selected along confessional lines, half by the Parliament and half by the Cabinet (article 18); the members are elected for 3 years, with the possibility of renewal (article 20). In reporting to the Minister of Information, the Council's main role is advisory. It reviews license applications, verifies that the applications meet the requirements of the law, advises the Cabinet whether to accept or reject a license and monitors broadcasting (article 19; Internews, 2003; Dabbous-Sensenig, 2007). The licenses, like the Press Law of 1962, were divided, in accordance with article 10, into political (Category 1) and non-political licenses (Category 2), thereby creating two categories of radio and television stations those that can broadcast political programs and those that cannot. The law placed the main power of the control in the hands of the Minister of Information, who now had the right to audit all financial records, since stations are not allowed to operate in deficit for a protracted period (Kraidy \& Khalil, 2009; article 8 of AVML 1994).

Under the law article number 13, no individual or family member (entity) can own, directly or indirectly, more than a $10 \%$ share in a television company and licenses can only be given to Lebanese joint stock companies, owned by Lebanese nationals, who are not allowed to hold stock in more than one broadcasting company . The husband, wife and all direct relatives are considered one entity. Fandy (2007) manages to list some of the shareholders of Future Television and of NBN to reveal that they mostly belong to close family members: 
Table 1

Future Television (Al Mustaqbal)

\begin{tabular}{lll}
\hline Name of shareholder & Relationship to Rafik Al Harriri & Percent share \\
\hline Nazik Harriri & Wife & $10 \%$ \\
Bahya Harriri & Sister & $10 \%$ \\
Saadeddin Harriri & Son & $8 \%$ \\
Bahaeddin Harriri & Son & $8 \%$ \\
Shafeeq Harriri & Brother & $7 \%$ \\
Ghaleb Al Shama & Close family friend & $8 \%$ \\
Mustafa Rizian & Chairman of the board of the Harriri & $1 \%$ \\
& owned Mediterranean Investment Bank & \\
\hline
\end{tabular}

Table 2

National Broadcasting Network (NBN)

\begin{tabular}{ll}
\hline Name of shareholder & Percent share \\
\hline Ahmad El Safadi & $6.24 \%$ \\
Samira Assi & $7.18 \%$ \\
Amina Berri & $6.18 \%$ \\
Ali Fran & $7.5 \%$ \\
Ahmad Hussien & $6.09 \%$ \\
\hline
\end{tabular}

Fandy (2007) asserts that "most of these shareholders are close affiliates of Berri or members of his family" (p.75). Samira Assi, for instance, is the sister of Nabih Berri's wife and Amina Berri is his wife.

Fandy (2007) does not disclose the source of his information and there is much difficulty in checking whether the numbers he states and the shareholders he provides are verifiable. Nonetheless, it remains common knowledge that the ownership of the television stations is within the hands of the main political patrons, whether they are direct owners or indirect owners through their family members or friends. What is important for the purpose of this study is that the women found among the shareholders are only present by virtue of kinship or marriage and not capital or expertise. 
It is clear then that the law is selectively applied to serve the interests of the political patrons in the country; the licensing of Lebanese television stations is yet another clear example of its violation. None of the television stations fulfills the legal requirements of ownership and capital. The National Broadcasting Network, mostly owned by the Nabil Berri, Speaker of the Parliament, was given a license even before it actually existed (Human Rights Watch, 1997; Kraidy, 1998; Sakr, 2001; Fandy, 2007).

Having set the background for Lebanese broadcasting, the following section will discuss how scholars of Lebanese media read the changes and developments in the media scene, in light of ownership patterns and political and religious struggles that have identified the Lebanese media system.

\subsection{The Lebanese Media System: Categorization and Financing}

In discussing Lebanese television, scholars agree that the Lebanese broadcasting model does not fit Western models where television mostly operates within the private sector, nor does it fit the many third world models where television mostly operates

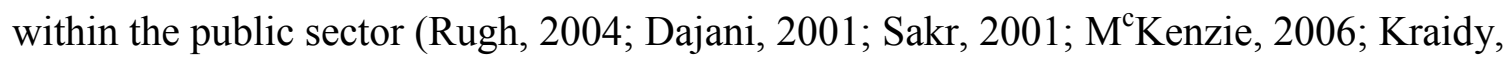
2009; Boyd, 1999). When analyzing the ownership patterns of the Lebanese media, most scholars do not rely on a specific Western theoretical framework but recount the ownership patterns along Lebanon's confessional lines, citing a unique pattern of ownership that combines the public with the private, the political, the sectarian and the commercial (Dajani, 2001 \& 2006; Kraidy, 2009; Rugh, 2004; Fandy, 2007; Boyd, 1999). It is important to point out that, unlike Western broadcasting companies, most Lebanese television companies do not publicly reveal their annual reports, full ownership patterns or organizational structures. Most media organizations in Lebanon, in fact, are 
very "opaque and resistant towards revealing information about their internal operations and management" (Internews, 2009, p.7). They also refuse to share information about their organizational policies, advertising revenues (Internews, 2009; MSI, 2013) and exact shareholders (Media Sustainability Index, 2013). This is probably one of the main reasons why scholars avoid delving into details of ownership and find it difficult to fit Lebanese media structures into a Western framework.

The difficulty of categorizing the Lebanese media systems is made clearer in $\mathrm{M}^{\mathrm{c} K e n z i e ' s ~ c o m p a r a t i v e ~ s t u d y ~ o f ~ m e d i a ~ s y s t e m s . ~ I n ~ c o m p a r i n g ~ d i f f e r e n t ~ a n d ~ i n t e r e s t i n g ~}$ media systems from around the world, $\mathrm{M}^{\mathrm{c}}$ Kenzie (2006) chooses to discuss Lebanon alongside France, Ghana, China, Mexico, Sweden, the United Kingdom and the United States of America. $\mathrm{M}^{\mathrm{c}}$ Kenzie (2006) classifies the media systems in accordance with six philosophies namely: authoritarian, libertarian, communist, social responsibility, developmental and democratic. Yet when it comes to Lebanon, $\mathrm{M}^{\mathrm{c}}$ Kenzie asserts that "the philosophies influencing media policy are difficult to identify" (p.87). Instead of placing Lebanon under one media system, $\mathrm{M}^{\mathrm{c}}$ Kenzie presents Lebanon's media system as a mix of systems; it is authoritarian when it comes to government restriction on ownership. It is developmental as the government chooses to ignore media violations of certain regulations partly because the owners of the television stations belong to the political regime and partly because the government hopes the media would contribute to the country's economy and infrastructure. Last but not least, the Lebanese media system is also libertarian since the television stations are privately owned and can set down their own standards for media content. In other words, the Lebanese media system fits none of the categories and cannot be molded within a western framework. 
While $\mathrm{M}^{\mathrm{c}}$ Kenzie attributes the difficulty of identifying the philosophies influencing the media system to the civil war whereby the government became weaker than the sectarian bosses, Dajani (2001) attributes the structure and the operation of the Lebanese media institutions to societal factors. In the case of Lebanon, the society is fragmented along sectarian lines (2001) and the Lebanese media "reflect and reinforce the characteristics and contradictions of Lebanon's political and tribal confessional society" (2006, p.1). What Dajani attributes to societal factors, Rugh attributes to the political system. Rugh $(2004,2007)$ argues that national political systems are the main variable affecting the structure of Arab media. Using this framework, Rugh (2007) reveals that the diverse Lebanese media environment is based on "a pluralistic Lebanese national political system" (p.17). He points out that in Lebanon the broadcasting media are partially private and partially owned and operated by the government (Rugh 2004). Rugh also shows how the television channels licensed in 1996 belonged to the members of the governing body. Future Television, for instance, was owned by then Prime Minister Rafik Harriri, NBN by the Speaker of the House, Nabih Berri and MTV by Gabriel El Murr, the brother of then Interior Minister Michel El Murr, while LBC had government officials among its shareholders.

To Rugh, the media in Lebanon present a unique case where they are neither fully commercial nor fully public. Kraidy (1998) argues that this media monopoly by the members of the regime "suggests that the Lebanese regime has become an oligarchy where political power and media ownership converge" (p. 397). Fandy (2007) does not offer a clear-cut classification of the Lebanese media, but suggests that the Lebanese channels can be classified in accordance with confessional interest, interstate and intra- 
state rivalries, or in terms of those that are allowed to broadcast political news versus those that are not. In showing how interstate conflicts between Syria, Iran, Saudi Arabia and Qatar are woven into the fabric of the Lebanese media, Fandy (2007) maintains that understanding Lebanon's political and social make-up is necessary for understanding its media. Syria and Iran, for instance, support the Shiite affiliated channels Al Manar and NBN whereas Saudi and Qatar support the Sunni affiliated channel Future TV.

In an attempt to devise a typology of ownership for Arab television, Sakr (2002) argues that classifying Arab satellite television channels, and in our case the Lebanese channels, according to whether they are commercial or state-owned is "not a productive exercise" (p. 10). Sakr (2002, 2007), like Rugh (2004, 2007), Kraidy (1998), Fandy (2007) and Dajani (2001), finds that the Arab television companies are either closely allied with governments that control them through regulation or are owned outright by the government. Sakr (2002) adds yet one more layer to her analysis when revealing that the most private channels do not belong to any single commercial entrepreneur but "to political groups with state-oriented agendas" (p. 4). Consequently, she concludes that separating the political from the economic, and the public from the private, is difficult, since economic liberalization in the Arab world is a "highly centralized and top-down process aimed primarily at cementing the regime's control over its population."

Ownership of Lebanese channels presents a curious web of links on the national and regional levels. Nationally, the channels are not only sectarian but also party affiliated. Regionally, the channels' local party and sectarian affiliations tie them with their state allies such as Syria, Iran and Saudi and by proxy their Western allies. The main question to be asked is not whether these channels are public or private but how the 
structures of media ownership tie all of the main media organizations in Lebanon into an opaque and overlapping network of national and regional families, power, politics and conflict to ultimately serve a politico-sectarian agenda that belongs to these owners, who are also the main funders of the television stations.

In light of the lack of transparency, scholars do not discuss funding or financial details, but rely on basic facts that are common knowledge in the Lebanese and regional Arab market. Television stations receive financing from two main sources: advertising and subsidies from owners or business/political groups, says Dajani ( $M^{\mathrm{c}}$ Kenzie, 2001). Panelists at the Media Sustainability Index (MSI) meeting in 2009 and in 2013 agreed that the media in Lebanon do not operate as financially efficient commercial businesses. Instead they rely on political subsidies, especially since the advertising market in Lebanon is too small to support all the private media that operate within it (MSI, 2013; MSI, 2009; Dabbous, 2010).

These local and regional financial agreements come at a price. The Lebanese media landscape is relatively free but it is not objective. Owned by political parties, it tends not to criticize its financial supporters (Rugh, 2004; Fandy, 2007; DabbousSensenig, 2000; Abu Fadil, 2009). The content is then governed by the same sectarian divisions that govern the media and the rest of society (Dabbous, 2010; Notzold and Pies, 2010; Cochrane, 2007 \& 2008; Abu Fadil, 2009). The result is a media system in which all of the players are politically partial and abide by an unwritten code of ethics (Dabbous, 2010), with complete editorial commitment to the movement or the country offering the funding (Fandy, 2007). The media's sectarianism becomes even more pronounced during times of political or military crises (Fandy, 2007; Cochrane, 2008; 
Dabbous, 2010). Dabbous (2010) attributes the media's political partiality to a number of factors including institutionalized sectarianism, the political leader or zai'm system, foreign patronization and the 15-year civil war. A number of panelists at the Media Sustainability Index (2013) noted that "higher wages were paid to journalists on the basis of loyalty to the political and sectarian position of their paymasters and this in turn encouraged self-censorship" (p.6).

Surveying the 15 minute introductions of news broadcast by six different television stations (LBC, Future TV, Al Manar, NBN, New TV and Tele Liban) for only one day, Tuesday, October 11, 2005, Dajani (2006) shows how television maintains and reinforces the sectarian divisions in Lebanese society, essentially leading to the refeudalization of the public sphere. The lack of objective socio-political coverage and the imposition of entertainment values prompted by television's commercial management are key characteristics of this result. Cochrane $(2007 \& 2008)$ dubs the media as "propaganda machines" and quotes Dajani who believes that the media deliberately promote sectarianism. Cochrane (2007) adds that sectarianism and the exchange of political insults are most apparent in news coverage and on talk shows. To Cochrane (2007) and Dabbous (2010), Saad Al Harriri's Future TV and Hizbullah's Al Manar are the most sectarian, as the former regularly airs montages praising the late Rafik Al Harriri's legacy whereas the latter airs montages that hail martyrs from the July 2006 war with Israel and highlights Hezbollah's military capabilities.

While Lebanon's media sectarianism makes it highly partial, Rugh (2004) and Hafez (2010) see this as a pluralistic media system that serves as a propeller for democracy and voicing of alternative opinions without fear of government retribution, 
especially when these opinions are voiced by journalists who enjoy political patronage. This patronage, says Dabbous (2010), characterizes the Lebanese media with a double social contract: the first is between the journalists and media organizations they work for. Since journalists know that they cannot broadcast or write material against their sponsor, they practice self-censorship. The second is between the Lebanese audiences and the media. The Lebanese audiences are well-aware of the affiliations of the media outlets and approach them as indicators of political opinions rather than sources of news.

Another price for the political patronization and affiliations of Lebanese media are the public service issues or human interest stories. Abu Fadil (2009), quoting a UNESCO supported report by Maharat (Skills) Foundation mentioned that Lebanese broadcasters have abandoned their raison d'etre of educating people and have become, instead, tools for promotion and propaganda. Notzold and Pies (2010) find that the news is mainly "elite-centered" and focuses on religious, executive and legislative officials. Dajani (2006) finds that there is an imbalance in the Lebanese television between "public interest and the interest of the political, financial and economic forces in the country" (p.5). This imbalance affects the free flow of knowledge that is necessary for wellinformed people. Dajani (2006) concludes that Lebanon has no free press, a view that most scholars share. While Notzold \& Pies (2010), Dabbous (2010), Abu Fadil (2009), Fandy (2007), Sakr (2007), Dabbous-Sensenig (2007) acknowledge the rich diversity of the Lebanese media and its freedom, they, nonetheless, point out that this media operate under the jurisdiction of the sectarian authorities that govern the country despite the presence of clear regulatory bodies and clear regulation as the next section will reveal. 


\subsection{Media Regulation: Law and Violations}

Scholarly discussions of the laws and regulations governing media in Lebanon reveal that Lebanon's introduction of the Audiovisual Media Law in 1994 set a precedent in the Arab world. Yet the law is archaic, inconsistent and contradictory. Its application falls prey to the whims of the political body that governs the country and the fact that the media themselves are tightly integrated with the political sphere and governing powers by ownership, financial considerations or sectarian alliances. In such an environment, laws and regulations are subject to both overt and covert manipulation.

Lebanese media laws in general, and the Audiovisual Media Law (AVML) of 1994 in particular, draw heavily on the French model of broadcast regulation due to the shared history of the two countries in the 20th century and because France as a whole offered a viable European model of democracy that some in Lebanon sought to emulate. The AVML made Lebanon the first country in the Middle East to authorize private radio and television broadcasting. As mentioned earlier, the law sought to regulate the media industry and the many unlicensed broadcasting stations that were introduced during and after the Civil War which extended from 1975 to 1990. It ended the state's monopoly and distinguished, between Category 1 licenses for political and news broadcasting and Category 2 licenses for non-political broadcasting (article 10). According to the law, television stations should broadcast for a minimum of 4000 hours per year, with $40 \%$ locally produced content to be transmitted across Lebanon. The applicants for licenses would be given a one year provisional permit, by the end of which they would receive a 16 year license provided they abide by all the asset, shareholding and programming requirements. The law promotes balanced news coverage thereby ensuring that all 
stations provide an equal airing of the different political perspectives found in the country. The reality of Lebanese television is far from ideal especially since the first four License 1 categories were granted based on specific political interest and to people in political power, as discussed earlier.

Despite its attempt to emulate the French model, the first draft of the Lebanese Audiovisual Media Law concentrated all of the main regulatory functions in the hands of the Minister of Information (Kraidy, 2011; Sakr, 2007; Dabbous-Sensenig, 2007). Lobbying by media representatives led to a compromise agreement and to the creation of the National Council for Audiovisual Media (NAC) (Sakr, 2007), which reports to the Ministry of Information (AVML 1994, article 19). The fact that that the NAC (also called the Audio Visual Media Council - AVMC) still reports to the Minister of Information as well as the Council of Ministers (articles 19, 22, 23), and its functions are mainly advisory, indicates where the real power lies (Kraidy, 1998; Sakr, 2007; DabbousSensenig, 2007; Kraidy \& Khalil, 2009). The broadcasting law does not clearly identify the authority of the NAC but limits its role to the monitoring of the adherence to the laws passed by the parliament and decrees issued by the government, besides providing feedback on broadcasting policy ( $\mathrm{M}^{\mathrm{c}}$ Kenzie 2006). Perhaps the wording of article 19 in the law speaks best to the lack of authority that the NAC has. The article's first three points stipulate that the Council only "studies" licensing applications, "ensures" all licensing requirements are fulfilled and "advises" the Council of Ministers on whether or not to approve that application. Effectively, the NAC does not have decision making power - an understandable consequence due to the political backing that most broadcasters have and impunity that comes with such a support. 
According to Dabbous-Sensenig (2007), the Council is supposed to have licensing authority by law, but is deprived from using it in practice. In fact, the Council of Ministers monitors content and licenses new broadcasters. The NAC does not have the facilities and enforcement powers to perform even "its watered-down role" (p.26).

The NAC is composed of ten members, five appointed by the council of ministers and five elected by parliament; the members are chosen from amongst "Lebanese artists, intellectuals, scientists and professionals," as stated by Article 18 of the 1994 AVML This very loose description as to who can occupy these positions has typically led to members being appointed who lack the necessary qualifications (Dabbous-Sensenig, 2007), but who fit the desire to fill seats on the Council according to the sectarian and political divisions described earlier ( $\mathrm{M}^{\mathrm{c}}$ Kenzie, 2006; Abu-Fadil, 2011). Of course, this weakens the NAC even further. Dabbous-Sensenig (2007) is sharply critical of the outcomes, stating: "It would seem difficult, if not ludicrous to speak of the 'powers' and of the 'independence' of the NAC as spelled out in the 1994 Broadcast Law" (p.27).

The Ministry of Information and the National Council for Audiovisual Media are not the only regulatory bodies. The Ministry of the Interior's General Directorate of General Security (Surete Generale) also regulates by conducting media censorship (Sakr, 2007; Dabbous-Sensenig, 2007). The Surete Generale's website indicates that its functions are to implement the censorship laws with regards to radio, television and movies.

If this set of regulatory arrangements is not confusing enough, Kraidy (2011) goes even further to show that laws governing the media "can be found in the penal code, the Elections Law, the Law of Publications, (and) the Military Justice Code . . creating a 
logistical nightmare of overlapping jurisdictions" (p.1) The fact that the laws are so Byzantine and hedged about by conflicting interests means that they can be selectively applied in ways that benefits patrons of the state. The most obvious violation of the law is in the licensing of the Lebanese television station, none of which fulfill the legal requirements of ownership and capital. The National Broadcasting Network, mostly owned by the Nabil Berri, Speaker of the Parliament, was given a license even before it actually existed (Human Rights Watch, 1997; Kraidy, 1998; Sakr, 2001). Further, most television stations rely on funds that cannot be traced to legitimate advertising or production sources although article 10 of the AVML stipulates that the Ministry of Information can ask the Court of Publications to suspend networks from broadcasting for a period extending from three months to two years and even annul the broadcaster's license depending on the case.

In the first few years of the law's implementation, the government media control mechanisms "led to several major political crises over media policy," concur Kraidy and Khalil (2009). The authors mention that the last two of these crises involved the closing down of MTV on September 4, 2002 and the disconnection of New TV in December 2002. The year 2002 ended with calls for media law and practice reforms. The most serious attempt to introduce a new draft for media law came from parliament member, (MP) Ghassan Moukheiber in 2010 (Kraidy, 2011; Abu-Fadil, 2011). Moukheiber's draft "claimed that Lebanon's Law of Publications violated the constitution and various United Nations charters and questioned the peculiar distinction between 'political' and 'nonpolitical' media" (Kraidy, 2011, p.1), a distinction that restricts broadcasters' freedom to send and listeners' freedom to receive information about public affairs (Human Rights 
Watch, 1997). Moukheiber's draft also allows for foreign ownership of media, which the MP claims would enhance transparency in ownership (Kraidy, 2011). Moukheiber explained "We simply want the reader or viewer/citizen to know who controls the media financially and politically and [for] the recipient to decide upon the value he or she wants to give to the information he/she reads" (Moukheiber quoted in Abu Fadil 2011).

Although Kraidy (2011) describes the Lebanese media landscape as "a cesspool of political patronage and domestic foreign influence peddling," he, nonetheless expresses hope that the upcoming debates about the nature of journalism and media work "could form a blueprint for a code of professional media ethics" (p.1). He also derives that hope from the failed attempt by then Minister of Information Tariq Mitri to pass a New Information Technology Law that would have restricted the civil and privacy rights of citizens and given the government "broad surveillance prerogatives" (Kraidy, 2011).

\subsection{Press and Broadcast Journalists: Bodies and Representation}

Violations of the Audio Visual Media Law and the weakened authority of the Audio Visual Media Council are not the only factors affecting the journalistic profession in Lebanon. The near absence of professional unions for press and broadcast journalists has further weakened journalists' sense of independence and security.

The 1962 Press Law had organized the Lebanese journalists into two syndicates, the Lebanese Press Association (also known as the Press Syndicate or Publishers' Union), which represents the owners of television stations and media publications, and the Lebanese Press Editors' Association/Syndicate, also known as the Lebanese Journalists Union (LJU) that represents all active journalists. Both syndicates had been 
formed in the early $19^{\text {th }}$ century and became official when recognized by the 1962 Press Law (Press Order Lebanon, n.d.).

The LJU, as stated in its charter, functions as both, a trade union in protecting the interests of members and as, accountability body, in monitoring the conduct of journalists and providing guarantees for their professionalism and ethics. In reality, both the Press Syndicate and the LJU have been ineffectual institutions (Richani, 2011), created only to give the impression that Lebanon respects international press organization standards (Trombetta, n.d.). Most Lebanese journalists who are accredited by the Ministry of Information are not even members in the LJU (Richani, 2011; Trombetta, n.d.). The lack of trust in the LJU's authority and credibility are the main reasons behind its failure to attract journalists who do not believe that the union can protect them.

Effectively, the two bodies have been and continue to be controlled by the political and sectarian carve up in the country. It was agreed that the head of the Journalists' Union would be a Christian, while the head of the Press Syndicate would be Muslim - a dictate of the sectarian system and the not the Lebanese Press Law. As such, Muhammad Baalbaki, a Muslim Sunni, has been the president of the Press Syndicate since 1989 and Melhem Karam, a Christian Maronite, had presided over the LJU for over four decades, from 1960 till 2010 (Lebanese Press Order, n.d.). Thirteen months after the death of Karam, in May 2012, the Journalists' Union chose a 12 member council presided over by Elias Aoun, a former member of the Press Syndicate who resigned from the Syndicate to be eligible for the Journalists' Union elections (Journalists' Union votes, 2012). The election of a new union head did not bring about 
positive change. The Union was unable to stand by over 2000 journalists dismissed since 2010 (Abouzaki, May 2012) and it was sued along with its new president "on charges of corruption, irregularities and violations of its bylaws" (Abu Fadil, September 2015). Before Aoun, Karam had only granted membership to the journalists who had reelected him as union head (Richani, 2011). The LJU's past and present situation and practices make it yet another site for politico-sectarian struggle. Engulfed in the struggle, the Union operates as a politico-sectarian mouthpiece stripped of its main functions leaving journalists to fend for themselves - mortgaged to a media enslaved by politico-sectarian patrons.

In addition, the LJU has never been open to broadcast journalists (Richani, 2011). Up till the date of the writing of this thesis, broadcast journalists have not had a union to represent them or defend their labor rights. Attempts to establish a union have been hampered by the deep political and sectarian divisions afflicting the media system in Lebanon.

When they do exist, the unions do not have the power or the competencies to support the journalists or keep an eye on media outlets. Their outdated procedures, partisan influences, membership conditions and restricted benefits render them ineffectual.

The media, the media industry and the industry unions are in definite need of reform. Many scholars, in fact, argue that there is a pressing need for new regulatory frameworks for media in Lebanon (Dajani, Sakr, Kraidy, Abu-Fadil, Dabbous-Sensenig). Among other things, they realize that the highly politicized nature of the country and entrenched sectarian divisions have had a debilitating effect on the media and for media 
workers and journalists in particular. There is also, however, keen awareness that new laws will likely destabilize the control that current patrons have over media, and thus be strongly resisted. This is probably why efforts for media reform have confronted an immovable wall. 


\section{Chapter: Women in the Lebanese Media}

As the literature review has revealed, not much is known about women in Lebanese television nor is there a detailed historical account of their early beginnings in the broadcasting industry. Jean-Claude Boulous' 1995 book Television: History and Stories recounts the beginnings of the first television station, Tele Liban and includes within that history the early workers of television. Boulous' book seems to be the only reference to document the beginnings of television in Lebanon. He wrote the book in French and it was later translated into Arabic. Boulous, a civil engineer by profession, was also an amateur singer and actor. Upon completing his engineering work on the Tele Liban building, Boulous became actively involved in the development of the television station, owned at that time by Wissam Ezzedine and Joe Arida. The two Lebanese businessmen had received licensing for the commercial television station in 1956. Tele Liban started out with two channels: Channel 7 (or Canal 7 as it was called) for Arabic programming and Channel 9 (or Canal 9) for French programming to cater to the Arabic speaking and Francophone Lebanese population.

On May 28, 1959 at 6:30 pm the first television signals were broadcast to Lebanese homes. The first person to be seen on Tele Liban was the female presenter Najwa Kazoun. Boulous mentions that she was hired because of her beautiful face and lovely voice. The other Channel 7 presenter was May Abdelsater (later May Menassa), known according to Boulous (1995) for her incomparable femininity. On Channel 9, the presenters were Andree Hani, known for her flirtatious attitude and Lenny Nawfal, whose seriousness was admired by viewers. "The four presenters were the face of Tele Liban" asserted Boulous (1995, p.43). The first news anchor, also a female, was Hind Al Sayed. 
It is clear, then that women were, not only, intensively present on the television screen but were the very first to present the new medium to the Lebanese public. Interestingly, Boulous' description of these women's qualifications is limited to their good looks, tone of voice or femininity - all of which are physical attributes. Boulous does not refer to the women's academic qualifications, skills, knowledge, or career accomplishments. May Abdelsater Menassa, for instance, had completed her bachelor degree in French Literature before joining Tele Liban. Ten years into her television career, Menassa became a critic for the prominent Lebanese newspaper An Nahar and an author of five novels. Yet Boulous never mentions her academic qualifications, but merely her incomparable femininity. The focus on women's physical attributes does not mean that women did not have their accomplishments.

Although little research has been done on women in Lebanese television and there is much to learn about their contribution to the Lebanese broadcasting industry, the history of Tele Liban reveals the active involvement of women right from the very beginning. The plethora of women's firsts in television marks a productive time for women and signals an early launch for their careers in the medium. Yet, despite their early contributions, those women were not in positions of control or power. Mostly, they were present as presenters. In citing the main pioneers of television, Boulous (1995) names Marie-Jose Khayyat, as the one female producer among male colleagues Elias Matta, Gary Garabedian and Issam Hamwi. The position of script commentator (as translated from Boulous), and not script writer, was mostly occupied by females such as Antoinette Hososian, Samira Akkawi, Francoise Yaghmour and Josette Tabet. 
Writing for the Institute of Women's Studies in the Arab World's monthly newsletter of February 1989, Rose Ghurayib, a prominent and pioneer Lebanese writer, describes women's role in the Lebanese media landscape. Ghurayyib (February, 1989) mentions there was a large number of women employed in radio and television. Yet these women were interviewers and broadcasters. The news broadcasts, on the other hand, were prepared by men. The women mainly handled programs that discussed women's issues or social issues. Ghurayyib cites three prominent women in television, namely Edvick Shayboub, Raymonde Angelopoulo and Charlotte Wazen El Khoury, who was voted as the best broadcaster by Tele Liban. Ghurayyib's descriptions of Charlotte Wazen El Khoury is particularly interesting in that it focuses on her physical attributes and attitude rather than intelligence or capabilities. Charlotte Wazen El Khoury, Ghurayyib (1989) says, "is distinguished by her reserve, her natural gracefulness, her micro-phonic voice and her tasteful attire" (p.4). Essentially even Ghurayyib's description falls into the trap of identifying television women mostly through appearance rather than capability.

Despite the fact that television's history shows a minimal presence of women in positions of power, nonetheless, the above shows that there was a presence from the very beginning. The question of why, after almost half a century, the literature on women mentions that they are still a minority in the higher positions becomes more pressing. It is one of the questions that this study seeks to understand despite the lack of historical and statistical data on Lebanese television in general and on women working within television, in particular. 


\subsection{The Media Workplace: Competencies and Constraints}

"Generations of Arab women journalists and activists are among the neglected historical forces" in the development of Arab television (Sakr, 2007, p.89). Sakr asserts "it is rare to see the altered landscape for public communication, after the advent of satellite television, analyzed in terms of how it relates to the changing climate of women's empowerment" (Sakr, 2004). As the above review of the literature on the media in Lebanon attests, women do not appear to have much of a role in a media system largely controlled by men as part and parcel of the politico-religious factions that rule Lebanon.

While women play little to no role at the upper reaches of the media economy in Lebanon, it is hard to determine what their role is elsewhere within the media landscape because, as Abu Fadil (2004) argues, "accurate figures are lacking on how many Arab women work in the media and in what jobs." Skalli (2006) concurs, noting that "research on women in the MENA region is relatively recent and scarce". Generally speaking, however, the main media, political, economic and religious centers of power in Lebanon remain male dominated. Women's participation in the Lebanese public sphere, consequently, is marginalized and incomplete. To examine the role that the Lebanese women play in the media and more precisely in television, what follows is a review of women's media education, their participation in the workforce and in the media workplace as well as the gendered media policy.

According to the United Nations' Human Development Report 2004 and Lebanon Millennium Development Goals Report (MDG, 2008), women's participation in paid economic activity reached $30.3 \%$ in 2002 , up from $17.5 \%$ in the early 1970 s. Despite this 
increase in the rate of working women, most scholars (Haidar, 2007; Sakr, 2004;

Dabbous-Sensenig, 2000; Jamali, Sidani and Saffieddine, 2005;Skalli, 2006) find that women's participation remains weak, especially when considering their high literacy rates and the fact that women make up the majority of journalism and media studies students (Melki 2009, p. 678; Obeidat, 2002).

While the enrolment rate for male and female students in Lebanese schools is universal at the primary level, enrolment in the intermediate and secondary levels is higher for females than it is for males (Lebanon MDG, 2008). According to the United Nations Development Program -POGAR, Program on Governance in the Arab Region, Gender Initiative (2005) - half of all university students are women. Add to that, female enrolment in media and communication studies is more than twice as high as male enrolment (Melki, 2009; Obeidat, 2002).

Table 3

Media Studies Students in Lebanon by Gender from 2001 to 2007

\begin{tabular}{lcccccc}
\hline Gender & Academic year & & & & & \\
\hline & $2001-2$ & $2002-3$ & $2003-4$ & $2004-5$ & $2005-6$ & $2006-7$ \\
\cline { 2 - 7 } Males & 726 & 952 & 919 & 1010 & 1191 & 1128 \\
$\begin{array}{l}\text { Females } \\
\begin{array}{l}\text { Male to female } \\
\text { ratio }\end{array}\end{array}$ & 2308 & 2370 & 2317 & 2286 & 2527 & 2506 \\
\hline
\end{tabular}

Source: Center for Educational Research and Development (2001-7) (Melki, 2009)

Dajani (quoted in Melki 2009) and Haidar (2007) attribute the higher rate of females in media studies to cultural and societal considerations. Dajani believes that males, being the major economic contributors, are pushed to pursue professional degrees unlike females whose choice of degree or career selection is not subject to social pressures since the female is expected to occupy the role of housewife and mother. Haidar (2007) argues 
that in traditional societies, degrees in science and technology are seen as more suitable for males and degrees in humanities and arts for females. Yet both Haidar (2007) and Melki (2009) recognize that these attitudes towards women are in decline.

The relative gender equality in terms of education is not paralleled in the work place. While female participation in Lebanon's economic activity is relatively weak, their access to senior positions of responsibility and decision making is even weaker. The Lebanon MDG (2008) report reveals that there is a concentration of female workers in the professional, office employees, service worker and unskilled labor categories compared to high male worker concentration in management and skilled labor categories. A report by the United Nations Development Program on Lebanon (2000) also reveals that only $1.92 \%$ of working women have executive level positions - a result that is matched by a 2003 Universite Saint Joseph survey which revealed that women's numbers are low in executive level positions compared to those of men (Tayar, 2013). Using qualitative research methods, Jamali, Sidani and Saffieddine (2005) interview 52 Lebanese women managers in different fields and 10 women in the political and administrative fields, to explore the constraints they face in their careers. They find that Lebanese women essentially reported the same constraints that women face worldwide, with an emphasis on how cultural values, patriarchy and other restrictions limit women to traditional feminine roles within organizations. Having chosen their sample equally from the Christian and Muslim faiths, the authors warn against simplistic explanations that equate Christianity with modernization and Islam with tradition, although the perception of Muslim and Christian women in their sample pointed in that direction. The authors 
insist that no general inferences can be made from their observations since the interplay of variables such as class and education has to be taken into consideration.

The Lebanese media workplace for women seems to be more discriminatory than the regular workplace. Dabbous-Sensenig (2000) notes, that there is "great discrepancy between the number of women who work in the field (of media) and those who occupy decision making positions." She emphasizes that Lebanon is the most flagrant example of this discrepancy, especially since $85 \%$ of journalism and communication students are women. Dabbous-Sensenig (2000) adds that female news journalists may reach up to $100 \%$ in some television stations but the top ranking positions are always monopolized by men, with women getting only $18 \%$ of these positions. An Internews (2009) report supports Dabbous-Sensenig's findings. The report reveals that in $75 \%$ of all television stations surveyed, over half of the staff was composed of women. Yet most of these women were hired as announcers or broadcasters, or admitted to lower management positions. Very few women were given access to the male-dominated area of political journalism. These findings are similar to those found in the Western world, where women are underrepresented in upper management (Strong, 2011; Ross \& Carter, 2011; Barber \& Ruahala, 2005; Robinson, 2005; De Bruin \& Ross, 2004; Rush, 2004; Mahtani, 2005; Meehan \& Riordan, 2002; Byerly \& Ross, 2004; Byerly \& Ross, 2006; Creedon \& Cramer, 2007; Bollinger \& O’Neill, 2008). Journalist Catherine Strong (2011) reveals in her doctoral dissertation that women journalists form a majority in New Zealand but are confined to lower career positions and are almost invisible at the top executive and editorial levels. Basing their study on the 2010 Global Media Monitoring Project, Ross and Carter (2011) mention that despite the strides that women made in British and Irish 
media, their inclusion as news producers, news subjects and news makers is still significantly lower than men, and argue more importantly that women's voices and experiences are considered less important by the news industry than those of men. In a multiyear study, Barber and Ruahala (2005) surveyed all Canadian news directors, or the men and the women who make the key decision in the Canadian newsroom, to find that both women and minorities were underrepresented in such senior roles.

In her study on Canadian, US and European media, Robinson (2005) clearly mentions that it is erroneous for scholarship to assume that "women's minority status in the media professions results from lesser numbers, rather than from systemic biases inherent in the social reproduction of the profession" (p.1). The findings in Lebanon corroborate Robinson's statement. Women in Lebanon form a majority in the media workplace but face, to use Robinson's words, systemic biases that restrain their progress. While to Robinson, these systemic biases are gender based relating to "how work and family obligations are to be combined" (p.82), in Lebanon one should dig a bit deeper into other profound reasons that hinder or help women progress, stay or leave the journalistic profession. The systemic biases may, for our study, include factors such as religion and political affiliation - factors that stem from the Lebanese context and are unique to the Lebanese environment. Patterson and Donsbach (1996) try to uncover the relationship between journalists' political partisanship and that of their news organization. Using random sampling, Patterson and Donsbach (1996) attempted to survey 600 journalists in each of the United States, Great Britain, Germany and Sweden to reveal whether the partisanship of journalists affected their news decisions. They arrive at an interesting finding that reveals a correlation between employment patterns and 
partisanship since "partisan opportunities are associated with the employment pattern of journalists" in each country. In the US, mainly in the broadcasting industry, no such correlation existed and the journalists' beliefs were not related to their organization's editorial position. In the European system, particularly in Italy and Germany, there was a closer connection between the journalists' partisanship and that of their news organization. In Lebanon, where media are divided along politico-sectarian lines, it is likely that political partisanship and religious belief would play a role, alongside gender discrimination, in determining the employment and progression of women in the media profession.

Yet, just like Robinson's study, many of the studies that deal with women and how they affect the field of journalism, focus mainly on gender and how gender influences the way journalists conduct themselves and the news content and not on the many other contextual factors that may come into play (Robison, 2005; Barber \& Ruahala, 2008; Ross, 2007; Craft \& Wanta, 2004; Rodgers \& Thorson, 2003; De Bruin \& Ross, 2004). Craft and Wanta's (2004) content analysis of thirty US daily newspaper websites revealed that it was the editor's gender that related to differences in what female and male journalists' covered. They ultimately found that studies "do not support drawing a straight line from reporter or editor to news content that somehow flows out of one's gender" (p. 136). Examining the print and broadcast news coverage of women's issues in English Canada between the years 1966 and 1971, Freeman (2001) shows how the context influences coverage and discourse. Freeman (2001) reveals the differences between the American and the Canadian contexts despite the general tendency to assume that both contexts are similar. She shows that in the Canadian society women were not 
“symbolically annihilated in media coverage and women's issues received more equitable recognition at the time" (p.239). Smith (2012) suggests exploring other lines of diversity such as race, class, age or parenthood experiences to uncover how journalists affect the news and whether or not contextual variables affect women's career abandonment or advancement. To Strong (2011) the unexplored reasons as to why women leave the journalistic profession are deeper than child rearing and family. In examining the process of gender stereotyping, through participant observation, in four Spanish newspapers and one news agency, Gallego, Altes, Canton, Melus and Soriano (2004) incorporate the sociocultural context, journalist culture, organizational culture and the individual journalist as factors that combine indistinguishably to affect the news discourse and implicitly bear the stamp of gender within their assumptions.

Robinson (2005), on the other hand, only refers to gender based biases to explain women's minority status in the US and Canadian newsroom, the glass ceiling they face as well as salary differences. In updating a 30 year old survey conducted in 1972, Rush, Oukrop and Creedon (2004) surveyed 1,100 women members in the Association for Education in Journalism and Mass Communication mainly employed in Canada and the US, to uncover the status of women in the field of communication education. The authors mention that their results are matched in the media profession. With a 55\% response rate, Rush, Oukrop and Creedon (2004) reveal that salary was the leading indicator of perceived sex discrimination, while in their 1972 study it was promotion. Bollinger and O'Neill (2008) assert that even with the Equal Pay Act in the US, data showed that there was a wage gap based on race and gender with a 75.6 cents for every dollar men earned. Rush, Oukrop and Creedon (2004) attribute other results to sex 
discrimination including the fewer number of women as administrators, and women's need to pull more effort to get respect from male colleagues and administrators. Yet when it came to finding a mentor, the study revealed that $50 \%$ of the women had a faculty member they could model themselves after, unlike studies in Lebanon which reveal a lack of mentorship. Interestingly, Bollinger and O’Neill (2005) found that women outnumbered men as professionals, managers and officials in US radio and television broadcasting. While their findings may be true, they nonetheless cannot be generalized to include the status of women in the newsroom where, as the literature review has revealed, they remain a minority in power positions, mostly faced by a glass ceiling- a concept that describes the barriers formed through attitudinal or organizational bias that prevent qualified personnel from advancing to management positions (Bollinger and O’Neill, 2008).

Abu Fadil (2001) quoting May Kahale, a veteran journalist and media adviser to the former Lebanese president Elias Hrawi, claims that there is a ceiling that women cannot penetrate in Lebanese media and government. Kahale explains that media jobs in Lebanon are "apportioned according to sectarian and political considerations" (Abu Fadil, 2001). Abu Fadil concurs with this claim, arguing that women face the "glass ceiling syndrome," in terms of career advancement and pay. Based on interviews with six Lebanese television journalists, she reveals that women face a number of difficulties that hinder their progress, including a lack of trust and comfort with women in leadership positions, social and cultural traditions, and lack of mentors. Although the 2011 Global Report on the Status of Women in the News Media, commissioned by the International Women`s Media Foundation (IWMF) and investigated by communication scholar 
Carloyn Byerly, does not directly refer to the glass ceiling, Byerly asserts that women`s progress in Lebanese news media rests at the senior professional levels where women who function in positions such as directors, producers and senior writers have established near parity with men, at $42.9 \%$. Climbing up the corporate ladder, in middle management and senior management positions where the major decisions shaping the news take place, women`s numbers become lower to reach $35.7 \%$ and $28.6 \%$ respectively. Men monopolize the technical functions in the news organization $(100 \%)$ and are a majority in production and design positions (67.1\%) (Byerly, 2011, p.64).

Dabbous-Sensenig (2000) also argues that equal opportunities for women within the conservative media firms of conservative Arab countries, is especially difficult. She insists that a careful understanding and analysis of media ownership and sources of income is vital in affecting the changes needed when it comes to the adoption of gendersensitive communication policy. Sakr (2004) agrees, arguing that opportunities for employment are controlled by the same powers that have excluded women while using hiring decisions to serve political or commercial purposes. She also argues, like Skalli (2006) and Obeidat (2002) that more women working in the media will somehow automatically affect the media environment or its content. Sakr seems to agree with Van Zoonen's structural approach, which contends that women are not the ones that introduce changes in the structure of media organizations. Instead, it is changes to these structures that open the way to women's increased participation. Van Zoonen argues that more female journalists are hired primarily as a way to attract more viewers in a multichannel environment, where "the human interest angle in news" is key. With this conclusion, Sakr goes back to her original premise, which is that changes in the media are introduced by 
and with the permission of the ruling elite, in this case, the owners of the media firms. Robinson (2005) makes an interesting discovery that somewhat puts the onus of advancement on women themselves. Women, Robinson (2005) says, are much more hesitant than their male colleagues to accept promotions into upper management positions. Yet that, she adds, does not explain the reason behind this reluctance - which may be due to what Robinson labels as the systemic biases inherent within the media organization. The main problem with Robinson's work on Canadian television is that it is outdated and relies on a study she had conducted in 1995 (Freeman, 2007).

Skalli (2006) and Dabbous-Sensenig (2000) argue that power differentials in the socio-economic, political and media structures ultimately determine outcomes in terms of employment opportunities for women. While many scholars agree with this broad proposition, the debate over what to do about it is considerable. Sakr (2004), for example, argues that even though Middle Eastern women face the state, that is, the patriarchal state and its laws, in radically different ways than women in the West do, they must play a key role in the public sphere to press their case and for effective changes to the media in the Arab world to have a chance of succeeding. Dabbous-Sensenig (2000), however, follows other scholars such as Mernissi, who argue that women need to incorporate religion into their feminist struggle to challenge the hegemonic politico-religious elite. Mernissi believes that women should use the same religious texts, here mainly the Islamic text or Quran, used by the elite to justify their conception of gender roles as a way to discredit their argument. Likewise, Moghadam (2007) and Treacher and Shukrallah (2001) argue that associating feminism or feminist struggle for equality with Westernization, sexual liberty and secularism undermines the discursive and political space within which men 
and women can deal with gender differences and inequality. Kraidy (2002) seems to concur, observing that Arabs see a Western cultural invasion as a threat to their tradition, language and social codes and conventions. "Arabs in general believe in the importance of the family as the social unit, and perceive the West's focus on the individual to be a threat" (p.9). Sanam Anderlini, co-founder of the International Civil Society Action Network (ICAN) and member, as of 2013, in the Working Group on Gender and Inclusion of the Sustainable Development Network for the United Nation's post 2015 economic agenda, asserts that the conservative forces in the Arab world associate women's rights with immorality and westernization as a strategy to counter the gains made by women in the past (Deen, 2014).

Treacher and Shukrallah (2001) explain that women will likely pay a heavy price for challenging patriarchy in a region where many countries are "in perpetual fear of losing their boundaries, of being taken over and engulfed economically by either a Western nation or the United States" (p.7). The implications of such statements are many. By associating themselves with Western-based organizations or NGOs, women's struggles risk being seeing as anti-nationalist. Women are then forced to choose between their own interests and those of their nation. Feelings of nationalism and anti-Western sentiments have been the drive behind the development of what some Western feminists term as Islamist Feminism (Treacher and Shukrallah, 2001). This form of feminism incorporates the religious text, or sharia, Mernissi and Dabbous-Sensenig (2000) say, to justify its claims.

Arab women and Lebanese women in particular are not unique in their struggle to become equally heard and equally effective especially in the male dominated area of 
news journalism. As revealed what is unique about their struggle is that it can incorporate a religious dimension since resorting to Western notions of feminism or simply human rights may be deemed unacceptable. Effectively, Western women journalists face discrimination in essentially different ways than Lebanese women do. Studies that deal with news production and the professional conduct of journalists point out that the newsroom is a gendered space that ultimately and often unconsciously governs the interaction of journalists within that space (Allan, 2010; Byerly, 2004; Melin-Higgins, 2004; Ross \& Carter, 2011; De Bruin, 2004). In surveying the existing literature on strategies used by women to either maintain their positions or advance in the maledominated newsroom, Melin-Higgins (2004) identifies three main strategies. The first is women taking on the role inscribed to them by the dominant male culture. Van Zoonen describes these women as marionettes since they do not threaten the status quo of the newsroom but do not have much of a status themselves. The second tactic is women acting as one of the boys and trying to infiltrate the male dominated areas of hard news, foreign correspondence and decision taking. Though these women become part of the male culture, they are seen as threat since they challenge male supremacy. The last strategy is what Melin-Higgins dubs as being one of the girls. To Melin-Higgins (2004), this is an oppositional strategy that attempts to make the newsroom more feminine and is seen as more threatening than the other two strategies. To counter this strategy, the dominant newsroom culture resorts to strategies such as name-calling and attributes terms such as aggressive and unfeminine to these women. Whether Lebanese women adopt the same strategies is not clear, since no academic study distinctly documents the strategies that women employ to counter male dominance in the Lebanese newsroom. 
Whichever form of struggle they choose to adopt, Arab women, and mostly Lebanese women have become highly visible on the Lebanese television screens. They have developed their own fan base and program followers. They have also daringly challenged traditional mindsets by discussing taboo subjects. The main issue to be tackled is how much decision making power these women have. This also necessitates a discussion of the ways in which these women resist male dominance through positions of power.

\subsection{Women, Labor Policy and Media Policy}

More than fifteen years after the World Conference on Women and the Beijing Declaration in 1995 (Beijing, 1995) gender-specific media policies are still non-existent in the Arab world. Though Lebanon seems to have the most potential to be gendersensitive among its Arab neighbors as it is the most Westernized (Dabbous-Sensenig 2002), its media policies have remained outdated. "The union of the journalists' code of ethics, dating to the pre-Civil War period remains unrevised....it does not include gender provisions concerning the fair portrayal of women" (Dabbous-Sensenig, 2002). The same is also true of Lebanon's 1994 Audio-Visual Media Law.

Women's rights seem to be included under the banner of human rights in the Arab world, but the problem is the human rights for men and women are not the same. While Lebanon ratified the Convention on the Elimination of All Types of Discrimination against Women (CEDAW) in 1996, it did so with reservations that helped maintain the personal status codes, which are governed by the eighteen religious sects, and kept the discriminatory practices found in the civil, penal and labor laws. In effect, Lebanon's laws dealing with marriage, divorce, child custody and inheritance remain discriminatory. 
Lebanon's reservations on CEDAW`s Article 16 dealing with family law also meant that women had to abide by personal status codes with respect to child custody, inheritance and divorce issues. Lebanon placed a second reservation on Article 9 preventing women from passing on citizenship to their children, whereas a Lebanese man's wife and children gain the citizenship automatically. The citizenship law has been one of the most controversial laws that women's movements in Lebanon have been working on (Haidar 2007). Yet these movements have made some advancement with regards to the domestic violence law number 293 which was passed in May 2014. The law advances women's rights to safety and recognizes that abused women need protection from their husbands. Another advancement includes implementing harsher sentences on honor crimes after parliament annulled article 562 which mitigated softer sentences for people who commit such crimes.

When it comes to labor, Lebanon signed the International Labor Organization`s convention number 100 on equal remuneration in 1951 and convention number 11 on discrimination in Employment and Occupation in 1958. Yet the actual implementation of the conventions only came in 2000 (Haidar 2007). In 2001 women gained equal rights in terms of retirement and dismissal procedures and it was only in 2002 that the National Social Security bylaws affirmed that women employees like men are included in the word 'the insured. 'Despite the progress made, these bylaws are still discriminatory. "Article 3 of the legislative decree No. 3950 of the Employment Act and Article 46 of the social security law stipulate in the bylaws that the spouse of the male insured benefits automatically from all the Social Security remunerations while the spouse of the female 
insured can benefit only if proven to be incapacitated or handicapped, even though women's contributions are equal to men's" (Haidar 2007).

Despite the fact that the penal law and personal status codes remain discriminatory in Lebanon, employment conditions seem to present a more positive outlook for women. In investigating seven Lebanese news companies, 2 newspapers, 2 television stations and 3 radio station that employ more than 800 people including 250 women and 564 men, Byerly (2011) revealed that almost all of the companies surveyed employed both men and women in full time jobs with benefits.

Women, then enjoy the same job security as men (Byerly, 2011, p.66) and are treated equally in terms of hiring conditions as well as dismissal procedures and work benefits. Yet women are severely under-represented in governance and top level management $(14.8 \%$ and $21.9 \%$ respectively) and are outnumbered by men at a ratio of 2:1. This shows their lack of access to the news profession in general. "With such a level of marginalization, women have no meaningful involvement in the policy-setting and highest management levels of these companies" (Byerly, 2011, p.63). Add to that none of the Lebanese media firms surveyed offered child care assistance and only one has a gender policy in place and one has a paternity leave policy. The lack of gender policy and even paternity leave may be an indication of the lack of awareness within the companies. Most Lebanese organizations are probably unaware of the necessity of having gender policies in place. 
Table 4

Gender-Related News Company Policies in Lebanon

\begin{tabular}{lccc}
\hline Company policies & Yes & No & N \\
\hline Has a policy on gender equality & $14 \%$ & $86 \%$ & 7 \\
Has a policy on sexual harassment & $29 \%$ & $71 \%$ & 7 \\
Has a policy on maternity leave & $100 \%$ & $0 \%$ & 7 \\
Ensures women get same jobs back & $86 \%$ & $14 \%$ & 7 \\
Has a policy on paternity leave & $14 \%$ & $86 \%$ & 7 \\
Offers child care assistance & $0 \%$ & $100 \%$ & 7 \\
Offers educational training & $100 \%$ & $0 \%$ & 7 \\
\hline
\end{tabular}

As the above table reveals, the majority of the Lebanese news organization lack a policy on sexual harassment. Byerly's finding is not surprising since the Lebanese penal code and labor law do not have provisions related to gender discrimination or sexual harassment - its definition, implications or criminalization. The Labor Law, article 75, only mentions the right of the victims to terminate the contract in case the employer or anyone representing him or her performs an unethical act towards the employee or any of his/her family members.

Moreover, no gender provisions or laws against sexual harassment exist in the press syndicate's codes of professional conduct (Meliki \& Mallat, 2013). The studies on harassment in Lebanon are not many and those that do exist offer somewhat contradictory results. A study done by the Institute for Women's Policy Research (IWPR) and the International Foundation for Electoral System (IFES) in 2010 showed that $76 \%$ of Lebanese women never experienced harassment in the workplace. A 2014 study done by Mallat and Melki on women in news institutions in Lebanon revealed otherwise. The study employed a mixed-methods approach that included surveying 250 and interviewing in-depth 26 female journalists working at 80 local, Arab and international news institutions operating in Lebanon, as well as 21 freelancers- with an 
average response rate of $73 \%$. The survey results revealed that 2 in every 3 females or $65 \%$ experienced a form of sexual harassment at least once in their career. The most prevalent form of harassment was verbal sexual harassment. $54 \%$ indicated that joking or talking about sexual matters sometimes or often occurs in their workplace.

Another more recent study done in 2015 (Hejase, 2015b) on harassment in the Lebanese workplace surveyed 150 individuals to uncover that only $9 \%$ of the males and $12 \%$ of the females were sexually harassed at work. The study interestingly revealed that sexual jokes and prolonged staring came at the bottom of the harassment list with $33 \%$ and $32 \%$, respectively. Both jokes and staring were considered as typical activities practiced by Middle Eastern persons of both genders and were not usually considered offensive. This somewhat contradicts the findings of Melki and Mallat (2014) when it comes to sexual jokes and goes to show that the different scales of harassment are culturally conditioned and cannot be unified across cultures, and at times even work groups. Doubtless, the lack of sexual harassment codes in Lebanon does not help identify what is considered as harassment and what is not.

The deficiency in the lack of gender-specific rules is matched by a lack in media policy to spread awareness through content. Dajani (2006) laments the absence of public broadcasting to assert that the Lebanese media lack the ability to contribute information "to the flow of socially and politically constructive ideas" (p.8). Dajani (2006) concludes that there is an absence of public interest in television content. This is compounded by the inability of the state to produce communication plans or policies founded on public interest. Dabbous-Sensenig (2002) cites the importance of public broadcasting in giving voice to all segments of the population, mainly in Europe and in North America 
(especially Canada) only to emphasize that Lebanon's 1994 Audio Visual Media Law totally ignores the role that the Lebanese public broadcaster Tele Liban could conceivably play in spreading awareness about women's role in society in general and the media in particular. Instead, Tele Liban has been kept in a vegetative state, awaiting death, lacking in resources and personnel. The weaknesses of the 1994 Audio-Visual Media Law and the National Audio-Visual Council referred to above further compounds the problem.

Dabbous-Sensenig $(2002,2000)$ finds that there is a pressing need for the development of gender-sensitive communication policy to improve women's representation on the screen. She finds the portrayal of women highly problematic. Lebanese viewers are often exposed to a broad range of programming that shows the highly liberated Lebanese woman, a model of Western woman alongside "the ultraconservative, submissive, dependent and chaste ideal of the Arab woman" (p.2). However, while television displays sexually liberated women, Lebanese women are punished openly by law and discretely by tradition for being sexually promiscuous or simply liberated. As a consequence, Lebanese viewers and youth face a "schizophrenic situation where easily available media products are entirely out of sync with the society they live and the laws that govern society" (Dabbous-Sensenig, 2000).

\subsection{Images of Women in the Media: Empowerment and Disempowerment}

The next section shows that scholars writing on Arab television and more specifically Lebanese television are divided among those who believe it is empowering or disempowering to women. To the former (Amin, 2001; Cestor, 2010), television is an educational tool and a platform of free expression. To the latter (Abou El Naga, 2004), 
television is a platform for the suppression of women's rights, with women's image and body becoming sites of struggle between the overtly sexualized and the extremely religious programs - both of which are far removed from the representation of the actual Arab woman. Between the extremities of these two views is a wide spectrum of discussion that situates women's image and work in the media within its context and judges it accordingly (Sakr, 2007; Abu Lughod, 2005; Skalli, 2006). Getting acquainted with these views is necessary to understand how the Lebanese woman's presence is viewed on television especially since Lebanese women display more openness than women in the region and are often judged for this openness.

Scholars like Hussein Amin (2001) and Cestor (2010) find that Arab satellite television helps empower women by allowing them to exercise their right to seek and receive information. Amin believes that talk shows, interviews and news feature female leaders in business, government and politics rather than cover their role solely in the home or as sex symbols. Cestor (2010) analyzes the Lebanese music industry to show how the emancipation of women and young people from traditional boundaries is due, in part, to the dissemination of new role models embodied by popular singers.

Shereen Abou El Naga disagrees. Using Foucault's theory of discourse, she (2004) finds that both the religious discourse in serious talk shows and the body discourse in video clips are disempowering for women. Women, she says, are "caught between two extremities, capitalist patriarchy and patriarchal fundamentalism. Paradoxically, or rather ironically, both ideologies take the body as their cult" (p.2). In discussing video clips, Abou El Naga uses the examples of Lebanese singers such as Elissa, Nancy Ajram and Haifa Wehbe, who "stand for the cult of femininity where the body takes hold of the 
consciousness"(p.2), thereby causing a radical change in women's self and social image. Because of these women, Abou El Naga asserts, Lebanon has become renowned as the place of 'femininity' and sensual pleasure; in the process, the Lebanese women in resistance have been forgotten. Abou El Naga asserts that these overly sexualized images of women have been attacked by the press and have led to the creation of an opposing fundamentalist discourse, creating a moral crisis that has put women's issues on hold. Elmessiri (2010) agrees, asserting that the focus on carnal pleasures has made the body the sole source of identity. Advertisers capitalize on the vivid display of flesh, a type of sexual consumerism, he argues, to sell commodities, a process that effectively "dissociates the individual from moral and social values" (p.168).

Claims that television either empowers or disempowers women present us with two opposing notions or binary opposites which blur situational realities that may fall between. Sakr (2007) adopts Curran's contextualization framework that she claims is in tune with the realities of women's place in the Arab world. The framework proposes a synthesis between affirmative narratives and radical counter narratives to show how one action can introduce advances in some areas and reverses in others. The synthesis folds media histories into a more comprehensive narrative of society and dissolves linear narratives to replace them with a "more contingent view of ebb and flow, opening and closure" (p.86). Sakr's aim is to show how the work of Arab media scholars on women's advancement falls within the framework of contextualization as it reveals that these advancements were driven by specific agendas that may have changed over time. Sakr (2007) reviews and analyzes the work of other authors such as Amin and Abu Lughod, but does not conduct a field study. 
Lila Abu Lughod, according to Sakr, adopts a contextualized approach. Abu Lughod (2005) places her questions within the public sphere framework to ask whether women's participation in popular media forms reflects their participation in the public sphere, from which, "according to stereotypes, Middle Eastern women have mostly been excluded" (p.18). Yet she directly warns that "it is dangerous to generalize about women" (p.18). Abu Lughod (2005) invites scholars to look at the "social relations embedded in and embedding a media form as they work themselves out within particular social and historical circumstances" (p.19). Abu Lughod's invitation seems to fit perfectly into Curran's framework but is less conspiratorial or agenda driven than Sakr thinks. Abu Lughod (2005) studies the difference between women producers, actors and watchers of Egyptian serial dramas, only to end up concluding that the drama serial produced for the purpose of the development of women by what she calls progressive or liberal directors and writers are often framed in paternalistic terms that reaffirm the power of the educated over those who are illiterate and marginalized. Lila Abu Lughod (2005) warns that pronouncements about the potential for media to contribute to women's progressive change need to be questioned carefully. It is important to know who is using television to communicate with whom. Many of Abu Lughod's assertions about viewers of Egyptian serial drama come from a small sample of rural women. She does not identify the exact number of women she dealt with, but merely refers to studying "some" women in television production and the contributions of "some" viewers. Furthermore, she does not identify the questions that she asked viewers. Nonetheless, in analyzing her conversations with these women, she attributes some change in women's lives to television, but she is more inclined to believe the change is not progressive. She hints that women's 
acceptance of low paying jobs and the increased material consumption that has negatively affected marriage prospects in poor rural areas have been encouraged by television. Abu Lughod's (2005) original question about whether or not women's participation in media reflects their participation in the public sphere seems vague to me. Who are the women she is referring to - are they the directors, writers, actors or the viewers? If it is all of them combined, then Abu Lughod finds that their participation in the public sphere has led to their regression rather than progression. She falls into the very trap she had warned us against - forgetting about context. The very fact that these women were allowed to have jobs - something she says was unthinkable before ten years - is progress. The pay gap these women suffer from is not unique to them. Most women in first world and developing countries suffer from a gender pay gap. To be fair, Abu Lughod (2005) does not entirely dismiss the progressive effects that television may have but invites her readers to take into account the complex dynamics of interaction between television and values, class position, social standing and economic circumstances.

Skalli (2006), more optimistic than Abu Lughod, discusses the contributions of female journalists, feminist film producers/directors, publishers and bloggers. She uses examples of women from different Arab countries to show how women are redefining the public sphere "by producing alternative discourses and images about womanhood, citizenship, and political participation" (p.1). Women's creation of these alternative discursive spaces is happening despite what Skalli (2006) refers to as the institutionalized norms of exclusion and marginalization that restrict the physical mobility and visibility of women in media. Women's inclusion in the actual public sphere remains contested, according to Skalli, since "the male dominated politico-religious centers of power in 
Muslim societies remain ambivalent” (p.38) toward women's visibility and mobility. Well-aware of the exclusion of women, Skalli (2006) resorts to Nancy Fraser's subaltern counter-publics as her main theoretical framework to explain Arab women's role in media. Women's access to media, from this perspective, becomes an act of resistance that could help transform their realities even if it does not translate into gender, economic or political equality. Unlike Abu Lughod (2005), Skalli (2006) believes that the opening of new and challenging discursive spaces is, in and of itself, an achievement for women whose rise to decision-making positions is happening slowly. "Being a vocal female media professional in the MENA is an act of heroism," says Skalli (p.41). She gives the example of Jordanian, Algerian and Moroccan female journalists who placed their lives at risk to discuss taboo subjects. Skalli agrees with Magda Abu Fadil (2001), a prominent journalist and media scholar, who perceives that progressive women journalists are targeted by political and religious groups who find their opinions threatening. Skalli (2006), like Amin (2001), believes that satellite television bears much promise for the advancement of women, especially those who have gained Pan Arab recognition and fame. Skalli expects these women to destabilize old images of passive women with images of powerful women whose appeal is not restricted to their physical traits. Skalli gives the examples of female satellite journalists like Ghada Fakhri and Jumana Nammour. Skalli's article serves as a quick overview of the most prominent women's contribution in publishing, television and cinema. The author does not conduct field research, nor does she discuss any of her examples in details; in supporting her opinions she relies on scholars like Sakr, Amin, Abu Fadel and Mernissi to provide insightful 
conclusions on the value of women's media work in an environment of patriarchy and religious control.

It is in this environment that Matar (2007) discusses the Heya satellite channel, a Lebanese channel and the first Arab channel dedicated to women. Like Skalli, Matar (2007) uses Fraser's theory to show how Heya contributes to the creation of an Arab feminist counter-public. Matar analyzes three episodes from Al Makshouf (or In the Open) to reveal how hegemony is challenged in a program that brings issues that have long remained uncontested in the private sphere into the public domain. The counterpublic is achieved through the "management of discussion topics, choice of panelists and the handling of debates that give voice to women representatives to talk about gender inequality, the need to incorporate women in decision making and changing the power dynamics in society." Matar (2007) mentions that assessing Heya's impact on attitudes towards Arab women is beyond the scope of her essay but she does make it clear that she believes that women's access to the previously male-dominated spaces of the media is a significant advance.

Scholars express admiration for the new professional Arab female journalists that have managed to open new discursive spaces (Abu Fadel, 2001; Sakr, 2007; Amin, 2001; Skalli, 2006; Matar, 2007; Mernissi, 2004). To Mernissi (2004), the increasing demand for women intellectuals provides the leeway for women to become part of the communication power game. Presenting a new view on the phenomenon of the intelligent woman on the screen, Mernissi (2004) asserts that the male viewer has abandoned the archaic notion of being threatened by a powerful woman. Mernissi implies that man's masculinity no longer feeds on the passivity of women, in the age of satellite 
television, or what she dubs digital Islam. She finds that television presents a highly politicized space for the discussion of vital issues.

Sakr (2007) also delves into this issue by placing the increase in the number of women working in the media in its historical, social and political context. She argues that women have been able to make their mark professionally as successful journalists in times of peace and war, on talk shows or in the news. She shows how women have been employed to report on war in the region, and cites the 2006 Lebanese-Israeli war a key instance when women journalists shone. Yet Sakr (2007) also notes that despite their journalistic skills displayed during the war in Lebanon, the public preoccupation with the crisis meant that there was little space left for gender issues. She also looks at how Lebanese satellite channels have exploited the disparity in women's visibility in Arab countries as a means to attract viewers. LBCI and Future Television, for example, employed women in "low-cut attire" to woo Gulf viewers who were not used to seeing women on their screens. A joke circulating at the time was that LBC meant "ilbissi" or "get dressed" in Arabic. Dabbous-Sensenig (2007) agrees with this assessment, attributing the increased number of women in Lebanese media to their visual appeal rather than their professional qualifications.

To Kraidy $(2000,2008,2010)$, the use of women on Lebanese satellite television channels is part of the channels' marketing strategy. LBCI and Future are primarily commercial firms and secondarily instruments of propaganda. They use the "relaxed sexual acceptability" allowed on Lebanese television, but barred from most Gulf national television stations, to attract advertising and audiences. Kraidy (2005) also uses fieldwork, textual analysis and interviews to show how the controversy surrounding 
reality TV shows such as Star Academy, aired by LBCI, Super Star and Future Television brought many of these competing arguments into the public sphere. "During the second two months of the first season [March and April 2004], Star Academy was invoked on television talk-shows and in newspaper columns as a code word for contentious issues such as Arab-Western relations, the status of women and youth, and elections" (Kraidy, 2005). The program generated intense debates because of its "display of bodies in motion and the self-made claim that reality TV represents reality." Star Academy triggered the issuance of fatwas from Saudi Arabia, parliamentary debate in Kuwait and Algeria and media conflicts between Lebanon and Syria (Kraidy, 2008). Kraidy (2005) asserts that the public discourse around Star Academy and other reality programs suggests that these shows have an impact on Arab public discourse and politics. By describing the discourse to be somewhat politically democratizing, Kraidy takes a positive stance with regards to the controversial discourse being generated by reality television. Overall, most scholars appear to agree that television has opened up a new professional and discursive space for women.

\subsection{Lebanese Television: Male Dominated but Women Populated?}

It seems that the structural integration of the media into the male dominated preserve of political factions and religious sectarianism has not opened up much space for women within positions of ownership, decision-making, and power. In terms of women's role as journalists, talk show hosts and a source of images on the television screen, the status and representation of women is much more ambiguous. Indeed, we can see that there has been significant progress, on the one hand, in terms of female television personalities and the range of positions that women play on the screen, while 
recognizing, on the other hand, that increased representation has not been matched by women assuming positions of power or a reconciliation between the seemingly more open roles they occupy in media depictions versus the legal and socio-cultural constraints they face in "real life."

This in-depth study of the Lebanese television will help show why a female populated medium is still mostly male dominated and why women end up not occupying the higher positions in the profession or leaving before they get promoted to these positions. Understanding the why behind their presence as a minority in upper management in a medium that has helped promote an image of the highly liberated woman to nearby stringent Gulf states will help reveal the internal and external factors that women need to work on to reach more effective positions. 


\section{Chapter: Field-Gender Theory Approach}

Choosing an appropriate theoretical framework for this study is conditioned by the elements that will be studied. The main concern of this study is the Lebanese women news journalists in television and their advancement. As observed in the literature review, the social, cultural and economic context in which the employment and progress of women takes place is highly politicized, sectarian and patriarchal. To examine the progress of women journalists in such a context entails an understanding of the cultural and social milieus which ultimately govern the existent gender relations and condition women's behavior and progress, both within the society and the newsroom. The study's central question of why and whether women remain under-represented in top management positions in the Lebanese television newsroom is to be answered through a number of inquiries. These inquiries include the positions that women occupy in the newsroom, the obstacles that hinder their progress, whether their religious and political affiliations have any implications on their employment advancement and departure from the profession, and finally the forms and the strategies of struggle that women and men in the field of the Lebanese television newsroom use. Another important issue to consider is whether or not women make professional or personal sacrifices to reach high positions.

The main theoretical frameworks best suited to conduct the study, then, would be theories that take into account the external, societal and cultural factors in terms of how they may translate in internal organizational constraints or incentives for the advancement of women. Those theories are the field theory proposed by Bourdieu and gender theory. The frameworks will be supplemented by the concept of the glass ceiling. 
The concepts of each theory will be discussed in details to show how the theories complement each other in studying women in the Lebanese television newsroom. The last part of this chapter shows how the gender theory and the field theory along with the glass ceiling concept can be analyzed within Bourdieu's logic of practice.

\subsection{Bourdieu's Field Theory}

Surely sociology would not be worth an hour's trouble ... if it did not give itself the job of restoring to people the meaning of their action. (Bourdieu 1962 as cited by Grenfell, 2004)

What makes Bourdieu relevant to this study is not only his field theory but his application of the theory to the field of journalism and its discussion within the context of television. To understand the theory, it is necessary to understand its four basics concepts of field, capital, habitus and doxa. How these concepts interact provides the key to Bourdieu's theory.

\subsubsection{Field}

Bourdieu rejects the empty and vacuous notion of society to replace it with that of field. Society becomes a set of related fields, each with its own rules, resources and logic. The field is the system of social relations where actors interact, a space where they express their disposition and compete over various forms of capital. It is the many spheres of play - "a patterned system of objective forces (much in the manner of a magnetic field) a relational configuration endowed with a specific gravity which it imposes on all the objects and agents which enter in it... A field is simultaneously a space of conflict and competition" (Bourdieu \& Waquant, 1992, p.17). The many social arenas then form semi-autonomous fields characterized by specialized action structuring social relations. All forms of human activity have their own fields: literature, art, 
religion, economics and even journalism (Neveu, 2007). Journalism is therefore a subfield situated within the bigger field of cultural production. In On Television, a book adapted from two televised lectures dealing with the issue of journalism, power and television, Bourdieu (1998) describes the journalistic field as "a field of forces, a force field. It contains people who dominate and others who are dominated" (p.40). In this field, where relationships are constantly characterized by inequality, actors strive either to transform or preserve the field (Bourdieu 1998, p.40). The actors' efforts, either to preserve or transform the field, are warranted since the field acquires a life of its own. Once the field is formed it gains a certain degree of autonomy from external pressures. It becomes a "microcosm with its own laws, defined both by its position in the world at large and by the attractions and repulsions to which is it subject from other such microcosms" (Bourdieu, 1998, p.39). Each field becomes endowed with its own logic, a set of formal and informal rules that characterize it and the agents that operate within it. Following this line of thinking, the newsroom, itself, becomes another microcosm "a hierarchal social space.... reflecting a position in the journalistic field as well a position in the field of cultural production, the field of power and in the overall social space" (Schultz, 2007, p.192, 193).

Yet the autonomy of the field is not complete. As a field of cultural production, the journalistic field, and the field of the newsroom for that matter, is more dependent on external forces than other fields of cultural production (Bourdieu, 1998, p.53). In effect, the field of media in general combines both the economic power reflected in the generation of revenue and the symbolic power or its "capacity to produce the reality effect" (Bourdieu, 1998, p.21). The media then provides a social construction of reality 
thereby imposing a new way of seeing and of conceptualizing the world (Bourdieu, 1998, p. 21-22). In other words, Bourdieu (1998) asserts that the journalistic field which is affected by economic forces, one form of which is audience rating, in turn affects other fields such as politics and other areas of cultural production (p.56). Journalism then functions as a somewhat autonomous field situated within a bigger field of power where each field's influence differs depending on the context within which the journalistic field exists. Journalism, in effect, dynamically interacts with the political, economic, and social spheres that exist within its context just as it may interact with other spheres of influence including patriarchy, religion, and the state, as is the case in Lebanon:

External determinants can have an effect only through transformations in the structure of the field itself. In other words, the field's structure refracts, much like a prism, external determinants in terms of its own logic, and it is only through such refraction that external factors can have an effect on the field. The degree of autonomy of a particular field is measured precisely by its ability to refract external demands into its own logic. (Johnson, 1993, p.14)

The excerpt above presents much insight about the dynamic relationship between the journalistic fields and the external fields that influence it. The nature of the relationship sets the everyday ground rules by which the field operates. The independence or the autonomy of the field relies on the extent to which the field intelligently blends the external demands into its own logic. The influence that other fields have on journalism does not deprive the journalists from agency. In fact, Bourdieu emphasizes the agency of the individuals in the field as they put the resources available to them into use in setting their strategies and reaching their goals, within the field. Interestingly, Bourdieu (1998) asserts that the "television now dominates the journalistic field both economically and symbolically" (p.41). 


\subsubsection{Capital}

The competition that occurs, among the agents in the field, is over the capital that is effective and is functionally specific for each field. Capital according to Bourdieu is understood as "the set of actually usable sources and powers - economic capital, cultural capital and also social capital" (Bourdieu 1984, p.114). The actors' position in the field is a result of their capital. Each form of capital has its own set of indicators. The indicators of cultural capital include education and skills, those of economic capital include income and material wealth, and the indicators of social capital include group membership as well as social networks. According to Bourdieu (1986), cultural capital can exist in three distinct forms:

- the embodied state or "the long lasting dispositions of the mind and the body" is essentially a fundamental state acquired through cultivation. This form of capital is linked to both hereditary transmission and acquisition. "It manages to combine the prestige of innate property with acquisition" (Bourdieu, 1986). It is generally marked by its earliest conditions of acquisitions - a good example of which is pronunciation.

-the objectified state: is cultural capital objectified in material objects and media or in the form of cultural goods such as books, instruments and paintings. This form of capital can be appropriated materially and symbolically. -the institutionalized state or a form of objectification - an example of which is the educational degree. By granting institutional recognition to cultural capital that is possessed by a social agent, the academic qualification, according to Bourdieu, allows for the comparison of qualifications and to an economic 
determination of the value of the cultural capital owned. Conversion can take place between the cultural capital and the economic capital since the academic qualification has a monetary value. Cultural capital can, then, facilitate "the acquisition, maintenance and growth of other forms of capital," (Karim, 2005, p.147).

For the purpose of this study only the institutionalized form of cultural capital will be examined. Examination of both the embodied and the objectified states would require an in-depth research into the personal life of those interviewed; an endeavor that is beyond the scope of the study. Nonetheless, the degree and the skills acquired will form an essential area of analysis. In terms of education, Lebanon is home to many universities, yet the most prominent ones that offer communication and journalism degrees are Notre Dame University (NDU), Universite Saint Joseph (USJ), American University of Beirut (AUB), Lebanese University (LU) and Lebanese American University (LAU).

Social capital or in simple terms group membership "provides each of its members with backing of the collectively owned capital, a 'credential' which entitles them to credit... These relationships... may be socially instituted or guaranteed by the application of a common name(the name of a family, a class, or a tribe or of a school, a party, etc.) and by a whole set of instituting acts designed simultaneously to form and inform those who undergo them " (Bourdieu, 1986). The person's social capital is then formed of the social connections that the person can mobilize for a specific benefit. These connections are not a natural given and a person has to invest in these relationships which are built on the basis of solidarity and are maintained through social obligations and commitments. In the Lebanese society, social and familial connections play a prominent 
role in advancing relationships on the social, economic and even legal levels. People, for instance, often use their connections to get to their objectives in round about ways. These connections may help them get employed or get a legal paper they would not have received otherwise. Familial connections are also very prominent since high ranking positions, especially in politics and at times in media firms are endowed by virtue of kinship ties. An example of both would be Nayla Tueini, daughter of murdered parliamentary member Gibran Tueini. Upon her father's death, Nayla was elected as a parliamentary member in 2009 to fill in for her father and after the death of her grandfather, Ghassan Tueini, owner and publisher of prominent Lebanese newspaper An Nahar, Nayla took over as chief editor of the newspaper. "Who you know" and "what family you are born into" then play a major role in the Lebanese community and help advance or hinder one's future prospects. The Lebanese community is well aware of the potential present in the social capital and members work on maintaining these social relationships, often nurtured through exchange.

What Bourdieu terms as "usable sources," are the chosen aspects of capital that can be used in a field in accordance with the specific logic of that field. To put it in simple terms, agents mobilize different forms of capital for different fields (Bourdieu, 1984, p.113).

\subsubsection{Habitus}

The interaction of agents within the field happens through habitus - a pattern of thoughts that actors acquire as they interact with their environment by acting on it and being acted upon by it. "Habitus is a structuring mechanism that operates from within agents, though it is neither strictly individual nor in itself fully determinative of conduct" 
(Waquant and Bourdieu, 1992, p. 18). Habitus then is formed by the interaction between free will and determined structures and as such is reproduced unconsciously. It allows agents to cope with changing situations. "The concept of habitus (dispositions) enters as an absolutely decisive connection in between individuals' objective positions in society and their subjective positionings (their choices)" (Jarvinen 1999, p.16). The habitus can be said to function through practical reason as it is a set of relationships where the objective and the subjective dispositions come together or collapse to coordinate interaction in specific settings. Habitus then mediates between structure and actor moving them from positions to choices (Jarvinen 1999). The habitus in Bourdieu's words enables "agents to cope with the unforeseen and ever changing situations.... a system of lasting and transposable dispositions which integrating past experiences,.. makes possible the achievement of infinitely diversified tasks" (Wacquant \& Bourdieu 1992, p.18). In other words, what directs the actors' actions are strategies that they have learned work in a specific system given through the utilization of a specific capital - "unconscious schemata acquired through lasting exposure to particular social conditions and conditionings" (Wacquant, 2006). Though actors may share the general experience, each essentially has a unique individual variant of what is shared (Wacqaunt, 2006). In more practical terms, habitus is a conceptual tool that allows us to analyze how different agents have different positions and how these positions serve as different dispositions for social action. Within the professional habitus then or professional game, a young intern occupies a different symbolic space within the newsroom than a seasoned editor. Their dispositions are not the same and therefore their opinions on the same issue are dealt with differently (Bourdieu, 1998). 
In explaining habitus, Bourdieu describes it as the "feel for the game", "le sens pratique" since it is what enables actors or agents of making an infinite number of moves, in reaction to an infinite number of "possible situations which no rule, however complex can foresee" ( Honneth, Kocyba \& Schwibs, 2000, p.8). Yet the actors play the game from different positions and have different dispositions with which they can master the game. To Bourdieu, then, people are not conditioned by the social forces but are actors whose actions are governed by their own assessment rather than by what makes the most rational sense - Bourdieu explicitly mentioned "the logic of practice is logical up to the point where to be logical would cease to be practical" (Bourdieu 1990, p.96).

\subsubsection{Doxa}

What is practical is also determined by the doxa where interaction between the agent and the field takes place. The doxa is a wider network of assumptions, mostly unconscious, within which the actors act, an often unconscious conceptual milieu. In explaining doxa, Melin-Higgins (2004) describes it as a "mere set of values, created meanings" an official definition "of what is reality, what is journalism" imposed by the dominant groups and accepted by both the dominant and dominated. The dominant groups are the established elite and the dominated are the newcomers to the field. MelinHiggins (2004) asserts that oppositional groups who oppose the doxa are aware it is merely formed of created meanings. In the battle for symbolic power, the oppositional groups oppose those meanings and form a threat to the dominant group.

In simpler terms, the doxa is a kind of common sense (Bourdieu, 1988; 2005). It is not questioned as it becomes perceived as natural. Practical schemes meant to organize the world are constitutive of the doxa. Yet they are hard to make explicit or hard to 
explain. Doxa clearly has a gender dimension. In La Domination Masculine (1998),

Bourdieu proposes that male dominance relies on the symbolic power to define the doxa which entails the belief that what is masculine has a superior status and what is feminine has an inferior status.

Bourdieu (2005) provides a fine example of an American sociologist who made a study on the opposition of "hard" and "soft" showing that hard which is masculine and soft which is feminine correspond to the distribution by sex of the various disciplines. “These seemingly vague, 'fuzzy' oppositions are very fundamental in that when a whole society has them in its head, they end up defining reality" (Bourdieu, 2005, p. 37). Given that each social field has its own doxa, in the above example which is gender-focused, Bourdieu warns that the practical schemes which constitute the doxa are never questioned as they define the field's reality.

\subsubsection{The Game Metaphor}

The doxa, along with habitus and capital form the key to Bourdieu's field theory. To illustrate how these concepts work together, Wacquant and Bourdieu (1992) relied on the game metaphor. Nonetheless, Bourdieu warns that unlike the game, the field follows rules that are not explicit or codified (Bourdieu \& Wacquant, 1992, p.98). In applying the game metaphor to journalism in the Lebanese television newsroom, the newsroom field becomes the newsroom game. The struggle within the game is defining what the game is and its logic of operation. It is therefore the struggle to define what the meaning of the field along with its internal logic of practice as a microcosm that exists in dynamic interaction with other microcosms, such as politics, economics, religion and patriarchy. The doxa then becomes the core beliefs that direct the newsroom practice. By agreeing to 
be part of the journalistic game, the journalists indirectly express the belief that the game is worth playing. Doxa is therefore the belief in the game and the stakes involved in playing that game. Habitus, on the other hand, is how the news game is played - it is simply the manner in which the journalists position themselves in the game, their strategic orientation toward the game and the force they have. It is something which Bourdieu would describe as their "game." This positioning is conditioned by the journalistic capital that the journalists possess. The capital is comprised of the game specific resources that are recognized as assets in the journalistic field. The field becomes a structured arena in which agents, who have different potentials and positions, struggle to define the structure of the field. Yet "they do not struggle freely: they struggle in a manner consistent with the position they occupy in the field" (Wacquant, 1989). The agents are differentiated based on the point of view they take on the field.

This leads us to questioning the classification of Lebanese women in the journalistic field of the Lebanese television newsroom. What is the status of these women journalists- are they the dominant or the dominated? What kind of capital do they possess and what kind of capital do they capitalize on to play their "game"?

Investigating women journalists in Lebanese television through the eyes of Bourdieu is, without doubt, an interesting endeavour. To Bourdieu, the "journalist is an abstract entity that doesn't exist. What exists are journalists who differ by sex, age, level of education, affiliation and medium" (Bourdieu, 1998, p.23). This journalist, then, exists in a field of forces, in this case the Lebanese television newsroom, where the main endowments that enable progress are formed of capital. The above definition places affiliation, education and skill within capital- they are, in effect, classified under the 
social and cultural capital - the only forms of capital that will be discussed in this study.

As the study takes place in a highly politicized and sectarian television environment, a Lebanese woman journalist's social capital includes her political and religious affiliations, along with 'who she knows' in and outside the field. Her cultural capital is her education, competence and knowledge. The various "species of capital" operate simultaneously within the field and will be examined as the major determinants of progress within that field.

After all, the task of science for Bourdieu is to "uncover the structure of the distribution of species of capital which tends to determine the structure of individual and collective stances" (Bourdieu and Wacquant, 1992, pg. 114). He does this through the examination of the forms of capital that operate in any given field and the practical logic according to which they operate. An example he provides to the field of education, in his On Distinction: A Social Critique to the Judgement of Taste can help explain Bourdieu's approach:

...in every relationship between educational capital and a given practice, one sees the effect of the dispositions associated with gender which help to determine the logic of reconversion of inherited capital into educational capital, that is, the 'choice' of the type of educational capital which will be obtained from the same initial capital, more often literary for girls, more often scientific for boys. Again, the relationship of a given practice to age may conceal a relationship to educational capital when age is in fact the key to different modes of access to the position. (1984, p.105)

Bourdieu, then, rejects the notion of "linear thinking" (Bourdieu, 1984, p.107) which can only be described in terms of linear relations, when there is a network of interrelated relationships functional in each of the factors. According to Bourdieu each factor carries a different functional weight depending on the field and it would be imperative for a 
study on Lebanese women journalists in television to determine what factors and what forms of capital carry more weight than others. Bourdieu explicitly mentions:

...the factors constituting the constructed class do not all depend on one another to the same extent and that the structure of the system they constitute is determined by those which have the greatest weight. Thus the volume and composition of capital give specific form and value to the determinations which other factors (age, sex, place of resident, etc..) impose on practices. (1984, p.107)

Bourdieu does not limit the endowments affecting the actors to capital but adds the factors of both age and gender. By factoring in age and sex (gender), Bourdieu's field theory becomes an effective tool for the explanation of the gendered structures within the Lebanese television, in general and the newsroom environment, in particular. In reviewing Bourdieu's gender theoretical reasoning, Jarvinen (1999) describes the doxa, habitus and symbolic power as essentially gendered. To Jarvinen (1999), the categorizations made in the social field are based on differences between the different habitus, basically the difference between men and women. The struggle in the journalistic field, then, becomes a struggle of the sexes - a concept, I do not fully agree with as it imposes much limitation on Bourdieu's theory. The struggle also includes capital, which excludes gender. Gender is, in fact, part of habitus - the structuring mechanism, but not all of habitus.

In Distinction, Bourdieu does not hesitate to mention that the lowest positions are occupied by immigrants and women. He also identifies a number of occupations in the social, medical and domestic services that are "reserved for women" (Bourdieu, 1984, p.108). It is as if Bourdieu was referring to the concept of glass ceiling, which describes how women remain bound to lower and middle management positions. The upcoming sections discuss the theory of gender and the concept of the glass ceiling. 


\subsection{A Gender Theory Medley}

Why use gender theory for this study? The main reason, to use Gertrude Robinson's words, is because "gender matters" (Robinson, 2005, p.1). And gender matters simply because women and men work alongside each other in media and each of them brings a gendered perspective into what is being delivered to the public. Although whether women bring a new view point to media content is still controversial (A. Joseph, 2005), international studies (IWMF, GMMP) as well as studies done by prominent scholars (Franks, 2013; Carter \& Ross, 2011; Made \& Morna, 2010; North, 2009; Creedon \& Cramer, 2007; De Bruin \& Ross, 2004; Robinson, 2005; Djerf-Pierre \& Lofgren-Nilsson, 2004; Chambers, Steiner \& Fleming, 2004) seem to directly or indirectly imply that women have an effect on media content. North (2009) asserts that newsroom culture is shaped by gender and "the news media represents the world to us, shapes our knowledge and histories and influences our thinking about everything from seemingly simple and non-political issues such as fashion and health to international politics" (p.23)

In theorizing gender, this study will mainly rely on Western notions of the theory of gender along with Suad Joseph's approaches to gender in the Middle East. Mixing both the Western and Eastern perspectives on gender will help enrich the study and elaborate the commonalities as well as the differences that both gender theories have while remaining sensitive to the Middle Eastern, and more specifically, Lebanese context.

The first part will entail a broad discussion of the shared assumptions that feminists have of gender theory and will also include a Middle Eastern perspective of gender through Suad Joseph's notion of patriarchal connectivity. Suad Joseph's 
patriarchal connectivity will help us deal with the Lebanese television as part of the cultural makeup of the Lebanese community; the newsroom then becomes defined through relationships of kinship and brokerage which may also be conditioned by political and religious affiliation - the two main areas under research as to how they affect women in this dissertation. The second part details shared observations that Western scholars have revealed in their studies within the gendered newsroom including: the masculine aura of the newsroom, gendered division of the news (hard and soft news), importance of context, young age of women journalists, women's family obligations, sexual harassment and strategies used by women. These observations define what women journalists experience in the newsroom and will form along with Joseph's patriarchal connectivity the main concepts that will be examined. . The investigation of these concepts will lead to the answering of the main question posed by this dissertation as to why women remain under-represented in power positions in the Lebanese television newsroom, along with the obstacles that women face, the strategies they use and whether they offer compromises. Ultimately, the purpose is to uncover how and to what extent these elements act as capital within this specific Lebanese newsroom, governed by a specific doxa and within which a certain type of habitus comes into play.

\subsubsection{Main Shared Assumptions}

Gender is socially constructed. Unlike sex, which is biological, gender is the result of interaction with culture and society. Considering that this interaction is fluid and ever changing in nature, perhaps it is Van Zoonen's definition of gender that best describes this flexibility. According to Van Zoonen (2006), gender is a "set of overlapping and contradictory cultural descriptions and prescriptions referring to sexual 
differences" (p.41). In other words, it comprises "the socially produced differences between being feminine and being masculine" (Holmes, 2007, p.2). Gender, therefore, affects the self-concepts of men and women, their social and political attitudes as well their relations and perceptions of others (Andersen \& Taylor, 2015). Like identity gender is a product of "circumstances, opportunities and limitations" (Van Zoonen, 2006, p.31). Gender's main focus is on men and women and the relationship between them (Van Zoonen, 1994). In investigating women as social actors, gender theory tries to uncover how women's asymmetrical power positions have come about relative to men. Conceptualizing gender as such allows for multiple subjectivities among men and women as well difference and variety.

In constructing a theory of gender, Robinson (2005) mentions that there are common agreed upon elements that feminists, in general, share. Maintaining that gender, like identity, is a social construction, these theories mainly focus on the female experience. This investigation of the female experience entails the creation of new categories to codify this experience to include factors such as emotions and subjectivity. Yet confining the investigation to gender as a single analytical category would be limiting (McCall, 2005). The investigation also requires the inclusion of "the multiple intersections in and around gender, gender relations and gender powers" (Lykke, 2005) or what is termed as intersectionality. These intersections between gender and power differentials based on age, class, sexuality, culture, economy, violence and other social divisions are continually changing (Lykke, 2005). Though the nature of the study does leave room for an in-depth exploration of intersectionality, nonetheless, the many intersections between gender and field theories provide an examination of gender within 
various power deferentials. Suad Joseph would include what she terms as patriarchal connectivity to describe how women experience the self within the Arab and more specifically, the Lebanese society which is governed by patriarchy and relationality.

\subsubsection{Patriarchal Connectivity}

According to Joseph (1999), the Lebanese society is neither individualist nor is it corporatist; it is relational and the relational matrixes are embedded in kinship and relationships of proximity forming a connective self. Combined with patriarchy, the connective self produces patriarchal connectivity, a construct which Joseph uses to explain the gendered relationships within the Lebanese community.

Joseph defines patriarchal connectivity as "the production of selves with fluid boundaries organized for gendered and aged domination in a culture valorizing kin structures, morality and idioms" (Joseph, 1999a, 2000). While both patriarchy and connectivity entail cultural constructs and structural relations, patriarchy privileges male and elders (both males and females) in directing the lives of others. Connectivity, on the other hand, implies inviting, requiring and initiating involvement with others in shaping the self. The combination of connectivity with patriarchy in Lebanon has led to the creation of "fluidly bounded selves oriented towards relationships organized by principles of gender and age hierarchy" (Joseph, 2004, p.274). Connectivity in patriarchal societies can therefore support and enhance patriarchal power as males and elders expect females and juniors to anticipate and respond to their wishes knowing that females and juniors have been socialized into a system of relational subordination. "The connective patriarch may view his wife (wives), sister, junior siblings and children as extensions of himself. He may speak for them, make decisions for them, read and expect to be read by them" 
(Joseph, 1999). Within such a system, all members including females and juniors are active participants in propagating relations of inequality. Yet the level of relationship inequality may differ considerably between the Lebanese families which may be classified into traditional and modern (Tayar, 2013). While the man is considered the absolute financial and social authority in traditional families, he tends to share these responsibilities with his female counterpart in the more modern family (Tayar, 2013).

In effect, none of the actors, in both the traditional and modern family, is without agency. Yet the agency they have does not conform to the Western individual-bounded, autonomous, self-contained, separated form of agency. Instead, it is "situated, contextual and relational" (Joseph, 1999a, p.15). The actors ambitions and desires are shaped by the web of relationships they are essentially part of. Women and children, operating within masculine and age privileged mechanisms of patriarchy, negotiate the outcomes that suit them best (Joseph, 1999). Joseph, then recognizes the power of the structure while insisting on the agency of the self, a reminder of Bourdieu's concepts of habitus and capital - where the individual has to deal with a structured doxa and habitus through use and manipulation of capital.

Joseph's patriarchal connectivity, in fact, deals with relational rights - or what Bourdieu would call social capital. According to Joseph (1999a), one comes to have rights or access to resources by being invested in relationships, particularly kin relationships. It is kin relationships that differentiate the Middle Eastern concept of patriarchy from what other feminists, term as "masculinist" states. The "kin based communal entities and their particular forms of incorporation into different systems of governance either as recognized parts of the political system or as the source of various 
forms of nepotism and clientelism" shows that centrality of kinship within Lebanese patriarchy (Joseph, 2000). That kinship is at the heart of social, political, economic and communal action in Lebanon is reinforced by the constitution which places family as the unit of society rather than the individual (Joseph, 2004). Therefore, the incorporation of patriarchal kinship modes of operation in the political, social, or economic arenas is not seen as a disruption to the boundaries of the state or the family but as continuous to them. In effect, the more invested individuals are in kin relationships the more access to state and public resources they have. Lebanese youth and women can be empowered by their kinship relationships. "Kin relations are the building blocks of brokerage (wasta), the first or intermediary nodes of political, economic and social networks" (Joseph, 1999).

Political leaders, for instance, often bring their own family members into governance and can mobilize parts of the population through family units (Joseph, 2000). Lebanon is more or less a state of connections or relations. Just like the male patriarch sees his wife and children as extensions of himself so do political leaders act like the male heads of a patrilineal decent and speak for their patrilineal members. They often distribute services or give access to resources through male elders. Political patrilineality is even more visible in the transforming of leadership from father to son in political parties, parliament, state positions and other public leadership positions. This has kept little room for women in the political arena. The very few women that have come to power, have reached these positions through inheritance. Nayla Tueini, a current member of the Lebanese parliament for instance, took the position in 2009 after the assassination of her father Gibran Tueini. Nayla Mouawad also rose to political power after the assassination of her husband, ex-Lebanese president Renee Mouawad. Moreover, 
Lebanese people often resort to their kin when they are in need for brokerage, loans, references, or any other form of assistance.

How have these kin relationships become possible and how have they led to patriarchal connectivity? The answer lies within the organization of the Lebanese state itself and the construction of an individual with a prominent political, religious and connected self. First, the Lebanese state is one organized around familial ties "reinforced by class, religious, ethnic, regional and ideological alliances” (Joseph, 1999). In such a state, "leaders and followers often offer and obtain access to information and services and protections by mobilizing networks grounded in relations of proximity, the most central of which is kinship" (Joseph, 1999). Relationality then becomes a mobilizing force - it is all about where you come from, who you know, what religion you belong to and what political and religious connections you can activate when you are in dire situations. It is a situation of fluid boundaries between the state and the family, the public and the private and the personal and the political. These fluid boundaries are augmented by the Lebanese civil war from 1975 to 1991 which weakened the state and making familial relationships the primary protector of a person's security (Joseph 2004).

Second, the individual is not just a human being with rights. In a confessional democracy like Lebanon, where political positions are divided in accordance with religious sects thereby reinforcing recruitment to state positions through religious identity, people's political and religious membership define them as citizens and define their rights and their access capabilities. While some rights are shared, the Personal Status Codes as mentioned in the literature review differ for the 18 recognized religious sects in Lebanon which abide by 15 recognized status codes. The Lebanese do not share a 
common legal culture with regards to basic issues related to women, civil rights and to children. In fact, they experience different legal realities depending on their patrilineal religious heritage. This condition of sectarian pluralism is one of the main sources of patriarchy and gender inequality, since most religious sects reinforce patriarchy under a general system of patrilineality imposed by the state. Ultimately, it is what religion you belong to, who you are and who you know.

Women then under patriarchal connectivity are conditioned by religious and political connections under conditions privileging males' rights. Women may use these connections as capital to mobilize conditions for their own benefit. Women will also have to negotiate the best possible working and living conditions within the boundaries of a patriarchal mindset reinforced by state and religion. Whether and how women mobilize their kinship based networks in the Lebanese television newsroom and how they negotiate the existing patriarchal connectivity structure are to be investigated in this study.

\subsection{Women in the Newsroom: Scholars Shared Findings}

Scholars dealing with women's experiences in the world of news have come upon similar findings. These findings form the main concepts through which the theory of gender will be investigated as they form a preliminary lens through which the female journalist's experience will be described. The main concepts include: soft and hard news, context and power, age as a discriminatory factor, women in management affecting content, sexual harassment, and newsroom strategies. 


\subsubsection{Gender: Soft and Hard News}

Gender research shows that gender operates on the individual, interpersonal and group levels. To put it differently, gender "informs the social and the symbolic work we do to identify ourselves as women and men in social situations as well as the meanings we attach to these behaviours" (Robinson, 2005, p.7).

As a system of classification, gender divides men and women into two mutually exclusive categories although all people have male and female traits such as honesty, individualism, perseverance and emotion within them (Robinson, 2005). It functions as a "structuring structure locating women and minorities into a dominant-subordinate caste system that requires women to constantly announce and act out their subordination" (Robinson, 2005, p.7). Van Zoonen (1998) explicitly states that the masculine norms in the journalistic profession become the professional routine by which all journalists must abide. As a result, research on women in journalism often shows how men's news selection differs from that of women and how women are often assigned to the lighter news items or soft news while men handle the more prestigious hard news (Franks, 2013; Ross \&Carter, 2011; Ross 2010; Robinson, 2005; Gallagher, 2005). Although scholars differ on the definition of what constitutes soft and hard news, there is a general agreement that soft news deals with social issues such as child care, the environment, the elderly, human interest, education and culture, while hard news deals with politics, business, economics, technology, science, and crime. Along the same lines, Djerf-Pierre (2007), in a historical study of the field of journalism in Sweden, proposes that dichotomous gender logic still governs the field. Masculine journalism is associated with more powerful male sources, is objective and neutral and is governed by professional 
ethic. Feminine journalism, on the other hand, deals with everyday issues, is governed by emotions, empathizes with given situations and is more likely to consult with female sources:

Table 5

Masculine and Feminine Traits

\begin{tabular}{ll}
\hline Masculine & Feminine \\
\hline The public sphere/ elites & Private/intimate sphere/everyday life \\
Male sources and perspectives & Female sources and perspectives \\
Distance/neutrality/objectivity & Intimacy/empathy/subjectivity \\
Autonomy ("professional" criteria) & $\begin{array}{l}\text { Oriented toward the reader's (etc.) needs } \\
\text { and interests }\end{array}$ \\
\hline
\end{tabular}

The dichotomy often described leads us, in fact, to wondering about how complex situations within this divide may be dealt with. Would, for instance, women's dealing with "hard" news undermine the news and relegate it into the soft realm? Would it entail a re-definition of that news? On the other hand, would a man endow soft news with more authority than the regular soft news or are men journalists undermined in the profession for dealing with soft news? This division, in effect, is influencing news perception among academics and journalists when it may not necessarily portray the reality of the news divide and the news division within the newsroom - it is in Bourdeausian terms shaping the reality of the doxa. Even journalists consider that there is a difference between female and male journalists (Djerf-Pierre \& Lofgren-Nilsson, 2004). The division is problematic especially with recent surprising developments in the field. A good example would be the emergence of female war correspondents. While historically war reporting was a male occupation, the journalistic field is now seeing an increasing number of women reporting from war zones and conflict ridden areas. In 2012, CNN's Lara Logan was in Egypt's Tahrir Square, Sky News' Alex Crawford was the first 
Western journalist in Tripoli after the ousting of Gaddafi and many of the journalists reporting on the Israel-Gaza conflict were women (Franks, 2013, p.29, 30). Lebanese women journalists were at forefront in reporting on the Israel-Lebanon war of 2006 from both local and regional media. Abu Fadil (2007) recounts how journalists like Rima Maktabi from Al Arabiya, Nancy Al Saba from Al Jadeed (New TV), Katia Nasser from Al Jazeera and Tania Mehanna from LBCI braved war odds to bring a fresh new perspective to reporting from the battlefield. The Lebanese women journalists belonged to both Pan Arab (Al Arabiya, Al Jazeera) and Lebanese media (LBCI, Al Jadeed).

\subsubsection{Minding the Context}

Scholars are somewhat aware of the complexities of this dichotomous divide. Though they often arrive to the conclusion that the newsroom is dominated by masculine norms, they remain wary of the gender divide with which they describe it. Therefore, in investigating gender in media institutions, scholars place much value on the historical, cultural and professional context within which women function. Van Zoonen (1994, 2006) calls for a case by case investigation taking into account the historical and cultural conditions not to fall into the trap of classifying media as ideological institutions that produce patriarchal and sexist content (p.43). Ross (2004) emphasizes that the cultural and professional contexts within which journalists function should be taken into consideration to reveal journalists' behavior and the meaning attached to that behavior. Uncovering the different accounts of women and men working in the media becomes necessary since diverse voices exist within the same community (Ross, 2004, p.154-155). So journalists functioning within the same professional context would help bring different perspectives to the same experience. Investigating the accounts of women and 
men in the media profession is also shared by de Bruin (2004). De Bruin (2004) discusses the intersection between gender, professional and organizational standards. In her analysis of the twenty in-depth interviews conducted on Caribbean women journalists, she is interested in how journalists perceive the interaction within the news room and not whether their statements about the newsroom are truthful or false. Djerf-Pierre and Lofgren-Nilsson (2004) suggest that studying women in the newsroom should entail a study of the power relations within the newsroom as well as the working conditions, in others words it is a study of status and power, varied forms of femininities and masculinities. Also taking considering the issue of power, Van Zoonen (2000) points out that gender studies consider power to be an effective factor alongside gender. Yet power distribution is not dichotomous or in possession of men or women:

Power is not a monolithic 'thing' that some groups (men, capitalists, whites) have and others (women, working class, blacks) have not. Society is not constituted by orderly and dichotomous divisions of oppressors and oppressed. As the experience of black feminists has made perfectly clear, one can be subordinated in one relation (of woman vs. man) and dominant in another (of white woman vs. black woman). (Van Zoonen, 2000, p.4)

Three interacting forces determine the place of women in the news, according to DjerfPierre and Lofgren-Nilsson (2004). The first is the social, political, cultural and economic forces of the gender system in a specific society at a specific point in time, the second is the journalistic culture in the newsroom and the third is the strategies that men and women journalists employ either to maintain or change the power structure within the newsroom. The gender dynamic within the newsroom then, seems to be a reflection of the larger gender dynamic within society. The strategies for coping with the dynamic may be also a reflection of the strategies that women use in their society or may be specific to the newsroom itself - considering that the newsroom is a small microcosm with a unique 
but not fully independent power system. The three forces suggested by Djerf-Pierre and Lofgren-Nilsson go hand-in-hand with Bourdieu's field theory which deals with the field of the news room along with the external factors that affect it and the internal factors that come to play within it. In the Arab world, religion becomes one of those essential factors. Arab scholars such as Mernissi (2004) and Skaill (2006) believe that women can use religious arguments to their favour. In a patriarchal society, where religion is used to dictate what should and should not be done or what is allowed and what is not allowed, scholars invite women to harness the power of the religious word to their own benefit.

\subsubsection{Only Young Women}

Another factor closely tied to gender is age. Age is used as a discriminatory factor in the newsroom especially when it comes to women (Franks, 2013; Gallagher, 2005; Chambers, Steiner \& Fleming, 2004). In the Global Report on the Status of Women in the News Media, Gallagher (2005) concludes that female media professionals disappear from the television screen as they get older. "For women, youthful appearance is more highly valued than experience" (Gallagher, 2005, p.18). While women form the majority of news reporters and presenters till the age of 34 , by the age of 50, they form less than $17 \%$ of reporters and $75 \%$ of presenters (Gallagher, 2005, p.18). Chambers, Steiner and Fleming (2004) mention that women are scrutinized for their appearance and do not stay in the profession as long as men. The authors point out how women are gazed at as physical objects and how women journalists become part of the spectacles or news objects. Despite this assertion, the authors hesitate to attribute the lower age of women in the profession to their physical appearance or age. Instead they wonder whether the difference may be caused by the male-dominated newsroom, lack of childcare or lack of 
promotion prospects. Franks (2013) described how female television news professionals in the United States and the United Kingdom are "let go" at a certain age (p.15-17), thereby linking physical appearance with work capability when it comes to women. The profile of the Western female journalist is "substantially younger, more junior and less well-paid than their male counterparts" (p.18). Of particular concern, Franks says, is the age gap in television.

The same aging concerns apply to India. Bhagat (2002) asserts that news organizations have a clear preference for younger women. Once these women gain enough experience, they become either overqualified or too old. As revealed in the literature review, scholars such as Naomi Sakr (2004, 2007) and Marwan Kraidy (2000) offered the same assertions when it comes to Lebanese women working in television. The authors mention that women on Lebanese television show a lot of skin and are used as a marketing tool to the nearby Gulf states. They should be young, beautiful and attractive. Age then seems to be a worldwide criterion when it comes to women working in television. Yet scholars do not specify whether that criterion affects only women appearing on the screen. There are many other women that work within the television newsroom but do not appear on television. Whether or not age affects these women in Lebanese television remains to be seen.

\subsubsection{Women Journalists: Critical Mass and Content}

Certain approaches to the study of women in media and particularly in the field of news journalism emphasize the importance of the number of women working in the field. According to these approaches, the higher the number of women the more balanced the news content and the news environment becomes. This establishes a connection between 
two different areas in gender studies: the representation of women in content and the positions that women hold as producers of content in the media organization. Whether there is truly a connection between representation of women and their positions in the organization is still controversial. A number of scholars believe that once women reach a critical mass within the newsroom, they affect news production and its content.

Selecting articles from the websites of 30 US daily newspapers, Craft and Wanta (2004) found that the number of women working in the newsroom, especially in executive positions affects the news agenda. With the presence of a majority of female journalists, the news covered is more positive and female journalists are more likely to be treated like their male counterparts. Van Zoonen (1998) believes that once women reach a critical mass, they affect the news values of the news room; women's work "feminizes" the news. Chambers, Steiner and Fleming (2004) are advocates of the view that the increasing number of women in journalism changes the news values and news room culture and challenges the masculine journalistic norms (pp. 9-11). Women have widened the definition of news and introduced topics that were not considered important such as sexual education, the elderly, rape, medical institutions and others (pp. 10, p.108). Historically, the authors attribute the rise in numbers of women in the British newsroom in the 1970 s to commercial interests as the media sought to attract female audiences with topics that interest them. The same trend is visible in today's new environment, still characterized by "man as norm, woman as interloper structure" (p. 123). While women have forged new approaches to war journalism especially post September 11, 2001, the authors point to worrying trends with the rise of a new form of journalism that seemingly supports female individualism but is covertly anti-feminist. Driven by commercial 
interest, this form of journalism or what Van Zoonen called the "Ken and Barbie format" emphasizes sensationalism, celebrities and sexualisation of presentation (p.13). This form of journalism ignores the political, pedagogic and professional feminism under the guise of celebrating popular culture (p.13). Djerf-Pierre and Lofgren-Nilsson (2004) related the increasing number of women to changes in the news. Like Chambers, Steiner and Fleming, they attributed the rise in the number of women in certain European countries to commercial interests thereby suggesting that the feminization of news was mainly driven by commercialization.

Not all scholars believe that growing numbers of women affect news work. Conducting a small scale postal survey on British women journalists, Ross (2001) came upon controversial findings. While most women agreed that they bring a different perspective to the news than their male counterparts, only $40 \%$ agreed with the statement that more women would bring a more woman-friendly output to the news. Frohlich (2007) in "Three Steps Forward Two Back? Women Journalists in the Western World between Progress, Standstill and Retreat" proposes that women journalists have taken two steps back since the 1990s. The field of journalism, she asserts, is marked by an imbalance between women's numbers or visibility in the field and their actual influence. In an earlier study, Frohlich (2004) acknowledges the increase in female communication students and female communication workers in Europe, the US and Canada, only to warn that this female boom in the communication sector is not the result of equal opportunity such a belief is a myth (p.73). Women's skills, Frohlich asserts, "are utilized less because of the gender-based, vertical segregation that routinely takes place once they are working in the sector" (p.73). 


\subsubsection{The Newsroom: Sexual Harassment and Old Boys' Club}

Studies done on women journalists often show how women are treated differently within the newsroom environment. Women often complain of sexual harassment as a direct form of discrimination yet they also complain of other forms of informal uneasy contact with their male colleagues - such a relationship may qualify as an indirect form of harassment.

In her study on Caribbean women journalists, Marjan de Bruin (2004) shows how harassment, its reality and its definition are seen differently by men and women. What is harassment to women is not necessarily so for men. To women harassment comes in different forms and for newcomers 'it seems a rite of passage - part of what 'everybody' is expecting to happen and it is up to the individual to resist" (p.9). Researching women in Indian media, Bhagat (2002) uncovered that harassment was a major concern among women although very few did anything about it. Those women who did object were brushed off and blamed since they were warned that they were working in a male environment and were supposed to bear the consequences. Women who have worked in the newsroom for some time find that harassment is part of the newsroom environment something that they learn to live with. Ross $(2001,2004)$ found out that women feel there is a price they have to pay for working in a male environment. Some cited examples of blatant sexism while others referred to indirect forms of harassment such as being cast out of an assignment. North (2007) who conducted 17 semi-structured in-depth interviews with Australian print journalists comes to the conclusion that sexually harassing behaviour is an essential part of journalism culture whether harassment is made visible through sexual jokes, advances or harassment. 
Another prominent problem faced by women in the newsroom is being cast away from leadership positions or prominent assignments as a result of their informal relationship with men- tactics used by men to consolidate and empower them within the newsroom environment. Scholars describe an "old boys club" (Franks, 2013; Robinson, 2004; Chambers, Steiner \& Fleming, 2004; Melin-Higgins, 2004) filled with male banter, sexist humor, and competition over prestigious news topics. In her study on journalistic practice in the Canadian newsroom, Robinson (2004) shows how the cultural capital of women, in reference to Bourdieu's field theory, will never be accepted as that of men. In effect males are able to utilize that capital to get preferential treatment and preferential story assignments. There is, in effect, an asymmetrical prestige exchange process (p.87). Add to that, the after-hours pub tradition (Robinson, 2004; Melin-Higgins, 2004; Ross, 2001). The tradition stretches the already long working day and "equates a reporters ‘competence' with total availability” (Robinson, 2004). Robinson (2004a; 2004b) mentions that the pub tradition is where informal male ties are formed and where decisions are assessed. The women that are able to join are the ones with no family responsibilities. Melin-Higgins (2004) shows how, in this old boys club, long working hours and stress on the job are glorified. In her study, she described the British newsroom environment as characterized by strict organizational and structural hierarchy with a strong old boys' network. Such an environment offers little support for women; it is very masculine and sexist.

\subsubsection{Women's Newsroom Strategies}

Research on gender often dubs the newsroom culture as masculine. Ross (2001) describes it best when she says the newsroom is organized around "man-as-norm and 
woman as interloper structure" (p.535). As discussed earlier, it is somewhat an old boys' club (Franks, 2013; North, 2009; Robinson, 2004; Melin-Higgins, 2004; Ross, 2001). North (2012) explains that women journalists consider male attitude to be the most common problem that hinders their progress in their journalistic career. She states that even in Nordic countries where "gender empowerment is rated high, patriarchal conservatism is noted as a central impediment to women's career advancement in journalism” (p. 262). Women journalists working alongside men in such a masculine newsroom environment have therefore come up with ways or strategies to live through and withstand a masculine environment and increase their chances of success. To Melin-Higgins (2004), warfare is one way of seeing the dynamic between men and women in the newsroom. Just as men use strategies or tactics to maintain their positions and define the journalistic doxa, women also use a number of tactics to survive this male dominated milieu. The marionette or the female ghetto tactics do not challenge the doxa. They comply with the dominant culture in meeting what is expected from a female journalist. These women journalists cover soft news, the women's page and women's magazines. The second threatens the dominant culture as women journalists strive to be one of the boys. They challenge male supremacy by stepping into male territory by covering hard news or becoming foreign correspondents. The dominant culture reverts back by resorting to strategies such as name calling. These women are often labelled as aggressive or unfeminine. The third tactic is an oppositional tactic that tries to make the doxa more feminine. It is the "one of the girls" tactic. Yet it represents a trap as women are criticized if they cover hard news (they are seen as aggressive and tough) and are criticized if they cover soft news as they are seen as incompetent little girls. Chambers, 
Steiner and Fleming (2004) avoid the sexism and discrimination found in the newsroom by working on freelance basis (p.102).

\subsection{The Concept of the Glass Ceiling}

The Annenberg Public Policy Center, in its study, The Glass Ceiling Persists: The $3^{\text {rd }}$ Annual APPC Report on Women Leaders in Communication Companies (2003) states the term glass ceiling was first introduced by magazine editor Gay Bryant in 1984 to describe the situation of working women who cannot move beyond middle management. The year after that, the National Organization of Women (NOW) adopted the term and its chair, Muriel Fox, mentioned that women cannot move beyond the ceiling without "the women's movement." In 1991, the United States set up the Glass Ceiling Act to identify barriers that block the advancement of women and minorities to top level management positions. The key concern of the Glass Ceiling Commission was that women were not given the chance to develop the necessary experience required for advancement.

The US Labor Secretary, Lynn Martin, defined in the 1991 report The Glass Ceiling Initiative, the concept of glass ceiling as "those artificial barriers based on attitudinal or organizational bias that prevent qualified individuals from advancing upward in their organization into management-level positions" (Bollinger and O'Neill, 2008, p.10). In the Global Report on the Status of Women in the News Media, researcher Carolyn Byerly categorizes the top level positions in journalism into four areas: governance (boards of directors); top-level management (publishers, CEOs); senior management (news directors, managing editors, bureau chiefs etc); and middle management (chief correspondents, senior editors). These categories will be used in the analysis of the Lebanese television newsroom. 
Quoting a 2010 study by Skillset on women in the United Kingdom television industry, Suzan Franks (2013) clearly states "the higher up the hierarchy, the fewer women and the wider the gender gap" (p.13). According to Franks (2013), women are not reaching the higher levels of the profession. The Global Wage Indicator Report (2012) on the gender pay gap in journalism reveals in a study conducted on 16 countries in the European Union, former Soviet Union and Central and South America that women's wages and benefits (holiday allowance, end of year bonus, performance bonus, insurance and others) are nowhere equal to those of men, despite decades of the equal pay legislation. The pay gap is most obvious in Belgium, the Netherlands and Indonesia. The glass ceiling then is a workplace bias that results from unspoken of cultural norms through which attitudes towards gender and class are developed. As such and in Bourdieu's terms the glass ceiling is what happens within the field and the extent of its application is dependent on both habitus and capital. Gender then structures the journalistic environment.

\subsection{Bringing It All Together: Bourdieu's Logic of Practice and Gender}

To investigate the situation of women in the Lebanese television newsroom, this study will use Bourdieu's logic of practice. Although Bourdieu insists that the theoretical and the practical or the application of the theory, are constantly in a state of dialectic, he nonetheless provides a research logic. "First, we must analyze the position of the field vis-à-vis the field of power," or determine, in effect, who the dominant and the dominated are. "Second, one must map out the objective structure of the relationship between the positions occupied by the agents or institutions that compete for the legitimate form of specific authority of which this field is a site. And, third, one must 
analyze the habitus of agents, the different systems of dispositions they have acquired by internalizing a determinate type of social and economic condition" (Wacquant and Bourdieu 1992, p. 105). The application of this research logic then entails identifying the various positions occupied by both men and women in the Lebanese television newsroom while dividing these positions into lower, middle and upper management. The third step entails an analysis of the habitus - a somewhat challenging endeavor since habitus is an unconscious mode of interaction. In the Lebanese context, habitus is linked to patriarchy and resulting gender relations. It is also linked to the unique mode of acquired interaction taking place within each specific newsroom. The actors, male and female, may share certain commonalities in terms of their disposition or habitus but each essentially forms a unique habitus of their own.

To complete the analysis a la Bourdieu, we need to also incorporate the actual structure that defines the television station. Bourdieu considers pure economic analysis to be inadequate (Bourdieu, 1998, p.39) yet he does fully not disregard it. To Bourdieu, the social actors in television "are the puppets of a necessity that we must understand, of a structure that we must unearth and bring to light" (Bourdieu 1998, p.38). Pure economic analysis of television stations and their economic weight in the market are not within the scope of this study. This study will, nonetheless, shed light on the ownership of Lebanese television stations to highlight their politico-sectarian nature and eventually identify whether or not the political and religious capital of women affects their employment and their progress. Bourdieu, in effect, uses an intersectional gender analysis. To Bourdieu the root of the social order can be explained through class structure, economic processes as well as patriarchy and masculine dominance. This is what Lykke (2005) argues an 
intersectional analysis would do. In using his field theory, the social world can be analyzed in terms of the many social categories that interact with each other and the effect that these categories may have on each other and the agents in the field.

The full investigation of women in the Lebanese television newsroom will then encompass their social capital (ties and relationship, religious, political affiliation - in other words investigating elements of Joseph's patriarchal connectivity), cultural capital (education and competence) along with the gender and age factors. It will also entail a study of women's division of labor within the newsroom as part of the masculine newsroom doxa and the strategies that women use through mobilizing their capital within specific habitus conditions. Having reviewed the strategies adopted by Western women journalists will enable us to infer whether Lebanese women use the same strategies or different ones considering the different patriarchal, religious, and social conditions they function within.

By answering these inquiries, the study draws a sketch of the basic properties of the Lebanese television newsroom field and identifies how the different endowments of capital are distributed within this autonomous microcosm and how the structure of the field itself directs the forms of struggle among the journalists. 


\section{Chapter: Research Methodology}

Choosing the research design for a study is guided by the purpose of the study. The most effective design for this study is the qualitative research design employing inductive reasoning. Once the research design is decided upon, it then dictates the subsequent research steps which include the data collection methods, the sampling strategy and data analysis techniques (Eid, 2011a). This chapter first explains the choice of the qualitative research design and reveals the five research questions developed for the study. It then explains the concepts developed in the theoretical framework and literature review in relation to the study of women in the Lebanese television newsroom. The data collection and analysis will then be discussed.

\subsection{Research Design}

As revealed in the literature review, women's presence in the Lebanese media is not paralleled with an equivalent presence in upper management positions. Since the purpose of this dissertation is to assess the status of women in the Lebanese television newsroom and whether they are under-represented in top management positions, a close in-depth look at these women and the newsroom environment is taken to address the dissertation's inquiries. Using the theoretical lens of Bourdieu's field theory, the theory of gender and the concept of the glass ceiling the dissertation studies women's potential, the obstacles they face, the effect of their religious and political affiliation along with the strategies of struggle they use within the newsroom.

The literature review has shown that studies on Lebanese media, in general, and on women in particular are few. Therefore investigating the reasons behind women's minimal progression through an in-depth study of the newsroom and taking the opinion 
of the women in the newsroom with regards to their status and their progression will help bridge the gap in the scholarly literature. To understand and assess women's situation in the Lebanese television newsroom, it is effective, for the purposes of this study, to hear from the women and the men who work in the newsroom. This would help formulate a somewhat complete holistic view of the status of women from both the male and female journalists who share the same workplace and function under the same contextual and cultural conditions. Taking both their perspectives would enrich the study and identify whether men and women read the situation and functions in the newsroom differently. Since the topic remains unexplored, the qualitative research design chosen for this study is optimal (Denzin \& Lincoln, 1998).

Qualitative research design is a holistic approach that studies "the whole person, institution, group or culture rather than one small, measurable aspect of it" (Jackson, Gillis \& Verberg, 2011, p. 237). It entails "seeing the world from the eyes of the participants in the study" (p.237), analyzing their everyday experiences (Kvale, 2007). In qualitative research, "we borrow ideas and viewpoints from the people we study and situate them in a fluid natural setting” (Neuman, 2011, p.145). Qualitative researchers mainly focus on the richness of viewpoints, since the qualitative research design employs an inductive reasoning that is concerned with the development of insights from the gathered raw data (Eid, 2011a). In the inductive approach, the researcher builds categories and themes from the 'bottom-up' and moves "back and forth between themes" until a comprehensive set of themes is established (Creswell, 2007, p.38). For the purpose of this thesis, the viewpoints and ideas of the men and the women working in the 
Lebanese television stations are gathered by examining the specific concepts generated by the research questions of the study.

Since this study examines the Lebanese television newsroom through the eyes and the experiences of the women and men who work in the newsroom, its qualitative design is governed by the interpretive paradigm and follows the phenomenological tradition. According to the interpretive paradigm, all human action is meaningful and is to be interpreted in relation to the participant's context of social practices (Creswell, 2009; Eid, 2011b; O'Donoghue, 2007). This paradigm views the individual and society as inseparable; they are "mutually interdependent" (O'Donoghue, 2007, p. 16) and can only be understood in relation to one another. For this study the individuals are the men and women journalists in the Lebanese television newsroom and the society is double-layered - it is the immediate society of the newsroom and the society beyond the newsroom that governs newsroom politics, gender relations and everyday interactions. Since this study seeks to provide an understanding of the individuals' experiences of concepts such as gender, patriarchy, cultural capital, and glass ceiling, it uses a phenomenological strategy. In seeking to reveal the essence of the lived experience, phenomenology seeks a deep understanding of the phenomenon under study through rigorous and systematic examination (Creswell, 2007; Eid, 2011b; Jackson, Gillis \& Verberg, 2011). In phenomenology, every person's view of the world or social reality is valid and is a valuable source of knowledge. Reality is constructed from the interaction of human consciousness and phenomena (Jackson, Gillis \& Verberg, 2011). This study explores the lived experiences of journalists in the Lebanese television newsroom as they act through system of dispositions, or what Bourdieu calls habitus, where actors are shaped 
and in turn shape the environment through their use of capital within the journalistic field, which in turn is governed by the context of the television stations.

\subsection{Research Questions}

This study deals with five main research questions that explore the status of women within the Lebanese television newsroom. The questions address the main concepts derived from the literature review and theoretical framework:

\section{$\underline{\text { Research Question 1: }}$}

How does women's cultural capital in terms of education and skills affect women's progression in the Lebanese television newsroom? Are the same skills required of men and women?

\section{Research Question 2:}

How do social and familial ties affect women's hiring and progression within the Lebanese television newsroom?

\section{$\underline{\text { Research Question 3: }}$}

How do religious and political beliefs and connections within Lebanese television institutions affect women's share in management positions in Lebanese television newsrooms? Why? What are the views of male and female employees on this?

\section{$\underline{\text { Research Question 4: }}$}

How does the patriarchal make-up of Lebanon affect the gender dynamic within the Lebanese television newsroom? Is the newsroom, like society, dominated by masculine norms? Are there male and female specific coverage areas and skills? Do age and appearance affect women more than men? 


\section{Research Question 5:}

What kind of strategies do women use in the Lebanese television newsroom? Do males and females use the same advancement strategies?

The research questions emphasize, not only women's status within the Lebanese television newsroom, but relate that status to the immediate environment of the newsroom and the Lebanese environment, in general.

The research questions then attempt to understand the newsroom and the Lebanese context to develop an understanding of the contextual conditions that govern the status of women in the Lebanese television newsroom. The first research question addresses the personal status and qualifications of women and whether the same traits are required of men. The second research question deals with the social and familial ties in the Lebanese community and the extent to which such ties affect women's progression in the newsroom. The third question explores the religious and political affiliation of women working in the newsroom knowing that the Lebanese television stations are politico-sectarian entities. The fourth question looks at how gender relates to news coverage by Lebanese television journalists in the newsroom. It also relates appearance to gender and evaluates the relationship between gender and appearance. The fifth research question explores the strategies that men and women use in the newsroom.

As previously mentioned, the research questions address concepts derived from the literature review and the theoretical framework. These research questions are investigated through the research design of the study. 


\subsection{Conceptualization}

Conceptualization is essential for the qualitative study. It is the "process of forming coherent, theoretical definitions as one seeks to make sense of the data, or organize preliminary thoughts" (Eid, 2011a, p. 7). The theoretical definitions of the concepts employed for the study rely, to a large extent, on the definitions provided by the theoretical frameworks as well as the literature review used for the study. Yet these concepts are also conditioned by the context of the study. As the researcher collects the data, new concepts as well as definitions for major concepts and relationships between them are formed (p. 7). Conceptualization then involves "an interaction between theoretical concerns and empirical observations" (Berg, 2011). In this section, the concepts in relation to the context of the study are discussed. These concepts are those of field, cultural capital, social capital, religious beliefs, political affiliation, gender, masculine norms, progression and management positions.

\subsubsection{Field, Cultural Capital and Social Capital}

This study adopts the definitions of field and cultural capital developed by Pierre Bourdieu. The field, and for the purposes of our study the journalistic field and more specifically the Lebanese television newsroom, is the system of social relations where actors interact (Bourdieu \& Waquant, 1992). In this field, where relationships are constantly characterized by inequality, actors strive either to transform or preserve the field (Bourdieu, 1998). Yet though the field is a microcosm with its own laws, its autonomy is not complete as it is dependent on external forces (Bourdieu, 1998). The Lebanese television newsroom is dependent on the political, economic and religious 
forces governing the country and is affected by the gender relations inherent within the Lebanese community.

The agents within a field compete over capital which is "the set of actually usable sources and powers" (Bourdieu, 1984, p.114). This study explores cultural capital composed of education and skills and the social capital formed of the social connections that the person can mobilize for a specific benefit. With respect to cultural capital, journalists are questioned about their educational background and the university they graduated from. The skills are composed of the experience that the journalists have accumulated from their work in the field; it is affected by years of work as well as positions occupied by the journalist. Social capital, on the other hand, is characteristic of Lebanon, a country where social and familial connections play a prominent role in helping people reach a desired objective. The study explores whether education and skills as well social and familial ties function as capital that leads to the progression of journalists in the Lebanese television newsroom.

\subsubsection{Religious Beliefs and Political Affiliation}

In Lebanon, religion and politics are closely intertwined; they are somewhat inseparable. As revealed in the literature review, Lebanon has 18 officially recognized sects that dictate marriage, divorce, political positions, inheritance and votes (Time, 2013). All public positions are divided along religious lines. Since the political seats are distributed along the lines of religious affiliation, the politicians function more as representatives of their own religious communities rather than the whole nation (Shelton, 2014). These politicians often control their own political parties, are prominent members of the party or belong to political parties that are also religiously affiliated. The majority 
of Lebanon's television stations are controlled by the elite members of the political parties, who are more often than not, part of the political body governing the country. An example is NBN which belongs to Nabih Berri, who is also the head of the Lebanese parliament; Nabih Berri also presides over the Al Amal, a Shiite political party. Since the Lebanese televisions are politically and religiously divided, the religious and political affiliation of the journalist becomes pertinent and may, in effect, function as capital, a la Bourdieu. Shiite channels such as NBN, for instance, may prefer to hire Shiite journalists who belong to Al Amal political party. On other hand, MTV, a Christian owned channel that is affiliated to March 14 may have preference for a Christian journalist who supports the March 14 coalition.

\subsubsection{Gender Contextualized}

Adopting the view that gender is socially constructed, this study uses Van Zoonen's definition of gender. Van Zoonen (2006) defines gender as a "set of overlapping and contradictory cultural descriptions and prescriptions referring to sexual differences" (p.41). Gender then becomes the product of culture. For the purposes of this study, the gender dynamic in the Lebanese television newsroom is conceptualized in terms of context, masculine norms, sexual harassment and old boys' club,

To contextualize gender means to take into consideration the gender construct within the Lebanese society. Suad Joseph explains the gendered relationships within the Lebanese society through the construct of patriarchal connectivity, which is "the production of selves with fluid boundaries organized for gendered and aged domination in a culture valorizing kin structures, morality and idioms" (Joseph, 2000). The male patriarch views his wife, sibling, and sisters as extensions of himself and may speak and 
take decisions for them (Joseph, 1999). Within such a system, all members including females and juniors are active participants in propagating relations of inequality. Women and children are not without agency but negotiate the outcomes that suit them best with the male patriarch. In Lebanon, families may vary between traditional where the male is the main breadwinner and modern where financial responsibility may be shared with the female (Tayar, 2013).

This patriarchal system is also characterized by kin relationships through which one comes to have rights or access to resources. In effect, the more invested individuals are in kin relationships the more access to state and public resources they have. Joseph (1999) explains how in the Lebanese state that is built on familial ties embedded in race, religion, ethnic, regional and ideological alliances, mobilizing such ties is essential for access to resources such as employment and services. In associating gender to kin relationships, Suad incorporates Bourdieu's social capital and diverges from the Western notion of gender. This study examines the role that the patriarchal context plays in influencing women's employment and progression; it also examines issues of relationality or kin relationships in promoting women's employment.

\subsubsection{Masculine Norms}

The masculine norms in the journalistic profession become the professional routine by which all journalists must abide (Van Zoonen, 1998). These norms are conceptualized in accordance with a number of studies done on the newsroom which concur that men's news selection differs from that of women and women are often assigned to the lighter news items or soft news while men handle the more prestigious hard news (Franks, 2013; Ross \&Carter, 2011; Ross 2010; Robinson, 2005; Gallagher, 
2005). For the purposes of this study, hard news deals with economics, war, politics, technology and science whereas soft news deals with human interest, education, culture, the elderly and the environment.

Age and appearance for this study will also be included under masculine norms. Age is used as a discriminatory factor in the newsroom especially when it comes to women (Franks, 2013; Gallagher, 2005; Chambers, Steiner \& Fleming, 2004). The study explores whether Lebanese women journalists, especially anchors disappear from the screens at an earlier age than men. It also explores whether appearance, in terms of beauty and clothing, matter more for women than men.

\subsubsection{Sexual Harassment and Old Boys' Club}

Studies have shown that women working in the newsroom have often complained of sexual harassment (Ross, 2001; de Bruin, 2004; Bhagat, 2002; North, 2007). As revealed in the literature review, the Lebanese Labor Law and Penal Code do not contain any stipulations with regards to sexual harassment, per se nor do they define it. This study will therefore rely on the definition of the United States Equal Employment Opportunity Commission (EEOC). According to the EEOC, sexual harassment is defined as "unwelcome sexual advances, requests for sexual favors, and other verbal or physical conduct of a sexual nature" that interfere with a person's employment or work performance or create a "hostile or offensive work environment" (EEOC, 2011, Para 12). It is worth noting here, that "the law doesn't prohibit simple teasing, offhand comments, or isolated incidents that are not very serious." Harassment then only becomes illegal when it is frequent or severe to the extent that it hampers one's work performance. 
For the purposes of this study, sexual harassment takes two forms. Direct sexual harassment is a straightforward sexual advance and indirect sexual harassment includes sexual jokes and flirting; this second form of harassment is the mild type that is not incriminated by the law

Closely related to harassment is a description of the newsroom as an old boys club. Scholars describe an "old boys club" (Franks, 2013; Robinson, 2004; Chambers, Steiner \& Fleming, 2004; Melin-Higgins, 2004) filled with male banter, sexist humor, and competition over prestigious news topics. The old boys club also includes men fraternizing together after hours and excluding women who may not be able to join due to home and family obligation.

\subsubsection{Newsroom Strategies}

The newsroom strategies to be examined in this study will be those developed by Melin-Higgins (2004). Melin-Higgins defined three main strategies employed by women to survive the male dominated milieu. These strategies are:

- The marionette tactic where women journalists comply with the dominant culture in complying with what is expected of her (mainly covers soft news) -One of the boys tactic is when women threaten the dominant culture and are often labelled as unfeminine or aggressive (often cover hard news and are challenged by men)

-Oppositional tactic where women try to make the doxa more feminine; they are seen as incompetent irrespective of what type of news they cover. In this case, women try to have the upper hand but are criticized as tough or aggressive if they cover hard news and are labelled as incompetent if they cover soft news. 


\subsubsection{Progression and Management Positions}

Women's progression in the Lebanese television is closely tied to management positions. This study examines, through the use of the concept of the glass ceiling, the extent to which qualified Lebanese women journalists have the chance of reaching management positions. According to the concept of the glass ceiling women are faced with artificial barriers and management biases that prevent them from advancing to management levels. To define newsroom positions, this study uses the newsroom occupational levels proposed by Byerly (2011) with minor modifications to cater to the specificities of the Lebanese television newsroom. As revealed in the table below, middle management includes positions such as senior reporters, senior editors and chief of correspondents. Senior management positions include head of news, editor in chief, and head of operations. Contextualizing the table for this study means the technical positions would include photographers and the production and design positions would exclude wardrobe designers, which are generally non-existent in the Lebanese television newsroom.

Table 6

Occupational Level and Description

\begin{tabular}{|c|c|}
\hline Occupational Level & Description \\
\hline Governance & $\begin{array}{l}\text { Members of the governing board who vote on the most } \\
\text { important decisions on policy and finances for this specific } \\
\text { company. }\end{array}$ \\
\hline Top-level & Report to board of directors. Includes the very top \\
\hline Management & $\begin{array}{l}\text { administrators, for example, Publisher, Chief Executive Officer } \\
\text { (CEO), Director General (DG) and Chief Financial Officer } \\
\text { (CFO). }\end{array}$ \\
\hline Senior Management & $\begin{array}{l}\text { Report to top-level managers. For example, Director of News, } \\
\text { President of News, Editor-in-Chief, Managing Editor, Executive } \\
\text { Editor, Bureau Chiefs, and similar titles. }\end{array}$ \\
\hline Middle Management & Report to senior management. For example, Senior Editor, Chief \\
\hline
\end{tabular}




\begin{tabular}{ll}
\hline \multirow{2}{*}{$\begin{array}{l}\text { Senior-Level } \\
\text { Professional }\end{array}$} & of Correspondents, Design Director, Creative Director \\
\cline { 2 - 2 } $\begin{array}{l}\text { Junior-level } \\
\text { Professional }\end{array}$ & $\begin{array}{l}\text { Professionally qualified. Report to senior-level management, } \\
\text { researchers, reporters, correspondents. }\end{array}$ \\
\cline { 2 - 2 } Production and & $\begin{array}{l}\text { Professionally qualified. Report to middle-level management, } \\
\text { e.g., junior/assistant writers, producers, directors, anchors, } \\
\text { reporters, sub-editors, correspondents, production assistants. }\end{array}$ \\
\cline { 2 - 2 } Design & $\begin{array}{l}\text { In print: graphics designers, photographers, illustrators. } \\
\text { In broadcast: scene designers and construction workers, graphics } \\
\text { designers, wardrobe designers, make-up artists, film/video }\end{array}$ \\
Technical & editors \\
\cline { 2 - 2 } Professional & $\begin{array}{l}\text { Those who do specific technical work. For example, camera, } \\
\text { sound and lighting technicians. }\end{array}$ \\
\hline
\end{tabular}

\subsection{Context and Composition of Lebanese Television Stations}

Placing emphasis on the context is a staple of qualitative research (Neuman, 2011a, p. 145). The context significantly “colors the activity's meaning. With different contextual meanings, the same activity or behavior may have different consequences" (Neuman, 2011a, p. 146). As revealed in the literature review, Lebanon is a confessional democracy where politico-religious considerations intertwine to affect all aspects of public governmental life from representative political positions in the cabinet of ministers and the parliament to positions in sectors such as the Lebanese University, press council and media. Add to that, the Lebanese are governed by a personal status code that adheres to dictates of each person's religious belief. Divorce, marriage, and inheritance, for instance, are not governed by civil law but by the religious code of the different religious denominations such as the Christian Maronites, Christian Orthodox, Muslim Sunni, Muslim Shiite, Druze and others. In this context, the media represent the different religious factions which are closely tied to political representation within the government and through political parties. As Lebanon is a relatively small country (10,452 square kilometers), it is serviced by nine official Lebanese television stations. One advantage of 
this study is that all the officially recognized Lebanese television stations, without exception, will be included in it. This is possible because of the small number of channels in the country. The study is therefore comprehensive and inclusive as it excludes none of the television stations and provides access to their diverse environments and perspectives especially since each Lebanese television station has its own unique political and religious composition. The television stations officially recognized by the Lebanese Ministry of Information are the ones chosen for this study (Appendix D):

1- Tele Liban (TL): It is the only state broadcaster in Lebanon. One of the first television stations in the Arab world, it started broadcasting on May 28, 1959. Three main phases mark its development (Tele Liban, 2014). The first was in the 1950s when the television, La Compagnie Libanaise de Television, SAL (CLT), was formed out of a private venture by two Lebanese businessmen namely, Wissam Ezzedine and Alex Moufarrej was granted a license in 1956. The license was not a monopoly and another license was granted in 1961 to another group of businessmen backed by the American Broadcasting Corporation (ABC) to form the Compagnie de Television du Liban et du Proche Orient (Tele Orient). Each television station was composed of two channels, one that broadcast in Arabic and another that broadcast in French. During an unsuccessful coup d'etat in 1976, one year after the start of the Lebanese civil war, the stations were occupied by the two warring factions- the Moslems took over CLT, the station in West Beirut and the Christians took over Tele Orient, the one in East Beirut (Dajani, 2001). This marked the start of media sectarianism. Even Beirut, the capital of Lebanon, became divided between East and West during the Civil War which lasted from 
1975 to 1990 . East Beirut became occupied by a Christian majority whereas West Beirut was occupied by a Moslem majority. The second phase was in 1978 when the two television companies, having incurred many losses, asked for government interference. The state acquired half of the television's shares and merged the two stations into one, which became known as Tele Liban. The third phase was in 1996 when the state took over the full ownership of Tele Liban. Due to dire economic conditions, Tele Liban was closed down for a period of 3 months in February 2001. Its re-opening in May 2001 was supposed to usher a new phase of prosperity for the station but Tele Liban is still suffering from lack of funds, little advertising money and state bureaucracy. Add to the fact, the positions within the station have to reflect the confessional make-up and power distribution within the government.

2- The Lebanese Broadcasting Corporation International (LBCI): August 23, 1985 marked the first broadcast for LBCI (LBC Group, 2015). It was founded by Christian Lebanese businessmen as the mouthpiece for the Lebanese Forces political party. After a legal battle with the Lebanese Forces, the station is now owned by Pierre El Daher, who was its chairperson since its launch. The station currently belongs to the Pro-Western sphere and is attempting to re-brand itself as a station for all Lebanese people regardless of their religious or political affiliation yet the channel is still most widely recognized as a Christian channel that speaks for the Christian population in Lebanon. It is one of the most popular channels in Lebanon. The LBC website is available in both Arabic and English. 
3- Murr Television (MTV): It was established in 1991 by Christian Lebanese businessman Gabriel El Murr. The station was closed down in 2002 due to promoting a parliamentary candidate, its own owner Gabriel El Murr, thereby violating rules prohibiting advertising for candidates near the end of the elections. The closing down of the station was, in effect, prompted by political intervention and Syrian interference and pressure. It reopened on April 7, 2009 (MTV, 2015). The station belongs to the pro-Western sphere of influence. The website provides a mixture of Arabic and English languages.

4- Orange Television (OTV): OTV is the only publically traded television company in Lebanon and the only television station that posts its general assembly minutes as well as management reports online. It began broadcasting in July 2007. It was founded by the Free Patriotic Movement (FPM), a Christian political party under the leadership of General Michel Aoun. The channel, like MTV and LBCI, is also recognized as a Christian channel but it speaks for the FPM, a Christian political party whose policies are in opposition to those of the Lebanese Forces (previously supported by LBCI and whose policies are closer to the supporters of MTV). The OTV website has the main titles in English but all other content is in Arabic; it does not have an "About" page but formal organizational documents signifying its foundation, progress reports and general assembly meetings (OTV, 2015).

5- Al Jadeed: It was originally founded under the name New TV in 1992 but was shut down in 1997 due to Syrian pressure. The station was re-launched by wealthy Lebanese Sunni businessman Tahseen Khayyat in October 2001 (Al Jadeed, 2015). In 2007 the station revamped its branding and corporate identity to adopt 
the name Al Jadeed - the Arabic translation of the word "New." Originally founded by members of the communist party (Kraidy, 2010), the station still retains a leftist stance and is mainly oppositional to the government.

6- Future Television: The station was launched on February 15, 1993 by Saudi Lebanese Sunni businessman and late Prime Minister Rafik Al Harriri. The station began satellite transmission in 1994 (FTV, 2015).Its sister channel, Future News, which was opened in 2007 merged its operations with Future Television as it was going through dire financial conditions in 2012 (Future TV, 2015). The channel is the mouthpiece for the Al Mustaqbal (Arabic word for Future) political party which was headed by Rafik Al Harriri and is currently presided over by his son Saad Al Harriri. The Future Television website is only in Arabic and has no English translation.

7- Al Manar: The channel is affiliated to and was launched by the Shiite party Hezbollah in 1991. It was granted a temporary license as a "resistance channel" in 1996 and gained its official government license in 1997 (Harb, 2011). It is part of the Lebanese Communication Group. All of its shareholders uphold Hezbollah's ideology and the channel itself has an Arab, anti-Israeli and anti-American rhetoric. The channel defines itself as "the channel for Arabs and Moslems; its programs reflect Arab and Islamic culture and values" (Al Manar, 2015). It is primarily a resistance channel that rallies for Arab causes and primarily the Palestinian cause, the resistance of the Israeli occupation and as well the Iraqi cause. "Al Manar was put on the US department's list of terrorist organizations in 
2004" (Harb, 2011). The Al Manar website is available in Arabic, English, French and Spanish.

8- National Broadcasting Network (NBN): It is the more moderate Shiite television station. It was founded by Lebanese Muslim Shiite speaker of parliament and leader of the Al Amal political party, Nabih Berri in 1996 (NBN, 2015). Amal is the abbreviation for Afwaj Al Mouqawama Al Loubnaniyeh - the literal translation of which is the Lebanese Resistance Forces. Yet the word Amal means Hope as well). The channel is sometimes sarcastically called Nabih Berri Network, after its founder. The channel mainly speaks to the Shiites in Lebanon and the diaspora. The NBN website features only the Arabic language.

9- Tele Lumiere: It is the only Christian channel in Lebanon and the Middle East and it was launched in 1991 by a group of committed lay people (Noursat, 2015). It is the only Christian channel in that sense that it is not affiliated to a Christian political party but its affiliation is to the Catholic Church. Its name is French, meaning Television of Light. Supervised by the Assembly of Catholic Bishops and Patriarchs in Lebanon and directed by religious leaders from various denominations alongside lay people, the channel is ecumenical and non-profit. It has no political affiliation and does not accept or promote any type of commercial endorsements. It only relies on donations from supporters and friends. In June 2003, Tele Lumiere launched its satellite station Noursat (Nour is the Arabic word for Light). The Noursat website is available in both Arabic and English. A quick look at the Lebanese television channels reveals their religious divisions and distributions. Lebanon has 4 Christian channels (LBCI, MTV, OTV, and Tele Lumiere), 
2 Sunni channels (FTV and Al Jadeed), and 2 Shiite channels (Al Manar, NBN). The current political parties in Lebanon, who are the owners of most of the channels, are, as mentioned in the literature review, divided into two alliances, namely the March 8 and the March 14 alliances. The March 14 Coalition so-called because of the Cedar Revolution which took place on March 14, 2005 to oppose the presence and influence of the Syrian regime on Lebanon is mainly formed of Harriri's Al Mustaqbal (or Future) Party, and the Pro-Western Christian parties such as the Phalangists and Lebanese Forces (original owners of LBCI). March 14 is mainly a Sunni/Christian coalition. March 8, on the other hand, is formed of the pro-Syrian parties which include the Shiite parties Hezbollah as well as the Free Patriotic Movement. March 8 is mainly a Shiite/Christian coalition. Each coalition has its own media mouthpieces. So the channels are effectively religiously and politically divided. The division below will show each coalition, its political parties, its religious affiliation and the channel or channels that speak for it:

Table 7

Breakdown of Stations by Political Affiliation

\begin{tabular}{|c|c|c|c|}
\hline & Political Affiliation & Religious Affiliation & TV Channel \\
\hline \multirow{3}{*}{$\begin{array}{l}\text { March } 8 \\
\text { Coalition } \\
\end{array}$} & Hezbollah & Shiite & Al Manar \\
\hline & Amal Political Party & Shiite & $\mathrm{NBN}$ \\
\hline & Free Patriotic Movement & Christian & OTV \\
\hline \multirow{2}{*}{$\frac{\text { March } 14}{\text { Coalition }}$} & Al Mustaqbal Political Party & Sunni & FTV \\
\hline & $\begin{array}{l}\text { Pro-Western Christian parties } \\
\text { (e.g., Phalagists, Lebanese Forces) }\end{array}$ & Christian & $\begin{array}{l}\text { MTV } \\
\text { LCBI }\end{array}$ \\
\hline
\end{tabular}

Al Jadeed is mainly leftist, anti-Western and oppositional to government policy (more affiliated with March 8 than March 14), while Tele Lumiere is Christian but nonpolitical. Tele Liban is the only government owned channel and it therefore tries to 
maintain a neutral political position by representing all factions of the Lebanese community equally and objectively.

The distribution of the channels shows that the Christian parties are divided in support between the Shiite parties and the Sunni parties. While LBCI is trying to speak for all Christians, its name is still affiliated with the Lebanese Forces although their influence on the channel ended with legal battles and its full ownership now belongs to its original chairperson Pierre El Daher, as discussed in the literature review. What is obvious from the division is the clear political and religious affiliations of the channels and therefore investigating the effect that the political and religious affiliation has on the hiring and progression of women is highly pertinent.

\subsection{Data Collection and Analysis}

This section identifies and justifies the choice behind the research method and the sampling strategies used for the study. It details how the research participants were approached and the challenges encountered in the field research. It also discusses the position of the researcher with respect to the research and participants. The section ends with an explanation of the data analysis method and an explanation of the validity and reliability of the study.

\subsubsection{Research Method: In-depth Interviews}

The opinions of the interviewees or respondents will form the data for the study. In fact, "the informant teaches the investigator about the culture surrounding the experience being studied. The investigator assumes ignorance of the lived experience of the participants" (Jackson, Gillis \& Verberg, 2011, p. 240). 
To collect the respondents' opinion with regards to the Lebanese television newsroom environment, in-depth interviews were conducted. In-depth interviews provide detailed information about a person's ideas, thoughts, and at times, behavior. Because interviews use an open-oriented, discovery method, in-depth interviews allow the interviewer to intricately explore the participants' feelings and perspectives. The main purpose is to learn from the participants who can be valuable in providing background information as well as expert knowledge that is otherwise not accessible. The participants in the interviews are the ones who have experienced the issue being studied firsthand. After all, "a qualitative research interview attempts to understand the world from the subjects' point of view, to unfold the meaning of peoples' experiences, to uncover their lived world prior to scientific explanations" (Kvale, 2007). Through an interview the researcher "can reach areas of reality that would otherwise remain inaccessible such as people's subjective experiences and attitudes" (Perakyla \& Ruusuvuori, 2011, p.529). Seidman (2006) gives interviewing a very human dimension when he says that the purpose of the interview is not getting answers or testing hypotheses, but "an interest in the lived experience of other people and the meaning they make from that experience" (p.9).

Interviews can be placed on a continuum from unstructured to semi-structured to structured interviews depending on the control that the interviewer exerts (Brinkmann, 2014). While unstructured interviews may be a source of rich information since the interviewer has minimal control over the course of the discussion, extracting information in this manner is time consuming. Structured interviews are highly controlled; the questions are pre-determined and are posed in order. It is very similar to a survey and is 
restrictive in that it does not allow for any flexibility in the posing of questions. Deciding on the type of interview that will be conducted is based on the aims of the research, and the research questions as well as feasibility (Hatch, 2002). Taking that into consideration, semi-structured interviews were chosen as the most suitable interview method for this research.

In semi-structured interviews, pre-set questions serve as a guide and include specific topics or themes that are pertinent to the research. Though the questions are standardized, probes were used to get detailed information or to ensure the researcher acquires the information required for the study, either for clarification or further exploration. Kvale (1996) asserts that the semi-structured interview is a sequence of themes to be covered and a set of questions to be answered. Yet he continues that "there is an openness to changes of sequence and forms of questions in order to follow up the answers given and the stories told by the subjects" (Kvale, 1996, p.124). This type of interview allows the researcher to get detailed information in a conversational style that leaves the participants more at ease than in a structured interview. The interview, then, is about the give and take - it is an inter-change of views (Kvale, 1996, p.14). Brinkmann (2014) sees the conversational aspect of interviewing as both a blessing and a burden for the qualitative interviewer. It is a tool that gives the interviewer access to a conversational world that describes human experience and interaction. Yet, using conversation to study a world saturated with conversation has its challenges because it entails seeing and understanding the obvious. It is "like fish wanting to study water" (Brinkmann, 2014, p.278). This is a drawback that can be countered by formulating the right set of questions that answer the study's main inquiries. To generate valuable 
knowledge, the questions should have an analytic focus. A good interview study, should speak to three aspects - "the purpose of the study, the project, and the institutional traditions behind it and the preferences of the person" (Brinkmann, 2013, p.140).

The questions asked for this research were, therefore, chosen to explore the five research questions of the study (Appendix C). Each research question covers specific themes pertinent to the study and is inspired by and generated through an in-depth understanding of the literature review as well as the theoretical framework.

The first six questions of the interview were designed to explore background information such as age, the television station the journalists are employed in, their current position, years of employment in general and years of employment with the current television station. Background questions help the participants ease into the interview as the participants talk about something that is familiar and develop a feel for what the interview might be like (Hatch, 2002). It is usually these questions that help distinguish one research participant from the other. Add to that, the question about the journalists' current position gave them the space required to explain what they did exactly and how they came to occupy that position. This description of their current work stance helped them clarify, in their own terms, the importance of their work and express to a certain extent their level of satisfaction or dissatisfaction with what they do.

The rest of the interview questions were divided into five parts, each corresponding to the five research questions pertaining to the study. Each research covers a specific theme or themes inspired by the literature review and the theoretical framework. The first set of questions asked mainly about the journalists' cultural capital and its effect on their job progression. It included questions on their educational 
background, the university they graduated from as well as their experience and whether or not their years of experience are commensurate with their bonuses and promotions. The last question in this set examined whether men and women get equally recognized in terms of bonuses and promotions.

The second set of questions dealt with social ties and patriarchal connectivity. It explored to extent to which the journalists' social and familial connections play a role in the employment and progression of newsroom personnel and the extent to which these connections are influential.

The third set of questions focused on the importance of the political and religious ties and their effect on the glass ceiling. The questions relied on the journalists' knowledge of the explicit and implicit ownership of television stations in Lebanon as well as their awareness of the importance of the religious and political make-up of society in general and the media in particular. It questioned to what extent the journalists' political and religious affiliation affected their employment and progression decisions and whether higher level management opportunities were available to women as much as they were available to men.

The fourth set of questions discussed the themes of gender, patriarchy and coverage. It included questions on the types of news men and women cover and whether both genders equally reported, covered or wrote about hard and soft news. It also dealt with the age up to which men and women can work in the newsroom to explore whether there was a different age bracket for each gender. This set also explored the effect that the patriarchal society has on women's potential for progression in the newsroom. 
The final set questioned the adaptation and advancement strategies of women in the Lebanese television newsroom. It comprised of issues related to unspoken of rules of conduct in the newsroom as well as the compromises that men and women have to present in their line of work, inside and outside the newsroom.

To ensure that the interviewer adheres to the answers provided by the participants, all interviews were digitally audio recorded. The interviews, stored on USBs were then transcribed by the researcher. Recording and transcribing the interviews ensure that the researcher has access to reliable, accurate and non-tampered with data for analysis throughout the research. The USBs as well as transcription files were encrypted and password protected to ensure that no party, other than the researcher, has access to the audio recordings or transcriptions.

\subsubsection{Sampling Strategy}

The participants investigated in the channels belong to the newsroom. Since the participants selected are the ones who have experience in the newsroom, its environment and the factors that affect it, the sample chosen was done using the nonprobability sampling strategy where the sampling satisfies clear selection criteria (Jackson, Gillis \& Verberg, 2011, p. 241). The specific non-probability sampling technique chosen was purposive sampling. In purposive sampling, cases are selected with a specific purpose in mind (Neuman, 2011b, p. 331). The selection of cases is usually based on the knowledge of the population and the purpose of the study. Since the status of women within the television stations will be assessed it was important to choose study participants that could give a clear picture of the newsroom situation. Out of the nine television stations, two main categories determined the selection of the participants: newsroom position and 
gender. The participants of the study should, therefore, be comprised of males and females and they should all have a position in the Lebanese television newsroom. Since the channels involved are nine in number, the number of participants proposed for the study was at least 2 interviewees per channel to 4 interviewees per channel. At least one man from every channel was to be interviewed. Gender division would help the study formulate a more holistic idea of the newsroom environment from both the male and female perspectives. Limiting the study to the opinion of one gender would be restrictive since males and females may have differing opinions with regards to the same situation. From the nine Lebanese television station, 9 males along with 18 females in different positions were interviewed. Thus, one male and two females from each Lebanese television station were interviewed bringing the total number of interviewees to 27 . Table 8

Gender Distribution of Respondents

Respondents by Gender

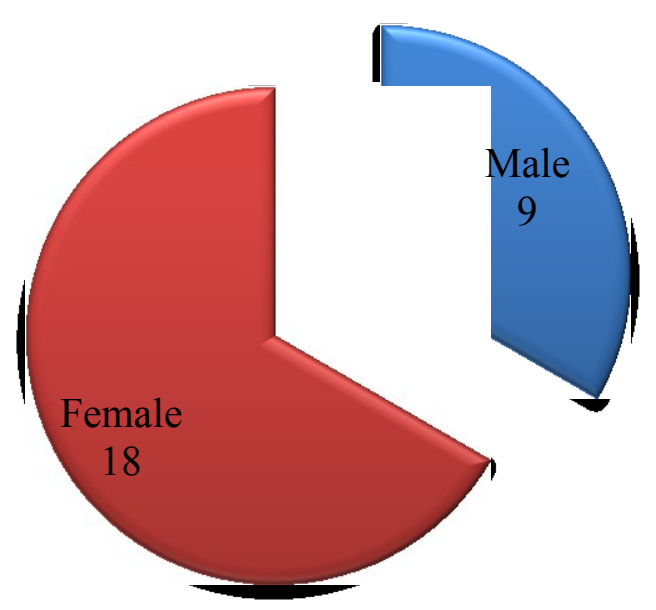


The positions of the participants ranged from news anchor, reporter, producer (executive, associate, others), news director, news writer (including economic and business news), news editor, editor-in-chief, and broadcast technician. The titles of these positions may differ from one station to the other. The years of experience also differed among participants, with the majority having between 11 and 15 years of experience as revealed in the chart below:

Table 9

Respondents' Years of Experience

Respondents' Years of Experience

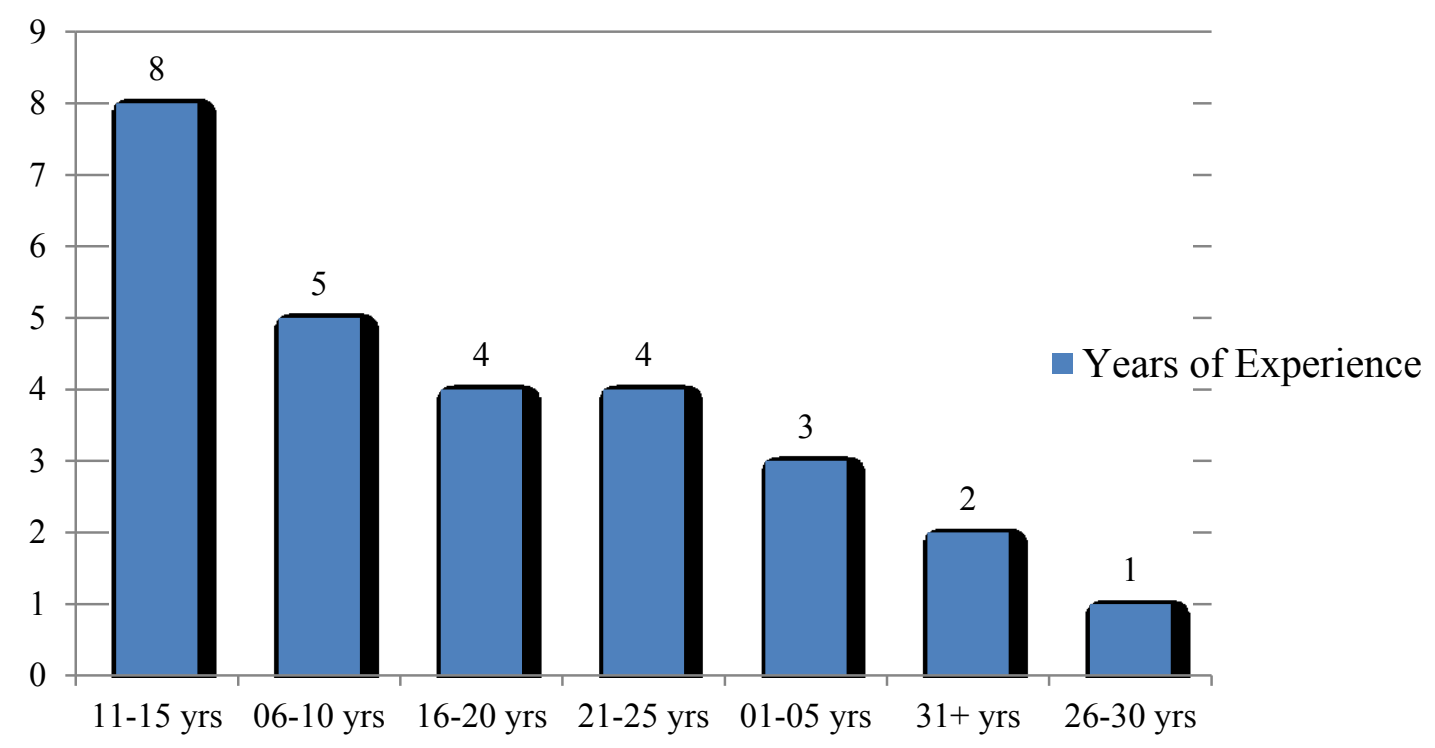

Age and years of experience were not considered as factors in the selection criteria of interviewees nor were the religious and political affiliations of the participants. The reason behind not factoring the religious and political affiliations of the interviewees themselves despite their importance to the study is due to two main considerations; the first is the fact that, in Lebanon, asking people about their religious and political affiliation may be considered intrusive and offensive and second because the Lebanese 
channels' political and religious affiliation is a not a hidden fact and people that apply or work for these stations know their affiliations. The purpose behind asking about the effect that the political and religious affiliation may have on employment, in general, was to the approach the topic and inquire about it without being offensive to the participants and to reveal to what extent the Lebanese television stations have a tolerance of "the other" in terms of employment. Disclosing the participants' political and religious affiliations was, therefore, left up to the participants themselves.

To ensure confidentiality, the 27 interviewees will be referred to as respondents. The respondents will be mainly identified as male or female, by their occupation or age when pertinent to the findings. This ensures that the respondents' identities are safeguarded throughout the study.

\subsubsection{Approaching the Research Participants}

Getting in touch with the research participants or the journalists working for the Lebanese television stations proved to be an arduous task that was somewhat timeconsuming. Contact with the human resource department of the television stations was avoided to preserve the anonymity of the participants and not to jeopardize their job positions. Instead, contact was established directly through obtaining the phone numbers of journalists.

The first three phone numbers were obtained from media instructors and the Department of Media Studies at Notre Dame University- Louaize in Lebanon. From then on, it became easier to get the phone numbers for other journalists. Once the journalists were informed of the purpose of the research being conducted and that it was part of the requirements of a doctoral dissertation, they willingly provided the phone numbers of 
their colleagues from the same television station and from other television stations. The email and letter invitations written to invite journalists to participate in the research were not of much value as they were not used at all. The journalists preferred direct contact by phone. The main advantages of phone contact were the responsiveness and cooperation of journalists. A phone call is more intrusive than an email and requires direct response, a factor which helped lower the rejection rate but did not eliminate it. Certain journalists used time constraints as reasons not to be interviewed and repetitively mentioned being preoccupied. Many journalists brushed off the first phone call and asked the respondent to call again. The many hurdles were overcome through persistence on the part of the researcher.

When a journalist was contacted by phone, he/she was informed of the name of the researcher, the researcher's university, the university where the researcher was employed and the purpose behind the research. They were also assured that they would remain anonymous throughout the process and their answers would remain confidential. The fact that the researcher is employed by Notre Dame University-Louaize (NDU) was of much help. NDU is one of the renowned universities in Lebanon; it adopts the American model of liberal arts education and working for NDU gave the researcher much credibility and trust. Realizing the value of being employed by NDU, the researcher used it in all approaches to journalists alongside Carleton University credentials.

Once all the basic research information was clarified, an interview time and place that were convenient for both the researcher and the interviewee were set. Whereas some journalists chose to have the interview conducted in a neutral location such as a coffee shop, the majority preferred that the interview be conducted in the television station itself 
during their break time or right before their working hours. This showed that the journalists had no qualms about being interviewed in the television stations or revealing the fact, within their workplace, that they were being interviewed for a doctoral research. No one seemed to question the researcher's presence at the television station or try to figure it out. To access the station, the journalist gave the researcher's name to the security personnel.

This contact process described above worked well for all television stations except for Al Manar. Establishing direct contact with Al Manar journalists proved to be somewhat difficult. Journalists from Al Manar refused to talk to the researcher without prior permission from the television's administration. After contacting the television station, I was asked to contact the head of the news department who in turn referred me to the head of the public relations office. At Al Manar, all contact with the television station has to go through the public relations office. After I explained to the public relations officer that I needed to interview two female journalists and one male journalist from the news department for my doctoral research, he asked me about the university I was affiliated with as well as official documents related to my research such as the ethics clearance (Appendix A) and the interview questions. He gave me his personal and work contact information in case I had any inquiries or wished to follow up on the process. Less than a week later, the Officer contacted me with optional interview dates with journalists from the newsroom. I interviewed all three Al Manar journalists in Al Manar offices, each at a different date- depending on their availability in the station. Al Manar, then, was the only television station that I had to contact directly to get access to its journalists and it was the only television station that asked for my academic credentials. 
The main reason for this is that fact that Al Manar belongs to Hezbollah and so do all its journalists besides the fact that it was placed, as mentioned earlier in this chapter, on the list of terrorist organizations by the US department in 2004 (Harb, 2011). Tight security measures are taken to ensure that research is legitimate and not being done for ulterior motives. Once that was established, Al Manar was highly cooperative and welcoming.

\subsubsection{Interview Process and Challenges}

Given the subjective aspect of the interview process which includes probing and exploration, face-to-face interviews were found to be the optimal choice, rather than phone or Skype interviews for this research. The main drawback of face-to-face interviews is the cost and the time involved:

Interviewing research takes a great deal of time and sometimes money. The researcher has to conceptualize the project, establish access, and make contact with participants, interview them, transcribe the data and then work with the material and share what he or she has learned....Any method of inquiry worth anything takes time, thoughtfulness, energy and money. (Seidman, 2006, p.12)

For this research, cost was not a major factor. There was no form of compensation given to the participants and reaching the interview location by car was not costly since Lebanon is a relatively small country; its total land area is 10,453 square kilometers and the longest distance from the north of the country to the south is $217 \mathrm{~km}$ and from its east to its west is $80 \mathrm{~km}$ (Sheehan \& Abdul Latif, 2007). Add to that, most of the Lebanese television stations are located within Beirut or the close by suburbs. Future Television (Sanayeh- Beirut), Al Manar (Jnah- Beirut), the National Broadcasting Network (JnahBeirut), Al Jadeed (Wata Al Msaytbeh- Beirut), Tele Lumiere (Dora- Beirut), Tele Liban (Tallet Al Khayyat - Beirut), and Orange Television (Sin El Fil- Beirut) are all located in Beirut and the suburbs of Beirut. Murr Television is in an area not too far from Beirut 
called Naccache in the Metn district. It is around 25 minutes away from Beirut by car.

The Lebanese Broadcasting Corporation International is the most distant from Beirut and is located in Adma in the Keserwan district, which is around 50 minutes away from Beirut by car.

Time, on the other hand, proved to be somewhat problematic. Each journalist had a different schedule and it was difficult to meet the contacted journalists at the same time, even if the interview was to be conducted in the television stations. So I had to meet each journalist at his/her own time and this proved to be time consuming since I was unable to conduct more than one to two interviews per day in optimal conditions. The average time for the interview was around 30 minutes depending on the extent to which the journalist was able to elaborate on the questions asked. The first interview was conducted with an LBCI journalist in a coffee shop. The second was conducted at Notre Dame UniversityLouaize (NDU) while the last was done in the LBCI offices. All NBN, OTV, Al Jadeed, Al Manar, Tele Lumiere, and Tele Liban interviews were conducted at the television stations. Two of MTV's and Future Television's interviews were conducted in the television stations and the last two were conducted at NDU.

Besides transcription, the other time consuming issue was the translation of most of the interviews from Arabic to English. All of the journalists that were interviewed knew one more language other than Arabic, mostly they were French educated. Many were trilingual and knew Arabic, French and English. Yet the vast majority was most comfortable answering the interview questions in Arabic, their mother tongue. Another reason for preferring Arabic is that Arabic is the language that they use for their work. So 
they were more able to express themselves in Arabic when it came to describing their work experiences.

Fortunately, the researcher is a native speaker of Arabic and is very fluent in the English language. This worked for the advantage of the research and the researcher, who translated and transcribed the interviews simultaneously. The advantages of this process are two-fold. First, all the interview information was kept confidential and was accessed only by the researcher. Second, first- hand knowledge of the content of the interview ensures that the information is well understood for translation.

Before the interviews, and in line with Carleton University's ethics protocol, the journalists were given the ethics clearance and they were asked to read and sign the Consent to Participate in Research form approved by Research Ethics Board at Carleton University. To ensure they are comfortable with what they are signing, the researcher went through the consent form in details with all the participants and answered all queries they had. None of the participants showed hesitation in signing the form; this indicated that they did not mind and were not worried about sharing their experience and that they had placed a certain level of trust in the researcher early on - perhaps the introductory phone call that included all necessary information about the research and the researcher had helped. Once the consent form was read, two copies of the form were signed by the journalist and the researcher. One was kept with the researcher and the other with the interviewee or journalist. The journalists were reminded that their responses were confidential and their identities kept anonymous. They were also reminded that they could take back anything they said during the interview any time during the doctoral research process. 
None of the journalists asked for the interview questions ahead of the interview. Although the researcher had offered to send the questions ahead of time by fax or email, the journalists felt comfortable knowing the general aim of the questions and did not find it necessary to know the details before the actual interview date. All the interviews were conducted and transcribed within six months between October 2014 and March 2015. The ethics clearances had been received on September 12, 2014 almost three weeks before the first interview since the researcher needed that time to network and establish contact with the journalists.

Choosing the right interview style determines the approach to the interview. Though there is no standard procedure for conducting an interview, there are however different approaches. Choosing the right approach is based on "the knowledge of the topic of the study, the methodological options available, their ethical implications and anticipated consequences of the choices for the entire interview project" (Kvale \& Brinkmann, 2009, p. 100). In interviewing professional journalists, who are interview experts, it is important to choose a style that shows respect for their knowledge and expertise. Since this study uses Bourdieu's field theory, the first evident style of interviewing to look at was Bourdieu's. Bourdieu employs a questioning method that pushes the interviewees into further exploration and self-analysis. Bourdieu is "not a neutral questioner, but expresses his own attitude and feelings... as well as taking critical attitudes towards accounts" (Kvale, 2007, p. 4). In his interviews, Bourdieu follows up on the subject's answers and tries to extend them through asking critical questions; they are not, as Bourdieu would say, merely "tape-recording sociologies" (Kvale, 2007). In a transcript of an interview, reported in his book The Weight of the World: Social Suffering 
in Contemporary Society, Bourdieu, questioning two young men on the situation of immigrants and the poor in France, uses upfront questions that are somewhat provocative. He uses interjections such as "You are not telling me the whole story" and he would even use inquisitive questions like "What were you doing bugging him?" that push the limits in an interview (transcript re-printed in Kavle, 2007). Though this style of questioning is meant for in-depth exploration of the subject, it is, however, quiet confrontational. For the purposes of this study, such a style may be inappropriate since the interviewees are experts in interviewing and may find such an approach disrespectful. Therefore, Bourdieu's interviewing style was discarded for the somewhat softer approach that Seidman suggests. Seidman (2006) emphasizes the importance of listening and of following up using exploration rather than probing. To Seidman (2006) probing feels uncomfortable and he compares it to "a sharp instrument pressing on soft flesh" (p. 86). Seidman (2006), like Hatch (2002) also emphasizes the importance of asking real open ended questions that the interviewer has no answer for and that do not influence the direction of the response. He also recommends following up without interruption by jotting down keywords and asking about them at a later stage without disrupting the speaker's train of thought.

\subsubsection{The Researcher - Participant Relationship}

Establishing the legitimacy of qualitative research has always been an issue for qualitative researchers (Jackson, Gillis \& Verberg, 2011; Bryman, 2012; Seidman, 2006; Reason, 1998; Lincoln, 1995). Yet in the assessment of quality, most researchers (e.g., Lincoln \& Guba, 1985; Eid, 2011b; Seidman, 2006; Lincoln, 1995; Elliot, 2007; Hatch, 2002), emphasize the importance of the researcher- participant relationship as well as the 
participant's stance with respect to the research. "Thinking through and describing the anticipated relationships between researcher and participants is a vital part of designing a qualitative project" (Hatch, 2002, p. 51). Because the researcher is the main tool of analysis, it is important that the researcher reflects on the actions, feelings and conflicts that are experienced during the research (Daymon \& Holloway, 2010).

The researcher- participant relationship should be one of equity (Bryman, 2012; Seidman 2006; Lincoln 1995). Lincoln (1995) includes the "sacredness of the relationship between the researcher and the participant" as one of the eight contemporary standards of research quality that she suggests. The sacred or the spiritual is in showing an actual concern for "human dignity, justice and interpersonal respect" (p. 284). It is about creating a relationship that is egalitarian and collaborative. Issues of equity, Seidman (2006) says, are affected by "the social identities that participants and interviewers bring to the interview" (p.101). The social identities are affected by the participant and researcher's experiences with issues such as race, class, ethnicity, age and gender. Since this study deals with the Lebanese television newsroom and the journalists as well as the researcher are Lebanese, race and ethnicity were not issues in this research. The issues of age, gender and class were overcome by what Lincoln (1995) calls reciprocity or a relationship of mutual respect, trust and intense sharing. In all the interviews conducted for this research, no issues with regards to violation of equity arose. Even gender and age issues were negligible considering the fact that the interviewees perceived of the encounter as a friendly meeting for the purpose of education. The Lebanese, in general, are appreciative of learning and place high value on education, especially since they consider it as one of the main endowments they can give to their 
children amid the political, social and economic instability in the country. They therefore considered their contribution valuable to both them, as contributors to knowledge, to field of media and to me, as a student researcher. The interview process was then approached as a learning and insightful experience. All the questions were posed with the utmost respect and appreciation for the expertise that the journalists have and the researcher does not have. This raises the issue of the researcher with respect to the research.

Qualitative research entails subjective analysis of the information that is collected and data collection through interviewing is a highly subjective process beginning with data collection to data analysis. The information can be interpreted in a myriad of ways and from different perspectives (Eid, 2011a). Therefore, besides adopting a critical stance with respect to the researcher- participant relations, researchers should acknowledge the biases that they bring with them to the research study or face their own assumptions and preconceptions. They should be aware of what Lincoln (1995) calls positionality, Elliot (2005) and Tracy (2013) term as self-reflexivity and Daymon and Holloway (2010) describe as simply reflexivity. Positionality entails an honest reflection of the author's stance with respect to the study; it is very similar to reflexivity through which the author critically considers his condition as a cultural, social and political agent in the interpretation of meaning. "Reflexivity is the active process of reflection that researchers using qualitative methods go through so as to how to document how the research process in general and often themselves in particular, construct the object of the research" (Bolam, Gleeson \& Murphy, 2003, p. 2). Elliot (2005) suggests documenting the research steps in details to ensure that they are transparent. Bourdieu takes this 
documentation a step further as he increases the scope of reflexivity to include the entire research process:

Now to objectivize the objectivizing point of view of the sociologies is something that is done quite frequently, but in a strikingly superficial if apparently radical manner.....But objectivation of any cultural producer demands more than pointing to - and bemoaning - his class background and location, his race or his gender. We must not forget to objectivize his position in the universe of cultural production. (Bourdieu \& Wacquant, 1995, p. 69)

Reflexivity, Bourdieu posits, then, should also encompass a description of the researchers' status in their cultural production field, which could be the academic field. This would help add another layer of "objectivation" to the research. Yet according to Lincoln (1995) "detachment and author objectivity are barriers to quality, not assurance of having achieved it" (p.280). In effect, detailed description of the research steps would help minimize subjectivity but they would not eliminate it. In one way or the other, the self is always part of the research process (Sclater, 2003). It is therefore important to describe the self, its knowledge and its involvement in the research to minimize its intrusion in the research and analyze the process to get as close as possible to objectivity and detachment.

The analysis of the data is reliant upon the researcher's knowledge of the research environment and the factors that affect that environment; it is what Bourdieu would refer to as the doxa. The doxa is a network of unconscious assumptions within which the actors act; in journalism, it is the core beliefs that direct newsroom practice (Wacquant \& Bourdieu, 1992). It is then the unspoken of rules of conduct and costumes that govern the newsroom. As an outsider to the newsroom, I am unaware of the dynamic and the unconscious rules of conduct in the newsroom. This can be advantageous and disadvantageous. It is advantageous in that the participants would feel comfortable 
revealing the inner workings of the newsroom as they see them knowing that as an outsider I would receive the information without pre-judgement of what the newsroom is like and would not be using this information in any way in the future. Another advantage is that I am not personally acquainted with the journalists in the field and this would make them more comfortable in revealing their true opinions, especially in a small country like Lebanon where all media workers are well acquainted with each other. The last advantage is that I have no preconceived notions or assumptions about the newsroom or the workings of the newsroom. The opinions of the journalists would, in this case, be received without predetermined judgements and would not be assessed in relation to prior experience, notions or expectations.

The disadvantage of being an outsider to the newsroom is that as a researcher I may not be able to describe in exact and nuanced terms what the journalists go through or I may not be able to grasp hints about their job or their environment. There were times when I would interrupt the interviewer to clarify certain technical words used in the field for clarification or further explanation. Add to that, at certain points in the interview process, the journalists perceiving me as an outsider felt compelled to explain certain comments they made or to resort to detailed explanations of certain aspects of their job to ensure I understood their point- without me asking for an explanation. This, however, added to the rigor of the interview and made the interviewers feel more at ease knowing that their point is well understood. One last drawback may be in the general perception of the Lebanese media. Like most Lebanese people, I perceive of the media as politicosectarian bodies whose main aim is to serve their political and sectarian affiliations. This, in turn, affects the perception that I have of the journalists as they are perceived to be 
affiliated to the same political parties and religious sects that their station is affiliated to. Yet well aware of this supposition, I was ready to listen, without judgement, to the journalists' explanations and their perspectives with regards to how that affiliation affected their employment, job positions and progression.

\subsubsection{Data Analysis}

Data analysis is the processing of data in such a way that communicates what has been learned to others. It "is a systematic search for meaning" (Hatch, 2002, p. 148). In analysis, data is organized in a manner that reveals certain themes, relationships, meanings and correlations. Analysis involves the organization and interrogation of data in such a manner that permits researchers to see patterns and identify themes to provide interpretation and explanations and at times formulate theories. For this study, the five main research questions identify the main themes derived both from the literature review and the theoretical framework. Having a pre-determined set of themes helps with the organization and the coding of the data derived from the semi-structured interviews. This does not mean that new themes may not be detected from the process of the analysis since the researcher may be able to detect new patterns or relationships that were not part of the pre-determined themes.

To analyze the data collected from the 27 semi-structured interviews for this study, the Computer Assisted Qualitative Data Analysis Software (CAQDAS), NVivo 10 was used. Using software for the analysis of data has become acceptable (Bazeley \& Richards, 2000) yet it still faces a certain degree of opposition. Opponents of software use find it threatening as it may distance the researcher from the data or restrict the analysis process into a fixed framework of analysis; those who advocate the use of 
software find it to be an efficient means for data processing and analysis (Bourdon, 2002; Welsh 2002).

To achieve the best findings, it is better to use the best features in electronic and manual methods rather than choose one (Welsh, 2002) It is not enough for data analysis to be done through software such as NVivo 10. The software can help with the mechanics of the analysis but it cannot do the mind work that is critical to qualitative research (Hatch, 2002). The program can organize the data and produce numerical results but it cannot influence the analysis or provide in-depth insight to the analysis that the researcher can. NVivo can record and it can organize data but it is the researcher who decides how to record and how to organize. The much needed role of the researcher is emphasized by the definition that QSR gives NVivo. According to QSR, NVivo "doesn't do the thinking for you; its powerful workspace helps you explore your information, so you can focus on making new discoveries and better decisions” (QSR International). Essentially NVivo is simply a tool that would not influence the data analysis procedure but would speed up the process of organization and analysis.

There are four stages of data analysis in NVivo. The first or the descriptive stage entails entering the data in NVivo, the topic stage is organizing and coding the data, the third or analytic stage is analyzing or querying the data and the final stage is the conclusion or the drawing of answers from the data (O’Neill, 2013). To go through the first or the descriptive stage, the 27 interviews were transcribed in full and imported into NVivo 10 as word files. The files were renamed to include gender, TV station, years employed at current TV station, age, current management position, level of education and original title ID. This was done to take advantage of the sorting feature in NVivo 10 
which sorts coding reports alphabetically according to the title of the document.

“Characteristics of the sources of data such as people's gender, the dates of events, locations of sites" (Bazeley \& Richards, 2000, p.41) are stored as attributes in Nvivo. Attributes can be used to filter the data and to search it. Each attribute has a set value. The chosen attributes for this study include gender (Male/Female), television stations (Al Manar, Future TV, LBCI, MTV, NBN, Al Jadeed, OTV, Tele Liban, and Tele Lumiere), age (the actual age), current management position (middle, upper, news anchor, news reporter, news anchor/reporter) as well as the level of education (Bachelor, Master or Doctoral degree).

The second and third stages of data analysis include coding and analyzing the data. "Coding is the process of gathering material by topic, theme or case" (QSR, 2014). Open coding is the "first pass" through the data to locate themes and assign category titles; it includes NVivo coding using specific words and phrases from the content. For this study coding was based on the pre-determined themes explored in the research questions. These themes include gender, glass ceiling, adaptation strategies, patriarchy, old boys' club and coverage. The next phase is axial coding which is clustering and eliminating categories as the researcher/coder gets deeper into the data. Selective coding is the deepest level of analysis as the researcher chooses themes and compares/contrasts after all data collection is completed. It is the final stage of analysis. The coding in this study is inductive, involving "first pass" and axial coding.

Nodes are containers for the coding (QSR, 2014). So in coding the groups of concepts related to the themes of the study were stored into nodes. The coding contains 10 main nodes composed of two main sets of questions - the general questions and the 
questions pertaining to the concepts found in the five research questions and labelled accordingly:

1. General Questions

2. II_RQ1_Cultural Capital_Skills_Glass Ceiling-Gender

3. II_RQ2_Social Ties_Patriarchal Connectivity

4. II_RQ3a_Political and Religious Ties

5. II_RQ3b_Glass Ceiling-Gender

6. II_RQ4A_Coverage

7. II_RQ4B_Gender_Patriarchy

8. II RQ4C ${ }^{-}$Gender

9. II_RQ5a_Adaptation \& Advancement Strategies

10. II_RQ5b_Old Boys' Club

In the categorization stage, each unit of data is allocated under a specific category within the coding structure (Berg, 2011). For this study, the 27 interviews imported into NVivo 10 were coded into 10 main nodes and 338 subcategories (Appendix C). For example in the node entitled "what hinders women's progression" which belongs to research question 5, the subcategories are composed of the various answers provided by the journalists interviewed. These answers include childcare availability, competition, lack of experience, gender bias, patriarchal society, political ties, priorities, luck, and religious issues.

Yet depending on the responses, the data may be coded to more than one category. This is called multiple coding. Multiple coding is conditioned by the nature of responses selected from a single interview. The responses may have meaning in more than one category. The interview is only counted once within the subcategory but certain participants may provide a variety of responses to a single question, and the same content or different selections of text from a single interview can be coded to multiple nodes.

Coding is a subjective process therefore coding is not exhaustive and does not include every line of text. Coding everything everywhere would make the analysis 
burdensome to read and analyze since connections can be made throughout the data collected. Though it is tempting to constantly re-code, the decision to stop coding and think of thematic connections and relationships can be made throughout the coding process (Welsh, 2002). In coding, it is important to code for context by capturing more content to every node to help with the final analysis. Context is essential for meaning in qualitative analysis since simple extraction of data may compromise meaning. It is imperative that the researcher checks the NVivo findings against the context.

Reading, comparing, and interpreting the reports are the final integral steps in this process. In this analysis phase, the text in the coded themes is reviewed to uncover patterns of emphasis and to show commonalities and the differences that the text has with the theoretical framework, leading to the analysis of the findings. The final step is relating the findings to the literature review to reveal where they converge and diverge from the literature (Merrigan \& Huston, 2009).

\subsubsection{Validity and Reliability}

Validity and reliability measures and procedures were followed in this study. Validity in qualitative research means truth as qualitative researchers are interested in authenticity rather than a single version of the truth (Eid, 2011a). This is established by providing a truthful or authentic account of the phenomenon experienced from the perspective of the person who experienced it. Authenticity, after all, is less about matching an abstract construct to empirical data than it is about giving "a candid portrayal of social life that is true to the lived experiences of the people we study" (Neuman, 2011a). It is about providing an inside view of the people under study and their understanding of the events. 
Credibility, dependability and confirmability ensure the validity of the research (Neuman, 2011a). Credibility is achieved through accuracy in describing the setting, participants and events observed. Dependability is achieved through trackability or the effective documentation of data generation and analysis. Confirmability is achieved through objectivity which is obtained when the researcher is explicit about the way in which personal biases or values may affect the study. To ensure the validity of this study, the researcher explicitly documented her biases as well as the data gathering and analysis processes while providing an accurate description of the context and participants.

Reliability was achieved through consistency of the findings under identical or similar conditions. Observations are consistently recorded to ensure data authenticity. This is employed from the early stages of data collection to the final stages of analysis. "Reliability is easiest to achieve when a measure is precise, concrete and observable" (Neuman, 2011a). To achieve reliability for this study, all abstract concepts, such as habitus and masculine norm, to name a few, were well defined as well as the measures required for these concepts. Asking specific questions in an interview helps produce reliable measures and ensures that other researchers would get similar results, if they reproduce the study.

\subsection{Chapter Overview}

Guided by the research questions of the study, the research design is determined by the objectives of the study as well as the research reality. For this study, face-to-face semi-structured interviews were deemed to be the optimal method of data collection. All the Lebanese television stations were included in investigating the status of female journalists in the Lebanese television stations. This was made possible thanks to the 
manageable number of the Lebanese television stations and their geographic proximity. Three journalists, 2 females and 1 male were interviewed from each television station. The interviews were transcribed then imported and analyzed through the qualitative analysis software, NVivo 10. The analysis ensured validity through authenticity, credibility through trackability, confirmability through objectivity and reliability through consistency. The following chapters will be comprised of the analysis of data collected in the light of the context of the research as well as the content provided by the interviews. The value of qualitative analysis is in the in-depth analysis and insight that the research can provide and can endow the NVivo as well as the themed interview data with. 


\section{Chapter: Uncovering the In-Depth Interviews: Ties, Coverage and}

\section{Appearance}

Both this chapter and the next chapter present the data gathered during the field research which included qualitative in-depth interviews with 27 Lebanese television newsroom journalists, 18 of whom were females and 9 of whom were males. The data presented answer the five main research questions: (i) How does women's cultural capital in terms of education and skills affect women's progression? Are the same skills required of men and women? (ii) How do social and familial ties affect women's hiring and progression within the Lebanese television newsroom? (iii) How do religious and political beliefs and connections within Lebanese television institutions affect women's share in top-management positions in newsrooms? Why? What are the views of male and female employees on this? (iv) How does the patriarchal make-up of Lebanon affect the gender dynamic within the newsroom? Is the newsroom, like society, dominated by masculine norms? Are there male and female-specific coverage areas and skills? Do age and appearance affect women more than men? (v) What kind of strategies do women use in the Lebanese television newsroom? Do males and females use the same adaptation and advancement strategies?

The findings of the data are categorized here in themes that are present in the open ended in-depth interview questions which answer the five research questions of the study. The themes derived from the theoretical framework, and described in the methodology chapter are spread across those research questions. Findings related to one theme may, therefore be found under a number of questions. The themes discussed in this 
chapter include (i) cultural capital, (ii) social ties and patriarchal connectivity, (iii) political and religious ties, (iv) masculine norm and (v) age bracket and appearance.

\subsection{The Significance of Cultural Capital}

This section provides the answers to the first main theme on how women's cultural capital and skills affect their progression. As explained in the theoretical framework and methodology chapters, the concept of cultural capital is studied through the sub-concepts of education including majors and universities, area of expertise, and field experience.

\subsubsection{Major and University}

Bourdieu's concept of cultural capital is explored through the respondents' education, in this case, the majors they chose and the university they graduated from. The purpose is to examine whether the area of specialization and the university chosen affect the job positions taken and job progression.

All of the respondents are educated and have at least a bachelor degree. 23 have a bachelor degree, 3 have a master degree and one is a doctoral degree holder. Most of the respondents came from majors that are related to the profession: 13 majored in journalism, 9 in audio-visual media or radio/TV, 6 in political science, 2 in English and French Literature, and 2 in Law. The other majors included business administration, Armenian studies, finance, information technology, insurance, international affairs, philosophy and religious studies, political Islamic studies and sociology.

The major counts exceed the number of respondents due to the fact that certain respondents did more than one major or continued with their graduate studies in fields other than their original major. One of the respondents (M, Personal Communication, 
2014) for instance, has three master degrees in Journalism, Political Science and English Literature. The respondent's bachelor degree is in Political Science. Another respondent (F, Personal Com., 2014) received a bachelor in Radio/TV and master degree in International Affairs, whereas a third (F, Personal Com., 2014) majored in Information Technology. This shows that though most respondents majored in specializations close to their area of work, that is, journalism or audio-visual studies, majoring in other specializations, such as Finance or Insurance, did not hinder the other respondents' entry into the field.

The Lebanese University, which is the only public university in Lebanon, is the university that most respondents graduated from. Two main reasons may justify this: the Lebanese University offers the oldest and most prestigious journalism studies program in Lebanon; it is also tuition free (Melki, 2009).

When asked whether the type of university they graduate from affects the positions they take in the newsroom, most respondents agreed that it did not:

No it does not. Most of the people working in the media are graduates of the Lebanese University. I would say around 70 percent of the people in the field. The Lebanese University offers specializations in everything; private universities started offering media studies about 10 years ago. (M, Personal Com., 2014)

Most concurred that the Lebanese University offers a rigorous journalism program and it was the most renowned at the time they had started their studies and it still is; "The Lebanese University is known for its excellent media program," (F, Personal Com., 2014). Yet though Lebanese University students were well equipped to cover the news and write news reporters, students from private universities were better technically equipped (F, Personal Com., 2014). 
Updated experience and skills, passion and a journalistic instinct as well as job availability and a network of connections in the field were cited by respondents as nonuniversity related factors that affect the position that one takes in the newsroom. Even when it came to hiring decisions, respondents in higher positions mentioned that the type of university journalists graduated from does not affect their decision. "When I hire people, the criteria to look for are expertise, passion and enthusiasm," said one of the male respondents in senior management (M, Personal Com., 2014). A top level female management respondent related job positions to the quality of work one delivers and not the university they graduated from (F, Personal Com., 2014).

Few respondents affirmed that the university plays a role in affecting job positions; most of them worked in the technical departments of the news. Despite being a Lebanese University graduate, a female web editor (F, Personal Com., 2014), mentioned that graduates from prestigious private universities, like the American University of Beirut, had higher chances of getting employed. A female Technical News Director (F, Personal Com., 2014), a Lebanese American University graduate, affirmed that students who graduated from private universities like the Lebanese American University, Notre Dame University-Louaize and Universite Sainte Esprit- Kaslik were more skilled to take on technical positions. These universities had updated facilities and qualified instructors to ensure their students were technically well-equipped for the market, besides having a better market reputation.

\subsubsection{Area of Expertise}

The area of expertise examines to what extent newsroom workers cover specialized areas in the news field. This helps identify whether the journalists have well 
defined roles and whether there are differences in news coverage in relation to gender. It also indicates whether news specialization is prominent in the Lebanese television newsroom.

Interestingly most respondents, both males and females, cover almost all types of news. Some expressed having preferences for one type of news over the other but insisted that they were able to cover and were assigned to almost all news types. This excluded sports and weather which were generally assigned to special correspondents in every television channel. One of the female respondents, who worked as a news reporter and a special presidential palace correspondent, asserted "I can cover all types of news and not just politics. I can cover economic and social news and other news types without any difficulty."

Most respondents found that reporting for a Lebanese television station entailed covering all types of news. They saw the lack of specialization as part and parcel of the Lebanese journalistic profession and the nature of the news business. A senior male respondent even maintained that journalists needed to rely on their journalistic sense and research, both conceptual and on the field.

Insisting on their capability to cover almost all types of stories, certain reporters expressed preferences to certain types of news. In this case, gender played a somewhat visible role. Many respondents showed preference for political news coverage and mentioned it as an area of specialization. 5 out of the 9 males and 8 out of 18 females mentioned that they cover almost all types of news with a preference for political news. This preference, among both genders, for political news in the Lebanese television newsroom may be attributed to the supremacy of political coverage and the high regard 
that political news is given versus other types of news. In highly politicized country like Lebanon, political news becomes even more valuable.

Whereas males, in general, did not express special interest in covering certain types of news, female respondents did. "I cover all types of news...However, I prefer to cover social issues and I love the economic sector," said a female respondent. Another female respondent expressed an avid interest in human stories, as she was most creative in developing such stories. A third, who specialized in political coverage, expressed her interest in documentaries. Only one male respondent mentioned that he was interested in covering environmental news alongside political news.

A special case to take into consideration when it comes to political news is Tele Lumiere. Tele Lumiere, as previously mentioned, is a non-profit organization with an ecumenical mission. It is supervised by the Assembly of Catholic Patriarchs and Bishops in Lebanon. One of its goals is not to present or market political news. Tele Lumiere, therefore, does not have a traditional newscast; it broadcasts a daily newscast that is limited to religious happenings, church concerns and news of prominent religious figures in Lebanon and abroad. The only messages of political nature that the station may broadcast relates to words of religious figures and are usually messages targeting the entire Lebanese population to promote the public good. A female respondent in a senior management position mentioned, for instance, that the station aired messages by Lebanese Maronite Patriarch Bechara El Rai urging the Lebanese political body to elect a president, since Lebanon had been suffering, to the date of the writing of this thesis, from presidential void which has lasted for over a year to date. Journalists at the Tele Lumiere newsroom mainly cover social and religious news as well as human interest stories. 
Political news, as mentioned before, is only covered from a purely religious angle. Most Tele Lumiere journalists cover most types of news broadcast by the station.

\subsubsection{Field Experience}

Alongside university education and university name, Bourdieu considers experience to be part of the cultural capital of a journalist. It provides the journalists with the skills necessary to advance in the profession. Asking the journalists about their experience is to examine to what extent experience affects job progression in the Lebanese television newsroom.

Most respondents interviewed, specifically 19 in number, had experience that exceeded 11 years. The 8 other respondents had experience that ranged between 1 and 10 years. Only 3 people interviewed had over 26 years of experience and 3 had from 1 to 5 years of experience. The majority (16 respondents) then had between 11 and 25 years of experience.

Almost all respondents placed much value on experience citing its importance for job progression. Improvements that respondents related to experience included confidence, knowledge of the field, connections, ability to deal with the camera, stress control, fame, trust from management, strength, work quality, self-censorship and credibility. A female respondent who occupied an upper management position, attributed success in the journalistic field mainly to experience:

Experience is very important.... I entered LBC at the lowest post available which is a writer. After six months, they moved me from writer to assistant bulletin editor in the satellite channel then after four years they moved me to the same position in the LBC International and after 6 years they moved me to the position which I currently occupy. All this advancement happened through work experience and practice and did not happen in any other way 
The years of cumulative experience that the journalist establishes in the field are years that they can carry with them from one position to the other and from one station to the other. Additionally, news anchors and reporters in Lebanon become famous all across Lebanon since all the Lebanese televisions are national stations and the Lebanese people are well acquainted with the content of most. A female respondent mentioned being given the head of reporters position at MTV due to the experience accumulated at LBCI. The respondent attributed the progress made to the fame established throughout the years, field capabilities and connections.

Understanding the political game or the news game was an interesting response attributed to experience. Having 11 years of field experience, a female respondent gave a professional example as to how picking up on certain political hints and knowing how to follow political leads as well as dealing with political figures could only be acquired through experience and was part of understanding the game. While being interviewed, the respondent received a phone call from a minister in the Lebanese government. The minister wanted to check on a story covered by the television station. The respondent emphasized that politicians needed the media just as the media needed the politicians; knowing how to play the game right could be beneficial for both, the respondent emphasized. Another female respondent also with 11 years field experience underlined the importance of the experienced journalists in understanding the news field, as if alluding to the game metaphor. New comers would not be sent to cover sensitive stories, the respondent said; such stories were reserved for those with the necessary experience in the field. 
A male respondent in senior management also alluded to the game metaphor. However, to him, years of experience did not necessarily mean a full grasp of the game. The understanding was associated to grasping the political and religious situation in Lebanon and producing a sound assessment of what to cover and when. The respondent mentioned that judging whether or not a journalist fits into a certain role, required a political evaluation of their awareness, how much they understood and "how capable they are of weighing matters properly... especially in a country like Lebanon."

Few respondents found that factors other than experience affected progression. These factors mainly related to fitting the politicized nature of the channel and practicing a form of self-censorship. "The media is so polarized and so politicized, so sometimes it does not matter how equipped you are and how experienced you are," asserted a female respondent in a senior management position. An opinion supported by a female reporter who stated that with experience "I know what I need to say and not to say, by heart, without asking anyone about it - more like self-censorship."

In reviewing the findings related to education, expertise and experience, respondents' answers revealed that the value of the university education and its importance for access to the field of journalism were paramount. While private universities were preferred for access to technical positions, the Lebanese University emerged as the most preferred for all other newsroom positions such as writer, editor, and anchor. When it came to progression, education was not as valuable as experience. The importance of understanding the political game emerged as a more pertinent asset to journalists in the Lebanese television newsroom. It is in effect the recognition of and interaction with the unwritten socio-political and organizational code that is acquired 
through years of experience in the field. Though the Lebanese socio-political and religious arena is visible to outsiders, understanding it and factoring it along with the organizational culture of the television station takes time and the in-depth insider experience of a journalist. Despite the value of experience, Lebanese television newsroom journalists do not appear to specialize in a specific area of coverage. Most of them, male and female, cover almost all types of news

Experience, as mentioned previously, then, is a major form of capital that ensures an understanding of the inside and outside factors affecting the newsroom. While university education is necessary for access, experience is necessary for progression. Other than education and experience, social ties and connectivity, discussed in the next section, also function as forms of capital.

\subsection{Social Ties and Patriarchal Connectivity}

This section provides answers to the second theme on social and familial ties and how they affect the hiring and progression of women within the Lebanese television newsroom. This theme relates to Bourdieu's social capital and Joseph's patriarchal connectivity. Both concepts discuss the importance of social ties and connections in helping the individual advance. Suad Joseph contextualizes these connections in the Middle Eastern environment through patriarchal connectivity. Joseph proposes that in countries like Lebanon family ties, mainly through the patriarch or the family name of the patriarch, are important for hiring, firing, and even advancement decisions. In such a close-knit community, connections play a vital role in providing access to amenities or favors. 
The social ties, as discussed in the theoretical framework, form the network of connections that the person can mobilize to reach a certain objective, whether that objective relates to getting a job or progressing in that job. Journalists were asked whether social ties matter to examine the influence that such ties have on the Lebanese television stations and the extent to which they affect journalists' career.

\subsubsection{Social and Familial Ties (12 respondents- 3Ms \& 9Fs)}

As previously mentioned, social and familial ties are part of the journalists' social capital and are established through patriarchal connectivity. Certain journalists found these social and familial ties or connections had an influence on the employment and progression of journalists in the Lebanese television newsroom; they identified different aspects of that influence including hiring, management influence, fast progression and job continuity.

Respondents who affirmed that familial and social ties play a role in getting a journalist hired presented highly affirmative answers, such as "It happens, yes," (F, Personal Com, 2014), "Yes 100 percent. This plays a big role in Lebanon. If you have a connection, you reach quicker," (F, Personal Com, 2014). Three male respondents attributed the effectiveness of ties to management and the extent to which management allowed such ties to be influential. One of the males in senior management asserted that for ties to work, the journalist should be skilled.

To certain respondents progression "in leaps" was attributed to familial and social ties. A newcomer who had no experience at all may be suddenly given the position of a news anchor or reporter, said a female respondent. This caused frustration as a journalist 
with an experience of ten years would "wonder what happened and how did this take place." Another female respondent with 11 years of experience asserted:

So if you have the skills and connections, you get what you want right away. If you don't have a connection but you have the skills and expertise, you will have to work very hard to get what you want

Connections played an even bigger role in guaranteeing not only a position but also continuity in that position, especially if the journalist were recommended by a certain politician. Such people would never lose their jobs unless they made a very big mistake. Journalists with ties did not even have to work asserted a female respondent in senior management: "There are people still at the station because of these connections. There is no need for them in work terms but there is pressure for them to stay in their posts."

\subsubsection{Social and Familial Ties as Effective (9 respondents -2Ms \& 7Fs)}

While the respondents in the previous section found ties to be highly influential, other respondents acknowledged the influence of ties but within certain limits. These respondents were not as assertive in their answers. They placed the power that ties have within certain boundaries since ties are not effective if the journalist is not endowed with the necessary skills and abilities.

The connections can get the potential journalist an interview but everything beyond that depends on the journalists' abilities. "There are few people that are hired based on connections but if they prove not to be qualified in their role, they would leave right away," asserted a female respondent.

Most respondents acknowledged the importance of ties in getting a person access to employment and in opening doors but agreed that such ties do not guarantee continuity or progression. "Ties cannot help on the advancement front;" it is all about hard work, a 
female respondent said concurring with four other female respondents and a male respondent who asserted the importance of ties in getting a journalist hired but not in guaranteeing their continuity or advancement in the job.

Interestingly a male respondent who found that ties were only mildly influential confirmed that a certain politician can "bestow his wishes" upon the television station:

No, that does not apply. Here at Tele Liban no one is related to any of the government officials. But maybe there is an official who may bestow his wishes and a request that we look after a certain person but that does not mean the official forces that candidate or employee on us

\subsubsection{Social and Familial Ties as Inconsequential}

Ties were not important to all respondents. To these respondents, ties are not part of the journalists' social capital and do not endow the journalist with advantages in terms of hiring or progression. "No. Not at all, it is not about familial and social connections," asserted one of the female respondents in senior management.

Most respondents who did not find ties to be consequential emphasized the importance of the journalists' skills and expertise. Yet in their responses these journalists did not consider knowing someone at the television station as a social connection. This could be attributed to the fact that, in Lebanon, having a connection meant knowing someone in high places such as politicians or people in senior management rather than regular individuals with positions in middle or lower management at the television station.

"It is not the familial and social connections that would bring journalists here but instead their capabilities, skills and expertise," said a male respondent in senior management. The respondent, nonetheless, did not disregard connections altogether. Yet the connections could be anyone, mainly at the station, recommending a journalist 
because of their expertise and knowledge. A female respondent in senior management asserted that connections do not play a role and cited her own personal experience as she was hired without knowing anyone. The respondent also mentioned that using connections is not a common practice at the station; "To be clear, I have never received a telephone call from upper management asking me to hire someone specific.” Another female respondent in senior management adamantly asserted "I do not recruit according to favoritisms and connections and I do not offer internships according to favoritism or through connections either." The Respondent, however, did not deny that if a journalist has a connection, that would get them an interview.

Ties are not consequential according to a male in senior management who acknowledged the station as a family business and mentioned that the vice chairperson was a family member, hired purely because of skill:

No it does not. New TV belongs to the Al Khayat family but if .... is vice chairman of the board and she is in charge of the news department and she is the daughter of the television station owner, it is not because she is his daughter and she is having fun but it is because she is competent and capable to assume these roles. She studied media at the university and therefore if she studied media and she is capable then why not?

Respondents' answers show that the role of favoritism or nepotism is underplayed by male and female respondents in senior management more than it is by other respondents. The reasons for this could be twofold- the respondents are either speaking out of experience or they do not wish to unveil the influence of ties since they may be involved in the hiring process of new journalists.

In all cases, in discussing the importance of social ties, respondents' answers uncovered interesting revelations. Though mostly deemed as a place where nepotism and favoritism play a somewhat important role, the Lebanese television newsroom 
environment materialized like a filter that expels the unwanted debris. The value of social connections is important and well acknowledged but it is not the maker of a career in journalism. Skill and knowledge are necessary for the continuity and progression of journalists. The next section examines the value of political and religious beliefs.

\subsection{Political and Religious Ties}

This question speaks to the nature of the Lebanese television stations that function and are recognized as religious and political entities by virtue of their ownership. As discussed in the literature review, the channels also become representative of the specific religious and political factions within the Lebanese community. The political and religious affiliations may therefore function as social capital according to Bourdieu. When their influence does exist, journalists can leverage this capital to ensure employment and progression.

\subsubsection{Political Affiliation as Inconsequential}

This question examines journalists' perspectives as to how the political affiliation of journalists may affect their employment and progression in a certain television station. As revealed in the literature review, most Lebanese television stations either belong to or are affiliated with a specific political party. Some are directly founded by and belong to a specific political party like Al Manar (Hezbollah- March 8), NBN (Al Amal- March 8), Future TV (Al Mustaqbal- March 14), and OTV (Free Patriotic Movement- March 8). Others are affiliated with specific political movements such as LBC (previously Lebanese Forces, currently affiliated with March 14), MTV (affiliated with March 14), and A1 Jadeed (leans towards March 8). The two remaining channels, namely Tele Liban and Tele Lumiere, are not politically affiliated. As the public broadcaster, Tele Liban is not 
partial and is supposed to speak for all the Lebanese people. Tele Lumiere, on the other hand, is a Christian television station supervised by the Assembly of Catholic Patriarchs and Bishops in Lebanon.

At first glance, when it comes to political affiliation, it seems that most respondents (14 out of 27) find that political affiliation is inconsequential. In effect, those whose answers can be considered affirmatively against the influence of political affiliation amount to six respondents. A female respondent in senior management, for instance, asserted that she was hired by the station despite the fact that her political views contrast with those of the station. Her affiliations, she said "were against (the station's) political views 1000 percent and despite that I was hired as a writer." To remain in that environment, the respondent mentioned that she kept her affiliation for herself and avoided inserting her viewpoint while working. In answering whether political affiliation affects employment, an Al Jadeed respondent said "Not at all... at New TV there are many political views... The person at the station or applying to the station does not get asked about their political affiliation." The same opinion was expressed by a Future TV respondent who asserted "I cannot talk about other stations but at Future TV it does not affect... I never felt they dealt with anyone here based on their political or religious affiliation." An NBN respondent also mentioned that she was never asked about her political affiliation. The same view was expressed by Tele Lumiere respondent who emphasized that, at the station, political affiliation does not affect employment or progression. An MTV respondent affirmed that MTV, which abides by a clear political view, is, in fact, a forum for all political views:

MTV prides itself to be a forum that is open to all political views to be expressed on the channel. The station does not speak in the name of one political party...(it) 
considers that the people working at the station (and sharing their) political vision would help the station

Most of the respondents who believed political affiliation is inconsequential qualify their answers by providing explanations that show the role that individual political affiliation plays in the newsroom. The qualifying arguments differ; a number of respondents mention that journalists should keep their own political views to themselves and should not express them around the television station especially if their views contrast with those of the station. "I cannot talk about other stations but at Future TV it does not affect.... There are many people at Future TV who have different political views than that of the station but don't express it and were never confronted based on their political affiliation," said a female respondent. A female respondent in senior management asserted that the station would not hire someone who would aggressively express their opposing views without respect for the other views.

Other respondents denied that political affiliation affects hiring and progression in their station but hinted that, at other stations, the situation is different. A Future TV respondent asserted that some TV stations, like Al Manar, and at one point LBCI were formed of people with unique political affiliations. An LBCI respondent commented on OTV saying “If you take OTV for example, they don't hire anyone who is not from the Free Patriotic Movement or does not support them.” An MTV respondent on the other hand, asserted, that "at LBCI I know when you apply for a post there, they ask the person which political party they are with. Here at MTV they don't ask such a question." The same respondent mentioned that unless you belong to the Party of God (Hezbollah), you would not get hired in Al Manar. A respondent from NBN said that if a person is 
affiliated to the Free Patriotic Movement, it would be hard for them to get a job at MTV "whose political affiliation is well known."

Certain respondents interestingly affirmed that journalists applying to a television station are well acquainted with the station's political affiliation and would not have originally applied had they been adamantly opposed to its political position:

At the end of the day MTV is a known organization and before you come to MTV, you know who works at MTV and what political view employees advocate so I don't think there are people at MTV that have a way far off view from the view of the station. (F, Personal Com., 2014)

This view was shared by other respondents such as a male respondent from NBN who confirmed that the station's well defined line of thought did not hinder the hiring of journalists affiliated to the March 14 coalition but these journalists "left and no one forced them out."

A senior management male respondent revealed that Future Television employed people from different religious sects and diverse political factions without discrimination. He praised the station as one of the most diverse but added that hiring people from opposing or different political viewpoints may not work for all departments. He gave the example of the Future TV promotion group that produces promotional video clips for the station and the late Prime Minister Rafik El Harriri.

\subsubsection{Political Affiliation as Effective}

Almost half of the respondents believed that a person's political affiliation affects their employment and progression in the Lebanese television newsroom. The support these respondents gave to their opinion was somewhat similar as they believed that a journalist, especially a newsroom journalist, should abide by the political thought of the 
station. It is worth noting that the station functions, in general, as the mouthpiece of the political party it supports.

Certain respondents expressed their opinion adamantly and assertively when it came to the influence of political affiliation. "Today, yes. It does affect for sure one million percent and who tells you otherwise would be lying," said a female respondent. "If I am against Hezbollah (Party of God) and what they believe in, what forces me to work at Al Manar TV?," asked a female respondent. Perhaps the best description of the influence of political affiliation comes from a senior reporter at NBN, who said:

Of course it does. For example Future TV will not hire someone who is a Hezbollah (Party of God) member or supports them blindly. NBN will not employ someone who is against the Lebanese resistance and against President Berri, Head of Parliament. Employment at NBN does not happen just like that. They need to know who the candidate is. At NBN the employment is done through references from within.... For example if tomorrow someone comes and applies to NBN and we discover she is from a small town called Bshareh which is a stronghold for the Lebanese Forces, she won't be hired. They investigate who the person is. They have to be in line with the channel's political view... There is nothing called impartiality in this case

The respondent asserted that journalists would not be put in high position if they did not support the political line of the station.

Respondents from OTV, Future TV, New TV, MTV and OTV believed that journalists should, in general, advocate the political opinion of the station they were working for. A female respondent in senior management took it a step further to indicate that watching over a person whose political opinions differ from those of the station can be tiring and troublesome. "I cannot employ someone who is going to hurt me politically or have to constantly follow up on their tracks to be certain if they are working correctly or no," the respondent asserted. A male respondent in senior management expressed the 
same concerns when it comes to hiring in the promotion department. "I don't think anyone who is in favor of 8th of March would do promotions backing 14th of March."

A male respondent, who works as a senior reporter, asserted that political affiliation is highly influential in Lebanese television stations. The respondent even gave approximate percentages of the journalists politically affiliated to the station they are working for- Al Manar (110\%), OTV (80 to 85\%), NBN (70\%) and MTV (60\%) whereas he believed that LBCI, Future TV and Al Jadeed were the least affected by political affiliation.

\subsubsection{Religious Affiliation as Inconsequential}

This question asks whether the journalists' religious affiliation affects the employment or progression of journalists knowing that the Lebanese television stations are not only political but also religious entities. As revealed in the literature review, Al Manar belongs to Hezbollah, a Shiite political party; NBN belongs to Al Amal, mainly a Shiite political party; Future TV belongs to Al Mustaqbal, a Sunni political party; OTV belongs to the Free Patriotic Movement, mainly a Christian political party; MTV is affiliated with March 14, mainly has Christian affiliation; LBCI is currently apoliticalbelonged to the Lebanese Forces, a Christian political party; Tele Lumiere affiliated to the Catholic Church; Al Jadeed, owned by Tahseen Khayat, mainly secular channel; Tele Liban, the state television.

The vast majority of the respondents ( 21 respondents) found the religious affiliation of the journalist to be inconsequential to employment decisions. One male and one female respondent from Future Television asserted that that station was one of the most diverse television stations in Lebanon; it had employees from all religious sects and 
even atheists. Al Jadeed respondents mentioned that the station was highly secular when it comes to employment and even programming; the channel did not even air Christian masses or Muslim prayers unless the religious ritual was related to, for instance, the death of a national figure or had a national dimension. One of the station's respondents asserted that all religious factions were well represented when it came to employment; in fact the station fixed the religious imbalance, if it ever occurred. Although identifying whether a journalist is a Christian or a Muslim may be generally known from someone's name, an OTV respondent affirmed that the station's newsroom was diverse and no one was asked about their religious belief or sect. The OTV male respondent also concurred commenting that religious affiliation was not as influential as political affiliation when it came to employment.

A number of respondents who found religion to be inconsequential noted, nonetheless, that the majority of those working at their stations belonged to a specific religious sect. At Al Manar, the Shiites formed the dominant sect in the station (F, Al Manar, Personal Com, 2014). NBN did not discriminate when it came to religion, provided people from other religions applied (F, NBN, Personal Com., 2014). The respondent mentioned that there were a few Sunni Muslims in the station but "the majority are Shia Muslims... perhaps people don't apply to NBN because they have this conviction that the station belongs to the Amal Political Party." An OTV female respondent mentioned that the station employed people from all religious beliefs but television stations in Lebanon were dominated by a specific religious sect, depending on their location since areas in Lebanon were religiously divided. The respondent asserted that around 2 to $3 \%$ of the station's newsroom was comprised of non-Christians. Tele 
Lumiere did not have religious discrimination, affirmed its respondents, but all of those working at the station were Christians since no Muslims have applied. The majority of the journalists at MTV were Christians, affirmed an MTV male respondent, but the station had "representation from other religious factions and their religious beliefs do not affect their employment, their position or progression in the job."

Certain respondents affirmed that some television stations became more or less religiously diverse over time. A Future TV female respondent commented that LBCI had become more diverse and was now home to employees from different religions. The LBCI female respondent referred to a change in administration that made the television station more diverse. Before that change, LBCI had been owned by the Lebanese Forces and only hired Christian employees. "We did a major hiring campaign four years ago," the Respondent said, "and we now have people from all religious sects." Almost half of the television station's employees are now non-Christians. Another female respondent from LBCI affirmed that the station is diverse but mentioned that it was still a Christian environment and journalists who applied to the station should be aware of that:

I will not hide that we in the Christian society sometimes get annoyed from someone who wears a hijab..... For a Sunni or Shia Muslim to think of coming to work at LBC they have to know deep inside that they are coming to an environment that differs from their own environment. This is a Christian environment and I know it is not nice to talk like this but that is reality

The NBN male respondent found that the station became less religiously diverse, although it had employees from all religions. "We currently have Sunnis, Shiites and Christians but in the past there were more in number," commented the respondent. While certain respondents affirmed that employment at their stations was not conditioned by religion, they expressed their uncertainty when it came to other stations. 
An LBCI respondent mentioned that Christian television stations employed nonChristians; "but Muslim dominated TVs do not; they do not accept anyone to enter it if they are not Muslim.” The respondent found Al Jadeed to be an exception. An MTV respondent concurred saying "I don't know if, as a Christian, if I apply to Al Nour Radio station (belongs to Hezbollah) for instance they would accept me or not. But I know for example, here at MTV we have Diana Fakhoury, Hussein Khrais; we have a group of Muslims at the station." According to the LBCI male respondent, LBCI was a diverse channel where religion was inconsequential but that was not the case for Al Manar or NBN which employed only Muslim Shiites belonging to Hezbollah or Al Amal political party respectively. Commenting on the other stations, the respondent continued that Future TV and Al Jadeed were the most religiously diverse whereas at MTV religious affiliation mattered to a certain extent.

\subsubsection{Religious Affiliation as Effective}

The respondents ( 6 in number) who believed that religious affiliation affects employment and progression opportunities gave reasons that mainly related to the politico-religious divide in the country, the nature of the politico-sectarian system or the nature of the television station itself.

For television stations like Al Manar, it is the religious tint of the television station that dictates the religious denomination of the employees working at the station. After all, Al Manar identifies itself as a Shiite resistance channel belonging to Hezbollah. The Al Manar male respondent, who occupies a senior management position, affirmed that religion affected employment in the television station. "Yes absolutely," he confirmed, "not because of religion but because of the political divide." The respondent 
continued admitting "We at Al Manar are less diverse than other stations." A female respondent, also from Al Manar affirmed "Everyone needs to be religious. Al Manar TV asks about the candidate applying." Al Manar occasionally employed people from other religious denominations and beliefs on part time basis to do certain tasks but these people were never admitted as full time employees.

When it comes to Tele Liban, the issue of religion takes a national dimension. The television station functions like a government office and has to follow the 6 by 6 repeated government law (referred to in Arabic as 6 w 6 mkarar) which dictates that for every 6 Christian employees there should be 6 Muslim employees and vice versa; this helps establish equilibrium in all government offices including the public university and state television or Tele Liban. There has to be religious equilibrium among staff members, affirmed the female respondent from Tele Liban. The male respondent asserted "we cannot deny that there are religious influences and you know that the political parties in general are religious parties." There is religious diversity at Tele Liban; there are Maronites, Sunnis, Shiites, Catholics and others and the purpose is to maintain religious equilibrium, he confirmed adding that Tele Liban was like any other government office; for high positions, the occupant has to of a certain religion. The respondent gave the example of the general manager of Tele Liban who has to be a Christian and the head of news who is, in general, a Muslim Sunni.

A female respondent from Tele Liban affirmed that she could not progress further because she did not have the right religion." I am more qualified than the head of news but for religious reasons he has a higher role. I should have been the head of news but the position is allocated to a Muslim Sunni," the respondent said with indignation. "At the 
end of the day Tele Liban reflects the image of the country," she said. The respondent lamented the fact that the even the politico-sectarian equilibrium being maintained at Tele Liban was now a chaotic endeavor just like the country's political situation and status; to the date of the writing of this thesis, Lebanon has been in presidential vacuum for almost a year due to disagreements among parliament members. Tele Liban reflects all this confirmed the respondent:

There used to be a quota at Tele Liban in the past.. it was split between the different religious groups. If they hired a Christian, they have to hire a Muslim. Now it has become extreme. You get calls from various politicians, and you stopped knowing how the quota is being distributed

A female NBN respondent found that Lebanese channels used to be more religiously diverse but the situation changed with the aggravated politico-religious situation in the country. According to the respondent, religious diversity caused awkwardness and was not desired:

Today religion plays a role. Today if you find a Shia member in Future TV you find his presence at the channel wrong. If you find someone a Sunni at NBN you also find it weird. It is now extremely difficult

Certain respondents believed that religion only played a role in progression to higher positions. A female respondent from Future Television mentioned that religious background as well as connections may play a role when it comes to higher positions. LBCI's female respondent concurred saying that editors-in-chief, in certain television stations may prefer to hire journalists who share their political and religious affiliation.

With regards to religious and political affiliation, Respondents' answers revealed that such affiliations did not seem to carry the same weight in all the Lebanese television stations. Some stations were religiously and politically of one color while others appeared to be more diverse. The image of certain televisions as representative of a specific 
religious group did not hinder their internal diversity. This intricate mix plays into and against the television's identity which is closely tied to religious and political identity in Lebanon. Lack of diversity, nonetheless, became an issue in higher positions as television stations preferred news workers of the same religious and political affiliation in top management.

\subsection{Masculine Norm}

This section provides answers to the fourth theme on the gender dynamic within the Lebanese television newsroom. As revealed in the theoretical framework and research methodology chapters, the gender dynamic is investigated through the concept of the masculine norm which is revealed through the areas of news coverage in terms of soft and hard news as well as the appreciation of professional women in the workplace.

\subsubsection{Soft and Hard News}

Male and female journalists are known to specialize in gender-specific areas of coverage. The literature review showed that women often cover the lighter news items that deal with human interest stories, education, culture, or the elderly while men often deal with the important areas of politics, war, economics, technology and science. To reveal if news coverage in the Lebanese television stations is divided along gender lines among the journalists, respondents of this study were asked about the type of news they cover and whether male and female reporters covered the same types of news.

Almost all respondents asserted that they covered most types of news depending on the assignment they were given. A female respondent attributed this to the nature of the news business in Lebanon. "We don't have a given reporter that is specialized in one genre of news than another. All the reporters work on all types of stories," she said. 
While respondents emphasized their ability to cover almost all types of news, some provided examples of the types of news covered including political news, security issues, bombings, explosions economics, conferences, meetings, social news and environmental news. Certain respondents mentioned focusing on certain news types such as politics, social, security or economic news more than others.

When the respondents were asked whether there are news types that are specific to women and others that are specific to men, they all answered that men and women alike covered most types of news. Assigning special types of news to men and others to women was a thing of the past noted four, two male and two female, respondents. The social and familial barriers that prevented women from covering political and war stories no longer exist, according to a senior management male Respondent. Women have managed to break the taboo of being only qualified to cover social or human angle stories, said another male respondent also in senior management.

Many respondents emphasized the equality in coverage when it comes to gender. At Al Jadeed, there was no difference between men and women when it comes to news coverage, a female Respondent said asserting "not for an instant do we think that a woman is suitable for certain types of stories and a man is suitable for other types of stories." A senior female respondent even went into the details. "No you cannot say that women cover social issues and men cover politics because it depends at the end of the day on what each person likes." Both genders covered all types of news including social, political and entertainment news concurred two other female respondents.

Respondents gave a number of non-gender related qualifications that determine the type of news coverage assigned to every reporter. A female respondent in top level 
management emphasized a reporter's courage, sense of inquiry, love for their job and endurance especially in times of war. Other female respondents spoke of potential, capability, experience and preference. "We have reporters who prefer to cover news at a politician's headquarter and we have reporters that prefer covering wars and troubled spots," indicated a female respondent in senior management.

To further emphasize the equality that female reporters have with their male counterparts, most respondents remarked that female reporters cover political news, security issues and wars. A female respondent, who worked a senior reporter, recalled how, despite the severity of the danger, she covered the Al Nusra Front (or Jabhat Al Nusra which is an Islamist group strongly allied with Al Qaeda) clashes in Tripoli and in Arsal where the Islamic State of Iraq and the Levant (ISIL) members also take base. Another female respondent recounted how female journalist Nada Andraos was sent to cover events in the war-ridden Syrian town of Qusayr after it fell in the hands of the Syrian army which was fighting the Syrian rebel forces. Both genders cover war and troubled spots, asserted a third respondent. "During the summer of 2006 war, women shined. I was one of them," a fourth female reporter said proudly. She continued to recount some of the many Lebanese female reporters that covered the July 2006 war between Lebanon and Israel. She gave the examples of Mona Saliba from MTV, Reema Maktabi from Al Arabiya, and Nancy Al Sabaa from Al Jadeed. A female respondent from Tele Liban also mentioned having covered the July 2006 war besides covering car explosion and political stories. Al Jadeed female respondent also pointed out, that female reporters were sent to cover the Nahr El Bared (Palestinian Refugee Camp) clashes between the Lebanese Army and Fateh Al Islam (or Conquest of Islam, a Sunni jihadist 
group strongly allied with Al Qaeda) in 2007. Tele Lumiere's respondent mentioned sending a female reporter to cover events in Iraq despite the grave security situation. The respondent added that female reporters were also often sent to interview Muslim sheikhs just like they interview Christian religious figures.

The preference to send men instead of women to hotspots or war-ridden areas was expressed by a few respondents. Most of these respondents attributed this preference to the fact that certain areas were occupied by religious extremists that had no respect for women and posed a real threat on their well-being. One of the female respondents, who had mentioned covering war, thought that there was a preference not to send women to areas controlled by religious or ethnic extremists. Another, in senior management, agreed citing the fear of harassment to women as the main reason that would lead a television's administration to her exclusion from such assignments:

If we know that today there is a big demonstration for the Islamists in Tripoli and it may get out of control and cause an issue. We as a management don't assign a woman to cover such a story because there is a risk not towards her as a person, because if something was to happen to her it can happen to her or to a male reporter equally, but we fear the female reporter might get harassed... there is no difference between men and women but the harassment issue is a bit sensitive for us

One male respondent observed that, in general, men were sent to cover dangerous stories, especially those having to do with Islamists. The respondent, nonetheless, remarked the both male and female reporters cover political stories.

The newsroom is populated by more females than it is by males affirmed a number of respondents. It was therefore only natural to send female reporters to cover explosions, bombings and war stories. A female respondent asserted "it is normal when the newsroom is mainly comprised of women that if an explosion happens or something 
big such as a crime, women reporters cover them like any man would as well." A Tele Liban female respondent recalled how when she joined the station in 2003, male reporters were few in number and women were sent out to cover all types of news including wars and explosions. There was no preference for sending male reporters to potentially dangerous spots to shield females from horrific scenes or in fear of their safety, the respondent asserted. While emphasizing how female reporters covered all types of stories, a female respondent noted, "we have a shortage of men at Tele Lumiere in the newsroom."

The preference to send female reporters to cover social issues or abuse stories was expressed by 2 females and one male respondent. "Women are more sympathetic to social issues," said a female respondent and their script may come out softer than that of men. Another concurred emphasizing that certain issues like abuse, for instance, may require more emotions and feelings. "Perhaps when it comes to human angle stories, we give women the upper hand," said Respondent. Only one male respondent felt that women can give more on the social front than men and men would be more versed in covering political stories. He, nonetheless, pointed out that "what is happening on the ground is they are being sent to the same types of stories."

Two respondents pointed out that very few women existed in the areas of sports and technology. But they were a majority in weather news. One of the male respondents noted that there were few women covering the sports news in television channels although female sports reporters were in demand. The respondent also noted that with regards to weather news, most of the weather correspondents were women who had no 
meteorological knowledge or expertise. The focus, in this case, was on their physical appearance and not their competence:

..there are a lot people that follow the weather segment but unfortunately the focus is on the beauty of the presenter...in Lebanon the segment is read off a teleprompter and weather presenters don't have the experience as a meteorologist. All the TV channels in Lebanon use the weather segment to feature a beautiful woman presenting the weather. But if you ask them what does a low pressure front with high clouds mean and what such front can do, they would not have an answer as these technicalities are beyond their comprehension

"In Lebanon in the areas of photographers, IT and technicians you don't find more than 5 percent females," noted a female respondent.

\subsubsection{Appreciation of Professional Women}

This question discusses women's role in management and their advancement opportunities. It investigates the full acceptance of women's role in the newsroom as an equal to her male counterpart. During the field interviews this question was not asked to all respondents, but to the vast majority of the respondents (22 in number) especially when, as a researcher, I felt that the answers had been already given.

Respondents who felt that women were less appreciated as professionals in the field gave a number of reasons including time allocated to the job and family obligations. It was felt that a man was more appreciated, said a female respondent, attributing that appreciation to the fact that men were available for more hours. When it came to married women "there is always that notion in the air that we are not giving enough time for the station," commented the respondent. Another female respondent also found that women's work in the newsroom was not as appreciated as it should be. She gave the example of a female colleague, Rindala Salameh, who overhauled the Tele Lumiere newsroom but her work, which elevated the quality of production at the newsroom, was somewhat 
unrecognized. A third respondent related the lack of appreciation to a patriarchal society's difficulty in accepting women in high positions especially in police and army jobs while citing the newsroom as a more equitable place.

Most Respondents believed that women's role as professionals in the media field was as appreciated as that of a man. "I think as professionals we are recognized and given our fair share of rewards like men. How society used to look at as women is behind us," a female respondent asserted. It was not just about the appreciation of the woman as a professional in the field, according to another, but it was also about "the recognition of her presence as an important element in the newscast and newsroom." Women should be even given more responsibilities and driven further into decision making position, the respondent added. Three other male and 2 other female respondents believed that women were equally appreciated as professionals in the newsroom. While one male respondent found that the field of news was highly demanding and certain issues like pregnancy may take its toll on a woman's career on the short term 2 other respondents (1M \& $1 \mathrm{~F})$ felt that women even received more appreciation than men.

To some respondents, the appreciation of women or men professionals was about character more than anything else. In both the newsroom and society, "it all comes down to you as a person and your personality," asserted a female respondent in senior management. She gave the example of a female reporter, Fouton Raad, who joined LBCI. Raad, the respondent said, came from a closed and reserved society in Tripoli but did not bring the dictates of that society with her to the newsroom as she was open and was treated equally as a professional. The respondent added that even when she was covering stories, conferences, meeting or events "I always feel 100 percent that I am taken 
seriously as other men around. It goes back to the personality and character of the person and how smart you are." When it came to reporting on politics, one female respondent felt that women may have the upper hand in Lebanon since male reporters were usually more confrontational than women and the reaction to women on the field was different than the reaction to a man especially since most Lebanese politicians were males.

When asked whether religion affects the progression of women as professionals, most respondents that were asked that question agreed that religion did not stand in the way of women progressing in their careers. "There is nothing religiously here at Al Manar TV that would stand in the face of the woman advancing," asserted a female respondent. Another female respondent from Al Manar even said that being religiously committed helped with advancement at Al Manar. Yet what helped her at Al Manar hindered her career in other stations which did not allow a woman wearing the hijab to anchor the news. Another aspect that the respondent spoke about was covering live events or happenings. Being religiously committed also meant having to avoid touching a person from the opposite sex, in her case a man:

For example a reporter was telling me when I go down to cover the news at a government session, she does not forcefully push in with the crowd to ask questions to the spokesperson of the government after the session. You know we cannot touch other men, so she passes the microphone to other colleagues and they push in on her behalf to get the story. At Al Manar TV we all know each other's limits and religious obligations. But outside, the people who do not know your religious boundaries, that will create a problem for you

Yet another female respondent mentioned how religiously conscientious organizations became inaccessible because the person was from a different religion. Respondents at Tele Lumiere mentioned that they watched the prayer times while at the station - whether 
it was in the morning or the afternoon but religion was not a factor that intruded or hindered their career progression.

This section revealed interesting findings with regards to women's career paths and outlook in the Lebanese television newsroom. Respondents' answers showed that women in the Lebanese television newsroom are on par with men when it comes to news coverage. Women cover wars, bombings, explosions, and political as well as social happenings. Their dominant presence in the newsroom contributed to women's access to the generally male-dominated areas of journalism. Women have managed to overcome the religious and cultural dictates of society to become appreciated as professionals in the news field. Their access to areas of hard news is more or less paralleled with an access to certain senior management positions within the television newsroom. Yet that does not cloud the fact that women may receive less appreciation when they prioritize family or have to take time off for pregnancy or child rearing. In this case, women are seen as less dedicated especially since they spend less time at work. Given women's contributions to the newsroom, they deserve to occupy more upper management roles that would reflect their actual ground contributions.

\subsection{Age Bracket and Appearance}

Inquiring about the age limit for people working in television provides insight into the length of the journalists' career. This section investigates whether the age limit differs between men and women and whether it differs for people in front of the camera and those who are behind it. 


\subsubsection{Newsroom Age Bracket Gender Sensitive}

When asked to what age people can work in the newsroom, certain respondents related the age to the field of work the journalist does in the newsroom. The age limit for employment differed among writers, news anchors and administrators. As an administrator herself, a female respondent, who is 47 years old believed she would not work beyond 55 since she would not be able to keep up with technology. "It depends on the role," said another female respondent. People in the editorial department could stay as long as they were able to write and think, even if they were in their 70s. Others concurred believing that on the camera looks impact the employment age but behind the camera people could work as long as they were productive and capable. A female respondent from Al Manar insightfully pointed out that Al Manar was a young station and the anchors who were hired since its beginnings were still valuable to the station. So there was no telling of the exact age limit although the respondent indirectly pointed out that in Lebanon there was a preference for young anchors.

It is all about appearance. It was not about the age but the aging, said a female respondent. "Obviously when a news anchor's face ages, she cannot continue to anchor the news," asserted the Respondent. News anchors should know when to retire on their own (F, Personal Com. 2014).

A male respondent in senior management emphasized the importance of viewer satisfaction with what was featured on the screen. "Sometimes you want to always renew and have new faces," the respondent asserted, indirectly succumbing to the preference of having young people on the camera. Another male, also in senior management, found that 
the maximum age for people working in the newsroom, mainly in news anchoring or graphics, should not exceed 50.

When asked if the age bracket for employment in the newsroom differed for men and women, 24 respondents were equally divided while the remaining three respondents gave indefinite answers. Very few respondents specified an age bracket for this question.

All respondents (12 respondents) who believed that the age bracket differed between men and women agreed that it was higher for men than it was for women. While certain respondents cited 50 as the maximum age for women, they believed that men's career in the newsroom could outlive women's career by 10 years. In effect, respondents believed that men could go longer in anchoring the news, but both could remain till the same age behind the camera. "In Lebanon it is not wrong to put an older man on the air but not right to put an older woman," commented a female respondent. She gave the example of LBCI's Dolly Ghanem who was removed from news anchoring and was now the presenter of the morning show Nharkoum Saeed. "We show wrinkles," another respondent commented but also remarked that cosmetic surgery was helping women stay longer on the air. One male and one female respondent expressed their disapproval with the attitude being adopted by the Lebanese televisions with regards to age.

Respondents (13 respondents) who believed that the age limit in the Lebanese newsroom was the same for men and women had differing answers. 3 male and 2 female respondents gave a straightforward "no, it does not differ," answer. While certain respondents believed that age limit for both, was between the $50 \mathrm{~s}$ and the $60 \mathrm{~s}$, others cited the preference for younger faces as a trend affecting both female and male journalists alike. Older news anchors were not accepted by viewers but that did not 
necessarily apply to presenters, said a male respondent in senior management. The male respondent from MTV dubbed the station as a television for the young commenting on the fact that the majority of newsroom workers were between the ages of 30 and 40. To 2 other male respondents it was not just about age. The physical and mental health of a journalist as well as their credibility and competence determined their longevity in the newsroom. The remaining two respondents did not give a straightforward answer but spoke of the general trend for younger faces on Lebanese televisions.

Interestingly both male and female respondents equally accept the importance of looks for reporters as part of the television business, or the doxa. It is not questioned as a discriminatory practice although the focus on appearance is deemed as unfair. It is likely that the respondents are aware of the commercial nature of the television channels and the need to present what they believe would attract a bigger audience. The fact that young faces has become a trend on Lebanese television does not leave room for questioning or for experimenting with older and more experienced faces.

\subsubsection{Age Limit for Female Anchors}

This question is a follow up question since most respondents found that age mattered more for people working in front of the camera than it did for those working behind it. The purpose behind asking about the age of female anchors is to identify whether the age was gender sensitive and identify the degree to which age mattered when it came to anchoring on Lebanese television, especially since respondents did not clarify whether age was gender sensitive and evaded giving an approximate age for female or male anchors. Answers to this question would document the current trend in the Lebanese 
televisions channels and identify, through future studies, changes that take place on the Lebanese television screens.

Nine respondents ( 3 males, 6 females) found that the age limit for female news anchors was within the 40s. Six of these respondents projected that 45 was the maximum age limit. A female respondent asserted that once women get to their 40s, television stations start searching for their replacements. "Here you have to ask these television stations if they consider themselves better than CNN of French TV5," commented a male respondent. A female respondent from Future TV remarked that no news anchors at the station were yet in their 50 s or 60 s since Future Television was a young television channel. This, in effect, applies to almost all Lebanese television stations. The stations are not old enough to document a real trend in preference for younger faces, but the isolated incidents such as removing Dolly Ghanem, George Ghanem and Denise Fakhry from the main newscast on LBCI as well as the supply of young, and often times, inexperienced news anchors on Lebanese televisions strongly point towards such a trend.

Twelve respondents ( 5 males, 7 females) held that women could anchor the news up to their 50s. Plastic surgery plays an important role in keeping those women on the air. "Today, with the advancement of plastic surgery which allows them to pull their faces or do Botox, women are now hitting 50 and still anchor the news," remarked a male respondent. After discussing the trend of bringing younger faces to the television screens and the overhaul that LBCI did to its news team, a male respondent in senior management confirmed that if other television stations had the chance to replace the older anchors, they would not hesitate:

Furthermore, if you look at other stations, we are seeing faces that been there for a while and in my opinion if the management of these stations had the chance to 
replace and bring fresh young people who they would make as the faces of these channels they would definitely do so

A male respondent who mentioned that Lebanese female news anchors can go up to 45

years of age, explained the cause of the trend:

Television is an image. As long as the woman news anchor is able to present herself in an image that is accepted to viewers then there is no problem to what age she gets. But if she reaches a point where viewers don't seem to accept her look to anchor on the screen then it is better that she works behind the scenes. Sometimes there are anchors than can stay till they are 50 years old or 60 years old as long as they are able to maintain their looks and appearance

The respondent then gave the example of Souad Karout Al Ashi, a famous Lebanese journalist, who now presents a program on Al Mayadeen, a pan Arab satellite channel. Interestingly Respondent 19 also gave the example of Souad Karout Al Ashi without referring to Lebanese television or female news anchors on Lebanese television although Souad Karout Al Ashi had started her career on Tele Liban:

A woman can be a news anchor or presenter until she is in her 50s and 60s. I can give you an example about a TV program that has been presented by $\mathrm{Al}$ Mayadeen called Ra'isiyat. Arafat Hejazi and Souad Arout Al Ashi present it and they are both over 60

The other respondents (3) did not specify an age limit but confidently asserted that it was all about looking young- a special requirement by Lebanese television stations. Female anchors could stay as long as their appearance permitted, until they felt it was time to step down, even if they were only 35 years old at that time. A female respondent commented:

The problem is that Lebanon's television station to selecting news anchors who is beautiful and their least interest is what is the anchors' credibility or how much they make errors on the air. The important thing for them is to attract viewers

One of the Al Jadeed female respondents asserted that the television tried to reconcile looks with competence and emphasized that as a television station, Al Jadeed had not been swept by the current Lebanese trend. 


\subsubsection{Age Limit for Male Anchors}

Inquiring about the age limit for male anchors showcases to what extent news anchoring age requirements differ between males and females. In case the difference exists, uncovering the reasons behind this difference becomes pertinent.

Only one female respondent identified the 40 s as the age limit for the male news anchor. She clarified that Future TV was a fairly new television which started its operations in 1993 and as such had no news anchors that were in their 50s or 60s.

Thirteen respondents ( 6 females, 7 males) believed that the age limit for male news anchors was in the 50s. One of the male respondents, nonetheless, noted that there was no male news anchor that was currently in his 60s in Lebanon since in Lebanon they care a lot about the appearance of both males and females.

Six respondents (4 females, 2 males) asserted that male news anchors could be in their 60s. "A man in his 50s and 60s can still be a news anchor and presenter," said one of the male respondents.

The two female respondents who did not specify an age for female news anchors also did not specify one for male news anchors mentioning that males could remain on the air as long as they considered their looks appropriate. One of the respondents deemed that the news anchor was the best authority on determining the age at which they should leave their jobs - it was the time when they look at themselves in the mirror and say "it is enough." And this "enough" could arrive at any age.

"I think a man can last longer on the air," affirmed a female respondent who mentioned that beauty was not as important for a man in the media as much as it was for a woman. This was characteristic of Eastern traditions. The Respondent retraced the 
current trend in preference for younger faces on Lebanese television to MTV which, according to the Respondent, introduced this trend 5 to 6 years ago. The respondent expressed admiration for MTV because it had managed to combine quality with good looks besides having a state of the art news facility. The respondent, nonetheless, disagrees with this trend:

within MTV at all levels that image is a priority. They introduced this trend. It is working because the eye loves looks and beauty but I don't agree with it. I am talking from the perspective of what viewers like. But I don't agree with the looks preceding the content. We should have both but the most important is not to just get on the air looking beautiful and lacking substance

The question on age has clearly shown that both female and male respondents believe men could age more on the screen than women. Plastic surgery procedures or enhancements seem to be more required of women than they are of women. Yet despite these procedures, men continue to be on the screen for an average of ten years more than women. This double standard in aging is well recognized by both respondents. While some male and female respondents see it as part of the television business, others expressed their indignation at the overemphasis of appearance, especially that of women.

\subsubsection{Dissatisfaction with Age Limit}

Few respondents expressed dissatisfaction with the age limits being imposed by Lebanese television and Lebanese market requirements. Age brought with it seriousness, trust and credibility - three crucial factors that could only result from experience in the field (Personal Com, 2014). Experience also resulted in viewer trust and in the professional ability to write a story (F, Personal Com., 2014). Comparing young anchors to older ones, a female respondent concluded that older anchors, like George Ghanem, from LBCI were more credible and exceled at their work. She lamented Lebanese 
television's preference for young female presenters who had no experience. Other respondents referenced Western television anchors to show that age should not be as restrictive as it is on Lebanese channels. Examples were given of television stations such as TF1 (F, Personal Com., 2014) or journalists such as Helen Thomas (M, Personal Com., 2014) and Barbara Walters who was in her eighties when she interviewed Syrian

President Bashar Al Assad in 2011 (M, Personal Com., 2014) and Christine Ockrent from France (F, Personal Com., 2014):

If you look abroad, the age is not 30 s and 40 s sometimes, it is more in the 50 s and $60 \mathrm{~s} . .$. The important thing at work is that your brain does not become old or age. In the Arab World, the problem is they love beauty and looks...If you watch them abroad, the more they age the more costly it become to acquire them. The issue in the Arab World is the mentality plus the problem with the people themselves. New TV is one of the few TVs that did not run after the new trend of hiring beautiful news anchors (F, Personal Com., 2014)

Well aware that there were Lebanese anchors and program presenters who had crossed the 40 year old mark, a female respondent nonetheless, was fearful of the current market trend for younger faces. The respondent did not see the same trend in Arab satellite channels or in Europe and the US:

When I look at Arabic satellite channels and when I see in Aljazeera a presenter who is 75 years old perhaps I get very impressed. There are women in their 40s at Aljazeera. In French channels or CNN for example, you find them older and it is normal whether men or women. Take for example Christiane Amanpoor. It is normal but here in Lebanon I don't think so and this applies specifically to news anchors

A female Tele Liban respondent in senior management also expressed dissatisfaction with the current trend in Lebanese television. She noticed that reporters, unlike news anchors, were not removed from their jobs even if they were older than what was required in the market. The respondent noticed news anchors and presenters were required to be young. She gave the example of Tele Liban news anchors who were taken 
off the air because of their age; "they now prefer younger age," the respondent commented, unlike French and US channels where they believe that credibility comes with age. "We have to see a beauty queen or a top model to bring her in as a news anchor... Stations in Lebanon are selecting news anchors that have nice bodies, wear nice clothes and had plastic surgery to look perfect to work as news anchors," asserted another female respondent.

\subsubsection{Appearance: A Gender Sensitive Issue}

This question deals with news anchors' appearance on the Lebanese television screens. The purpose is to find out to what extent appearance counts and whether it matters for both men and women. While the literature review revealed that Lebanese channels flaunt skin daringly to attract viewers, findings of this question would either agree with or diverge from the literature.

When asked whether appearance mattered for both males and females, 17 respondents answered it did. 6 male and 11 female respondents asserted that male and female news anchors should watch out for the way they looked on the screen.

“Appearance matters to TV stations because they convey their image to viewers through the good looking news anchors working at these stations," remarked a male respondent. These anchors were given a total make-over and were trained to look and sound their best. The remaining 8 ( 1 male, 7 females) respondents believed that appearance mattered more for women than it did for men. Nonetheless, respondents in both groups had more to say about women's dress code and appearance than they had about men. The reason behind that being that male news anchors dressed in a suit and a tie whereas female news 
anchors did not abide by a specific dress code. Women are then under more pressure in choosing what to wear than men are.

A considerable number of respondents mentioned that news anchors had to look acceptable for the newsroom. Respondents who used the word acceptable or appropriate associated different meanings to it. Three main meanings were detected: acceptable dress code, acceptable looks, both acceptable dress code and looks and the religious dress code. Acceptable dress code should match the nature of news reporting, asserted a female respondent. A reporter covering the parliament would not wear the same outfit as a field reporter from a war zone. Similarly, news anchors (10 females and 2 males) should abide by a respectable dress code. Both female and male reporters and anchors had to be tidy as they represent the channel they were working for. News anchors should wear a jacket along with a formal shirt that was not revealing; the colors should be soft and classical, said a female respondent. To others it was about acceptable physical looks in that a news anchor should have an acceptable face that could be taken in by the camera and easily received by viewers. The female news anchor did not have to be a beauty queen, asserted a male respondent, but "her presence on the screen should be acceptable."

To Al Manar respondents, acceptable appearance entails committing to the religious dress code of the television station. The Al Manar male respondent mentioned that both male and female respondents should be presentable, follow the religious dress code, and wear classical colors. Appearance was not important agreed Al Manar female respondents. They both made it a point to mention that Al Manar news anchors did not put full make up but only foundation so the face does not shine on the camera. The news anchors try to look as natural as possible. "Anything that highlights beauty or makes you 
more beautiful is something in religious terms not allowed," noted the Al Manar female respondent. Women are not allowed to wear flashy colors or colors that bring out their beauty. So they refrain from wearing purple or pink and stick with the very classical colors of grey, brown, and olive colored clothes. Women have to wear the hijab or the head cover. For men, it was less restrictive and men were seen wearing soft colors like pink added the respondent.

Almost all respondents agreed that the newsroom should have specific dress code. Most also agreed that the dress code for news anchors is the standard formal business suit for a man and a shirt with a jacket for a woman. The colors should be classical and not flashy and the news anchor should have minimal make up on. Unfortunately, this dress code was not being implemented in most Lebanese television newsrooms, especially when it came to women. An advocate of a well-defined work ethic, a female respondent in senior management, was against the wearing of revealing clothing for women as she was against the wearing of shorts for men in the newsroom. She asserted that reporters should be sensitive to the context around them and not oblivious to it. To give an example, she recounted how odd and insensitive female reporters looked when they wore make up while covering the 2006 war in Lebanon. An Al Jadeed female respondent emphasized that the television, known for the seriousness and vigor of its newscast, was not interested in following the market trend; Al Jadeed still relied on the familiar faces and credibility of its news team. Two male respondents concurred that no proper dress code was being implemented, concurring with a third male respondent who mentioned:

Now if you ask me is a dress code being applied in other newsrooms in Lebanon's television stations I would say of course not in all. There are news anchorwomen that get on the air as fashion models. It is good to break away from tradition and to be original. But here there is a fine line if you like from being original and 
break away from traditions and from crossing the boundaries... Sometimes I feel they cross the limits. Not always but sometimes yes. (M, Personal Com., 2014)

A considerable number of respondents from both genders (10 females and 4 males) expressed their dissatisfaction with the dress code of female news anchors on Lebanese television stations. It is worth noticing that the respondents communicated their dissatisfaction without being asked about their opinion. Perhaps one female respondent's outlook clarifies the situation as she said, "we are headed... in Lebanon, if you notice, to a newscast fashion show more than it is content driven." Other female respondents pointed out how the camera takes in the full body of a female news anchor at the beginning of the newscast and throughout the weather forecast. "In the weather forecast we are taking the full body shot angle through the camera and we are not just taking the face or the bust for example," said a male respondent. This is what viewers in Lebanon and the Arab countries, mainly the Gulf, look for.

Lebanese female news anchors went on the air wearing short tight dresses, showing cleavage and wearing sleeveless shirts, said a female respondent. The women were often dressed in attractive clothing with their hair buffed up instead of it being neatly tied or tucked behind their ears. The respondent also commented on the weather forecast that is delivered by "a top model" as if it is a fashion show. Female news anchors should be more decent, said another female respondent, who asserted that "they are not going on the air to feature their dresses or their bodies or even their hair...All this excessive make up and inappropriate clothing should not happen."

Female news anchor Dima Sadek on LBCI, for instance, was being called "a fashionista," said the female respondent who emphasized the importance of allowing 
female news anchor to express themselves and show who they were without pushing the limits. The respondent agreed and disagreed with the trend:

Our Lebanese televisions aim to seduce to an extent. Take a look at the weather segment where all television stations film the weather presenter in full body shot. This becomes fashion more than news worthy

A male respondent in senior management remarked that proper news attire was not being followed in Lebanon. He observed that the focus on the physical appearance of the news anchor was a trend that was started a few years back by MTV and was picked up by other Lebanese televisions like Future TV and LBCI. The respondent gave an example to show how the basis of hiring female news anchor had become skewed as televisions looked for young, beautiful and attractive females. Another male respondent agreed and expressed his indignation at both the hiring and attire of the news anchors:

..stations are using looks as the basis of hiring news anchors...But the viewer wants to hear the news and not just watch the news... The attraction is important but attraction to what? To the news or modeling? To the news or the hair cut? or the makeup?

A third male respondent also commented on the hiring process. He mentioned when television stations did not find an attractive female with a media background; they hired beauty queens, singers, or models. This, the respondent added, compromised the credibility of the station. The focus on appearances had been exaggerated to the extent that it had become a competition over who could have the sexiest news anchor, according to a female respondent. The television stations are commercial and use these anchors to attract viewers, especially Gulf viewers.

A few respondents ( 4 females \& 2 males) attributed this trend to "the way our society is," the male-centric society" or patriarchy. In the East, women have been traditionally and historically tied to magic, charm and beauty more than males, said a 
male respondent. It is an attribute for patriarchal society to look for attractive women. A female respondent emphasized the importance of physical beauty and being attractive as we "live in a male-centric society." The respondent asserted that women have always been used as a tool to attract viewership to Lebanese television.

Interestingly one male and one female respondent found that this trend imposes harsher requirements on male news anchors. Viewers would not watch a male news anchor who was not good at what he did, said the female respondent asserting that viewers would continue watching a female news anchor because of her physical beauty even if she were not smart or intelligent. "What is expected from a male news anchor is more difficult than what is required of the female news anchor," said the male respondent.

Only one female respondent remarked that just like female news anchors, male news anchors were being watched too:

Today, also the man is required to be handsome and therefore even male reporters or anchors take care a lot when it comes to their appearance and image. We think they don't but they actually do. They want to look good on the air and comfortable, their haircut is nice, the cravat is tied well and properly so yes they do want to also be nice looking. The woman viewer likes to watch the man and the man viewer likes to see the woman. For the woman, she has to be of younger age and she has to be within the levels of set beauty that she abides by.

In sum, respondents' answers revealed that the Lebanese television prefers young, vibrant and good looking people, both male and female. Though age and beauty are more restrictive when it comes to females but they are a requirement for both males and females. More focus is placed on the female appearance as most Lebanese televisions have abandoned the traditional dress code to opt for a more daring look for its female anchors. The excessive emphasis on women's physical attributes and dress code puts 
more pressure on women to live up to the ideal image that the society projects. Though men's physical appearance is also scrutinized, the fact that they have a specific dress code and are not required to be overly attractive as women are, puts less pressure on them.

In detailing findings from the interviews, the chapter has shown the value of cultural and social capital as well as the importance of age and appearance. More importantly, findings revealed that the many strides that women journalists have accomplished in accessing the bastion of hard news have not eliminated the prominence placed on their appearance and the fact that they cannot age on the screen as much as men can. The fear of aging and the uncertainty that age brings are more of a concern for female respondents than they are for males. This focus on appearance is a double edged sword for women- for beautiful women, it is form of capital that provides access to the profession but it also places much value on appearance which may dwindle with age rather than on competence, which supposedly multiplies with the passage of time. Women have proven themselves competent but the competence should by necessity be accompanied by physical beauty - an unfortunate finding that makes a woman's competence subsidiary to her appearance. 


\section{Chapter: Findings from In-Depth Interviews: Management,}

\section{Obstacles and Advancement}

A continuation of chapter 6 , this chapter reveals the findings of the in-depth interviews with the 27 journalists in relation to the themes of gender, glass ceiling and progression. The themes found across a number of interview questions will be discussed through (i) glass ceiling and gender, (ii) recognition and gender, (iii) obstacles and advancement strategies and (iv) the newsroom environment.

\subsection{Glass Ceiling and Gender}

This section explores the positions that women occupy in the newsroom questioning whether management opportunities are equally available for men and women journalists. As revealed in the literature review, women seem to face a glass ceiling that stops them from advancing into upper management positions due to invisible and artificial barriers (Boyd, 2012). The information in this section is based on the answers of the respondents who shared their insights on the current state of television and the current positions occupied by male and female newsroom workers. As required by the ethics clearance, approaching the human resource departments of the television stations would risk confidentiality. Nonetheless, respondents' answers qualify as a reliable source especially considering that most television stations do not have organizational charts and would not divulge, as mentioned in the literature review, ownership structures or statistics on pay- if they did exist.

\subsubsection{Positions in the Newsroom}

All respondents, without exception, believe that women can occupy the same positions as men in the Lebanese television newsroom. Women are writers, video editors, 
editors, producers, anchors, and reporters (F, Personal Com., 2014). At Al Jadeed, the vice chairperson is a woman and this is a rarity in Lebanese television (F, Personal Com., 2014). At Future Television, women occupy senior management positions including the head of the programming, the head of the IT department and the head of the marketing departments (M, Personal Com., 2014). Women journalists also proved themselves in the field as war correspondents and reporters, asserted a male respondent. He gave the example of Yumna Fawaz who covered events in Turkey, got kidnapped during the Syrian war and covered Arsal clashes in Lebanon. The respondent continued "at New TV the female element is prominent and in large numbers. For example the Head of News and vice chairperson, Mariam Al Bassam, is also a female." At Tele Liban two females and one male occupy the position of editor-in-chief (M, Personal Com., 2014).

Getting to a position or advancing to higher positions is not a matter of gender. It has to do with skills and connections:

At the end of the day to reach a high position, either a male or female, there are the three things that I mentioned earlier that play a role; skills, luck and sometimes connections. All three things play a big role in Lebanon. (M, Personal Com., 2014)

Two female respondents noted that women are given equal opportunities to progress but may willingly choose not to. Half of the chief editors at Al Manar are also women, asserted one of the respondents. Yet women directors were less in numbers than men since "women have not pushed into that type of role" although the opportunity was available to them.

While most respondents agreed that women occupy almost all positions in the newsroom, few respondents remarked that there were barely any women camera operators. All camera operators at LBCI were males, asserted a female respondent, 
attributing the reason to their presence with the channels for the past 16 years. The same respondent also commented that there was a female majority in the graphics department. A female Al Jadeed respondent presented the same finding to emphasize the lack of women camera operators but their presence in equal numbers in the graphics department.

Not only did women occupy most newsroom positions, but they also formed the majority of newsroom employees. Female respondents from Al Jadeed, Tele Liban, LBCI, NBN and OTV remarked that women outnumbered men in the newsroom and they were occupying the higher positions. At Al Jadeed, the head of news and her assistant alongside many producers and directors were women. OTV had three female and three male bulletin editors and the editor-in-chief was a female.

\subsubsection{Management Opportunities for Women}

This question follows up on the previous one to affirm if management opportunities are available for women at the Lebanese television stations. Inquiring about the availability of management opportunities is inquiring about the chances that women have for advancing into management, thereby revealing the nature of the organizational environment and the opportunities it can offer women.

Most respondents (23 in number) found that management opportunities were equal for both men and women. Very few answers were qualified with further explanation. A female respondent in a senior management position, for instance, insisted that in the field of media, women were not only empowered but they were also more powerful than men. A male respondent concurred:

at New TV the female element is prominent and in large numbers. For example the Head of News is a female - Mariam Al Bassam and vice chairman of the board is also a female - Karma Khayat 
The television's organizational environment was equitable, a female respondent remarked, attributing discrimination to the Lebanese laws and patriarchal society:

Yes they (management opportunities) are equal to both genders.... The laws of the country are unjust to me as a woman and not my work in this organization. My problem is with the law and patriarchal society

Patriarchy was also cited as a hindrance to women's formation of political relations - an essential stepping stone into newsroom management, according to a female respondent in a senior management position. A man, the respondent emphasized, could easily form such relations but they were more difficult and less culturally acceptable for a woman. A woman would be questioned with regards to social gatherings and dinners with politicians but a man would not:

They look at a woman from a wrong angle when it comes to this, for example from the angle that you are having dinner every night with someone. But for the male, he does not have that problem. It is how society looks at you in this case. At the end of the day you force your respect on people. But the woman has to work double and if not double then one and half times more to prove herself

Most of the male respondents gave examples of females that occupied management positions in their television stations as if proving, through real examples, that there was no discrimination between male and female journalists. Examples included the news operations manager at LBCI, head of programming at Tele Lumiere, editors-in-chief at NBN, and upper management roles at FTV.

Four of the respondents ( 3 females and 1 male) disagreed with the majority insisting that management opportunities were not equal for both genders. Two of these respondents cited patriarchy and a preference for males to assume management roles more than females. The respondents attributed this preference to the patriarchal society, emphasizing that males were the ultimate decision makers in the Lebanese television 
channels. Women did not have the same opportunities as men, according to one male respondent:

It (opportunity to reach management positions) is a possibility but it does not exist now. It did not exist in the past either to my knowledge. But a woman becoming for example editor-in-chief would be no problem at the station

\subsubsection{Women's Presence in Management}

Whereas the previous question inquires whether the same management opportunities are present for both, men and women, this question asks if these opportunities have materialized into actual management positions at the television stations. In this case, respondents that found women to be well-represented in management (19 respondents) were less than those who found that management opportunities were available to them (23 respondents).

Most of these respondents gave examples of women in management positions at their television station or other television station. The examples, which the respondents provided by name, include LBCI's head of news operations, head of web presence and head of programming as well as OTV's editor-in-chief, head of producers, head of operations and human resource manager. A female respondent maintained that women were more powerful in the media field than men were. She even insisted that saying that women were less empowered or less privileged was mere talk:

At Al Jadeed you have Mariam al Bassam who is head of news. Who would tell her anything when she takes the decisions? It is more of a theory they promote but I can assure you that in the media field the woman is stronger than the male. I can give you another example. The National News Agency, for example, the manager is a woman and she has been in the post for a while. She is strong and she has proved herself. Her name is Nour Suleiman 
“Only at our television station," and nowhere else in Lebanon were women wellrepresented in management, said a female respondent confidently. Revealing that there were no women on the Tele Liban Board of Directors, a male respondent, nonetheless, insisted that women reach senior management positions. He gave the example of the previous lawyer for the television station as well as the current head of the union who was also the assistant head of news, both of whom were women. The respondent pointed out that Tele Liban had been highly supportive of women ever since it started its operations in the late 1950s.

Acknowledging women's presence in upper management positions, certain respondents mentioned that higher positions were occupied by men. These respondents, nonetheless, emphasized that women take most of the crucial decisions, especially when it comes to the day-to-day operations. Women managers were assigned to all the Tele Lumiere affiliated stations, including Noursat, Nour Al Sharq and Nour Al Shabab, said a female respondent from the station. Although the $\mathrm{CEO}$ of the station was a man, women took most on-the-ground decisions either independently or in consultation with the CEO. The male respondent from Al Jadeed affirmed that the head of news and the vice chairperson were both women who consult with the male owner of the station only when it came to crucial decisions. The respondent emphasized that these consultations had nothing to do with gender, for even a male head of news or a male chairperson would have to consult with the station's owner.

While two female respondents tied women's advancement to having a supportive management, another linked it to women's status in politics. Classifying television stations as highly politicized organizations, the respondent compared women's presence 
in Lebanese politics to their presence in the management of Lebanese televisions. After all, the television channels are owned by political parties whose representatives are in the government:

I will give you an idea... the high posts at the station where decision making takes place and the political line of the station is formulated...have to be related to the political party the station represents or follows. On the political front, now they began a more open approach but they are represented more by men than by women although women are being given many positions but you still feel the dominance is more male because they are more politically aligned and involved

The respondent acknowledged that there were more women in politics but their presence was still minimal. The respondent prioritized the political affiliation of the journalist over their gender in making them eligible for upper management positions Lebanese televisions.

Another interestingly different opinion is related to trustworthiness. Women were more trustworthy than men, said a female respondent. Men were more ready to employ "twisted ways" to reach their objectives, she insisted. That was why, the respondent reasoned, women were becoming more present or preferred in upper management positions.

Not all respondents agreed that women were well represented in the upper management of Lebanese television stations. Those who did not agree (8 respondents) presented reasons ranging from patriarchy to qualification. One female respondent observed that the culture was not very accepting of women taking on managerial positions but remarked that the situation was changing because women were becoming more qualified. Perhaps the most vocal answer about women's lack of representation in management emphasized that despite women's presence in large numbers in all the Lebanese television stations, the decision making was often left to the man. The 
extensive quotation below in which the female respondent provides an overview of the managerial situation at a number of television stations reveals her point clearly:

No they are not well represented. We need more women in management levels. In other television stations at their newsrooms, we are seeing women as a majority and we are seeing women who are editors-in-chiefs and heads of news but the decision is not theirs at any of these stations. Women are available in larger numbers as an executing tool and as people responsible with limited boundaries. And when you come to the decision making, it is always that a male has to take the decision. This applies to all television stations including MTV

While the above quotation recognizes that women have reached senior management positions, it also asserts that they are still a minority in top management. The eventual decision taking is left in the hands of men while women handle the everyday decisions in television stations.

Other respondents expressed similar opinions and attributed women's underrepresentation in management to patriarchy or culture. At Tele Liban the female editorin-chief took most of the day-to-day decisions but had to revert back to the male head of news when it came to bigger issues or policy (F, Personal Com., 2014). There was never a female general manager for any of the Lebanese television channels, asserted one of the female respondents. When it came to hiring women for upper management positions: there is still that skew towards the patriarchal thinking... The preference is for males to assume such a role more than women although there are no specific qualities in the person to become a head of news whether male or female

Another female respondent, who had managed to impose herself as a high ranking official in television, remarked, nonetheless that advancement in a patriarchal society was difficult for women, especially since men had a hard time accepting women in a position of authority. "They are underrepresented of course," affirmed a male respondent in senior management. He took the responsibility for women's minimal presence in top 
management away from the organization's hands and attributed it to the Lebanese culture. "It is the culture," he commented, "and it goes beyond a decision of not having women assume higher level positions."

To other respondents, women's presence in management was a matter of organizational structure or organizational inheritance. "We don't have a professional administrative skeleton or chart," observed a female respondent from FTV. She attributed the lack of structure to the fact that Future Television was a family owned business. The respondent emphasized that women's lack of presence in upper management was not a conspiracy against them but rather a matter of fact situation in a family owned organization. Another female respondent noted that the males in top management had occupied these positions since the launch of the television station itself. These men were from the older generation and did not believe in women's advancement. The respondent, nonetheless, noted that the situation was changing and more women were present in the management of the Lebanese television stations.

Findings in this section paint a somewhat rosy and hopeful picture for women in the Lebanese television newsroom. Answers by respondents revealed that the Lebanese newsroom is mostly female dominated and women seem to run the day-to-day operations. The presence of the male has become a rarity in certain aspects of the field; an observation that changes the whole newsroom environment. Interestingly women's presence is also becoming more prominent in senior level management positions proving a penetration of the glass ceiling and inviting a new look at women's professional career paths in Lebanese television news. Yet top level management is still barely accessible to women and it is often men who occupy such positions. Culture, patriarchy and the 
minimal presence of women in politics play against women's advancement. Add to that, the fact that three Lebanese television stations, namely Al Jadeed, MTV, and Future TV are family owned business and may act as a catalyst or hindrance to women's advancement. Qualified women in the family business may inherit their high level media positions. On the other hand, family owned businesses impose restrictions on both men and women who do not belong to the family. The "systemic biases" at play against women's advancement are tied to societal dictates in the form of patriarchy, family responsibilities and appearance, organizational structures that are either chaotic or family owned and political structures that do not trust women in leadership in both politics and perhaps the media. Women have made courageous strides in the newsroom but whether these strides will take them to the very top remains to be seen.

\subsection{Recognition and Gender}

Closely tied with the concept of the glass ceiling and advancement into management positions is the gender pay gap. The literature review revealed that women, who occupy the same position as men get paid less than their male counterparts. Investigating whether women receive equal moral and financial recognition in the Lebanese television newsroom shows if women suffer from pay discrimination and are paid at a scale different from that of men.

\subsubsection{Moral and Financial Recognition}

Respondents were asked whether the bonuses and promotions they received paralleled their skills and years of experience in the profession. They were not asked about their exact salaries as that would be deemed as highly intrusive and inappropriate. Almost all respondents affirmed that the financial recognition they received was 
insufficient and did not parallel their experience. Some attributed this lack of recognition to the media sector in the country as whole:

In Lebanon especially in local channels, it is known that the salaries are too low compared to what we do and the amount of work we perform.

(F, Personal Com., 2014)

Many cited the lack of financial recognition as a major issue plaguing the field of media.

In mentioning the lack of recognition, certain respondents compared Lebanon's

media to those of the Gulf region where they believed media personnel were better

financially rewarded. Local channels are not as well financed as the Arab channels, asserted a male respondent.

Respondents in Al Manar, OTV, NBN, Tele Lumiere and Tele Liban felt that their salaries were less compared to other local television stations. "If you take the private sector or television stations I think they are better compensated" said the male respondent from Tele Liban. The female respondent expressed the situation in more explicit terms:

I consider myself and not just myself but all the employees who work at Tele Liban as being underprivileged. In the beginning I wasn't saying it but now I say it because we are frustrated. The work we do is harder than any work carried out at other television stations

Al Manar female respondents also expressed dissatisfaction; "In the media in general, salaries are a bit better than Al Manar TV." OTV's female respondent mentioned that the station had a limited budget that did not enable it to reward its employees like the other bigger local stations. An NBN respondent also asserted that salaries were lower than other television stations in Lebanon.

Interestingly certain Al Manar and Tele Lumiere respondents referenced their station's mission as a priority as if elevating it to a level of higher importance than being 
financially rewarded. Al Manar was the voice of the Lebanese resistance, said the female respondent; it could not be compared to other television channels that focused on entertainment. Despite agreeing that the financial rewards were lacking, a female respondent from Tele Lumiere thought of the station the ideal platform for the delivery of a spiritual message that brings much gratification to those who work in the station.

Certain respondents (3Females \& 1Male) highlighted the moral recognition that they received from management. Gratitude came in the form of an expression for a job well done and the assigning of the reporter on similar topics in recognition of their skill.

Yet this gratitude was not enough to some respondents who resorted to finding other sources of income to supplement their salaries. A female respondent mentioned doing production work. Besides his job as an anchor, a male respondent teaches at the university and acts as a master of ceremony for certain events and conferences. Another supplements his salary through teaching. Both respondents asserted that they cannot maintain a family on the salary they get from their work in the media.

Only two male respondents mentioned that there was suitable financial recognition. Interestingly, both these respondents were males in upper management positions - something which may help explain their satisfaction with the pay compared to their colleagues.

\subsubsection{Gender and Financial Recognition}

The previous section questioned whether media workers and more specifically newsroom journalists felt they were fairly recognized for their skills and years of experience. This section questions whether this recognition is conditioned by gender. 
Respondents were therefore asked if women, who have education and skills, equal to those of their male colleagues, are recognized equally in terms of pay.

Most respondents asserted that recognition was not gender sensitive and there was no discrimination between men and women journalists with regards to pay. "They are equally recognized in everything; as there is no difference," asserted a female respondent.

The difference in pay was attributed to experience, qualifications, skills, seniority and connections. Salaries were not based on whether a journalist was a man or a woman but on the position that the journalist occupied and the seniority in the television station. Women's experience and capabilities were being recognized like those of men asserted a female respondent. Another female respondent mentioned the importance of experience in affecting the salary but was the only one to add the factors of the financing of the television station and the personal connections that the journalist has, thereby implying that the better connected the journalist is, the higher is his/her salary.

A number of female respondents emphasized that women had a prominent presence in the newsroom and their numbers exceeded those of men. Some even went to the extent of saying that it was men who should claim their rights in the newsroom, considering women's dominating presence. At LBCI, the operations manager was a female as well as most of the anchors, editors and producers, a female respondent said. Another female respondent spoke for her male colleagues who considered that they were being treated unfairly in the field of media since female journalists were taking the opportunities away from them:

The males in this profession are becoming very few in numbers and I don't know why the female face is more in demand in television than the male's face.... Today I am feeling that yes there is a lack of males in the newsroom in editorial, anchor and news reporters' positions 
Male respondents also spoke of the dwindling number of male journalists in the newsroom. One emphasized it was men who should claim their rights in the newsroom. Another maintained that with the exception of the camera room, all other newsroom departments' journalists were mostly women. A third respondent asserted that:

The woman was the base of the newsroom. Men are in both the higher and lower positions. In many cases, women occupy higher positions as well

To some respondents female and male journalists are not equally recognized. Patriarchal dictates including family responsibilities as well as inequality in strength were cited as reasons. Women were considered the weaker gender, said a female respondent and she was ready to accept a lesser salary than man. According to her interpretation of Islam, a female respondent justified the difference in pay between men and women by mentioning that man was the one who should provide for the family and not the woman, who did not have to inject her salary into the house's budget. The only difference was in the benefits that the head of the household received, asserted a male respondent; it could be the woman or the man provided these benefits were not duplicated.

Respondents' responses showed that women are on par with men when it comes to pay, breaking yet another glass ceiling barrier. This posits that the Lebanese television newsroom, as a workplace, is characterized by fair and equitable pay for journalists of both genders. The Lebanese Labor Law, adjusted in 2000, also plays a role in ensuring men and women receive equal benefits.

\subsection{Obstacles and Advancement Strategies}

This section provides answers with regards to the adaptation and advancement strategies that women use in the Lebanese television newsroom. This question indirectly 
tries to uncover whether an unspoken rule of conduct or behavior governs the newsroom. In other words, it tries to examine "the field" that women work in and how women have learned to interact within that field. It also tries examines if women have had to present compromises to advance in the newsroom. It questions the types of compromises and inquires if the same compromises are asked of male journalists.

\subsubsection{Obstacles to Women's Advancement (10 obstacles)}

This question explores the hindrances that may prevent women news journalists in the Lebanese television from advancing or moving forward in their careers. Specifying obstacles that women specifically face would also shed light on the type of environment that the women journalists work in and the difficulties that this environment presents. The question was asked without hinting at any of the obstacles that were uncovered in the literature review. Instead it was left for the interviewers to present the obstacles that they had detected. The obstacles discussed included family responsibilities, patriarchy, gender bias, childcare availability, harassment, competence, physical limitations, religious limitations and personal choice. Respondents may mention one of the obstacles or a number of obstacles while answering the question. Therefore, a respondent's answer may be found under different categories depending on the obstacles he or she discussed. While 22 respondents provided one or more of the above mentioned obstacles, 5 respondents found that there were no female-specific obstacles that hindered the progression of women journalists in the Lebanese television.

Family responsibilities and having to balance work and family were the main obstacles referred to by most respondents (14 respondents). Yet the respondents' answers 
differed when it came to the details. Family became an obstacle to advancement especially when women journalists chose to prioritize it over work.

Balancing work and family responsibilities comprised the formula for success according to a number of respondents. A female respondent in senior management insisted that women were capable of effectively juggling their role in the family and at work. As women's liberation was actually a lie, according to the respondent, women were forced to take on their responsibilities and those of men as well. Another female respondent, also in senior management, believed that if a woman "aligned her (personal and work) life from the very start of her television career then she can be successful on both fronts." Otherwise she would have to give up either her family or her career. The respondent mentioned that three women journalists submitted their resignations because they were unable to cope with work. She noted that very few women journalists were married and happy:

The majority of women that work in this field either never marry or marry late or you see them they get married and divorce afterwards

Respondents were divided among those who believed that women journalists can effectively balance their work and family lives and those who thought women would have to prioritize one over the other and accept not advancing in their careers.

Whereas certain respondents found that family responsibilities are the same for men and women journalists, others had a totally different opinion. Male journalists were less bound by family responsibilities than female journalists. Many female colleagues left their jobs to cater to their families, noted a female respondent, indicating how the television's administration had no qualms about calling a married male journalist at night to cover a story but could not do so with a female journalist who may choose to stay with 
her kids. "The mother has a bigger role at home unlike the male reporter who is married and who can leave at any time and come to cover news," another female respondent said. "The father leaves the kids with the wife but if it is the other way around, the woman will have a problem," noted a male respondent in senior management. The respondent nonetheless mentioned that the station often took such cases into consideration and supported the female journalist in her role as wife and mother.

Certain respondents who also spoke of family responsibilities added that men do not really help working women juggle their work and family responsibilities. Women as wives, mothers, sisters or daughters have a lot of responsibilities in society; the field of media could become exhausting to them, remarked a female respondent. The respondent asserted that men did not help enough:

The woman is expected to work outside and in the house with double the effort and the man comes home and expects everything to be ready for him

"The man does not have any sense of responsibility to realize that he has to help at the home front," asserted a female respondent who finds that women carry the burden of responsibility both at work and at home.

Yet another female respondent gave examples of female journalists who became successful thanks to their husbands' support. She mentioned LBCI's reporter Nada Andraous who covered the war in Syria. Nada, said the respondent, was a mother and wife who had her husband's support; this helped her focus on her work since she was comfortable knowing that her husband was handling the responsibility of the house and the kids. The other journalist that the respondent mentioned was Tania Mhanna, also a wife and a mother who was strongly supported by her husband. Both reporters are well renowned in Lebanon. 
The second obstacle which is closely related to the issue of balancing family life and work is the availability of a daycare next to or within the television station. Very few respondents discussed the issue of a daycare facility which is not available in any of the channels. The respondents focused on the convenience of having a daycare for journalists who have kids. A daycare was important, emphasized one female respondent, as the mother or father would feel psychologically at ease if they gave their son or daughter half an hour of attention per day, in other words if they could spend some quality time with them during the regular work day. But "it needs funding." A female respondent, whose baby girl was with her during the interview, mentioned that there was a daycare next to the station. She pointed out that she had to bring in her daughter to work because the daycare was closed for the day but expressed the fact that it was convenient to have such a facility close to work. "When LBC was in a good shape ... and had 70 employees (with children), management had the intention of opening a kindergarten but then it was scrapped," commented a male respondent seemingly expressing the importance of having such a facility in the television station. It is worth noting here that most working women in Lebanon hire internal home help, to aid with the house work and kids. Yet home help does not necessarily eliminate the need for kindergarten but it is considerable aid with respect to many of the responsibilities a mother or a wife would have had to handle on her own. In tight knit community like Lebanon, mothers may also receive the help of their extended family - mostly from the wife's or husband's parents.

The third obstacle that is also closely related to family life and responsibilities is patriarchy. Most respondents ( 7 respondents) referred to patriarchy by name - mojtama' zoukouri in Arabic, others simply alluded to it. "The society we live in is patriarchal," 
said the female respondent from Al Manar. She associated patriarchy with the mentality in the station where they could not see women in upper management positions. The respondent mentioned that patriarchal society is conservative but that was slowly changing. Her colleague from Al Manar agrees. "We live in a patriarchal society ...we also have an oriental Arab culture ... the man is given more presence than females. So yes it is one of the obstacles." Pointing out that many women work at Al Manar, the respondent, nonetheless, noted "even Al Manar TV is based on a patriarchal society." The patriarchal society restricted woman's advancement, said a female respondent, who occupies a senior management role in Tele Liban. It was up to women to prove themselves.

A Future Television female respondent presented an interesting viewpoint that specified the trigger for patriarchal thought which was not often visible in Lebanese television. According to the respondent the trigger was marriage, and especially pregnancy:

The nature of Lebanon where there is still an open free society with a bare minimum of democracy.. has facilitated for many women the reaching of high positions. Even men reach in crooked ways sometimes. It is not contained to being a male or female in my opinion. That is not to say that our society is not patriarchal in nature but where does that become visible? It is when one of the women wants to get married or is pregnant. Private talk would spill and displeasure is voiced and calls ...increase to perhaps get more males hired to avoid such scenarios

A female respondent from Al Jadeed alluded to patriarchy by referring to how males in society, and not in the newsroom, viewed females. Another Al Jadeed female respondent lamented the fact that women journalists who had much potential chose to abandon their careers mainly because of their family responsibility or the Eastern society that they lived in: 
In this domain you find many women who are so energized and love to work ...who have a lot potential yet they reach a certain point and hit the brakes. This brake they hit is due to our Eastern society or they would have to raise their kids and it comes down to a choice

The respondent criticizes this as a disappointment to the television's administration which invested in these women and foresaw advancement to specific positions for them.

"I belong to the people who believe that women's liberation is the biggest lie," asserted a female respondent from OTV. "In Lebanon the makeup of society is male centric," and families became more concerned about the lives of female reporters than those of male reporters instructing them on what stories to cover and what not to cover. Add to that, women, in high positons, who had to dine with politician or businessmen were scrutinized and criticized. The respondent, who had a high position herself, pointed out that if the women were willing to work then society's dictates would not stand in their way. $90 \%$ of women in the media field managed to find equilibrium between their homes and work, she emphasized.

The fourth obstacle that could be detected from the respondents' answers was gender bias. None of the respondents mentioned gender bias directly but they pinpointed certain practices that discriminated between male and female journalists. It was easier for men to build social relations that are necessary for the advancement of a journalist, asserted a female journalist. Another form of gender bias is when the television administration chose not to send a female reporter to a place which it deemed inappropriate or risky, remarked another female respondent. The type of assignment may, then, be classified as an obstacle to women.

Somewhat related to gender bias is the issue of harassment and abuse which was referenced by one respondent as an obstacle. The female respondent discussed two main 
issues: the first related to discrimination on the ground as women were belittled

physically and psychologically by men present at the time and place of live reporting and the second related to being harassed by male politicians when covering a story. Although the respondent did not categorize these incidents, nonetheless, the incidents could be classified under physical and verbal abuse. She attributed these incidents to Lebanon being a patriarchal society. The respondent provided fine details relating how such incidents would not happen with a male journalist:

It is the way males look at females and what you may hear from them while covering a story on the ground. It can be in the form of belittling. For example, I have been hit twice and attacked by a man and hit on my back ....The issue is you as a female could be looked at as a weak gender ... So it is the belittling of the woman's psychological state and physical capabilities that can be an obstacle and stand before a woman's career progression. Furthermore, you may hear a nasty word from someone about the television you represent or about you as a person. If it was a male reporter in the place of a woman, he would not have perhaps heard this type of remarks. Maybe the displeased person if he sees a male reporter may avoid creating a problem with him ...As a woman, I have felt and faced this. Also maybe when a woman meets politicians to interview them, if these politicians have bad intentions and no manners they may throw remarks at her as well or advances but such things can be handled by the journalist who knows how to impose her limits on such behaviors. Ultimately it is up to you in general but we live in a patriarchal society where you as a woman have to prove yourself over and over again

Physical limitations and the unavailability of a certain position for females were mentioned as obstacles. Both obstacles were related to the position of camera operator, conveniently described as cameraman by all respondents since there were barely any women camera operators in Lebanese television. MTV was the only station with a camerawoman but she films in the station, noted a male respondent. The respondent attributed the lack of women camera operators to two things: the heavy weight of the equipment and the risks of on-the-field coverage: 
Nowadays, fights can erupt in a split second with cameramen who are told not to film in a certain place and they get beaten for it. They avoid putting women in such a position but they can send a camerawoman to film a conference at any event

"With regards to camera operators they are all men," asserted a female respondent in senior management. She attributed the lack of women to the fact that the camera operators had been with the station for the past 16 to 17 years. So the position was not available for women.

Another limitation is related to skills and knowledge. Respondents emphasized that the journalist, male or female, should be qualified to fill in a specific position. Female respondents placed much value on competence insisting that a lot of women were highly skilled and qualified. Once women had the skills and expertise, asserted a female respondent, they became more successful administrators than men. It was not "because they are more diplomatic," the respondent said, but because influencing a female manager was less likely than influencing a male manager especially when the opposite sex was involved. The respondent was indirectly addressing rumors whereby women in the media field get hired thanks to their looks and to influencing a male superior.

The seventh obstacle is that of religious limitation. This obstacle is interesting especially since the majority of Lebanese television stations function as politico-sectarian bodies. The religious limitation was only given as an obstacle by a Tele Liban female respondent who said "To me, the obstacle to reach the position I want is a religious limitation." The respondent was qualified for the head of news position, but being a Christian she could not vie for that position which belongs to Muslim Sunnis. Tele Liban, like the government, divides its upper management positions in accordance with religion. It follows the government formula dubbed as 6 and 6 repeated (or sitteh $w$ sitteh mkarar), 
which means there should be six Christians and six Muslims in all upper governmental posts including institutions like Tele Liban, the Lebanese University, the army and others.

The ninth obstacle is also related to governmental issues since it has to do with the Lebanese law. Only one respondent highlighted that the discriminatory nature of the Lebanese law may stand in the way of women's advancement:

The stations in Lebanon fall under the Lebanese laws but the problem is when the law is unjust to us as women- like the laws of marriage, motherhood, divorce and what have you. All these laws are unjust towards women. Don't forget we have a free economy in the country where an employer can employ you or fire you and give you a salary that is up to their discretion

Yet discrimination was not left undetected and was not ignored. The respondent mentioned that what was lacking in governmental control or administrative policy was compensated for through organizational culture. "There is a community inside the Future TV and I think in all the televisions where people would meet and lobby and question unjust actions and this puts pressure on the administration."

The last and tenth obstacle is not external but rather internal. It is comprised of a decision taken by the respondents themselves not to take on the additional responsibility or advance. "I am happy where I am as a news anchor," said a female respondent. The respondent expressed her lack of interest in administrative roles that involved paperwork, filing, and managing people. She preferred the peace of mind she had at her work. Another respondent emphasized that male and female journalists had equal chances at advancing but females might prioritize their families.

"I put the blame on women," said a female respondent in senior management bluntly. "In many places, 80 percent of (media) students are women and we are not 
studying to take a degree, hang it on the wall and sit at home." The respondent described how the upward career of women may come to an abrupt stop or take a whole new turn once she married or got kids. The respondent expressed her disappointment as women were ready to give up what they had strived for and she questioned whether children provide them with an alternate form of satisfaction.

While the above respondents uncovered a number of hindrances that stand before women's progression, a few respondents, mostly males, did not believe that there were female-specific obstacles that disrupt a female journalist's career in media. "I don't feel there is a difference between the man and woman in the media field," said a female respondent from OTV who believes that women are stronger than men in the field and have more chances at advancing. Nothing stands in the way of a woman who was hard working and capable, according to a male respondent who gave the example of Linda Mishleb, a female reporter specialized in war coverage. Al Jadeed's male respondent agreed, "To me there are no obstacles," that stand before women he said. "In the media field, the woman has been able to break all the obstacles and has managed to advance to a great extent."

Perhaps the two surprising answers came from two other male respondents who felt that in the field of media, men were the ones facing obstacles and not women. "Men are suffering and not women," asserted a male respondent. It was easy for a woman "to get employed in this field without experience if she is presentable and beautiful. She would apply and they would take her right away." The respondents agreed that looks mattered more than experience in Lebanese television:

I am not saying they are better and we are not or vice versa. But for us, the woman can be 80 percent of the time a model who may or may have not 
undergone plastic surgery in addition to the makeup she has on etc. This is the style of our women in the field in Lebanon. Viewers are accepting this and are happy to see this. I am not attacking this style but do a comparison between how outside televisions in the world (CNN, TV5, TF1) are and compare them with our television stations

It was easier for women to establish connections with politicians who preferred to deal with women more than men, asserted the other respondent. This helped women acquire information, provided they knew how to put limits to such special connections or relationships.

Four out of the five respondents that found women faced no obstacles in the field of media were males. These respondents comprise over half of the male interviewees who are 7 in number. Only one female respondent out of 18 comprising $5.56 \%$ of the total respondents believed women encountered no obstacles in the field of media. This finding shows the difference in perspective that male and female journalists have of the field. Despite the noticeable progress, women journalists in Lebanon still have to face patriarchal dictates and gender bias while balancing home and work responsibilities, often without real support from their partner.

\subsubsection{Compromises and Advancement}

The literature review revealed that women or men may present certain compromises that would help them advance faster in the newsroom. This question reveals whether there are known compromises in the news field that would help women advance; it would also identify if the compromises are the same for men and women.

Although most respondents denied giving any compromises themselves, the answers they provided revealed a number of recurrent compromises that can be grouped under two main titles, the first is airing a story and the second is sexual compromises. 
While the first compromise is purely editorial, the second is sexual in nature and may range from flirting to engaging in sexual intercourse with a supervisor or a politician. While respondents spoke with ease about editorial compromises, their answers with respect to sexual compromises were indirect in that none of the respondents defined the actual form of the compromise or who that compromise concerned. The indirect references included words such as "doing such a thing," "going out with," "dating." One of the female respondents provided an overview of the compromises that exist in the profession:

Both men and women can present compromises. You have political compromises such as covering events requested from outside sources to cover and you as a reporter may have questions to ask but cannot ask them given that you are in a station that has a certain political view. Sometimes you do compromise on content but you have to do it in a way to safeguard your credibility of course. With regards to sexual advances, it is always there and it is not only in the media but the media is an industry where nothing stays hidden especially for people on the camera. Let's say you as an anchor got on the air and messed up pretty badly. You won't be able to continue. This is not a job that is behind the scenes to remain backstage if you don't have the qualifications of course. The media world is small and under the spotlight

A male respondent affirmed that "In Lebanon it (compromising) is available in large numbers but it is not the right thing to do." Ultimately putting a limit to compromise has to be done by the television station first and the journalist second.

Respondents identified tweaking a story as required by the editor-in-chief or including a segment of the story, as a compromise, that the journalist should make for the station which follows a specific line of thought. "We work in line with the country's political positioning and objectives. You have to reflect that image," a female respondent commented. A male respondent mentioned that a journalist may be asked to change the view from which a story was presented since all the stations were highly politicized. 
Religious stations mainly like Al Manar and Tele Lumiere adamantly expressed rejection of any form of compromise especially sexual compromises. When it came to airing a story, Al Manar ensures that everything aired is representative of Hezbollah and adheres to its policy. Requests for airing outside stories are not entertained at all, affirmed a female respondent. Sexual advances are not permitted either as Al Manar is highly conservative. Flirting may happen indirectly and discretely (example look in the eyes, smile,..) but it is not tolerated or allowed. If uncovered it leads to immediate dismissal. "We are a religious and reserved society and abide by our eastern tradition," said another female respondent. Female field reporters even avoid touching males or pushing forward to get a story or an interview so as to avoid contact; the same was true of males. "If your shoulder brushes another shoulder, it is different than going out of my way to touch someone," the respondent clarified in case she was on the ground covering an emergency situation. When it comes to sexual advancement, "for sure at NBN and Al Manar you will not see these things and you won't find them in conservative societies," commented a female respondent from NBN. "We do not entertain compromises. Period," the Al Manar male respondent said. Tele Lumiere female respondents expressed the same idea without rejecting that such compromises may be found in other stations. A form of compromise that is practiced at the station is reworking a news story upon request when someone is not covered for enough time. "We argue not to give in to such requests," the respondent said.

A number of respondents acknowledged that the field does include compromises but affirmed "Passing a story on the air or sexual concessions unfortunately they exist and a lot too. People are getting used to such rhythm and they think all journalists are the 
same," said a female respondent. "It is known that in certain places that if the woman gives in to concessions she may reach but may not last in that position," affirmed the female respondent who occupies a senior management position revealing that she had to leave her first job due to harassment. Other female respondents also ascertained that people who reach high positions through compromises tend to fail and exit the field if they were not skilled at what they did. The male respondent at Tele Liban affirmed that sexual compromises were unheard of at the television station; the same view was shared by Al Jadeed female respondent who mentioned that the bosses at the station were females and no sexual compromises were permitted. The other Al Jadeed female respondent confirmed that if sexual advances ever happened, an investigation would be launched and the people involved would get fired. "..At OTV there has never been even half a rumor about something like this unlike other television stations," said a female respondent who mentioned not trusting rumors about sexual advances in other television stations but wondered if there was ever a smoke without fire.

Female journalists who present compromises advance faster revealed respondents. "I am certain 100 percent that the woman who is ready to do such things for sure reaches faster," affirmed a female respondent. "I will be extremely blunt," announced a male respondent, "when we speak about females the compromises are two at levels," either a female sacrifices time with her family to become skilled and advance or she opts for sexual compromises. There were rumors in the field of X dating $\mathrm{Y}$ or $\mathrm{Y}$ going out with $\mathrm{X}$, said a male respondent. Then you find that a certain female advances faster than the others. The respondent affirmed if such a thing were really happening, it would be very frustrating for men in the field. 
Affirming that sexual compromises did not last, a female respondent mentioned being able to acquire a news scoop or a story from a politician thanks to her experience and connections not compromises or concessions:

I travel and cover battles in Syria and I go in with Hezbollah (Party of God) to do my assignments and it is known that these guys are very religious and they have never given me less than what I deserve. On the contrary, through my skills and hard work they trust me and they take me to places and it has nothing to do with me being a woman. They take me with them to battles and other places and they give me scoops

Other compromises mentioned by respondents include money and gifts for the purpose of airing a news story. A male respondent also added "there are some (female journalists) that go out with politicians and there is money as well in the equation...But everything comes out in the open at the end," he affirmed. Another male respondent presented an interesting twist on compromise whereby the television station would be willing to send a journalist that the politician prefers to get the story or the scoop but that was where the compromise ends. Politician would more readily give a story to female reporters than they would to males, concurred a number of female respondents. In a patriarchal society like Lebanon, interaction between a male and a female was easier than interaction between a male and a male or a female and a female, said another. "Women do acquire the story faster because they appear charming to politicians," said respondent the Al Manar male respondent emphasizing that "if a female reporter from our station came and tell us she got harassed, we would be reserved in sending her again to the same place... That I would not allow here." The respondent affirmed:

Our female reporters cover everything and even if she has to engage with politicians we send them and they are excellent reporters in acquiring news stories. it has something to do with the personality of the reporter, her ability and etiquette 
A witness to favoritism, one of the female respondent asserted "I also saw with my own eyes what it means for a politician to give preference to a female reporter over other reporters or flirt with X person or give Y person a news tip.” A seasoned reporter, one of the female respondents described how a good working relationship can be established between the female reporter and the politician, although that same relationship may have gotten off to a wrong start. The respondent, giving an example of how she established good sound connections with politicians and other sources, emphasized her ability to shape the relationship. She mentioned, for instance, calling the politician for news and him calling her to just say hello or check on her taking into consideration that she has a vital role in delivering his message to the viewers or readers.

While the sexual advances exist in the field, it was up to the female journalist to know how to deal with them (8 Females, 2 Males). Female respondents recognized sexual advances as part and parcel of the field, especially since Lebanese politics is mostly populated by male politicians. Female reporters, most respondents agreed, should device smart rejection strategies that keep the relationship intact without presenting actual compromises; what they meant is using charm and sexual innuendo without engaging in any physical act:

You have to be smart in dealing with them...You don't stop them directly because you want to safeguard the point of return... but you also do not give the person what they want

Female respondents affirmed that female reporters have the power to reject or allow for such advances; one even went as far as blaming women, "If you are opening the door to harassment then you are to blame," she said. Another affirmed that if a female dresses and behaves in a decent manner, then she would not be harassed. The two male 
respondents put the onus of responsibility on women emphasizing their ability to limit and discontinue the sexual advances:

If the circumstance presents itself that she is willing to go forward with such advances then it is not the man's fault. Each dance requires two people

The respondent emphasized that the female journalists could put a limit if she wanted to.

Respondents ( 7 Females) believed that women that present compromises advance faster in the field and reach high positions. Yet if they did not prove themselves in the field, they end up exiting it. All of these respondents emphasized that this field of work exposes people's strengths and weaknesses and by virtue of it being a small community, everything becomes known. Although the respondents did not directly mention the type of sexual compromises, it could be deduced from their words that the compromises referred to engaging in sexual behavior within the station or with politicians.

While underlining that sexual advances do not generally happen in the newsroom, a number of respondents spoke of a number of behaviors that may be encountered and how they dealt with them. These include flirtatious comments, sexual jokes, foul language, and friendly gestures. A female respondent, who mentioned that she may occasionally say a sexual joke, emphasized that men tend to say such jokes more. "When there is a sexual joke, we all laugh together and it stops here," the respondent said. It was only normal for a beautiful woman to suffer from advances inside and outside the newsroom, said another but it all depended on how she chooses to handle them:

There is no man when he sees a beautiful woman passing by him and in whatever dress she is in, that he will not look at her and throw a remark or even just give her a look without saying anything. It goes back to her to react to such things

The example of a producer giving a flirtatious comment to a female colleague was given by a female respondent who did not qualify the act as harassment. Harassment can only 
happen if the female did not put a limit to it, the respondent insisted. A female occupying a senior position at OTV insisted that the newsroom had boundaries set by the people in charge, "I don't even allow anyone to ...communicate with anyone inside the station with ...language that is sexual in nature." If people wanted to use foul language or make jokes of a sexual nature, they were required to do so outside the station:

I am not sure if the behavior in the station would have been different if a man was in my shoes. I know for a fact that even men who were higher than me and if they stepped out of line with me I used to set them straight and I did not allow them to speak this way to me

Female respondents from Tele Liban, LBCI, NBN, Al Jadeed, Al Manar and Tele Lumiere affirmed that no sexual advances happen in the newsroom. Such behavior, they insisted was not permitted by the administration of the television station. There is a family like atmosphere around the station, an LBCI female respondent said, indicating that team members eat, drink coffee and joke around together.

Newsroom interaction between men and women appears to stand on a fine line between brotherly relations and flirtatious behavior. This form of interaction is in general subtle and if there were to be advances, they would be indirect and they can be restricted, by the female concerned. One female respondent presented an interesting observation from her experience in the newsroom. In describing the interaction with male colleagues, the respondent mentioned that gestures like putting a hand on one's shoulder, accidental touching or giving a comment may be interpreted in different ways. Interaction with male colleagues happens on daily basis and sometimes "you cannot distinguish whether their intentions are good or not." You can take such gestures in a brotherly manner but if they exceed the limit, then the female journalists can "politely" put an end to them. Another female respondent mentioned that such behaviors were rare in the newsroom and if they 
do happen, then they are indirect and discreet; there is decency to conduct in the newsroom.

In discussing compromises that can be offered in the newsroom, respondents mainly spoke of airing a story and sexual advances. While the first seems to be part of the career in a highly politicized and religious environment, the second also seems to be a common recurrence in the field with women having the upper hand in rejecting or allowing sexual advances. When it came to obstacles, women cited family responsibility as the main hindrance to their career. Other obstacles included patriarchy, knowledge, laws, religious limitations, personal choice and harassment.

\subsection{The Newsroom Environment}

The newsroom is a dynamic workplace where men and women journalists interact on daily basis. The more women are present in the newsroom, the more comfortable they feel voicing their opinions at editorial meetings and presenting different perspectives to the male approach (Poindexter, Meraz \& Weiss, 2010). Women's presence in larger numbers empowers them to affect their workplace. Having a female majority, the Lebanese television newsroom may offer women journalists a comforting environment that invites them to uncover their potential. The next section explores the male-female interaction in the newsroom to identify the effect that such interaction has and the ways in which it has affected men and women journalists.

\subsubsection{Interaction in the Newsroom}

The way that male and female journalists in the newsroom interact shows the manner in which they deal with other. By asking journalists what they have learned from 
their interaction with their colleagues, an idea can be formed of the type of gender relations that exists in the Lebanese television room.

When respondents were asked whether being in the newsroom has taught them to act in certain ways, some related the question to interaction between genders. A few respondents (7 Females, 4 Males) stressed the fact that they deal with male and female colleagues in the same manner:

It does not matter if I am dealing with men or women. I am the same with both genders. In this field there is not much difference in the way you talk to men and the way you talk to women. (F, Personal Com., 2014)

A female respondent in senior management added that she would congratulate, reprimand or direct male and females in the same manner. Another mentioned that as an older woman in the profession she was highly respected by both genders and wondered if it would be the same for a younger woman.

To identify the characteristics of interaction in the Lebanese newsroom, a female respondent related her experience in Iraq where she had to be careful in her interaction with men and had to somewhat hide the fact that she was a female team leader. In Lebanon, she said, there is mutual respect among all team members:

...whether men or women. I don't have a problem to direct them. They look up to me. When I tell them something I say it out of experience and I justify it to them

Being part of religious society where the mixing of men and women was limited, a female respondent found in the newsroom environment a freer space that is more relaxed for interaction with colleagues.

A number of respondents ( 3 Females \& 3 Males) disregarded the gender dynamic altogether to emphasize that dealing with colleagues in the newsroom depended on the personality of the colleague and how one learned to interact with them. These 
respondents emphasized the value of experience in learning how to deal with people, developing a sense of diplomacy with team members and the deeper knowledge of the field:

The newsroom taught me to act in a certain way. I know now what a person is made of and how to deal with them. I learned the issues that would provoke them and what wouldn't and I deal with people accordingly. So you learn how not to challenge people and how to get your things done in a smooth manner

The respondent nonetheless mentioned that as a producer, she dealt with male and female colleagues in a similar manner. Two female respondents referred to establishing a kind of chemistry in interaction with the news team:

As a segment head, I deal with around 5 or 6 people between reporters and at times up to a maximum of 10 people. It is very easy for me because I was in their shoes at one point. I am still their colleague and we are a team. I am not a manager but I am tasked with a specific role and I work with them as a team to make things happen. (F, Personal Com., 2014)

Females may be dealt with in a "nicer" manner:

The editor-in-chief might be more pleasant and nicer with a female reporter than a male counterpart and a lot calmer especially if he is in a bad mood. (F, Personal Com., 2014)

One female respondent in senior management observed that women felt more guilt if they used harsh words with their male colleague especially since the society they were raised in is patriarchal. The respondent, nonetheless, remarked that in education and work, men and women have established parity and she therefore dealt with both genders equally most of the time. A male respondent who reported to a female, affirmed that a woman imposes herself through her character though she may not be as comfortable giving a direct order to a male as she was to a female.

Certain respondents related the question to personal development and improvement. They mentioned that newsroom experience taught them how to handle 
shocks, work stress, political events, and anger bursts. Each respondent had a different formula for success. Female news anchors may imitate what has proven to be successful such as a dress code or a haircut or use their beauty to get to places, a female respondent said. Other success factors cited by respondents include being respectful of the other who had a different political or religious affiliation, continuous learning, effective stress management, focus on news work, writing and production as well as mutual understanding and respect among team members.

The number of women in the field of media is on the increase whereas the number of men is dwindling, noted a male respondent. He mentioned that men in the media field did not make enough income to sustain a living. Those who remained in the field either left Lebanese television for Gulf or Pan Arab stations or took on a second job. The respondent gave George Kordahi, the journalist who only became known after presenting Man Sayarbah Al Malion (Who's Going to Be a Millionnaire?) on MBC, a Pan Arab television station. He also gave his own example, as he works both as a news anchor and a media instructor.

\subsubsection{Old Boys' Club}

As revealed in the literature review, the newsroom is described as an "old boys' club,” (Franks, 2013; Robinson, 2004; Chambers, Steiner \& Fleming, 2004; MelinHiggins, 2004) filled with male banter, sexist humor, and competition over prestigious news topics. The old boys club also includes men getting together after hours and excluding women who may not be able to join due to home and family obligation. This question inquires whether the Lebanese television newsroom is an old boys' club where 
men and women compete over topics, men have the upper hand in imposing their ambiance and get together after hours while excluding their female colleagues.

When asked if the Lebanese newsroom was an old boys' club, most respondents (23 respondents) answered that it was not. The reasons that the respondents gave included having a female majority in the newsroom, a lack of men and mixed socializing after work hours. At LBCI women outnumbered men even in management and the control room was mainly controlled by women, female respondents noticed. Most news editors and reporters at MTV were women asserted female respondents. The NBN newsroom only had two men (F, Personal Com., 2014). Al Jadeed has many women in all its ranks, since the head of news and the editor-in-chief are both women and they take decisions on the news agenda, the type of news to cover, who to interview and what to investigate. Tahseen Khayat, the owner of the station, takes decisions on the overall political viewpoint of the station (F, Personal Com., 2014). At OTV, the editor-in-chief, operations manager and segment head are all women. "There is a lack of men. We are mostly women in the newsroom. Men are mainly in technical and as producers," said the female respondent. There were more women than men in the Tele Liban newsroom, affirmed the female respondents. Women at Tele Lumiere, who comprised $90 \%$ of the newsroom, recently, overhauled the whole newscast and changed the spirit of the news reports; they were now tackling more daring topics even those having to do with pedophilia and heresy, a female respondent asserted. The male respondent from LBCI gave a rundown of the whole news team to show how women existed in bigger numbers and in all ranks:

For example at LBCI you see that the percentage of women is much more than men in the newsroom. In editing for example, we have 3 men and 5 women. In 
the assistant producers, we have 3 women and one man. In the producers, we have two females and one man. With reporters, we have 4 men and 7 women. The editor in chief is a female as well. News head and assignment desk are both men. The secretaries are females. News graphics we have 7 women and no men. The operations manager is a female and she reports to the general manager who is Pierre Al Daher

The male respondent from Al Jadeed described a newsroom overflowing with females emphasizing he was the only male news anchor. The respondent revealed that the television station was looking for another male anchor and they were having a hard time finding one. Perhaps the most descriptive statement of all was the one uttered by the Tele Lumiere respondent, "I am the only guy here," he said.

Two respondents compared the Lebanese television newsroom to their Western or Arab counterparts. "We as institutions are amateurs compared to western counterparts," said a female respondent who believed that Lebanese newsroom are much smaller than Western ones. "Our scale is limited and friendlier," she asserted and Lebanon is therefore an exception compared to the male dominance that is found, in general, in Western televisions and in Arab ones. Male and female newsroom workers go out together after work and there were no exclusive male or female groups. Respondents (3 Females, 1Male) asserted that male and female went out together after hours. There were no groups only for girls and others for guys.

In certain television newsroom departments, males were more than females. In all Lebanese television stations and as seen throughout the findings chapter, almost all camera operators are men. Policy decisions in Tele Liban are taken by the head of news and the general manager, both of whom are males. In Tele Lumirere, the Board of Directors is formed of males especially since the station is governed by the Catholic Bishops who are all bound to be males. 
Only 4 out of 27 Respondents (3Females, 1Male) described the Lebanese television newsroom as an old boys' club. There had been much progression when it came to women, but the newsroom was still more skewed towards males, a female respondent said (F, Personal Com., 2014). All television owners and in general board of directors were males, asserted a female respondent whose answer presented a somewhat unclear position as she emphasized that "not everything goes back to the top of the station. It goes back to the team that is working." Also "it differs from one television channel to the next." A female respondent in senior management identified the atmosphere that was required by the newsroom as masculine. Her definition of the old boys club is women having the attitude that men generally have to be able to survive the newsroom environment:

Even if it was a girls club, it is still a masculine atmosphere. I don't mean masculine by men. I mean you have to be harsh, firm, strong, have a strong personality that enables you to reach your objectives

"It is a very difficult question to answer," said a male respondent, who in relating the newsroom to politics found that men retained the control despite the presence of women in large numbers. Yet women's involvement in decision making had also increased and women's numbers in the newsroom were also much bigger.

\subsubsection{Dominant Presence of Women in the Newsroom}

Having concluded from the respondents' answers that the majority of people working in the newsroom were comprised of females, the respondents were asked about the reason behind this phenomenon. Some of the reasons included women developing media skills, low salaries in the field of media, and low male student enrollment in media. 
Most respondents confirmed the increasing and even dominating presence of women in the Lebanese television newsroom. "In all the television stations, there are no men or they are much less in numbers," said a male respondent. The LBCI graphics department was almost exclusively female and in the editing department, females outnumber males (M, Personal Com., 2014). "We strive to find men to work in the news," remarked a female in senior management. Over $70 \%$ of all newsroom workers are women:

Ten or twenty years ago and until recently, you see that the number of women has increased a lot. I think in the near future it will increase even more and women will be in upper management positions more than males. (F, Personal Com., 2014)

"We are telling management that there should be more males with us," a female respondent said. A female respondent in senior management even provided an inventory of the newsroom employees at the station to show that women were more than men in almost all positions:

Let me tell you as well that we have four producers - three are women one is a man. We have news anchors; two men and the rest are women. Of course the heads are women. There is Mariam Al Bassam who is head of news and myself. The reporters, we have five men and the rest are women. They are around 15 news reporters in total... In editing we have half and half representation of both genders approximately. Graphics, we have one woman and two men. It is diversified. In the archive department they are mostly women

The increasing presence of women in the Lebanese television newsroom was attributed to their strong character and effective skills in the field. Women in key positions in the newsroom "possess a very strong character... Females have the looks, have the character, the skills, the will, the passion and the courage," remarked a male respondent. He, nonetheless, commented that males did not like females with very tough characters as they did not have a problem being strongly addressed by a male but they had a problem 
being strongly addressed by a female. Thinking in somewhat similar terms, a female respondent asserted "I sometimes feel I am more male than female and sometimes I look at men as females." Women are as effective and as skilled as men in the field (F, Personal Com., 2014). "Women are achievers," remarked a female respondent.

The loss of men in the field was attributed to the insufficiency of the monetary compensation that men were receiving. Men could not live off of their media salaries and end up either travelling abroad or getting another job alongside their media work. "Men are finding posts in Dubai or Qatar or anywhere else with higher pay," (M, Personal Com., 2014). Women who are married or engaged, on the other hand, cannot just travel. "I stay in the media field because I love it. But I work three things at the same time to sustain a living," said a female respondent who works for LBCI, is a correspondent for Voice of American Radio in Arabic (or Radio Sawa) and teaches media courses. The respondent asserted "I cannot rely only on the media salary. I think this is why we don't have enough males working in the media." Many Lebanese men and women media workers travel abroad to get higher salaries and they are highly effective in all major regional media outlets (M, Personal Com., 2014).

Salaries abroad were much higher prompting men to leave the Lebanese media (F, Personal Com., 2014). "We have a hard time finding a male news anchor and sometimes we cannot find any...You receive 20 resumes from females and one from a male." With men looking for other fields that provide them with more money, the field became more advantageous for females, agreed three female respondents. Men are the prime breadwinners in our society, asserted others (4 females) and are therefore forced to look for jobs that provide them with monetary sufficiency. "Check Dubai and check Saudi, the 
UAE or even Bahrain. Most of the (media) have a high rate of Lebanese males working there," said a female respondent.

Doubtless men's exit from the media field is a unique phenomenon that opens the door to women's advancement. This exit is prompted, as respondents mentioned by the low salaries offered by the field. Yet this invites us to question whether it is advantageous for women to stay behind in a field that men are exiting. Economic studies reveal that this situation may not be unique to the media, although men's exodus from the newsroom may be more remarkable than it is in other fields. The Millennium Development Goal report prepared for 2008 for Lebanon reveals the high rate of unemployment rates among Lebanese youth from both genders:

The resident Lebanese population, estimated at 3.75 million, has a young age structure with approximately $37.2 \%$ under 20 years of age. The labor force, at roughly 1.2 million, is estimated at approximately $45.2 \%$ of the working age population (15-64 years). This indicates that, whilst two thirds of the resident Lebanese population is of working age, only one third is actually working

Given the high rates of unemployment along with challenging socio-economic conditions, the report revealed that most Lebanese young people aged between 25 and 45 prefer to emigrate to the countries of the Gulf Cooperation Council (GCC), Europe and North America where they can find more attractive job offers and better living conditions - an inference that reflects respondents' opinions. An updated 2015 report coordinated by the Arab NGO Network for Development with the support of the Fredrich Ebert Stiftung foundation revealed that the huge influx of Syrian refugees (over 1 million) has negatively impacted the Lebanese economy. Add to that, the minimum wage in Lebanon which is settled at 675,000 Lebanese Liras, the equivalent of US $\$ 450$, is not enough to 
sustain a living. The last amendment to the minimum wage was done in 2012 and it does not reflect the $38 \%$ rate of inflation for 2015 .

While the reports show that the dwindling economic conditions are affecting female more than male employment, we find that both genders are emigrating in search of better prospects. In a patriarchal society where males are the main breadwinners, there is more pressure on the males to leave than there is on females. This may be one of the reasons that explains the female majority in the Lebanese television newsroom.

Another reason is that most media students and therefore media graduates are females rather than males. Female students "comprise 80 percent if not 90 percent of the media students," said a male respondent. "Men are not even studying media at universities. It is very puzzling." Women were specializing in media more than men. A female respondent attributed this to women thinking that "the media field is an opportunity to become a star and become famous." Speaking along the same lines, a male respondent commented that females were attracted to the field because of camera life and glamour. Dajani (quoted in Melki, 2009), in the literature review, had proposed another reason. He mentioned that the females' choice of degree was not subject to social pressure unlike the male who, being the main economic contributor in the family, was pushed towards professional degrees.

Other reasons given by respondents include attracting viewers, having flexibility, handling stress and conveying feelings. It was about requiring a certain standard of beauty and increasing the viewership of the channels, a male respondent asserted. "Some television stations deal with the presence of women as a commercial product offered to viewers as a beautiful person to ...increase viewership ... (and) advertising rates," 
especially through targeting the Gulf market, another male commented. Another reason given to having more women in the field of media was women's flexibility. "A woman is more fluid and dynamic in the media field especially in dealing with people and they don't find her bitter or confrontational in the way she deals with them," affirmed a female respondent. Women can handle stress better, commented another. They are also better able to convey feelings to viewers, especially when it comes to social issues.

One of the male respondents, found the increasing number of women to be advantageous for men in the field as they had become rare and in-demand.

\subsection{Findings Overview}

The findings chapters presented the findings revealed from the face-to-face interviews of 18 female and 9 male journalists working in the newsrooms of the nine Lebanese television stations. The findings demonstrate the richness and vibrancy that characterize the Lebanese media. More importantly, these findings uncovered the intricacies of the Lebanese television newsroom through the eyes of the journalists working in it. This inside view of the newsroom has helped shed light on it as a field where cultural, social, religious and political factors are constantly at play in a patriarchal and yet liberal work environment in which women outnumber men.

In this environment, the woman emerged as a preferred newsroom worker who is skilled and talented enough to get a story as much as her male counterpart, if not more. This prominent and powerful presence of women in the television newsroom came as a result of many factors including men's migration from the field and women's academic and on-field qualifications. 
Women may not figure prominently in the top management positions yet but their strong presence in middle management and strong penetration of senior management positions are tangible signs of progress. Men's exit from the field has helped women realize their potential and become role models for other women that strive to prove themselves in television journalism. Could it be that women's advantageous position in the media today is thanks to men's alternative work preferences and blessings? 


\section{Chapter: In-Depth Analysis of the Lebanese Television Newsroom}

This chapter links the findings presented in Chapters 6 and 7 to the theoretical considerations of the study and the discoveries of the literature review chapter. While discussing the findings in relation to the theoretical concepts and the literature, the chapter unveils pertinent results concerning the profession and practices of the Lebanese television newsroom journalists. These results will be discussed through five inter-related themes namely: cultural capital: education and experience; social capital: familial/social, political and religious connections; gender divisions: coverage, age and appearance; glass ceiling: management, recognition and progression; newsroom interaction: a site for negotiation. The five themes uncover the connection between the personal, social and professional identity of the journalists and their position in the field or in the Lebanese television newsroom.

\subsection{Cultural Capital: Education and Experience}

The main idea behind the concept of cultural capital is for field actors, in this case, journalists to harness factors that can render them more powerful in the field. Bourdieu's capital ultimately originates from the individual but is rendered meaningful in relation to the field, the rules that govern the field and the other actors in that field. Journalists possess different forms of professional capital comprised of their educational background as well as their field experience - both of which form what Bourdieu terms as cultural capital. Only the journalists working in a specific field are able to define how the different forms of capital are valued in that field and how they can leverage them to their own benefit. The value of each capital becomes clear through uncovering the association between the professional identity of the journalists and their position in the 
field or their perception of what works and what is of value in the field. This section discusses journalists' perception of education and experience as forms of capital.

\subsubsection{Value of Education}

Bourdieu thought of the educational system as one which dispenses cultural capital thereby reproducing power through the promotion of the dominant ideology in the field. The degree symbolizes cultural competence and authority. Ideally a professional degree in journalism serves two main purposes; it prepares future journalists for the occupation and grants them entry into the field. The value of formal education seems to be high in the field of journalism but as a mere formality. The professional degree is a formal requirement that does not have consequences over access to the profession or the professional identity of the journalist. Its requirement is to satisfy field and social criteria when its value as a professional upholding has somewhat dwindled. The professional degree therefore has a diminished value as a qualifying element and has been replaced by a random degree. To explain, all the respondents interviewed had at least a bachelor degree; 3 even had a master degree and one was a doctoral degree holder. Therefore, the university degree is a requirement in the field of journalism irrespective of the major. Although most of the respondents' bachelor degrees were from the field of journalism or a field related to it (18 respondents), such as audio-visual media or radio/TV, having a degree in other majors did not prevent entry into the media. Respondents that majored in Law, Information Technology, Political Science, Finance, or religious studies were equally admitted into the profession of journalism. The findings then show a preference for the professional or journalistic degree but do not make it a mandatory requirement. There does not seem to be much difference in the professional trajectory of the journalist 
with a professional degree or any other degree. This has been the case since the beginnings of television in Lebanon. Jean-Claude Boulous, one of the early TV personalities who had been instrumental in the development and later management of Tele Liban, had a civil engineering degree.

The fact remains that the majority of the respondents qualify from journalistic schools. In Lebanon, the most prominent universities that grant a degree in communication, media, radio/tv or journalism include the Lebanese University, American University of Beirut, Lebanese American University, Universite Sainte Esprit - Kaslik, Saint Joseph University and Notre Dame University-Louaize. Each university has its own program of study and the reputation that the program upholds. The journalist applying to a certain position bears the image of the program. The value of the degree, as cultural capital, then, may decrease or increase, depending on the university granting that degree. While most respondents agreed that the type of university one graduates from does not affect the job position they take, the university's reputation, nonetheless, endowed them with a certain degree of cultural/competence authority. Most respondents (22 in number) graduated from the Lebanese University which has the longest running journalism program in the country. Despite competition from private universities, the Lebanese University still gets the biggest number of journalism students due to its tuition free policy and the reputation of its prestigious program. In terms of student enrolment in private universities, the findings coincided with the literature in that the Lebanese American University came second followed by Notre Dame University-Louaize (Melki, 2009). 
Lebanese University graduates dominate the news industry, and the Lebanese television newsroom, especially in print and editorial positions, a finding that concurs with that of Melki (2009). This is somewhat predictable due to two main reasons: when the main private televisions were launched between the mid-1980s to the 1990s, the majority of the graduates in the Lebanese market were those of the Lebanese University, which was the most prominent university offering a journalism program at the time; second the Lebanese University offers rigorous Arabic writing and editing courses, both of which are a requirement in Lebanese televisions that mainly use Arabic, both colloquial and formal, as a language of communication. "The Lebanese University is a pioneer in the field," affirmed a male respondent and its main strength lies in equipping its graduates with the tools necessary for putting together a good news story.

In certain endowments, private universities have the upper hand. First, they better equip their students technically. Most of the creative, production and technical positions are occupied by graduates of the Lebanese American University (LAU) and Notre Dame University - Louaize (NDU) (Melik, 2009). The two respondents with technical positions interviewed for this study graduated from private universities. The quote below sums it up

I did not study at a private university but I have seen many examples ... from a technical perspective, I can tell you those private universities are much better with respect to media studies than the Lebanese University. On the other hand when it comes to the level of working in the field, from putting together a news story to how news reports are written and if you want the content of a report, in my opinion it is stronger at the Lebanese University. (F, Personal Com., 2014)

Private universities also seem to endow their graduates with the prestige of having graduated from a private institution. The Lebanese community, in general, places much value on private education especially since the public school system had fallen prey to 
years of neglect due to the civil war years and lost much of its value to its private counterparts. "I feel that students at private universities have more opportunities than students of the Lebanese University and maybe that is so because companies look at them in a better way," asserted a female respondent. Yet these remain as dispersed voices compared to those of the opinion that the Lebanese University program is still the most sought after. While Melki (2009) states that there is an increase in enrolment in media programs at private universities, the Lebanese University is still ahead in terms of student numbers. One drawback is that Melki (2009) places journalism, communication, radio/tv and public relations programs under media studies without differentiating between them. Questioning the enrolment in each major at the different universities would provide insight as to how and in which programs the universities are competing especially at a time when enrolment in media studies programs at private universities is on the increase.

The cultural value of the type of university one graduates from may not have received much significance from respondents for the simple reason that most of them had graduated from the same university, the Lebanese University. The area of differentiation, then, could not be academic. Many therefore cited non-university factors that affect newsroom positions. Intrinsic factors such as having a journalistic instinct, passion for the news business and the necessary skills were qualities that figured more prominently as capital in the Lebanese television newsroom.

\subsubsection{Value of Experience}

Bourdieu spoke of skills as separate from education and in this study they are associated with experience. As a form of cultural capital, the experience and skills acquired from that experience differ depending on the field. Experience, unlike 
education, was given prominence as a cultural capital. Almost all respondents cited its importance in the field associating it with attributes like confidence, field knowledge, connections, maneuverability, stress control, management trust, strength, credibility, and work quality. In effect, much of the success in the journalistic field was associated with experience. Bourdieu would link experience with the formation of habitus or what he terms as "the structuring structure." The habitus, which enables "agents to cope with the unforeseen and ever changing situations" (Wacquant \& Bourdieu 1992, p.18), integrates past experience to direct the future action of the agents successfully. As a heuristic tool that is affected by past experience it is dynamic. As a set of dispositions, it is not limited to perception but transcends it to choice, desire and action. To Bourdieu, habitus is "the feel for the game" (Honneth, Kocyba \& Schwibs, 2000, p.8). Interestingly, a number of journalists alluded to the game metaphor describing it as a product of extensive experience. An understanding of the "news game" (F, Personal Com., 2014) entails an understanding of Lebanese politics and culture. It entails picking up on certain political hints and knowing how to follow political leads as well as dealing with political figures. It also means having connections in the field:

With time and with increasing relationships and contacts especially with politicians you begin to understand the issues more and become more focused. For example I used to cover the Government sessions when I started with NBN but it is not like how I cover it today. You become more experienced in covering the news and you understand the game. You have to understand the game and how it is played. Either you do, or you don't understand that game

A newcomer would not be able to play the game as well and would not be sent out to cover sensitive issues; they would not be able to make the right judgment (F, Personal Com., 2014) or have a thorough understanding of the political and religious forces at play in the Lebanese environment (M, Personal Com., 2014). 
Tying the understanding of the news game to politics is quite expected and understandable. After all, politics makes news. Yet with the Lebanese television stations, politics takes an even bigger dimension. The inner field of the Lebanese television newsroom is an internal microcosm that functions under the influence of the politicoreligious forces that direct the government, the laws and the media. Journalists within that field should, in field theory terms, play the game right, factoring both the internal and external forces. As revealed in the literature review, the Lebanese television stations are located at crossroads of influences- confessional interests, interstate and intra-state rivalries (Fandy, 2007), the simultaneous public-commercial ownership (Rugh, 2004), and the political and tribal confessional society of Lebanon (Dajani, 2006) all functioning under a mixed media system that is concurrently authoritarian, developmental and libertarian ( $\mathrm{M}^{\mathrm{c}}$ Kenzie, 2006). Having experience entails having an in-depth understanding of all the factors that govern the Lebanese media system, in general, and those involved in governing each television station in particular. This understanding filters into the everyday conduct of journalists and also into the making and delivery of the news - it is more or less a self-censorship process:

At the end I say we are in a television station that has its own political views and line and this political line imposes on you certain work ethics and restrictions that you are not necessarily always convinced of, but you feel you have an entourage you cannot skew away from and over time you begin to know what you can say in a story and what you cannot. (F, Personal Com., 2014)

Experience also meant fitting into the politicized nature of the channel (F, Personal Com., 2014). Doubtless, having the same political and religious affiliation as the television station would make abiding by the editorial line of the station much easier. Even journalists that did not belong to the same political line had to respect the political 
boundaries of the station. Such respondents are able to isolate their personal opinions from station requirements, thereby practicing what may be termed as "station objectivity," which is, in effect, a form of partiality. The content then becomes partial as it is governed by the same politico-sectarian divisions that govern the media and the rest of society- a finding that concurs with the literature (Dabbous, 2010; Notzold and Pies, 2010; Cochrane, 2007 \& 2008; Abu Fadil, 2009). Van Zoonen (1994) argues that journalists always report in contexts: economic, political, cultural, social or technological. Even organizational policy is a context and in Lebanon that policy is formulated in tandem with the politico-sectarian leanings of the television stations in line with country politics and inter-state dynamics. Journalists are well aware of the politico-sectarian nature of the television station and become part of the politico-sectarian game with experience.

Another consequence of experience is fame (F, Personal Com., 2014), which functions as a form of cultural capital. Interestingly experience in Lebanon is always national. Given that Lebanon is a small country, every television station is a national station. Reporters or news anchors that appear on one station become renowned across the country. This makes them national figures and once well renowned for their work their move from one station to the other becomes easier. Such moves usually happen among stations that have more or less the same political leanings or at least non-opposing ones. A recent example is Firas Hattoum moving from Al Jadeed to LBCI. Another example is Denise Rahme Fakhry moving from LBCI to MTV and Dima Sadek moving from OTV to LBCI. Fame, associated with experience and field capabilities, becomes 
another form of cultural capital that can leverage a journalist's value in the Lebanese and Gulf markets.

\subsection{Social Capital: Familial/Social, Political, and Religious Connections}

Like cultural capital, social capital can also grant journalists power in the field. Its power and value are dependent on the field and are only meaningful in relation to the field. Social capital is what Suad Joseph (1999a) would term as connectivity and more specifically, patriarchal connectivity for Middle Eastern societies. This connectivity is, in effect, the network of connections that an individual uses to reach a specific objective. While Joseph restricts connections to the patriarch of the family, Bourdieu (1986) maintains that the connections can happen through any individual that is influential within a specific field. The main value of social capital is that it can heighten the value of other forms of capital thereby acting as a catalyst. Social capital, can, for instance, work alongside cultural capital to hasten a journalist's advancement or progression. In effect, Bourdieu uses it to explain social inequality and the exclusivity in certain social circles. This section discusses the value of social capital on the level of social and familial ties, religious ties and political ties when it comes to Lebanese television journalists. Social capital, here, is not to explain social inequality but to evaluate its efficacy as a viable tool for access and advancement in Lebanese television.

\subsubsection{Social Connections as Capital}

Doubtless connections have a role to play in giving individuals certain privileges they may not be fully entitled to, or in granting them faster access to employment or progression. These connections become more enhanced in societies where families are divided into well-defined political and religious affiliations. To Dajani (2001), these 
divisions do not simply make societies traditional but also tribal as the connections are weaved along inter-familial, inter-religious, and inter-party lines. In general, in Lebanon families, have the same religious beliefs and adopt the same political affiliations, both of which they can leverage to their own benefit. As a form of capital, then, connections are of a high value in the Lebanese society (21 respondents). "It is a world of favoritism or nepotism," asserted a female respondent.

While almost all respondents agreed on the importance of social connections, the disagreement was on its value. To some, social capital took on the full potential of the saying "It's not what you know, it's who you know." For people running in highly influential circles this is good news but to others, social capital acts as a force of exclusion. It is powerful to the extent that it can guarantee continuity in certain positions (F, Personal Com., 2014) and the retention of individuals despite redundancy (F, Personal Com., 2014). In such cases, social capital can cause frustration and indignation as journalists find out that advancement and access are not defined through merit. Journalists with connections do not need experience to "leap" into higher positions (2Fs, Personal Com., 2014) thereby gaining years without the trouble of investment.

When social connections do not have an ultimate value, they have to be tied to qualifications to become effective. In this case, social capital acts as a catalyst to other forms of capital such as education and experience. Social connections turn into a "door opener" that grants the journalist access to employment provided the journalist is skilled and qualified. Progression and advancement remain within the hands of that journalist (4Females \& 1Male). Journalists that prove themselves retain their positions but those who do not put their jobs at risk. The value of social capital then is tied to the social 
power that the connection has. The bigger the power, the higher the social capital and the more likely is the journalist to get and retain the job with or without qualifications. The potential for social connections can be minimized or maximized depending on the television's administration (3Male Respondents).

Few respondents (7) believed that skills and experience, not social connections, give journalists access to jobs in the journalism sector. Yet two of these respondents did not count knowing someone at the television station itself as a connection. This could be attributed to the fact that having a connection in Lebanon means knowing influential people in high places and not simply a connection at the television station. A male respondent, who thought of social connections as inconsequential, remarked that the vice chairperson of Al Jadeed, who was the daughter of the owner, was hired purely out of skill. Doubtless, the vice chairperson is qualified but she may not have had this opportunity had Al Jadeed not been a family owned business. This is a prime example of Joseph's patriarchal connectivity. In effect, then, around half of the respondents who did not believe in the potential of social connections cited an example of effective connections that gave access to employment or progression.

\subsubsection{Political Affiliation as Capital}

Another form of connection is political affiliation. Being politically affiliated to a certain political party or having the same political leanings as the television station has proven to be valuable as a form of capital. Patterson and Donsbach (1996) arrived to the same conclusion as their study on 600 journalists in the United States, Great Britain, Germany and Sweden revealed a correlation between employment patterns and partisanship. Lebanon is no stranger to such studies. In a country where most television 
stations function as mouthpieces of the political parties that own them or that they support, this is not a surprising finding. While there are flagrant examples of highly politicized stations, others are not that obvious as the stations are much less politicized. Certain Lebanese television stations have unique political leanings while others are more diverse and employ people from diverse political backgrounds. Both ends of the spectrum exist and none is, in effect, free from politics.

Al Manar which defines itself as the channel for Arabs and Moslems is a resistance channel with a clear line of politico-religious thought. Owned by Hezbollah, the channel has no qualms about hiding its identity or its mission. Journalists who do not advocate Al Manar's political thought do not work at the station (3 Female Respondents). In reality, journalists who do not support Al Manar would not apply for work there. Capital for Al Manar then is being Shiite and affiliated with Hezbollah politics. Journalists at Al Manar believe in its mission and have no issues abiding by the station's policy. There is no objectivity here but a full expression of a perspective and a conviction.

In general, it is safe to say that journalists who advocate the political opinion of the station are preferred over other journalists ( 2 Females \& 4Males). Journalists who do not support the station's politics could be more worrisome as their work would have to be monitored more closely to ensure it abides by the policy of the station ( 1 Female $\& 1$ Male). Though this may be deemed as a threat to the freedom of expression, it is not necessarily so. Each political faction in Lebanon has its own media mouthpieces through which it can communicate. Supporters, of each of these parties, are well aware of their 
affiliate station and, in general, prefer it over other opposing stations. No voices are stifled but each is only heard through its own venue.

Television stations may hire journalists of differing political points of view provided these journalists abide by station's policy and keep their opinions to themselves. Findings revealed that the most diverse television stations were Future Television, LBCI and Al Jadeed. When it was under the ownership of the Lebanese Forces, LBCI journalists were all party affiliates. This changed when ownership of the station became in the hands of Pierre El Daher, who strove to make LBCI speak for all the Lebanese people. A female respondent, who was hired at LBCI despite her differing political affiliations, affirmed, "Today in the newsroom, we have employees belonging to the Lebanese Forces, Tayyar (Free Patriotic Movement), Kawmi (Syrian Social Nationalist Party), Ishtiraki (Progressive Socialist Party), Al Moustakbal (Future Movement)...” Having moderate positions in their political leanings is what enables stations like LBCI and $\mathrm{Al} \mathrm{Jadeed} \mathrm{to} \mathrm{become} \mathrm{home} \mathrm{to} \mathrm{journalists} \mathrm{from} \mathrm{more} \mathrm{or} \mathrm{less} \mathrm{diverse} \mathrm{backgrounds.}$ With Future Television, the situation is somewhat different. Future Television was launched by late Prime Minister Rafik Al Harriri whose declared mission was to work for all the Lebanese people and the station served as a unification platform. The other television stations including OTV, MTV and NBN have political diversity among their journalists in fewer proportions.

\subsubsection{Religious Affiliation as Capital}

In Lebanon, politics and religion go hand-in-hand. As revealed in the literature review, the political parties that make up the government are also religious. Just like politics, a journalist's religious affiliation acts as capital. Interestingly, journalists found 
religion to be less valuable as a form of capital than politics. This could be attributed to the fact that the two main political movements in the country have Christians among them. While the March 14 Coalition is mainly comprised of a Sunni-Christian affiliation, the March 8 Coalition is mainly comprised of a Shiite-Christian affiliation. This mix also creates an amalgam within certain stations. If stations were to be placed on a religious amalgam continuum, Al Manar, Tele Lumiere and NBN would be on one extreme and Future TV, LBCI and Al Jadeed on the other. The most politically diverse stations are also the most religiously diverse. In Lebanese television stations then, religion and politics act, to various degrees, as capitals of inclusion and exclusion. With Al Manar, both forms of capital are highly valuable. As mentioned previously, to become part of Al Manar the journalist should be a religiously committed Shiite and Hezbollah affiliate. Though Tele Lumiere and NBN respondents affirm that the stations can be religiously diverse, both stations are mainly of one religious color- Tele Lumiere is mostly Christian and NBN is mostly Shiite. The one Christian respondent from the NBN newsroom (F, Personal Com., 2014) attributed this to the fact that no Christians apply to the station, just like no Muslim would apply to Tele Lumiere (F, Personal Com., 2014). This opinion may hold true. The politico-sectarian image of the television may stand as an exclusion barrier preventing diverse applicants from considering it. The well entrenched sectarian mentality does not help. The situation has become more aggravated with rise of sectarian conflict in nearby countries such as Syria and Iraq and inter-state tension that these conflicts cause to countries of the Gulf region. These tensions become reflected in the Lebanese media and more particularly, the Lebanese television newsroom where the presence of "the other" may become awkward: 
Today religion plays a role. Today if you find a Shia member in Future TV you find his presence at the channel wrong. If you find ... a Sunni at NBN you also find it weird. It is now extremely difficult. (F, Personal Com., 2014)

MTV and OTV are a bit more diverse; both stations have minority non-Christian journalists in their newsrooms (1Female \& 1Male). With television stations like Future TV, Al Jadeed and LBCI, the religious mix is seen as a sign of richness and advantage. Al Jadeed prides itself in being secular and like Future TV and LBCI, the station strives to ensure diversity among its journalists. Al Jadeed even tries to maintain a religious balance in employment (1Female \& 1Male), much like the Lebanese government.

While religious diversity has been a staple of Al Jadeed and Future TV since their formation, LBCI only embraced diversity under the ownership of Pierre El Daher. In their recent hiring campaign, journalists from diverse religious affiliations were hired to the extent that half of the newsroom became non-Christian:

The LBCI advantage, which people don't believe, is that in our newsroom we have Christians, Druze, Shia, and Sunni employees. And this has not been in existence since a long time. I confess that because Pierre Al Daher is liberal and against any sectarian mentality or racism. (F, Personal Com., 2014)

While Al Jadeed, Future TV and LBCI maintain religious diversity as a sign of representation and solidarity, Tele Liban does it out of obligation. Employment and progression at Tele Liban are religiously bound. A reflection of the government, Tele Liban follows the 6 by 6 repeated government law which dictates that for every 6 Christian employees there should be 6 Muslim employees and vice versa. The religious diversity at Tele Liban is mandated by government law. The law is restrictive in that religion also dictates the position. Just like the prime minister of Lebanon has to be Muslim Sunni and the President, Maronite, the head of news at Tele Liban is, in general 
Sunni, and the station manager Christian. Tele Liban is, in effect, a reflection of the Lebanese government.

The politico-religious composition of Lebanese television stations speaks to their nature. Even the most diverse stations, still have politico-religious leanings. This is a reflection of the politico-sectarian system that treats the Lebanese, not only as citizens, but as politico-sectarian entities that are crucial for the survival of the politico-sectarian divisions just as they are necessary for the maintenance of a unified Lebanese identity. The Lebanese television stations are characterized by partiality; every television station speaks with perspective and has its own audience. Certain scholars find the plurality of the Lebanese media system to be a propeller for democracy (Rugh, 2004; Hafez, 2010), while others see the television stations as propaganda machines (Cochrane 2007) that promote sectarianism (Dajani 2006). It is, in fact, both. The unconventional freedom that the Lebanese television stations practice is allowed thanks to their connection with the political body. Yet it is that same connection which makes them political and sectarian. The health of the Lebanese media, then, is also its source of ailment. By virtue of their ownership and financing, the Lebanese television channels cannot be objective. Their true reflection of the struggles of the political system can mean only one thing- either the media has to feign objectivity or the intimate connection between the political body and the media has to be severed. Only then will Lebanon have a true healthy media system.

\subsection{Gender Divisions: Coverage, Age and Appearance}

The Lebanese television newsroom environment has changed considerably. Once heavily populated by males, the newsroom is now home to a female majority (Internews, 2009; Dabbous-Sensenig, 2000; Personal Findings, 2015). This considerable change in 
composition seems to have led to changes in established practices and perhaps also attitudes. Practices that were accepted as a given eventually become outdated, a thing of the past. The division between hard and soft news is a good example of this. While the change may not have affected the other areas of age and appearance as much, it nonetheless is a change that impacts the Lebanese television newsroom and makes it stand out in terms of the near parity it has established between men and women.

\subsubsection{No More Hard or Soft News}

Western research on women in journalism shows how women are assigned the lighter news items or soft news while men handle the more prestigious hard news (Franks, 2013; Ross \&Carter, 2011; Ross 2010; Robinson, 2005; Gallagher, 2005). An Internews report (2009) on Lebanon concurs with the research as it reveals that

In Lebanese society, politics and political journalism still constitute a maledominated area due to the prevalent belief that politics is men's domain exclusively, while women are relegated to the cultural and social domains. Accordingly, seldom is a female political journalist part of a newspaper team despite the existence of a large number of female university graduates of journalism and political science

The Internews findings may be true when it comes to women's participation in Lebanese politics and their handling of political news in the Lebanese newspapers but it does not hold true when it comes to women in the Lebanese television newsroom.

Findings of this study show that the Lebanese television newsroom appears to be unique when it comes to the elimination of the soft/hard news dichotomy. "There aren't fields for women and others for men" (F, Personal Com., 2014). The change in the nature of the Lebanese television newsroom is what caused a change in the distribution of news assignments. All respondents of the study affirmed that men and women are assigned to 
almost all areas of news irrespective of gender. Having women assigned to soft news and men to hard news was a thing of the past (2Fs \& $2 \mathrm{Ms})$ :

In the past women covered social news and men covered political news because our Lebanese society was closed more than it is today but today it is different. (F, Personal Com., 2014)

Interestingly female respondents ( 5 Females) mentioned covering and having a preference for political news.

The area of political news was not the limit for women in the Lebanese television newsroom. Women journalists pushed further into the coverage of dangerous war and crime zones. This may be attributed to two main reasons. First, the aggravated security situation that Lebanon has been going through helped widen the scope of women news journalists' coverage. Second, the existence of women in larger numbers in the newsroom, compared to men, acted as a catalyst that pushed them to the forefront in the coverage of hotspots. After all, the Lebanese television newsrooms are more populated by women than they are by men ( 3 Females). Women became instrumental in the on-theground coverage of high level security issues, bombings and explosions (4 Females). They (3 Females) were also assigned to the coverage of the July 2006 war between Lebanon and Israel. Lebanese female journalists that covered that war include Mona Saliba from MTV, Reema Maktabi from al Arabiya and Nancy Al Sabaa from Al Jadeed (F, Personal Com., 2014). Scholars such as Sakr (2007) and Abu Fadil (2007) agree that the 2006 July war was a key instance when women journalists shone. But for women in Lebanese television, that instance was not solitary, women have shone sporadically before that and have been shining constantly ever since. Tania Mhanna was an LBCI journalist who covered the 15 year Lebanese civil war besides covering wars in 
Afghanistan and Iraq (Abu Fadil 2007). War coverage is not new to Lebanese women. What is new, is them becoming on par with men when it comes to that coverage.

Women journalists even played a role in covering the Islamist clashes that have been raging across Lebanon. A female respondent mentioned covering the recent 2015 clashes in the border town of Arsal, where members of ISIL (Islamic State of Iraq and the Levant) and Jabhat Al Nusra or Al Nusra Front (literally meaning The Victorious Frontan Islamist group strongly allied with Al Qaeda) take base. A female respondent mentioned that female reporters were sent to cover the Naher El Bared area clashes in Northern Lebanon between the Lebanese army and Fateh Al Islam (literally translated as Conquest of Islam - a Sunni jihadist group strongly allied with Al Qaeda) in 2007.

The elimination of the role of gender from discrimination in news assignments does not mean that gender has no role to play. Gender still plays a role in terms of mere preference. Sending women to areas controlled by Islamists may be a cause of concern (4 Females). These are not simply war-ridden areas; they are hostile to women, in particular. There is the fear of harassment and abuse. Preference, in this case, is for men. Lebanese television administrations take into consideration actual ground situations before dispatching a man or a woman reporter for the job. Findings have shown that experience is a highly valued factor in the decision making process. The more experienced the journalist, whether a man or a woman, the better. Another form of preference comes in the coverage of social news. Few respondents (3Females, 1 Male) who emphasized that women cover all types of news, mentioned that women may be more sympathetic when it comes to social issues or abuse stories (1Female). Women's 
intrinsic feminine feel is invoked as they are deemed better at recounting topics that require empathy and a certain degree of human proximity.

Despite these concerns, coverage in the Lebanese television newsroom is mainly conditioned by efficiency and not by gender. The type of coverage assigned to journalists depends on their experience, potential, preference, courage, inquisitiveness, endurance and love for the job. Women broke the barriers that made political news and war reporting a male bastion. As previously mentioned, the opportunity to prove themselves has been enabled by the security situation in Lebanon and the region and the change in the newsroom structure, add to that women's competence and the breaking down of the socio-cultural barriers that stood in their way.

\subsubsection{Age for Men and Women Journalists}

The near parity that women established with men journalists when it comes to coverage in the Lebanese television newsroom, only occasionally applies to age. The line of work that journalists do in the newsroom is what affects their age limit. The limit is different for journalists that work in front of the camera and those who work behind it. For journalists that work in front of the camera, the age also differs between men and women journalists. Women, therefore, experience a glass ceiling that is different from that of men when it comes to age. Age limitations seem to be culturally bound in a society that places much preference on appearance and looks.

Journalists behind the camera can work as long as they are capable and productive (respondents 8 Females, 2 Males). In this case, it is not about the age but about aging (F, Personal Com., 2014). Journalists working as editors and writers retain their positions provided they are able to think and write. Handling the stress of the news jobs is also a 
requirement. This category of journalists, both male and female, can go well into their 60s (2 Females \& 1 Male).

While age is not problematic for journalists working behind the camera, it is a pertinent issue for journalists in front of the camera. Journalists going on the air should be physically acceptable and should satisfy viewer expectations. News anchors and reporters can retain their jobs as long as their looks permit (7 Females, 1 Male). This translates to: In Lebanon, younger is better (4 Females) and when news anchors age, "their airtime becomes limited" (F, Personal Com., 2014). In fact, almost all Lebanese news anchors on television today are quite young; very few are in their 50s. In the past few years, television stations like LBCI, MTV and Tele Liban overhauled part of their news teams. The trend, which was primarily started by MTV, involved bringing younger and fresher faces to the news and getting rid of the older ones. This extreme preference for youth has been worrisome especially since it also translates differently for men than it does for women.

Aging on the camera is not equally applicable to men and women. The findings of this study concur with the existing literature which has shown that women's careers on the camera do not last as long as those of men and there is a clear preference for younger women (Franks, 2013; Gallagher, 2005; Chambers, Steiner \& Fleming, 2004; Bhagat, 2002). The age bracket for men is higher than it is for women ( 9 Females, \& 3Males). When respondents were asked to give an approximate age for news anchoring, their answers showed that men's career may outlive that of women by around 10 years: 
Table 10

Age Range for Female News Anchors

\begin{tabular}{ll}
\hline Number of respondents & Age range \\
\hline 9 respondents & $40 \mathrm{~s}$ \\
12 respondents & $50 \mathrm{~s}$ \\
2 respondents & $60 \mathrm{~s}$ \\
4 respondents & All about the looks \\
\hline
\end{tabular}

Table 11

Age Range for Male News Anchors

\begin{tabular}{ll}
\hline Number of respondents & Age range \\
\hline 2 respondents & $40 \mathrm{~s}$ \\
13 respondents & $50 \mathrm{~s}$ \\
6 respondents & $60 \mathrm{~s}$ \\
4 respondents & All about the looks \\
\hline
\end{tabular}

While a considerable amount of respondents ( 9 in number) believed women's on-camera career should end in her 40s, few respondents ( 2 in number) said that of men's career. The 50s seem to be the average agreed-upon age for both men and women. When it comes to the $60 \mathrm{~s}$, few respondents ( 2 in number) believed women could retain their oncamera careers, but three times (6 respondents) the amount of respondents believed men could.

"A man going on the air with white hair is stylish but a woman with white hair is wrinkled," said Respondent 14 whose comment describes the current reality that women news anchors deal with. The fear of aging and associating women's on-air competence with their appearance rather than their skill led to a somewhat unhealthy focus on looks. Plastic surgery and Botox have helped women stay on the air, even as they age (2 Females, 2 Males). A quick look at Lebanese television female news anchors shows that plastic surgery is rampant even among the younger anchors - plumped up lips, tattooed 
eye brows and lifted cheeks seem to be a common undertaking. To qualify as a news anchor, the female journalists should be a "top model" or "beauty queen" (F, Personal Com., 2014). This concurs with Kraidy (2000) and Sakr's (2007) assertion that women on Lebanese television should be young, beautiful and attractive. Such requirements drive younger women to non-surgical and surgical procedures that make them qualify for the screen. "It is all about appearance for easterners," said a female respondent who refused to specify an age limit, implying that women should step down when they feel that they look old on the screen - and old may come as early as the age of 35 .

The trend for the young and attractive news anchor appeared to be a cause of indignation to many in the field. The preference for the young meant a devaluation of experience as well as an unending struggle to fight the passage of time. "I am 27 and I feel there are many that are younger than me," said the female respondent. "I fear this topic, to be honest," confessed the 30 year old female respondent, "I feel there is an expiry date when it comes to this profession unlike abroad." The comparison with other television stations where news anchors were retained till an older age caused even more dissatisfaction and a feeling of inequality. Examples were given of news anchors on $\mathrm{Al}$ Jazeera, CNN, White House correspondent Helen Thomas, Christine Ockrent from France, BBC journalists, TF1, French and US channels. Seriousness, trust and credibility which come with experience (4 Females) have fallen prey to the trend of youth and age restriction imposed by Lebanese television. Young news anchors are not as skilled in the field and some lack substance. Interestingly, a female respondent, who disagrees with the trend for young anchors, thought MTV has done a good job at combining good looks while presenting a quality news cast. 


\subsubsection{Appearance for Men and Women Journalists}

Closely tied to age is the appearance of men and women on the Lebanese television screens. Similar to age, appearance in relation to dress code, make-up and hair, is different for men and women. While appearance seems to matter more when it comes to women, it is important for both and it is closely tied to the television station. On Lebanese television screens, the appearance of female news anchors hits both extremes; it ranges from highly traditional to scantily clad.

Television is about image and the news anchors are bearers of the image. As such, the appearance of the news anchor affects and is a direct reflection of the image that the television wishes to convey. All respondents emphasized the importance of appearance for male and female anchors, but ten respondents (7 Females, 3 Males) believed that appearance mattered more for females than it did for males. Respondents agreed that news anchors and reporters should have an acceptable dress code; they have to be tidy, well-dressed and well-groomed (7 Females). They should dress up formally in soft neutral colors, and they should be mindful of the news reporting context. Dressing up for an assignment in the parliament differs from dressing up to a street protest.

The common standards for journalists' dress codes do not apply to Al Manar, which follows the dictates of religion in that regard. Al Manar female anchors wear the hijab (head cover) and put only foundation without additional make-up. "We cannot wear lipstick or any other type of makeup given that we are religious," said the female respondent. Women are not allowed to wear anything that brings out their beauty and have to restrict themselves to the neutral classical colors of grey, brown and olive. Men 
wear jackets and formal shirts without a tie. In general, they have an unshaven look but not beards as this complies with the religious grooming requirements.

While Al Manar has a standardized dress code for both male and female anchors, this is not the case in other television stations. The way that men and women appear on the screens and the dress code they choose to adopt shows a preference for the traditional look for men and a non-traditional daring look for women. Contingent upon the trend for attractive, young and beautiful female news anchors, this unconventional presentation method does not come as a surprise. But it is a source of dissatisfaction for many in the profession (11 Females, 4 Males). Lebanese female news anchors wear short tight dresses, sleeveless shirts and show cleavage; their hair is buffed up instead of being neatly tied back (F, Personal Com., 2014). The overemphasis on attractiveness and appearance makes the newscast a fashion show (F, Personal Com., 2014) and the female news anchors fashion models (4 Females, 1 Male). Female news anchors should be more decent, a female respondent remarked as she asserted that "they are not going on the air to feature their dresses or their bodies or even their hair... All this excessive makeup and inappropriate clothing should not happen.” Dima Sadek, the LBCI news anchor, for instance, is being called a fashionista (F, Personal Com., 2014). While the respondent finds that allowing the expression of individuality is important for female news anchors, she is against them pushing the limits. The issue becomes more compounded as the camera takes in the full body of a female news anchor at the beginning of the newscast and throughout the weather forecast ( 2 Females, 1 Male) thereby making the news into an actual fashion show. This exaggeration in appearance led to television stations competing over which of them can have the sexiest news anchor on the air (F, Personal Com., 2014). 
This trend was started by MTV and followed by other television stations (1 Female, 1 Male). It is less visible in Al Jadeed (F, Personal Com., 2014) despite the fact that the station overhauled its newsroom etiquette and has of late begun also to feature a full body shot of its female news anchors at the beginning of the newscast.

Interestingly, objections on overemphasizing appearance come from newsroom workers who seem to be part of the phenomenon taking place in their television stations. This makes the trend even more intriguing as news workers' lack of outright objection could be an implicit approval. In effect, the existence of this trend can only be explained in terms of market demand. As commercial stations, Lebanese televisions vie for higher audience ratings and profits. Major audience ratings usually come from Gulf countries that are, in general, more stringent when it comes to their own communities and their television stations. Lebanese televisions, therefore, use their anchors to attract viewers in nearby countries (1 Female, 1 Male). This concurs with the findings in the literature as Kraidy (2000) and Sakr (2007) confirm that women on Lebanese television are used a marketing tool to the nearby Gulf States. After all, the way that women or men appear on television is a result of directives from that television's administration (1 Female, 1 Male) and the administration looks out for the financial wellbeing of the television.

While the literature does not explore other reasons behind the trend for young and attractive women, findings of this study revealed that the trend is, in effect, socially and culturally entrenched. Having an alluring young attractive female is part of the long held Eastern tradition and it has always been part of the Lebanese society. In the East, women have been traditionally and historically tied to magic, charm and beauty (M, Personal Com., 2014). Respondents (4 Females) translated this by saying, in one way or the other, 
"this is the way our society is." Beautiful women are a requirement in our society (3 Females). Such a requirement becomes even more accentuated in a male-centric patriarchal society (F, Personal Com., 2014). Though expressed by only four respondents, the reasons hold true. Lebanon has always prided itself on its openness and especially when it comes to women. It has never shied away from revealing that on television and, at times, to an exaggerated extent. This is what differentiates Lebanon from the countries in the region. Add to that, urban women in the Lebanese society emphasize looks and appearances; they have been known to set and follow fashion trends. Television reflects these aspects of society. The newsroom may not be the right venue for such reflections, but the news remains one of the programs with the highest ratings and it is, therefore, the right avenue for the attraction of an increased audience.

The emphasis on women's appearance takes the attention away from men because women have a liberal dress code whereas men are confined to wearing a suit and a tie. Nonetheless, a quick look at male television news anchors reveals that most of them are fairly young and attractive. Just like their female counterparts, men also have to take care of their looks (F, Personal Com., 2014). In fact, while viewers may indulge a beautiful female news anchor even if she were not intelligent, they would not watch a male news anchor, who is not good at what he does, one female and one male respondent asserted. The respondents believe then that the conditions become harsher for the male news anchors than they are for the female. This could also be prompted by the fact that women outnumber men in the Lebanese television newsroom. 


\subsection{Glass Ceiling: Management, Recognition and Progression}

The presence of women in large numbers in the Lebanese television newsrooms is not surprising given that women comprise the majority of journalism and communication students (Melki, 2009; Obeidat, 2002). This increased presence in the media automatically affects its environment and its content (Dabbous-Sensenig, 2000; Obeidat, 2002; Sakr, 2004). It even goes beyond that to alter the landscape of public communication as Sakr (2004) argues "if the mass media form part of the apparatus through which particular gender roles and attributes are defined and assigned, it follows that the media will also be a site for negotiating changes in those definitions" (p.4). It is not within the scope of this study to investigate the connection between media and the changing gender environment in Lebanon, but, in concurrence with Sakr's statement, previous literature has suggested that women's access to management positions in media influences how women conduct themselves and the news content (Robison, 2005; Barber \& Ruahala, 2008; Ross, 2007; Craft \& Wanta, 2004; Rodgers \& Thorson, 2003; De Bruin \& Ross, 2004), besides affecting women's employment opportunities (Skalli, 2006). Women's position in the management of Lebanese media organizations is, therefore, pertinent, both on the conceptual and practical levels.

Fortunately, women in Lebanese media appear to be taking forward strides when it comes to media management opportunities. While studies on Lebanese media show that the overwhelming presence of women in media is not paralleled by an equal representation in top management or decision making positions (Internews, 2009; Dabbous-Sensenig, 2000), these studies tend to ignore the historical advancement that women have done in that regard. After all, one cannot climb the corporate ladder in one 
step. In a study conducted on Lebanese media in 2000, Dabbous-Sensenig mentioned that women get only $18 \%$ of the top ranking positions. Eleven years later, Byerly (2011) writing the Global Report on the Status of Women in the News Media, surveys 2 television stations, 2 newspapers and 3 radio stations to uncover that women occupy $35.7 \%$ of middle management, $28.6 \%$ of senior management, $21.9 \%$ of top level management positions. There is thus a forward improvement into management positions, to say the least. Even in countries with better gender equality, women are underrepresented in upper management (Strong, 2011; Ross \& Carter, 2011; Barber \& Ruahala, 2005; Robinson, 2005; De Bruin \& Ross, 2004; Rush, 2004; Mahtani, 2005; Meehan \& Riordan, 2002; Byerly \& Ross, 2004; Byerly \& Ross, 2006; Creedon \& Cramer, 2007; Bollinger \& O’Neill, 2008). In Lebanon, this study shows that the forward strides that women have been doing are quite visible in the Lebanese television newsroom where women are gaining more grounds in middle and senior management. The findings also show that gender discrimination in pay is practically non-existent and when it comes to career advancement, it does not pose a major hindrance.

\subsubsection{Women in Newsroom Positions and Management}

Women form the majority of the Lebanese television newsroom personnel $(5,6$, $7,13,21,23$ ). As news journalists, they may even reach up to $100 \%$ in some television stations (Dabbous-Sensenig, 2000). They are also capable of occupying almost all positions in the newsroom (all respondents). Women can be writers, video editors, producers, anchors, graphics, illustrators, directors and reporters. Findings of this study show that women have the upper hand in the Lebanese newsroom. In terms of 
occupational status, women have established parity with or superiority to men at the junior and senior professional levels and also in middle and senior management.

To define newsroom positions, the study, as mentioned in the research methodology chapter, uses the newsroom occupational levels proposed by Byerly (2011) with minor modifications to cater to the specificities of the Lebanese television newsroom.

An informal recount of the roles in some of the Lebanese television newsrooms, uncovered through the interviews with the respondents, shows that women are available in all departments except for the camera operations, which are mainly occupied by men. The findings of this study concur with the findings of Byerly (2011) who found that men monopolize the technical functions in the news organization (100\%). Camera and consequently lightning operators are almost all men. Out of all the Lebanese television stations, only MTV has a camera woman and she generally films inside and not outside the studio.

Yet when it comes to the production and design positions, the findings somewhat diverge. Byerly (2011) found that men occupy $67.1 \%$ of all production and design positions which include graphics designers, photographers, illustrators, wardrobe designers and others in the creative roles of news production. This study investigated the graphics department which includes the illustrators. Wardrobe designers do not exist in Lebanese television newsrooms and photographers are part of the camera team. Findings show that when it comes to the production and design positions, the Lebanese television newsroom comprises an equitable space for women. In LBCI, for instance, the graphics department is populated mostly by women with 9 females and one male. In MTV, there 
are two females and two males in the graphics departments. In Future TV, there are 3 males and 2 females. The difference in the findings between this study and that of Byerly's may be attributed to the fact that this study deals solely with the television newsroom while Byerly's (2011) study includes radio and print media. This study shows that women are, in fact, equally, if not more present than men in the production and design departments.

At the junior and senior professional levels, women's presence is substantial and exceeds that of men. The fact that women are a majority in the newsroom helps explain why they occupy the main professional positions which include those of reporters, anchors, producers, directors, editors and writers. In both OTV and LBCI, for instance, there were no male producers but only 4 female producers; In NBN there were two male and two female producers. When it comes to anchoring and reporting, the number of females is considerably higher than that of males. At the time of the study, in LBCI, there were 5 female and 3 male news anchors; In NBN, there were only 12 female and no male news anchors; in Future TV, there were 7 female and 5 male news anchors. The numbers of female news anchors and reporters exceeded the number of male news anchors and reporters in all Lebanese television newsrooms.

Women have also proven themselves at the middle management level. As assistant editors-in-chief, bulletin and web editors, their numbers exceed those of males. In LBCI, for instance, both assistant editors-in-chief were female; MTV and Tele Lumiere had one female assistant editor in chief each. In OTV the positions were equally divided among men and women as there are 3 female and 3 male bulletin editors. Female journalists overtaking men in middle management editorial positions, is not reflected in 
the creative or graphic departments which are mostly handled by men, but are nevertheless mainly populated by women. Worth noting is that the graphics department often serves as the department for the whole television station and not only the newsroom. In Future Television (3Ms, 2Fs), LBCI (1M, 9Fs) and Tele Lumiere (1M, 1F), the graphics department directors are males.

In certain senior management positions, women in Lebanese television newsrooms have established near parity with men. Women have come to occupy main managerial positions including editor in chief, head of news, and head of operations. At the time of the study, women editors-in-chief were almost equal to men in most of the Lebanese television newsrooms (Appendix B).

This shows that women are capable and are in fact reaching senior management positions faring relatively better than women journalists in New Zealand who are almost invisible at the top editorial levels (Strong, 2011) and in British and Irish media where their inclusion as news producers, news subjects and news makers is still significantly lower than men (Ross \& Carter, 2011). Yet, still in Lebanon, this near parity was not established across all senior management levels. Most Lebanese television stations namely NBN, LBCI, MTV, Future TV, Al Manar and OTV have a male as a head of news. This does not mean that women cannot vie for that position considering their major strides in management, especially since the heads of news for Tele Lumiere and Al Jadeed are women. Add to that, the current heads of operations in LBCI and in OTV are females and so is the head of programming at Tele Lumiere and the head of web news operations at Future Television. 
The above conclusions were reached thanks to the input of the respondents interviewed for the study. Uncovering detailed numbers of positions in the newsroom was not the original intention of this study but they were uncovered a result of inquiring whether management opportunities were available to women. The significant presence of women in middle and senior management positions means that women are somewhat involved in the formation of station policy and are even more involved in managerial decisions. This offers women an environment that is conducive to progress. In effect, the Lebanese television newsroom seems to provide the equitable environment that women lack in other forms of Lebanese media, as seen in Byerly's (2011) and DabbousSensenig's (2000) studies. It provides equal chances for both men and women to reach management positions ( 23 respondents). The environment is non-discriminatory and fairly supportive:

I don't feel there is a difference between the man and woman in the media field. Perhaps in other positions in different companies/fields yes but in the media field no. I repeat that the woman is stronger than the man in the media. (F, Personal Com., 2014)

Respondents' assertiveness in emphasizing women's climb to the top ranks is visible through the examples of the highly accomplished women in Lebanese television today. LBCI's head of news operations, head of web presence, and head of programming are all women (F, Personal Com., 2014), OTV's editor in chief (F, Personal Com., 2014), head of producers, head of operations and human resource manager are all woman (respondent 14), Tele Liban's Assistant head of news and head of journalists' union as well as two editors-in-chief are women (M, Personal Com., 2014), Future TV's head of programming, head of IT, and head of marketing departments are also women (M, 
Personal Com., 2014); women managers are assigned to all Tele Lumiere affiliates namely Nour al Sharq, Noursat, and Nour al Shabab (F, Personal Com., 2014).

Perhaps Al Jadeed presents itself as an ideal example of women's presence in all the occupational levels in the newsroom. Most of Al Jadeed's management positions are filled by women. "Only at our television station," and nowhere else in Lebanon are women well represented in management, asserted Respondent 12 from Al Jadeed. The station's deputy director/vice chairperson (top management) and head of news (senior management) are both women. Most of its producers and executive producers are also women (senior level professionals).

The well-established presence of women in high ranking positions makes them instrumental in managerial and day to day on the ground decisions. While the top management positions may be run by men, such as the CEO of Tele Lumiere or Chairperson of Al Jadeed, it is, in fact, women who take most of the crucial decisions (1 Male, 1Female). This view (shared by 19 respondents) proves to be somewhat controversial as very few respondents found that women can also be seen as executing tools in a media system run by men ( 8 respondents). Women's majority presence does not match their decision taking power:

We need more women in management levels... it is always that a male has to take the decision. This applies to all television stations including MTV. Take for example NewTV and Mariam Al Bassam who is the editor-in-chief. When she has to take a decisive decision in something, it is done by Tahsin Khayat, the owner of the station and not her. At LBC for example it is Pierre Al Daher that takes this decision and not Lara Fadel for example... I feel that in every television channel there is a male who is the ultimate decision maker. (F, Personal Com., 2014)

Women's presence in top level management in Lebanese television stations is minimal as most televisions are run by male executives. In the case of New TV, the female vice 
chairperson, though highly qualified, is, in fact, the daughter of the owner, Tahseen Khayat. Respondents cited a number of social and organizational factors that prevent women from reaching top ranking positions. These factors include patriarchy (F, Personal Com., 2014), culture (2 Females), organizational chaos (F, Personal Com., 2014), lack of trust of women in leadership positions (F, Personal Com., 2014) and forming political relations (F, Personal Com., 2014).

Undoubtedly women have come a long way and in many ways they are the rulers of the internal workings of the newsroom. If anything, findings of this study have shown that women are quiet influential in the decision making process and have established near parity with men at the middle and senior management levels. Most operational decisions do not require top management intrusion or approval; as a majority in middle and senior management, women are the ones who take these influential decisions. Their access to senior management also gives them a say in policy; the extent of their influence in that area remains to be seen. What is not to be forgotten is that women's access to the upper echelons of media in Lebanon is tightly knit to politics. After all, most Lebanese television are owned or affiliated to political parties whose representatives occupy government positions. Unfortunately, women's presence in decision making positions in both Lebanese political parties and the government is minimal. Although Lebanese women earned the right to vote in 1953 only 17 women have served as parliamentary members since then (Khoury, 2013). Many gained their seats through political familism, a practice whereby women inherit the seat upon the death of a male family member such as father or husband. To be able to occupy top management positions, women, therefore need to penetrate political parties lines; they need to become actively involved in the 
Lebanese political scene since the patrons of that scene determine media policy, guidelines and executives. So far, women seem to have fared much better in the Lebanese television newsroom than they have in politics. Perhaps this media access to the political work will be a door opener to a wider participation in the Lebanese political scene.

\subsubsection{Parity in Insufficient Pay}

Female journalists may not have established full parity in newsroom positions, but they have established parity with men in pay. The terms for employment of female journalists (salary and benefits) in the Lebanese television newsroom equate with those of males. This updates Abu Fadil's (2001) findings that women face a glass ceiling syndrome in advancement and pay. In fact, female journalists in Lebanon fare better than their counterparts in Canada and US (Rush, Oukrop, \& Creedon, 2004; Bollinger \& O'Neill, 2008) and in countries in the European Union, former Soviet Union and Central and South America (Global Wage Indicator, 2012) where studies revealed the presence of a gender pay gap.

Pay in the Lebanese television newsroom is not conditioned by gender (all respondents). Financially, men and women are equally recognized across all positions in the Lebanese television newsroom, a finding that concurs with Byerly (2011) who uncovered that, men and women in Lebanese media enjoy equal compensation at most occupational levels. The difference in pay results from factors such as experience, qualifications, seniority or connections. It may even be related to the financing that the television station has (respondent 3).

The pay may be equal to men and women journalists, but it is not sufficient. "You don't make what you deserve," said a female respondent, a view that was shared by most 
respondents (25 respondents). In the field of media, salaries are low and do not equate with the work done. Lebanese journalists lament the fact that Gulf televisions are better financed (M, Personal Com., 2014) and offer better salaries (F, Personal Com., 2014). Many, especially men who are the main breadwinners in the family, have resorted to taking on other jobs such as teaching to supplement their incomes (1 Female, 2 Males). Al Manar, OTV, NBN, Tele Lumiere and Tele Liban respondents felt that their salaries were lower than other television stations.

The parity in pay becomes a questionable issue especially when men are a minority in the newsroom. It invites us to question whether work in the newsroom has become feminized, making low pay a natural consequence in a professional milieu mostly inhabited by women. This may have been true were it not for two main observations, the first concerns the economic situation in Lebanon and the second relates to the existence and non-existence of gender pay gaps. As previously mentioned, Lebanon's current minimum wage rests at around US $\$ 450$ and its economy has been hit hard by nearby regional conflict and the large influx of Syrian refugees. Lebanon's media, like other businesses, has been suffering from this economic situation. Second, while a study conducted on two banks by Hejase et al. (2015) showed the existence of a gender pay gap which was also detected by Dah, Abosedra and Dahbora (2014) in their study on a random sample of more 17,000 households, Jamali, Sidani and Kobeissi (2008) showed that the gender gap was only salient in the higher education sector but not in banking or nursing. The authors asserted that the inequity and discrimination at work are alleviated by a fair and equitable compensation scheme. The studies seem to contradict each other, but they shed light on the fact that the gender pay gap in Lebanon 
is controversial and is conditioned by the organization. This leads us to the conclusion that the low pay in Lebanese television is a result of the tough economic situation the country is going through and the non-existence of a gender pay gap is not unique to the newsroom; it does exist in other Lebanese organizations. In this case, the newsroom is not feminized but equitable. Men end up leaving the newsroom because of the financial burdens they have to bear. Men, in Arab culture, in general, are considered the primary breadwinners of the family whereas women's income is considered supplementary (Eid, 2013).This forces men and women as well, to look for better prospects in the media field outside Lebanon. Yet attachment issues, belonging to a conservative milieu and being supplementary income makers may be factors which drive women's preference to stay in the field of media. And this stay has served them well.

\subsubsection{Impediments to Women's Advancement}

Female journalists have proven themselves in the Lebanese television newsroom. The newsroom appears to offer women a space that is more equitable than other media in terms of career, management and advancement opportunities. Yet despite their accomplishments and qualifications, women's career in the newsroom generally plateaus at middle or senior management. Women still face cultural, organizational and personal challenges that impede or decelerate their progress towards higher positions and at times compromise their longevity in the profession.

Socio-cultural variables play an instrumental role in influencing women's career choices and everyday work experience. Lebanese culture places much value on a woman's role as a mother and a primary care-giver for the family. Women bear the bulk of the responsibility at home ( 5 Females, 1 Male) without receiving much help from their 
male partners (2 Females). In prioritizing family, women settle for the job prospects they have or abandon the career (2 Females). Though Strong (2011) believes that there are deeper reasons than child rearing and family behind women's abandonment of their careers, family responsibilities was the reason most cited by respondents of this study. Very few women journalists are happily married; most are single or separated, asserted a female respondent in senior management. Effectively juggling work and family responsibilities and having a supportive partner are crucial for the success of the female journalists (2 Females). Lebanon, after all, remains a patriarchal society. "Tradition, patriarchy and culture are generally expected to exert less weight against the forces of education and modernization," (Sidani, Jamali, \& Saffieddine, 2005), but such cultural constraints differ by region and religion. In traditional patriarchal societies, it is hard to accept women in positions of power (4 Females). Female journalists also get scrutinized for relations with businessmen and politicians, although this is part of the job requirements (respondents 3,14 ) and they may be looked down at by males while covering a story (respondent 11). As previously mentioned, this may be largely dependent on the area of the coverage. The stereotypical attitude with which women are viewed as individuals in need of guardianship or monitoring does not help. This is even detected when women are conveniently kept out of the camera operators department out of fear for their wellbeing, especially in the filming of hotspots (M, Personal Com., 2014) or coverage of risky places (F, Personal Com., 2014). Women are seen as weaker physically and emotionally (F, Personal Com., 2014).

Women's careers can also be affected by a number of organizational factors. As Sidani, Jamali and Saffiedine (2005) state, women still pose a higher employment risk 
than males as they allow their families to take precedence over their careers. Television administrations that invest in women and foresee them in higher careers become disappointed by their lack of readiness to advance (F, Personal Com., 2014). In an interview with a news director at a Lebanese news organization, Melki and Mallat (2014) uncovered the same finding. While women's advancement to senior positions is an extension of the patriarchal society in Lebanon, women also seem to compound the imbalance when they voluntarily choose not to advance to senior management to devote more time to the family.

Yet organizations also falter in their support of women journalists. Pregnancy is not exactly welcome in such a career (F, Personal Com., 2014). More importantly, television stations do not offer childcare services in a facility within or next to the television station (2 Females, 1 Male).

While the above impediments may be grouped under the lack of gender sensitive policy which scholars reference (Dabbous-Sensenig, 2000), religion has not been discussed as an organizational obstacle. This is perhaps unique only to Lebanon. As a government organization, Tele Liban follows the politico-sectarian division applied by the government for upper management positions. Tele Liban's head of news should be Muslim Sunni and its editor-in-chief, a Christian. A female respondent asserted that as a Christian, she cannot even hope to fill the head of news position despite her expertise and qualifications. In Al Manar, for instance, religion is tied to the identity of the television and the hiring of anchors is conditioned by their religious commitment which includes women wearing the head cover. This same commitment may be an obstacle to getting hired in other television stations: 
At Al Manar TV this is a helping catalyst. Being religious helps us advance at $\mathrm{Al}$ Manar TV. But at another station, of course they won't let a woman with a hijab anchor the news at a television station that is not religious. For me, other television stations and opportunities in them is a closed door for my career

In both cases, religion becomes part of the organizational structuring of television station, effectively functioning as a discriminatory factor for both men and women.

Closely related to organizational policy or the lack-thereof is the issue of harassment. Like the majority of Lebanese news organizations, the Lebanese television stations do not have a policy on sexual harassment (Byerly, 2011). In fact, no such policy exists in the Lebanese lawThe Lebanese penal code only grants victims the right to resign without providing a notice (Gatten, 2012). Interestingly out of the 27 respondents interviewed, only one (respondent 11) discussed the issue of harassment detailing forms of physical and verbal harassment by men on the field, by male colleagues and by male politicians. The lack of attention that the issue of sexual harassment received is intriguing and can be mainly attributed to cultural factors instituting it both as a taboo and acceptable behavior. While outright physical and verbal harassment is condemned, its materialization in more subtle forms is acceptable and welcome. Culturally, verbal sexual innuendos, jokes or advances are not seen harmful as long as they remain within acceptable cultural limits. These forms of mild flirtatious behavior are not even incriminated by the US law, as revealed in the literature. In fact, in Lebanon, they are not even seen as harassment, a finding that coincides with the study done by Hejase (2015b) which showed that staring and sexual jokes were not considered offensive. Developing laws for sexual harassment would set standard stipulations thereby giving journalists the chance to judge competently where cultural allowances end and legal action begins. The 
lack of organizational policy and legal codes on harassment is matched by a lack of advancement criteria.

Interestingly, none of the respondents mentioned the lack of standardized organizational merit criteria as a hindrance to advancement. The absence of organizational structures, organizational policies, job descriptions and regular job appraisals is not an anomaly in the Lebanese televisions (Internews, 2009). Respondents' neglect of the role of the organization in advancing or hindering the advancement of its employees comes either as a result of their awareness of the organizational lack or a blinding habituation that does not allow them to see the lack as an irregularity. Scholars amazed by the lack of gender-specific policies in Lebanese media organizations should reconsider. Lebanese media organizations need to formulate an overall organizational policy before thinking of gendered-specific stipulations.

A final impediment that respondents mention is comprised of a personal choice not to advance. While the other impediments fall outside of women's control, this one is totally within their hands. Women who have equal chances at advancement may choose not to progress in their career for a number of reasons including unwillingness to take on more or different forms of responsibility (F, Personal Com., 2014), being satisfied with their current position (F, Personal Com., 2014), and prioritizing family (2 Females). In her work on Canadian television, Robinson (2005) found that women are much more hesitant than their male colleagues to accept promotions into upper management positions. This could perhaps be the case for Lebanese women journalists. Yet instead of linking this hesitation to systemic biases in the newsroom, women choosing not to 
progress may be simply due to their satisfaction with what they are doing as respondent 2 stated.

The socio-cultural and organizational impediments that hinder women's progression have not kept them from reaching decision making positions within the newsroom. Over half of the male respondents (and one female respondent) who have seen an increase in the numbers of women in all newsroom positions and in women's access to management find there are no female specific obstacles (2Females, 1 Male). The Lebanese television newsroom may be less kind to men as women have easier access to employment in the field thanks to their looks, which have become a requirement in today's newsroom (2 Males). Yet that last view was expressed solely by males who seem to feel the underprivilege of having a minority presence in a newsroom that was once mostly male inhabited.

\subsubsection{Compromise and Advancement}

Compromise for the sake of advancement exists in all professions, including those of the media. All forms of compromise put at risk the integrity of the journalistic profession. Though altering a news story or presenting it from a different perspective is not as grave as offering sexual favors, both qualify as compromises. In fact, these are the two common types of compromises cited by Lebanese television newsroom respondents, although most respondents for this study denied having done any compromises themselves.

Compromises that include producing news stories that fall in line with the television station's editorial policy(4 Females, 1 Male) or receiving money/gifts to air a story (2 Females, 2 Males) were not discussed as much as sexual compromises 
(11Females, 2 Males) . Whereas the first two were considered gender-neutral, sexual compromises concerned mainly female journalists. Though respondents did not directly label the forms of sexual compromise, it was deduced from their answers that sexual compromise generally ranged from providing sexual favors to mere sexual advances or subtle forms of sexual advances. Female journalists who offer sexual favors advance faster in the field but may not guarantee continuity ( 7 Females). Considering that the media field in Lebanon is small, these journalists become well known within its small circles. Respondents mentioned hearing rumors of sexual favors, but refused to provide details or confirm the rumors:

What you hear is that a person reached to a certain position because she did so and so, but the question is did you see her in the act? ...I don't deny or confirm these things but I say there is no smoke without fire. Maybe it is happening. (F, Personal Com., 2014)

In their discussion of sexual advances, respondents implied that such advances can happen within the television station or outside it. When sexual advances happen outside the television station, they are mainly initiated by politicians. In this case, the onus of responsibility falls on the female journalists who should know or decide how to deal with such advances (8 Females, 2 Males). They either open the door to further sexual interaction or put a limit it to it. Female journalists have to tactically reject the advancement not to jeopardize their relations with the politicians, who are considered a prime source of news (F, Personal Com., 2014). Avoiding advancement or situations that make such advancements possible is also another tactic (F, Personal Com., 2014).

Sexual advancement is part of the hazards of the journalistic profession (Byerly \& Ross, 2006; North, 2007; Ross, 2010). Though some place the responsibility for inviting (2 Females) or limiting such sexual advances on women, doubtless the organizational, 
legal and socio-culture environment plays a role in putting a limit or allowing such advances. Many respondents emphasized that sexual behavior is not tolerated in the newsroom. Having females in senior management in television stations like OTV, LBCI and New TV helps put a limit on such behaviour. In the more conservative stations like Al Manar, NBN and Tele Lumiere, the organizational culture stands firm against promiscuous sexual conduct. Yet, as discussed earlier and in the literature review, organizations do not have policies on harassment nor does the Lebanese law. The lack of legal and organizational stipulations does not encourage women to speak out in case they felt harassed. Out of the 18 female respondents, only one mentioned leaving her previous job due to harassment. Doubtless, many others like her exist in the profession.

\subsection{Newsroom Interaction: A Site for Negotiation}

The increasing number of women in the news room influences the news content and the news environment. Once women reach a critical mass, they affect the news agenda (Craft \& Wanta, 2004) and the news values (Van Zoonen, 1998) besides challenging the news room culture and the masculine journalistic norms (Chambers, Steiner and Fleming, 2004). A female majority in the newsroom, then, is more than likely to cause changes to the very nature of the newsroom and re-condition the gendered forms of interaction. The newsroom becomes a site where new forms of gender interaction are negotiated and re-structured to fit the critical changes in its male-female division.

Undoubtedly, culture plays a major role in this interaction but even culture may be negotiated within a microcosm where gendered interaction may be different from what it is in society. This assertion was inspired by a story shared by a female respondent who mentioned that a female reporter or anchor coming from a very rural area in Lebanon 
where women do not enjoy the equal treatment that they have in Lebanese urban areas would be integrated into and become accustomed to a new form of more equitable gender interaction conditioned by the newsroom. Another female respondent also asserted that the newsroom provides a more relaxed environment for gender interaction especially since she comes from a conservative religious community.

\subsubsection{New Boys' and Girls' Club}

The Lebanese television newsroom is not an "Old Boys' Club." This characteristic title used by scholars (Franks, 2013; Robinson, 2004; Chambers, Steiner \& Fleming, 2004; Melin-Higgins, 2004) to describe the Western newsroom does not seem to apply to the television newsroom in Lebanon. The competition over prestigious news topics, the sexist banter and the after-work pub hours, which characterize the Old Boys' Club, have been somewhat re-defined.

That is, not to say, that the harsh competitive atmosphere, over prestigious news topics, no longer characterizes the newsroom, but it is characteristic of men as much as it is characteristic of women. As for the sexist banter, the existence of women in large numbers and in high ranking positions as well as the television's organizational culture have limited it. The after-work socializing or pub hours have become a mixed endeavor and not a boast of "total availability" (Robinson, 2004) or a formation of after-hours cliques.

The Lebanese newsroom is populated by a female majority and a minimal presence of the male element (23 respondents). Al Jadeed, Tele Liban, Tele Lumiere, OTV, LBCI, and NBN respondents affirmed that the female element in the newsroom is overwhelmingly present and overwhelmingly dominant. At LBCI, women outnumber 
men, even in management (F, Personal Com., 2014). At Al Jadeed, the head of news and editor-in-chief, both females, take decisions on news agenda, type of news to cover, who to interview, and what to investigate. The female head of news at Tele Lumiere overhauled the newscast and changed the spirit of the news report to tackle more daring topics such as heresy and pedophilia. The fact that women form a majority of the reporters and are in near parity with men as editors-in-chief equalizes the competitive terrain over prestigious topics. The prestigious area of political journalism is no longer the realm of men. Women cover politics, wars, bombings, economics, and many other topics that were previously exclusive to male.

As for the sexist banter, it seems to be somewhat limited in the Lebanese television newsroom. At the more conservative stations like Al Manar, NBN and Tele Lumiere, such banter is neither permitted nor allowed. This goes in line with the organizational culture of the television station. At OTV, for instance, a female respondent asserted how the use of bad language, sexual jokes, or out-of-line banter is not permitted within the newsroom and if it does happen, they put limits:

It does not happen inside the newsroom at OTV. I don't even allow anyone to speak or communicate with anyone inside the station with terms or language that is sexual in nature. I follow my people on every word. Sometimes a joke passes but you cannot open the door to anyone because they all would want to. So from the beginning you have to set the boundaries that this is a newsroom and not a street. You want to curse, you can go curse outside the station. You want to talk sexual content you can do it outside the station. . I am not sure if the behaviour in the station would have been different if a man was in my shoes

A female respondent from Tele Liban mentioned that such jokes are not limited to men; women belonging to the younger generation joke as equally as men do. In Lebanon, mild sexual joking and sexual innuendo are cultural and permitted as long as they do not exceed the limits. 
The after-hours pub tradition where male ties are formed and decisions are informally assessed is not applicable to the Lebanese television newsroom. Culturally, the after-work pub tradition per se does not exist and culturally Lebanese drinking habits and rituals differ from those in the West. Not to digress, men and women from the Lebanese newsroom may socialize after work but when they do so, they do it together. There aren't exclusive male or female groups or predominantly male groups (3 Females, 1 Male). This is not to say that the formation of cliques does not happen in the newsroom; it does. The main difference is that in an environment that is predominantly female, the cliques are less female exclusive and more female inclusive.

Perhaps what distinguishes the Lebanese television newsroom is its friendly size.

What is applicable in Western newsrooms is not applicable to the newsroom in Lebanon.

"Our scale is limited and friendlier," asserted a female respondent:

We as institutions are amateurs compared to western counterparts. You are referring to huge institutions with 100s and even 1000s of employees and offices scattered all over. This is not the case here. Our scale is limited and friendlier when it comes to this issue. If you ask me about Al Arabiya and Al Jazeera, I would say definitely yes. It is classified as an old boys' club for sure. An institution like Al Arabiya it's a man's club and the women there are the beauties that get on the screen. Al Jazeera in Qatar for example, you cannot get into the station wearing a half sleeve shirt. There is not one woman in a leading position in Al Jazeera. Lebanon in this is definitely an exception

A male respondent in senior management compared NBN's newsroom to that of NBC in the US. He mentioned that men were more in control at NBC and the administration was more male-centric:

I feel that the difference between NBC and NBN for example, women have more leverage and justice than they would over there. At NBC's administration even if the woman had a larger leverage in the field, the man decides what she needs to cover and sets her work parameters. So in general at NBN we cannot call the newsroom an old boys club but at NBC we can 
Undoubtedly, women's presence in large numbers in the newsroom changes the nature of the newsroom interaction and if that the changes is not total, at least it is equitable. To one of the female respondents, the atmosphere is still masculine:

Even if it was a girls club, it is still a masculine atmosphere. I don't mean masculine by men. I mean you have to be harsh, firm, strong, have a strong personality that enables you to reach your objectives

Success at almost all jobs requires a strong, firm, personality. Such attributes are not solely male. Females who wish to succeed need to prove themselves and at times be competitive. As an environment, primarily populated and managed by women, the newsroom may still have "masculine attributes" but it no longer is an Old Boys Club, at least not in Lebanon.

\subsubsection{Culturally Bound Interaction}

As revealed in the literature review, women journalists use three adaptation strategies or tactics to maintain their positions or advance in a male dominated newsroom. The strategies according to Melin-Higgins (2004) are comprised of:

- women taking on the role ascribed to them by the dominant male culture

- women acting as one of the boys and infiltrating male areas of hard news

- women being one of the girls or feminizing the newsroom

The three strategies that apply to the male dominated newsroom may not be applicable to the Lebanese television newsroom which is mostly female dominated. As a majority in the newsroom, women have infiltrated the male areas of hard news; they cover political news, war, economics, and bombings. Women journalists, then, do not have to act as one of the boys to gain access to the area of hard news; logistically they are almost the only ones available to cover hard news since the percentage of women 
reporters exceeds that of men. In an environment populated more by women, women journalists may have to act like "one of the women" to succeed. One of the female respondents described an environment characterized by jealousy and competitiveness. Success would be in imitating the haircut, style or dress code of a female news anchor that had become successful. Women journalists, in this case, have many role models to look up to and to learn from.

In many ways, the majority presence of women journalists has made the newsroom more feminine; moreover, women's occupation of senior management positions as editors or operations managers have gotten male and female journalists used to the idea of having women in leadership positions. As Melin-Higgins (2004) mentioned feminizing the newsroom may entail resistance strategies including name calling to women, such as calling them unfeminine or aggressive. One respondent mentioned that women in leadership are strong women and those among them who are too strong, are generally not liked by men:

The presence of females in the newsroom is not only positive but it is also giving women more power because the women who are in key positions in the news or indulged in the news environment possess a very strong character. There are females with very tough characters that males do not like much. So that is why she would have more power and control. The male does not have a problem to be humiliated by another male but he has a problem being humiliated by a female if they were in an environment where all of them are present. (M, Personal Com., 2014)

Men do not like to be put down by women superiors, especially in the presence of colleagues that are mostly female. This feeling is only natural, given that historically men used to be in control of the newsroom and socially, the Lebanese society is still mostly traditional and patriarchal. In the newsroom, women function in an environment where they have the upper hand and this contrasts with what they face in society. As liberated as 
Lebanese women are and despite the many strides they have taken towards their near parity with men, they are still bound by the dictates of the patriarchal society and they still form the minority in senior management positions in most firms. The Lebanese television newsroom then is an interesting anomaly. Women in senior management are respected by both male and female colleagues ( 2 Females) and men and women journalists are generally dealt with in the same manner in the newsroom (7 Females, 4 Male). Yet gender differentiation is not absent from the newsroom. Interestingly one male and one female respondent mentioned that women may not be at ease giving direct orders to a male colleague and may do that in less direct ways but more often than not, they give out their orders and impose their presence through their character. Though most respondents asserted that women and men are dealt with in the same manner and are given orders in the same manner, men and women journalists cannot fully escape sociocultural dictates. Yet gender considerations do not overshadow their roles within the newsroom. They are, nonetheless, part of their communication and logistical strategies. So, a male editor in chief may be nicer to a female reporter (F, Personal Com., 2014) and women in management may get a sense of guilt if they use harsh words with a male colleague (F, Personal Com., 2014) but that does not stop them from getting their point through or from being assertive. Undoubtedly, age and experience play a role in demanding respect (F, Personal Com., 2014).

In the newsroom microcosm, women seem to employ the strategies of being "one of the girls" or that of feminizing the newsroom- something which they have done considerably in most Lebanese television stations and perhaps very obviously in Tele Lumiere, Al Jadeed, and OTV. Melin-Higgins (2004) strategies would apply for women 
vying for top management and governance positions as these remain areas inhabited by

very few women. When women climb further up the media ladder, they would be able to reach out from it and into politics or should it be the other way around?

\subsubsection{Where are the Boys?}

In a newsroom that has become more populated by women than it is by men, the question is where the male have journalists gone and why. Though not part of the original set of questions, this question emerged every time a respondent asserted that women exist in larger numbers in the newsroom, while men are becoming a minority.

The male migration from the Lebanese television newsroom seems to be prompted by many factors, the most important of which, is insufficient pay. As the primary breadwinners of the family, men contribute the largest portion of the household income. Male journalists, therefore, relocate to nearby Gulf countries such as Dubai or Qatar where they get higher wages (4 Females, 1 Male). Lebanese media professionals are hired by many of the regional stations:

The Arab world has 350-370 million people. We in Lebanon comprise of 1 percent of the Arab world population. Yet fifteen to twenty percent of the total workforce in Arab media television is Lebanese. Stations like Aljazaeera, Alarabia, Sky News Arabia, Dubai TV, the Arabic economic stations, free airing channels (Alqanawat al hurra), France 24 Arabic and any other television station all employ Lebanese media professionals

The intensity of male migration made it hard for local television channels to find male news anchors (2 Females, 1 Male). Those who choose to stay in Lebanon, have to supplement the media pay with other sources of income (1 Female, 1 Male).

Women, who are more ready to accept the lower salaries imposed by the industry, have managed to prove themselves in the media field (4 Females, 1 Male). Women have 
coupled their academic qualifications with on-the-ground skills and expertise. They also "have the looks, the character, the skills, the will, the passion and the courage" (F, Personal Com., 2014). Television's focus on looks and the attraction of the bigger Gulf market (M, Personal Com., 2014) have also helped women gain access and advance in the media.

Male migration has proven to be momentarily advantageous to women. Whether, this trend stays advantageous on the long run remains to be seen. Ultimately, Lebanese television stations, like other commercial media organizations, are profit oriented. Media owners would rather hire qualified female media personnel for lower salaries. If the trend continues, women would push further into senior management and perhaps top management positions. Women in the Lebanese television newsroom have already set a precedent for the Lebanese and regional media.

Like other forms of media, though, the newsroom plays a role in affecting public consciousness. The newsroom should, therefore, reflect the society it is reporting on and this reporting cannot be representative unless both men and women are equally present at all occupational levels. If the male migration trend from the newsroom continues, the struggle for establishing equality for women in top management may be accompanied by a struggle for establishing equality for men at almost all other occupational levels. 


\section{Chapter: Concluding Insights into the Lebanese Television}

\section{Newsroom}

This study set out to explore the status of women in the Lebanese television newsroom using gender and field theories. It sought to identify how the different forms of cultural capital in terms of education and experience and the forms of social capital in terms of social, religious and political connections affect women's employment and progression in the newsroom. In exploring women's status, the study investigated the effect of factors such as age and appearance on women's career longevity in front of and behind the camera. It also uncovered the professional endeavors undertaken by women including areas of news coverage, advancement strategies and management roles. The methodology used in this study comprised of in-depth interviews with 18 female and 9 male newsroom journalists in Lebanon's nine television stations. This chapter provides a synthesis of the main findings, and the limitations of the study as well as recommendations for future research.

\subsection{Conceptual and Practical Reconsideration}

The literature review showed that despite women's presence in large numbers in the Lebanese media landscape, research on women is relatively recent and scarce (Abu Fadil, 2004; Skalli, 2006; Sakr, 2007). There appeared to be little research on the role of women in the Lebanese media landscape, particularly in relation to Lebanese television. This dissertation constituted the first structured effort to take an in-depth look at the Lebanese television newsroom as a microcosm of interaction between male and female journalists and to investigate its potential in catering to professional female journalists and their chances for advancement. Employing the theoretical lens of Bourdieu's field 
theory alongside the theory of gender meant a conceptual exploration of the newsroom as a field of forces where gendered players utilize the different forms of capital conditioned by their habitus. Various studies have incorporated concepts related to the theory of gender in exploring women's status in Middle Eastern and Lebanese media (DabbousSensenig, 2000; Abu Fadil, 2004; Sakr, 2004) however combining gender with field theory has not been used in previous research on Lebanese media. This framework helped form connections between women journalists and the forms of capital they rely on to access the profession and advance. Combining the concepts derived from gender theory along with those of field theory revealed a new dimension of gender as potential capital that can be effectively employed in the Lebanese television newsroom. This appears to challenge Bourdieu's limited view of capital or his reference to gender as simply a part of habitus. In the Lebanese television newsroom, this new form of capital which relies on gendered appearance and looks provides women with access to the profession. The dwindling of this capital leads women out of the profession or relegates them to offcamera positions.

Despite the emphasis on appearance, the Lebanese television has been relatively kind to women. Women were hired as writers, presenters, show hosts and anchors in the Lebanon's first television station and public broadcaster, Tele Liban, since the mid to late 1950s. Women continued to be part of Lebanon's private television stations, the most prominent of which was LBCI that opened in the mid1980s. Though there is no detailed documentation of women's history in Lebanese television, women seem to be progressing through the medium's echelons of power. This study of the newsroom, supposedly a bastion of male territory, has shown strong and persistent female 
infiltration. Female journalists in the Lebanese television newsroom form the majority of the newsroom workers. They have established parity in pay and have managed to reach senior management positions thereby altering the news environment altogether. Women found in the Lebanese television newsroom a microcosm of near equality with men where socio-cultural consideration may cease to exist but are, simultaneously, effective as outside forms of capital influencing employment or progression. Gender can be capital in a newsroom that finds it financially more viable to employ qualified female journalists who have learned how to play the socio-political and cultural game right by dealing with obstacles ranging from family responsibilities to harassment. Male journalists' leaving of the television because of low pay would not have been advantageous for women had these women not been well equipped to handle the many areas of the news and, in certain capacities, the management of the newsroom. Women have now established themselves as news journalists in every sense of the word, as leaders in handling the workings of the newsroom, and as role models for other aspiring female journalists. This outlook may be deemed as overly positive but perhaps it is time to revisit what we think we know about women in the Lebanese media and more particularly in the Lebanese television newsroom.

Whereas lower representation of women at decision making levels has direct consequences on the content produced (Byerly and Ross, 2006; North, 2009; DjerfPierre, 2007) and may not be effective in combating discriminatory hiring practices (Byerly, 2006), their increasing numbers in decision making position would limit discriminatory practices and alter content. Women in Lebanese television newsroom do not only form the majority, but they also occupy decision making positions. Their 
presence in critical numbers has caused a change in newsroom assignments and the newsroom environment. The gender inspired theoretical concepts that make hard news a male domain and the newsroom an Old Boys' Club may not be fully applicable to the Lebanese television newsroom. This study revealed that Lebanese television journalists, both male and female, cover almost all types of news. Women have proven themselves in the coverage of war, bombings, security events and political happenings. They are also working in a more female-friendly newsroom environment either due to their presence in management positions or thanks to the reserved organizational culture of the television station. This calls into question the concept of the glass ceiling - the constructs of which do not fully apply to the Lebanese television newsroom. Glass ceiling which indicates lower pay and lower status for females in the same jobs as males (Falk \& Grizard, 2003) is not applicable. Women's prospects of reaching senior management positions are available to them, their pay is equal to that of men and the newsroom environment is friendly and equitable.

Yet though women have taken big strides into leadership positions in the Lebanese television newsroom, they are still a minority in top management positions and governance. Having family owned channels such as MTV, Future Television and New TV means that these channels operate as family owned businesses and women or men journalists best chances of reaching top management positions would be through familism. Otherwise women would have to become more involved in Lebanese politics especially since the Lebanese television channels remain politico-sectarian mouthpieces that are tightly linked to the political body of the country. 
The Lebanese television newsroom as a media workplace still suffers from a lack of organizational policy. Instituting policies on issues such as merit, harassment, and child support may provide women with a more supportive work environment that allows them to progress even further. The existence of organization policy ensures the equitable treatment of both male and female journalists when it comes to progression and conduct. Doubtless, Lebanese television stations still have a long way to go in that regard. Until then, the newsroom is governed by the unspoken of rules of conduct that both male and female journalists internalize with time and experience. Utilizing this knowledge allows them to prosper and progress in the television newsroom.

Female journalists do not only have a profound understanding of the newsroom as a field, but are also aware of the effect of the external politico-sectarian variables. They have become the news players par excellence, governing a lot of the day-to-day operations and at times, the bigger picture within the newsroom. Whether that newsroom will give women bigger and better access to the field of politics, remains to be seen. Their beauty may stand in the way.

The beauty standards required of female journalists by Lebanese television act as a double edged sword. Findings of the study revealed that female news workers are in general young and attractive. While both attributes may serve as capital for female journalists who meet the required standards, they also serve to undermine women's intellectual capabilities and give women journalists a career span that is ten years less than their male counterparts. It also perpetuates the thinking that certain women only access the field thanks to sexual favors they present or their appearances. Changing this image would take time especially since women seem to adhere with the current beauty 
trend to gain access to the field. Doubtless, women who prosper and remain in the field are the ones who have the expertise and the knowledge, not just the appearance. This, however, does not deny that women suffer from a glass ceiling when it comes to appearance and aging, more than their male counterparts. Women still have to bear the brunt of appearances while proving themselves simultaneously capable and qualified in an industry that demands both requirements and seems to make looks as important as qualifications.

It can be said, on the other hand, that in almost 60 years of television, Lebanese female journalists have taken tremendous strides in the news work and newsroom management. Their stronghold in the Lebanese television newsroom is an attestation of their competence and their perseverance, especially since women have managed to gain grounds in media that is an extension of a political system that has largely excluded them. Women may still have a long way to go but they have, without doubt, accomplished much. Today, they constitute the building blocks of the Lebanese television newsroom and may be on their way to re-defining its attributes on their own terms.

\subsection{Limitations of the Study}

The current study faced certain limitations that could be avoided in future studies on female journalists in the Lebanese television newsroom.

One of the limitations is an inability to fully assess the percentage of women in governance, top management and senior positions. Though such an assessment was not an aim of this study, access to information such as a television station's organizational charts, would have helped with a more exact assessment of women's presence in management. Most of the information gathered was acquired by respondents and its 
validity and reliability checked by virtue of its recurrence. This provided an approximate overview of the positions that women occupied in newsroom management as well as other professional positions.

Another limitation is the inability to paint a deeper political sociology underlying the workings of Lebanese television since respondents were to be kept anonymous. As such, the respondents' answers could not be linked to particular television stations or confessional identities thereby limiting the analysis.

A third limitation is not exploring in-depth the reasons behind women's opting out of their career or not progressing. Though obvious reasons may relate to family responsibilities or personal choice other reasons may have included differing career outlooks and objectives or a lack of persistence. Ultimately, women may not want the same things man wants from a career (Ely, Stone and Ammerman, 2014).

\subsection{Future Research}

This study has shown that common beliefs about women in the media need to be questioned and examined closely. Conceptual and theoretical frameworks that apply to Western contexts may not be applicable to other contexts. Lebanon's liberal society is unique to the region and its media, which exists at a smaller and friendlier scale compared to Western media. It is a portrayal of a liberal society and an entrenched politico-sectarian system that is both authoritative and libertarian, restrictive and encouraging.

Taking into consideration the Lebanese cultural and media contexts, future research would delve deep into other media newsrooms such as those of newspapers, radio and web to uncover the status of women. Contrary to previous findings and popular 
beliefs, this study has shown that women are empowered within the Lebanese television newsroom. Studies into other newsrooms may also reveal surprising results.

Future studies should also investigate the career paths of male and female journalists. Despite forming the bigger percentage of media students, many women opt out of their career in journalism (Griffin, 2014; Franks, 2013; Melki, 2009). While many studies posit the hostile news environment, lower pay and family responsibilities as some of the main reasons behind women leaving the journalism profession (Franks,2013; Everbach \& Flournoy, 2007; Griffin, 2014), in-depth investigation beyond these taken for granted reasons may reveal a different story altogether. A study on 25,000 Harvard Business School graduates, revealed that the conventional wisdom about women's careers and the glass ceiling may not all hold true (Ely, Ammerman \& Stone, 2014). Women's attitudes, expectations and career goals have a lot to do with their decisions to leave their careers. The same may be true of women in media careers. After all in Lebanon, not all constructs of the glass ceiling concept held through and it is possible that women's opting out of a career in journalism or the reasons behind opting out may not hold true.

Other avenues of study include investigations into organizational policy and media law. Such investigations may serve to suggest policy stipulations for Lebanese media especially since most Lebanese media organization remain without proper organizational policies. The studies can uncover the relation between policy and media law and detail gender policy stipulations to ensure that the media workplace is less discriminatory than the country's personal status laws. 


\subsection{Brave Female Journalists}

Bravery in journalism does not simply entail coverage of war or highly dangerous areas, bravery entails defying the odds to deliver a near objective portrayal of the truth. In Lebanon, it is more about surviving the politico-sectarian dictates that govern the media sector while trying to preserve the freedom of speech and delivering a near objective truth tarnished with a politico-sectarian perspective. Women journalists, just like their male counterparts, have understood the journalistic game. They have managed to prove themselves despite the many socio-cultural odds and societal expectations that accompany their careers as professional journalists, wives, mothers, companions, sisters and daughters. Female journalists in the Lebanese television newsroom do not simply constitute a pretty face but well-rounded, competent, smart and capable women that are handling the field as well as men, if not better. 


\section{Bibliography}

Abou El Naga, S. (2004). Arab women and the new media: Empowerment or disempowerment? Transnational Broadcasting Journal. Retrieved from: http://www.tbsjournal.com/Archives/Fall04/campabouelnaga.htm

Abouzaki, R. (2012, May 14). Lebanon's media industry: Jobs with expiry dates. alakhbar english. Retrieved from http://english.al-akhbar.com/node/7345

Abu Fadil, M. (2001). A long way to go. Global Journalist. Retrieved from: http://www.globaljournalist.org/stories/2001/07/01/a-long-way-to-go/

Abu Fadil, M. (2004). Straddling cultures: Arab women journalists at home and abroad. In N. Sakr (Ed.), Women and media in the Middle East: Power through selfexpression. London: I.B. Tauris.

Abu Fadil, M. (2007). Lebanese women journalists brave war odds. Arab Media and Society. Retrieved from: http://www.arabmediasociety.com/?article=22

Abu Fadil, M. (2007, February). Lebanese women journalists need better jobs, regular training, more money. Huffington Post. Retrieved from:

http://www.huffingtonpost.com/magda-abufadil/lebanese-womenjournalist_b_78050.html

Abu Fadil, M. (2009, June 6). Lebanese media freedom decline, management "opaque" on operations on election eve. The Huffington Post. Retrieved from: http://www.huffingtonpost.com/magda-abufadil/lebanese-media-freedomde_b_212180.html

Abu Fadil, M. (2011, August). New draft Lebanese media laws limping through parliament. Middle East Media Educator, Vol. 1, 21-27.

Abu Fadil, M. (2013, February). Lebanese media far from being accountable. Huffington Post. Retrieved from: http://www.huffingtonpost.com/magda-abufadil/lebanesemedia-far-accountable_b_2607122.html

Abu Fadil, M. (2015, September 17). Lebanese journos contest union election results. The Huffington Post. Retrieved from: http://www.huffingtonpost.com/magdaabufadil/lebanese-journos-contest_b_8152722.html

Abu Lughod, L. (2005). On- and off-camera in Egyptian soap operas: women, television and the public sphere. In N. Fereshteh (Ed.), On shifting ground: Muslim women in the global era (pp. 67-87). New York: The Feminist Press.

Allan, S. (2010). News culture. Maidenhead: Open University Press. 
Al Jadeed TV. (n.d.). Man Nahnou - About Us. Retrieved from: http://www.aljadeed.tv/arabic/about-us/aljadeed-history

Al Manar (n.d.). Man Nahnou - About Us. Retrieved from: http://www.almanar.com.lb/aboutus.php

Amin, H. (2001). Arab women and satellite broadcasting. Transnational Broadcasting Journal. Retrieved from: http://www.tbsjournal.com/Archives/ Spring01/Amin.html

Andersen, M. \& Taylor, H. (2015). Sociology: The essentials. Boston: Cengage Learning.

Annenberg Public Policy Center. (2003). The glass ceiling persists: The $3^{\text {rd }}$ annual APPC report on women leaders in communication companies. Edited by E. Falk and E. Grizard. University of Pennsylvania: E. Falk and E. Grizard (Eds).

Baker, A. (2013, April 9). Lebanon's sects game: The problem with its byzantine political system. Time. Retrieved from: http://world.time.com/2013/04/09/lebanons-sects-game-the-problem-with-itsbyzantine-political-system/

Barber, M. \& Rauhala, A. (2005). The Canadian news directors study: Demographics and political leanings of television decision-makers. Canadian Journal of Communications, 30(2) 281-292.

Bazeley, P. \& Richards, L. (2000). The Nvivo qualitative project book. London: Sage.

Beijing declaration and platform for action: The fourth world conference on women. (1995). United Nations Entity for Gender Equality and Empowerment of Women. Retrieved from: http://www.un.org/womenwatch/daw/beijing/platform/index.html

Berg, B. L. (2011). An introduction to content analysis. In M. Eid (Ed.), Research methods in communication (pp. 209-233). Boston, MA: Pearson.

Bhagat, P. (2002). Status of women journalists in India. National commission for women. New Delhi: Press Institute of India.

Bolam, B., Gleeson, K., \& Murphy, S. (2003). "Lay person" or "health expert"? Exploring practical and theoretical aspects of reflexivity in qualitative health research. Forum Qualitative Social Research, 4(2), 1-13.

Bollinger, L. \& O'Neill, C. (2008). Women in media careers: Success despite the odds. New York: University Press of America.

Boulous, J.C. (1995). Television in Lebanon: History and stories. Beirut: FMA. 
Bourdieu, P. (1977). Outline of a theory of practice. London: Cambridge University Press.

Bourdieu, P. (1984). Distinction: A social critique of the judgement of taste. Oxon: Harvard University Press.

Bourdieu, P. (1986) The forms of capital. In J. Richardson (Ed.), Handbook of theory and research for the sociology of education (pp. 241-258). New York: Greenwood.

Bourdieu, P. (1990). In other words: Essays towards a reflexive sociology. Cambridge: Polity Press.

Bourdieu, P. (1998). On television. New York: The New Press.

Bourdieu, P. \& Wacquant, L. (1992). An invitation to reflexive sociology. Chicago: The University of Chicago Press.

Bourdieu, P. (2005). The political field, the social field and the journalistic field. In R. Benson \& E. Neveu (Eds,), Bourdieu and the journalistic field. Cambridge: Polity.

Boyd, D. (1991). Lebanese broadcasting: Unofficial electronic media during a prolonged civil war. Journal of Broadcasting \& Electronic Media, 35(3), 269-287.

Boyd, D. (1998). The evolution of the electronic media in the contemporary Middle East. Revue de l'Occident musulman et de la Méditerranée [Journal of the Muslim West and the Mediterranean], Vol. 47, 23-34.

Boyd, D. (1999). Broadcasting in the Arab world. Iowa: Iowa State University Press.

Boyd, K. (2008). Glass ceiling. Encyclopedia of race, ethnicity, and society (pp. 549552). Thousand Oaks: Sage.

Brinkmann, S. (2013). Qualitative interviewing: Understanding qualitative research. New York: Oxford University Press.

Brinkmann, S. (2014). Unstructured and semi-structured interviewing. In P. Leavy (Ed.), The Oxford handbook of qualitative research (pp. 193-357). New York: Oxford University Press.

Bryman, A. (2012). Social research methods. New York: Oxford University Press.

Byerly, C. (2004). Feminist interventions in newsrooms. In K. Ross and C. Byerly (Eds), Women and media: International perspectives (p. 109-131). Oxford: Blackwell. 
Byerly, C. \& Ross, K. (2005). Women and media: International perspectives. Oxford: Blackwell.

Byerly, C. \& Ross, K. (2006). Women and media: A critical introduction. Oxford: Blackwell.

Byerly, C. (2011). Global report on the status of women in the news media. International Women's Media Foundation.

Carter, C. \& Ross, K. (2011). Women and news: A long and winding road. Media, Culture and Society, 33(8), 1148-1165.

CEDAW. (2005). Second Periodic Report of States Parties, Consideration of Reports Submitted by States Parties under Article 18 of the Convention on the Elimination of all Forms of Discrimination against Women. United Nations.

Cestor, E. (2010). Music and television in Lebanon. In M. Frishkopf (Ed.), Music and media in the Arab world. Cairo: The American University in Cairo Press.

Chambers, D., Steiner, L., \& Fleming, C. (2004). Women and journalism. New York: Routledge.

Cochrane, P. (2007, May). Lebanon's media sectarianism. Arab Media and Society. Retrieved from: http://www.arabmediasociety.com/articles/downloads/ 20070520151707_AMS2_Paul_Cochrane.pdf

Cochrane, P. (2008, September). Lebanon's media battle. Arab Media and Society. Retrieved from: http://www.arabmediasociety.com/articles/downloads/20080929132929_ AMS6_Paul_Cochrane.pdf

Craft, S. \& Wanta, W. (2004). Women in the newsroom: Influences of female editors and reporters on the news agenda. Journalism and Mass Communication Quarterly, 81(1), 124-127.

Creedon, P. (1989). Women in mass communication: Challenging gender values. Newbury Park: Sage Publications.

Creedon, P. (1993). Women in mass communication. Beverly Hills: Sage Publications.

Creedon, P., Rush, R., Oukrop, C. (2004). Seeking equity for women in journalism and mass communication education: A 30-year update. New Jersey: Taylor \& Francis.

Creedon, P. \& Cramer, J. (2007). Women in mass communication. London: Sage Publications. 
Creswell, J. (2007). Qualitative inquiry and research design: Choosing among five approaches. London: Sage Publications.

Creswell, J. (2009). Research design: Qualitative, quantitative, and mixed methods approaches. London: Sage Publications.

Dabbous, Y. (2010). Media with a mission: Why fairness and balance are not priorities in Lebanon's journalistic codes. International Journal of Communication, Vol. 4, 719-737.

Dabbous-Sensenig, D. (2000) Media vs. society in Lebanon: Schizophrenia in the age of globalization. World Association for Christian Communication. Retrieved from: $\mathrm{http}$ ://waccglobal.org/en/20003-women-and-media-the-need-for-policy/768Media-vs-society-in-Lebanon-Schizophrenia-in-an-age-of-globalisation.html

Dabbous-Sensenig, D. (2002). The Arab world and the challenge of introducing gendersensitive communication policies. United Nations: Division for the Advancement of Women. Retrieved from: http://www.un.org/womenwatch/daw/egm/ media2002/reports/OP5Dabbous.PDF

Dabbous-Sensenig, D. (2007, May). ACRLI 2007 country report: Media in Lebanon. Arab Center for the Development of the Rule of Law and Integrity.

Dah, A., Abosedra, S. \& Dahbourah, F. (2010). Gender pay discrimination in Lebanon: Assessment of recent data. Oxford Journal: An International Journal of Business and Economics, 5(1), pp. 138- 147.

Dajani, N. (1979). Lebanon: Studies in broadcasting. London: International Institute of Communication.

Dajani, N. (Fall 2001). The changing scene of Lebanese television. Transnational Broadcasting Studies Archives. Retrieved from: http://www.tbsjournal.com/ Archives/Fall01/dajani_refs.html

Dajani, N. (2006). The re-feudalization of the public sphere: Lebanese television coverage and the Lebanese political process. Transnational Broadcasting Journal. Retrieved from: http://www.tbsjournal.com/Dajani.html

Daymon, C. \& Holloway, I. (2010). Qualitative research methods in public relations and marketing communications. London: Routledge.

De Bruin, M. \& Ross, K. (Eds). (2004). Gender and newsroom cultures: Identities at work. Cresskill: Hampton Press

De Bruin, M. (2004). Organizational, professional, and gender identities - overlapping, coinciding and contradictory realities in Caribbean media practices. In M. De 
Bruin and K. Ross (Eds.), Gender and newsroom cultures: Identities at work (pp. 197-222). New Jersey: Hampton Press.

Deen, T. (2014, March 6). Women still walk two steps behind in Arab world. Inter Press Service. Retrieved from: http://www.ipsnews.net/2014/03/women-still-walk-twosteps-behind-arab-world/

Djerf-Pierre, M. \& Lofgren-Nilsson, M. (2004). Gender-typing in the newsroom: The feminization of Swedish television news production, 1958-2000. In M. De Bruin \& K. Ross, (Eds.), Gender and newsroom cultures: Identities at work (pp. 81 106). Cresskill: Hampton Press.

Djerf-Pierre, M. (2007). The gender of journalism: The structure and logic of the field in the twentieth century. Nordicom Review, Vol. 28 (pp. 81-104).

Economic and Social Commission for Western Asia (ESCWA). (2011, December). Committee on Women-fifth session. Retrieved from: http://www.escwa.un.org/information/publications/edit/upload/E_ESCWA_ECW _11_IG-1_7_Report_e.pdf

Eid, M. (2011a). Introduction to communication research. In M. Eid (Ed.), Research methods in communication (pp. 3-14). Boston, MA: Pearson.

Eid, M. (Ed.). (2011b). Research methods in communication. Boston, MA: Pearson.

Eid, M. (2013). A multi-sphere violence against Arab women. In G. A. Bonin and Y. Pasadeos (Eds.), Media research: Learning from the past, strategies for the future (pp. 127-142). Athens, Greece: Athens Institute for Education and Research.

Elliot, J. (2005). Using narrative in social research: Qualitative and quantitative approaches. London: Sage.

Ely, R., Stone, P., \& Ammerman, C. (2014). Rethink what you "know" about highachieving women. Harvard Business Review. Retrieved from: https://hbr.org/2014/12/rethink-what-you-know-about-high-achieving-women

Everbach, T. \& Flournoy, C. (2007). Women leave journalism for better pay, better work conditions. Newspaper Research Journal, 28(3), 52- 64.

Fandy, M. (2007). (Un)civil war of words: Media and politics in the Arab world. Westport: Praeger.

Faour, M. (2007, November). Religion, demography and politics in Lebanon. Middle Eastern Studies, 43(6), 909-921. 
Federal Glass Ceiling Commission. (1995). A solid investment: Making full use of the nation's human capital. Retrieved from: http:/www.dol.gov/oasam/programs/ history/reich/reports/ceiling2.pdf

Franks, S. (2013). Women and journalism. London: I.B. Tauris.

Freedom House. Freedom of the press 2012: Lebanon. Retrieved from: http://www.freedomhouse.org/report/freedom-press/2012/lebanon

Freeman, B. (2001). The satellite sex: The media and women's issues in English Canada, 1966-1971. Ontario: Wilfrid Laurier University Press.

Freeman, B. (2007). Review of the books 'Gender, journalism and equity: Canadian, US and European Perspective' and 'The reading list'. Canadian Journal of Communication, 32(2), 323-325.

Frohlich, R. (2004). Feminine and feminist values in communication professions: Exceptional skills and expertise or "friendliness trap?" In M. De Bruin and K. Ross (Eds.), Gender and newsroom cultures: Identities at work. Cresskill: Hampton Press.

Frohlich, R. (2007). Three steps forward and two back? Women journalists in the western world between progress, standstill and retreat. In P. Creedon and J. Cramer (Eds.), Women in mass communication. London: Sage.

Future TV. (n.d.). Man Nahnou - About US. Retrieved from: http://www.futuretvnetwork.com/about-us

Gallagher, M. (1995). An unfinished story: Gender patterns in media employment. Reports and Papers on Mass Communication 110. Paris: UNESCO.

Gallagher, M. (2005). Who makes the news? Global media monitoring project. World Association for Christian Communication.

Gallego, J., Altes, E., Canton, M., Melus, M. \& Soriano J. (2004). Gender stereotyping in the production of news. In De Bruin, M. \& Ross, K. (Eds.). (2004). Gender and newsroom cultures: Identities at work. Cresskill: Hampton Press.

Gatten, E. (2012, May 8). Sexual harassment rife in workplaces. The Daily Star. Retrieved from: http://www.dailystar.com.lb/News/Local-News/2012/May08/172647-sexual-harassment-rife-in-workplaces.ashx\#axzz2vpAKdkUz

Gender Links. (2009). Glass ceilings: Women and men in Southern African media. Morna, C. \& Rama, K. (Eds.). Retrieved from: http://www.mdda.org.za/Glass\%20Ceiling\%20\%20\%20South\%20Africa\%20CR \%20REV2.pdf 
Ghurayyib, R. (1989, February). Women and the media in the Arab world. Al Raida, 3(47). Retrieved from: http://iwsawassets.lau.edu.lb/alraida/alraida-47.pdf

Global Media Monitoring Project (GMMP). (2010). Who makes the news? Retrieved from: http://pages.cmns.sfu.ca/kathleen-cross/files/2010/11/GMMP-global.pdf

Grenfell, M. (2004). Pierre Bourdieu: Agent provocateur. New York: Continuum.

Griffin, A. (2014). Where are the women? Why we need more female news leaders. Neiman Reports. Retrieved from: http://niemanreports.org/articles/where-are-thewomen/

Haidar, K. (2007, August 27). Antiquated laws violate women's civil rights. The Daily Star: Lebanon Examiner.

Haidar, K. (2007, September 17). Economic empowerment: Cornerstone of equality. The Daily Star: Lebanon Examiner.

Hafez, K. (2010, March 22). How liberal is soft authoritarianism when compared to democracy? Arab and Western media systems typologies. Paper presented at the Georgetown University: Arab Media Symposium: Information Revolution in the Arab World. Retrieved from: http://www.uni-erfurt.de/fileadmin/user docs/philfak/kommunikationswissenschaft/files_publikationen/hafez/Georgetown paper_neu.pdf

Harb, Z. (2011). Channels of resistance in Lebanon: Liberation propaganda, Hezbollah and the media. London: I.B. Tauris.

Hatch, J. A. (2002). Doing qualitative research in education setting. New York: State University of New York Press.

Hejase, A., Hejase, H.J., \& Hejase, H.A. (2015). Gender wage gap in Lebanon: Explorative analysis. Journal of Applied Economics and Business Research, $5(1)$, pp. $1-19$.

Hejase, H. (2015b). Sexual harassment in the workplace: An exploratory study from Lebanon. Journal of Management Research. Retrieved from http://dx.doi.org/10.5296/jmr.v7i1.6965

Holmes, M. (2007). What is gender? Sociological approaches. London: Sage Publications.

Honneth, A., Kocyba, H., \& Schwibs, B. (2000). Field work in philosophy: Pierre Bourdieu interviewed by Honneth, Kocyba \& Schwibs. In D. Robins (Ed.), Pierre Bourdieu, pp. 3-27. London: Sage Publications. 
Human Development Report. (2004). Cultural liberty in today's diverse world. New York: United Nations Development Program (UNDP).

Human Rights Watch. (2011). Lebanon: Law reform targets 'honor' crimes. Retrieved from: https://www.hrw.org/news/2011/08/11/lebanon-law-reform-targets-honorcrimes

Human Rights Watch. (2014). Lebanon: Domestic violence law good but incomplete. Retrieved from: https://www.hrw.org/news/2014/04/03/lebanon-domesticviolence-law-good-incomplete

Hussein, A. (2001). Arab women and satellite broadcasting. Transnational Broadcasting Journal. Retrieved from: http://www.tbsjournal.com/Archives/Spring01/ Amin.html

International Press Institute. (2006, December). Media in Lebanon: Reporting on a nation divided. Retrieved from:http://www.freemedia.at/fileadmin/media/ Documents/IPI_mission_reports/Lebanon_Mission_Report.pdf

International Women's Media Foundation. (2011). Global report on the status of women in the news media. Washington, D.C.: Carolyn Byerly (principal investigator). Retrieved from: http://iwmf.org/pdfs/IWMF-Global-Report-Summary.pdf

Internews Network. (2003). Lebanon. In Internews (Ed.), Study of media laws and policies for the Middle East and Maghreb. Retrieved from: http://www.internews.org/regions/mena/amr/lebanon.pdf

Internews Network. (2009). Behind the scenes: Transparency in Lebanese media business practices 2009. Retrieved from: http://www.internews.org/researchpublications/behind-scenes-transparency-lebanese-media-business-practices

IWPR. (2012). Focus on Lebanon: Women's freedom of movement, and freedom from harassment and violence. The Status of Women in the Middle East and North Africa. Institute for Women's Policy Research. Retrieved from http://swmena.net/library/uploads/pdf/Freedom_and_Limits_Topic_Brief.pdf.

Jackson, W., Gillis, A. \& Verberg, N. (2011). Qualitative research methods. In M. Eid (Ed.), Research methods in communication (pp. 237-266). Boston, MA: Pearson.

Jamali, D., Sidani, Y. \& Safieddine, A. (2005). Constraints facing working women in Lebanon: An insider view. Women in Management Review, 20(8), 581-94.

Jamali, D., Sidani, Y., Kobeissi, A. (2008). The gender pay gap revisited: Insights from a developing country context. Gender in Management: An International Journal, 23(4), pp. $230-246$. 
Jarvinen, M. (1999). Immovable magic- Pierre Bourdieu on gender and power. NORA, 1(7), 6-19.

Johnson, R. (1993). Editor's introduction: Pierre Bourdieu on art, literature and culture. In P. Bourdieu's, The field of cultural production: Essays on art and literature. Cambridge: Polity Press.

Joseph, S. (1999a). Intimate selving in Arab families: Gender, self and identity. New York: Syracuse University Press.

Joseph, S. (1999). Descent of the nation: Kinship and citizenship in Lebanon. Citizenship Studies, 3(3), 295-318.

Joseph, S. (2000a). Gendering citizenship in the Middle East. In S. Joseph (Ed.), Gender and citizenship in the Middle East. New York: Syracuse University Press.

Joseph, S. (2000b). Civic myths, citizenship and gender in Lebanon. In S. Joseph (Ed.), Gender and citizenship in the Middle East. New York: Syracuse University Press.

Joseph, S. \& Slyomovics, S. (Eds.). (2001). Women and power in the Middle East. Philadelphia: University of Pennsylvania Press.

Joseph, S. (2004). Conceiving family relationships in post war Lebanon. Journal of Comparative Family Studies, 35(2), 271-293.

Joseph, A. (2004). The gender (dis)advantage in India. In De Bruin, M. \& Ross, K. (Eds.), Gender and newsroom cultures: Identities at work. Cresskill: Hampton Press.

Journalists' Union votes for Elias Aoun's list in council elections. (2012, May 30). Daily Star, Lebanon News. Retrieved from http://www.dailystar.com.lb/News/Local-News/2012/May-30/175073-journalistsunion-votes-for-elias-aouns-list-in-council-election.ashx

Karim, K. (2005). The elusiveness of full citizenship: Accounting for cultural capital, cultural competencies and cultural pluralism. In C. Andrew, M. Gattinger, M. Jeannotte and W. Straw (Eds.), Accounting for culture: Thinking through cultural citizenship (p.146-158). Ottawa: University of Ottawa Press.

Kassir, S. (2010). Beirut. (M.B. DeBevoise, Trans.) Los Angeles: University of California Press. (Original work published 2003).

Kraidy, M. (2011, January 26). Media reform in Lebanon: New media, new politics? Arab Reform Bulletin. Washington, D.C.: Carnegie Endowment for International 
Peace. Retrieved from: http://www.carnegieendowment.org/arb/?fa=show\& article $=42368$

Kraidy, M. (1998). Broadcasting regulation and civil society in postwar Lebanon. Journal of Broadcasting and Electronic Media, 42(3), 387-400.

Kraidy, M. (1999). State control of television news in 1990s Lebanon. Journalism and Mass Communication Quarterly, 76(3), p. 485-498.

Kraidy, M. (2000). Transnational television and asymmetrical interdependence in the Arab World. The growing influence of the Lebanese satellite broadcasters. Transnational Broadcasting Studies. Retrieved from: http://www.tbsjournal.com/ Archives/Fall00/Kraidy.htm

Kraidy, M. (2001). Between globalization and localization: Television, tradition and modernity. In Y. Kamalipour and K. Rampal's (Eds.), Media, sex, violence and drugs in the global village. England: Rowman and Littlefield Publishers, Inc.

Kraidy, M. (2002, Fall). Arab satellite television between regionalization and globalization. Global Media Journal, 1(1).

Kraidy, M. (2005). Reality television and politics in the Arab world: Preliminary observations. Transnational Broadcasting Journal. Retrieved from: http://tbsjournal.arabmediasociety.com/Archives/Fall05/Kraidy.html

Kraidy, M. (2008). Star academy as Arab political satire. International Journal of Middle East Studies, Vol. 40, 369-371.

Kraidy, M. \& Khalil, J. (2009). Arab television industries. London: Palgrave Macmillan.

Kraidy, M. (2010). Reality television and Arab politics: Contention in public life. New York: Cambridge University Press.

Kvale, S. (1996). Interviews: An introduction to qualitative research. London: Sage Publications.

Kvale, S. (2007). Doing interviews. London: Sage Publications.

Kvale, S. \& Brinkmann, S. (2009). Interviews: Learning the craft of qualitative research interviewing. London: Sage Publications.

Labaki, B. (1998). Confessional community, social stratification and wars in Lebanon. Social Compass, 35(4), 533-561. 
La Rue, F., Haraszti, M., Botero, C., \& Tlakula, F. P. (2009). Lebanon Media sustainability index 2009 (MSI). Retrieved from: http://www.irex.org/sites/default/files/MSIMENA09_Lebanon.pdf

La Rue, F., Haraszti, M., Botero, C., \& Tlakula, F. P. (2009). Lebanon. Media sustainability index 2009. Retrieved from: http://www.irex.org/sites/default/files/MSIMENA09_Lebanon.pdf

La Rue, F., Haraszti, M., Botero, C., \& Tlakula, F.P. (2010). Tenth anniversary joint declaration ten key challenges to freedom of expression in the next decade. Retrieved from: http://www.article19.org/pdfs/standards/tenth-anniversary-jointdeclaration-ten-key-challenges-to-freedom-of-express.pdf

La Rue, F., Haraszti, M., Botero, C., \& Tlakula, F. P. (2013). Lebanon. Media sustainability index 2013. Retrieved from: http://www.irex.org/sites/default/files/u128/Lebanon\%202013\%20english.pdf

LBC Group (n.d.). About LBC Group. Retrieved from: http://www.lbcgroup.tv/about-lbci

Lincoln, Y. (1995). Emerging criteria for quality in qualitative and interpretive research. Qualitative Inquiry, 1(3), 275 - 289.

Lykke, N. (2010). Feminist studies: A guide to intersectional theory, methodology and writing. New York: Routledge.

Made, P. \& Morna, C.L. (Eds.). (2010). Glass ceilings: Women and men in Southern Africa media. Johannesburg: Gender Links.

Mahtani, M. (2005). Gendered news practices: Examining experiences of women journalists in different national contexts. In Allan, S. (Ed.), Journalism: Critical issues, pp. 299-311. Maidenhead: Open University Press.

Matar, D. (2007). Heya TV: A feminist counter-public for Arab women. Comparative Studies of South Asia, Africa and the Middle East, 27(3), p. 513-524.

$\mathrm{M}^{\mathrm{c}} \mathrm{Kenzie}$, R. with contributions by Dajani, N. \& Weber, I. (2006). Comparing media from around the world. Boston, MA: Pearson.

McCall, L. (2005). The complexity of intersectionality. Journal of Women in Culture and Society, 30 (3), p. 1171- 1800.

Meehan, E. \& Riordan, E. (Eds). (2002). Sex and money: Feminism and political economy in the media. Minneapolis: University of Minnesota Press. 
Melin-Higgins, M. (2004). Coping with journalism: Gendered newsroom culture. In De Bruin, M. \& Ross, K. (Ed.), Gender and newsroom cultures: Identities at work. New Jersey: Hampton Press.

Melki, J. (2009). Journalism and media studies in Lebanon. Journalism Studies, 10(5), pp. 672- 690 .

Melki, J. \& Mallat, S. (2013). Lebanon: Women's struggle for gender equality and harassment-free newsrooms. In C. Byerly (Ed.), The Palgrave International Handbook of Women and Journalism. New York: Palgrave Macmillan.

Melki, J. \& Mallat, S. (2014). Block her entry, keep her down and push her out: Gender discrimination and women journalists in the Arab world. Journalism Studies. Retrieved from http://dx.doi.org/10.1080/1461670X.2014.962919

Merrigan, G. \& Huston, C. (2009). Communication research methods. New York: Oxford University Press.

Mernissi, F. (Spring 2004). The Satellite, the prince, and scheherazade: The rise of women as communicators in digital Islam. Transnational Broadcasting Studies. Retrieved from: http://www.tbsjournal.com/Archives/Spring04/mernissi.htm

Millennium Development Goals: Lebanon Report 2008. United Nations Development Program. Retrieved from: http://www.undp.org.lb/communication/publications/ downloads/MDG_en.pdf

Moghadam, V. (2007). From patriarchy to empowerment: Women's participation, movements and rights in the Middle East, North Africa and South Asia. New York: Syracuse University Press.

MTV (n.d.). About MTV. Retrieved from: http://mtv.com.lb/About

NBN (n.d.). Man Nahnou - About Us. Retrieved from: http://www.nbn.com.lb/ index.php/نحن-من

Neuman, L. (2011a) Qualitative and quantitative research. In M. Eid (Ed.), Research Methods in Communication (pp.131-207). Boston, MA: Pearson.

Neuman, L. (2011b). Qualitative and quantitative sampling. In M. Eid (Ed.), Research Methods in Communication (pp. 303-337). Boston, MA: Pearson.

Neveu, E. (2007). Pierre Bourdieu: Sociologist of media or sociologist for media scholars? Journalism Studies, 8(2), 335-347.

North, L. (2007). "Just a little bit of cheeky ribaldry"? : Newsroom discourses of sexually harassing behavior. Feminist Media Studies, 7(1). 
North, L. (2009). Rejecting the 'F word': How 'feminism' and 'feminists' are understood in the newsroom. Journalism, 10(6), 737-757.

North, L. (2012). Women's struggle for top jobs in the news media. Social Science Research Network. Retrieved from: http://papers.ssrn.com/sol3/papers.cfm? abstract_id $=2215397$

Notzold, K. \& Pies, J. (2010). Going 'local' as a strategy to enter Arab national television markets: Examples from Lebanon and Jordan. Middle East Journal of Culture and Communication, Vol. 3, 43-62.

Obeidat, R. (2002, November). Content and representation of women in the Arab media. Expert Group Meeting held in Beirut on participation and access of women to the media, and the impact of media on, and its use as an instrument for the advancement and empowerment of women. United Nations: Division for the Advancement of Women.

O’Donoghue, T. (2007). Planning your qualitative research project: An introduction to interpretivist research in education. London: Routledge.

Ofeish, S. (1999, Winter). Lebanon's second republic: Secular talk, sectarian application. Arab Studies Quarterly, 21(1), 97- 116.

O’Neill, M. (2013). The NVivo toolkit: How to apply NVivo in your PhD for research and publishing success.

OTV (n.d.). Corporate- Legal Documents. Retrieved from: http://www.otv.com.lb/beta/v/our-channel/Legal-Documents-11

Patterson, T. \& Donsbach, W. (1996). News decisions: Journalists as partisan actors. Political Communication, Vol. 13, 455-468.

Perakyla, A. \& Ruusuvuori, J. (2011). Analyzing talk and text. In N. Denzin \& Y. Lincoln (Eds.), The Sage handbook of qualitative research. London: Sage.

Pies, J., Madanat, P., \& Elsaeßer, C. (2011). New media, old problems. Retrieved from: http://www.mediaact.eu/fileadmin/user_upload/WP4/WP4_Lebanon.pdf

Press Order Lebanon. (n.d.) History of the Lebanese Journalists' Union. Press Order Lebanon. Retrieved from: http://pressorderlebanon.com/about.php

QSR International (n.d.). About QSR. Retrieved from: http://www.qsrinternational.com/about-qsr.aspx 
QSR International. (2014). NVivo 10 for Windows: Getting started. Retrieved from: http://download.qsrinternational.com/Document/NVivo10/NVivo10-GettingStarted-Guide.pdf

Reason. P. (1998). Human inquiry in action: Developments in new paradigm research. London: Sage.

Richani-El, S. (2011, August 27). The Lebanese media landscape. Muftah. Retrieved from http://muftah.org/the-lebanese-media-landscape/\#.VyIacPkrLZ4

Riley, M. (2008, March). A feminist political economic framework. Center of Concern. Retrieved from: https://www.coc.org/files/Riley\%20-\%20FPE_0.pdf

Robinson, G. (2004). Gender in the newsroom: Canadian experiences. In Ross, K. \& De Bruin, M. (Eds.), Gender and newsroom cultures: Identities at work. Cresskill: Hampton Press.

Robinson, G. (2005). Gender, journalism, and equity: Canadian, U.S., and European perspectives. Cresskill, NJ: Hampton Press.

Rodgers S. \& Thorson E. (2003). A socialization perspective on male and female reporting. Journal of Communication, 53(4), 658-675.

Ross, K. (2001). Women at work: Journalism as an en-gendered practice. Journalism Studies, 2(4), 531-544.

Ross, K. (2004). Sex at work: Gender politics and newsroom culture. In De Bruin, M. \& Ross, K. (Eds.). Gender and newsroom cultures: Identities at work. New Jersey: Hampton Press.

Ross, K. (2007). The journalist, the housewife, the citizen and the press: Women and men as sources in local news narratives. Journalism, 8(4), 449-47. Retrieved from: http://jou.sagepub.com.ezproxy.library.uvic.ca/cgi/content/short/8/4/449.

Ross, K. (2010). Gendered media: Women, men and identity politics. Lanham: Rowman \& Littlefield Publishers.

Ross, K. \& Carter, C. (2011) Women and news: A long and winding road. Media Culture \& Society, 33(8).

Rugh, W. (2004). Arab mass media: Newspapers, radio and television in Arab politics. Westport: Praeger.

Rugh, W. (2007, May). Do national political systems still influences Arab media. Arab Media and Society, Vol. 2, 1-21. Retrieved from: http://www.arabmediasociety.com/?article $=225$ 
Sakr, N. (2001). Satellite realms: Transnational television, globalization and the Middle East. London: I.B. Tauris.

Sakr, N. (2002, Fall). Arab satellite channels between state and private ownership: Current and future implications. Transnational Broadcasting Studies. Retrieved from: http://www.tbsjournal.com/Archives/Fall02/Sakr_paper.html

Sakr, N. (2004). Women and media in the Middle East: Power through self-expression. London: I.B. Tauris.

Sakr, N. (2007). Arab television today. London: I.B. Tauris.

Schultz, I. (2007). The journalistic gut feeling. Journalism Practice, 1(2), 190-207.

Sclater, S. (2003). What is the subject? Narrative Inquiry, 13(2), 317-330.

Seidman, I. (2006). Interviewing as qualitative research: A guide for researchers in education and the social sciences. New York: Teachers College Press.

Shukrallah, H. \& Treacher, A. (2001). The realms of the possible: Middle Eastern women in political and social spaces. Feminist Review, Vol. 69, 4-14.

Sheehan, S. \& Abul Latif, Z. (2007). Lebanon: Cultures of the world. New York: Marshall Cavendish.

Shelton, T. (2014, February 22). Why Lebanese politics are so messed up. Global Post. Retrieved from: http://www.globalpost.com/dispatch/news/regions/middleeast/140221/why-lebanese-politics-so-messed-up

Skalli, L. (2006, Spring). Communicating gender in the public sphere: Women and information technologies in the MENA. Journal of Middle East Women's Studies, 2(2), p.35-59.

Smith, V. (2012). All the resistance that's fit to print: Canadian women print journalists narrate their careers. Unpublished PhD Thesis, University of Victoria, Canada.

Strong, C. R. (2011). Female journalists in New Zealand daily newspapers: From early careers to gender gap in editorship. Unpublished PhD Thesis, Massey University, New Zealand. Retrieved from: http://mro.massey.ac.nz/bitstream/handle/ 10179/2780/02_whole.pdf? sequence $=1$

Tayar, H. (2013). Valeurs, croyance, et pratiques religieuses aupres de la jeunesse chretienne au Liban: Prospectives psychosociologiques [Values, beliefs and 
religious practices among the Christian youth in Lebanon: Psycho-sociological perspectives]. Zouk Mosbeh: Notre Dame University Press.

Tele Liban (n.d.). About Tele Liban. Retrieved from: http://www.teleliban.com.lb/about

The Arab NGO Network for Development. (2015). The universal periodic review: Lebanon 2015 - Civil society reports. Retrieved from: http://www.annd.org/data/item/pdf/139.pdf

The US Equal Employment Opportunity Commission (EEOC). (2011). Sexual harassment. Equal Employment Opportunity Commission. Retrieved from http://www.eeoc.gov/laws/types/sexual_harassment.cfm

Thomas, D. (2003, August). A general inductive approach for qualitative data analysis. Retrieved from: http://www.frankumstein.com/PDF/Psychology/ Inductive Content Analysis.pdf

Tracy, S. (2013). Qualitative research methods: Collecting evidence, crafting analysis, communicating impact. Oxford: Wiley-Blackwell.

Trombetta, L. (n.d.). Media landscapes: Lebanon. European Journalism Center. Retrieved from: http://ejc.net/media_landscapes/lebanon

United Nations Development Program (UNDP). (2005). The Arab human development report 2005: Towards the rise of women in the Arab world. Retrieved from: http://www.arab-hdr.org/publications/other/ahdr/ahdr2005e.pdf

United Nations, Scientific, Educational and Cultural Organization (UNESCO). (2009). Getting the balance right: Gender equality in journalism. Belgium: International Federation of Journalists.

United Nations: Economic and Social Commission for Western Asia (ESCWA). (2009). Consolidated Arab report on the implementation of the Beijing platform for action: +15. Retrieved from: http://css.escwa.org.lb/ECW/1065/ECW4e6.pdf

United Nations Development Program and Consultation and Research Institute. (2006, March). Mapping of gender and development initiatives in Lebanon United Nations Development Programs - Arab Fund for Economic and Social Development. Arab Human Development Report: Towards the rise of women in the Arab World. Retrieved from: http://www.arab-hdr.org/contents/ index.aspx?rid=4

Van Zoonen, L. (1998). A heroic, unreliable, professional marionette (M/F): Structure, agency and subjectivity in contemporary journalism. European Journal of Cultural Studies, 1(1), 123-143. 
Van Zoonen, L. (1998). Rethinking women and the news. European Journal of Communication, Vol. 3, 35-53.

Van Zoonen, L. (1994; 2006). Feminist media studies. London: Sage Publications.

Wacquant, L. (1989). For a socio-analysis of intellectuals: On "Homo Academicus." Berkeley Journal of Sociology, 34, pp. 1-29. Retrieved from: http://www.jstor.org/stable/41035401

Wacquant, L. (2006). Pierre Bourdieu. In R. Stones (Ed.), Key contemporary thinkers. New York: Macmillan.

Wage Indicator Foundation \& Central European Labour Studies Institute. (2012). Gender pay gap in journalism: WageIndicator global wage report in journalism. Retrieved from: http://www.loonwijzer.nl/home/documents/120307-IFJWageIndicator-PayGap-Journos-2009-2011.pdf

Welsh, E. (2002). Dealing with data: Using NVivo in the qualitative data analysis process. Forum: Qualitative Social Research, 3(2), 1-10. 


\title{
Appendices
}

\author{
Appendix A
}

Ethics Clearance

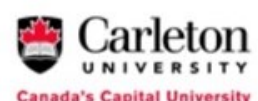

Ethics Clearance Form - New Clearance

\author{
Carleton University \\ Research Ethics Office \\ Research Ethics Board \\ 509C and 511 Tory, 1125 Colonel By Drive \\ Ottawa, ON K1S 5B6 Canada \\ Tel: 613-520-2517, ethics@carleton.ca
}

This is to certify that the Carleton University Research Ethics Board has examined the application for ethical clearance. The REB found the research project to meet appropriate ethical standards as outlined in the Tri-Council Policy Statement: Ethical Conduct for Research Involving Human, 2nd edition, and the Carleton University Policies and Procedures for the Ethical Conduct of Research.

Date of Clearance: September 12, 2014

Researcher: Christy Mady (Student Research: Ph.D. Student)

Department: Faculty of Public Affairs\Journalism and Communications (School of)

University: Carleton University

Research Supervisor (if applicable): Prof. Karim Karim

Project Number: 101807

Alternate File Number (if applicable):

Project Title: How Far They Have Come: Assessing the Status of Women News Journalists in Lebanese Television

Clearance Expires: May 31, 2015

All researchers are governed by the following conditions:

Annual Status Report: You are required to submit an Annual Status Report to either renew clearance or close the file. Failure to submit the Annual Status Report will result in the immediate suspension of the project. Funded projects will have accounts suspended until the report is submitted and approved.

Changes to the project: Any changes to the project must be submitted to the Carleton University Research Ethics Board for approval. All changes must be approved prior to the continuance of the research.

Adverse events: Should a participant suffer adversely from their participation in the project you are required to report the matter to the Carleton University Research Ethics Board. You must submit a written record of the event and indicate what steps you have taken to resolve the situation.

Suspension or termination of clearance: Failure to conduct the research in accordance with the principles of the Tri-Council Policy Statement: Ethical Conduct for Research Involving Humans, 2nd edition and the Carleton University Policies and Procedures for the Ethical Conduct of Research may result in the suspension or termination of the research project.

Andy Adler

Chair, Carleton University Research Ethics Board
Louise Heslop

Vice-Chair, Carleton University Research Ethics Board 


\section{Appendix B}

Demographics of Respondent

Table 12

Editor-in-Chiefs by Gender

\begin{tabular}{lcc}
\hline Television station & Female Editor-in-Chief & Male Editor-in-Chief \\
\hline Tele Liban & 2 & 1 \\
Tele Lumiere & 1 & 0 \\
LBCI & 0 & 2 \\
NBN & 1 & 1 \\
Future TV & 1 & 1 \\
OTV & 1 & 0 \\
New TV & 1 & 0 \\
MTV & 0 & 1 \\
Total & 7 & 6 \\
\hline
\end{tabular}


Appendix C

In-Depth Interview Questions

Communication Program

School of Journalism and Communication

\section{Methodology/Procedures}

Title: How Far They Have Come: Assessing the Status of Women News Journalists in Lebanese Television

Primary Researcher:

Methodology: Qualitative - Interview

Please find below the themes related to the study of women in Lebanese television and the relevant questions to be asked on each theme. The themes will be divided in accordance with the research questions asked within the study.

\section{I - General Questions}

Name

Age

Television Station

Current Position

Years of employment

With this television station :

\section{II- Interview Questions}

The interview questions are based on the five main research questions of the study.

\section{Research Question 1- Theme: Cultural Capital/Skills/Glass Ceiling- Gender}

How does women's cultural capital in terms of education and skills affect women's progression? Are the same skills required of men and women?

1- What did you major in?

2- $\quad$ From which university did you graduate?

3- Does the kind of university you attend affect the position you take in the newsroom?

4- What are your areas of expertise? Can you cover all types of news?

5- How many years of experience do you have?

6- How does experience affect your job progression?

7- $\quad$ Do you get recognized, in terms of bonuses and promotions, based on those skills?

8- $\quad$ Are women and men recognized equally in terms of education and skills? 


\section{Research Question 2- Theme: Social Ties/Patriarchal Connectivity}

How do social and familial ties affect women's hiring and progression within the Lebanese television newsroom?

1- $\quad$ Do you believe that social and familial connections play a role in the employment and progression of newsroom personnel?

2- $\quad$ To what extent are such connections influential?

3- $\quad$ Does the effect of these relationships differ if you are a male or a female?

\section{Research Question 3- Theme: Political and Religious Ties/Glass Ceiling}

How do religious and political beliefs and connections within Lebanese television institutions affect women's share in top-management positions in newsrooms? Why? What are the views of male and female employees on this?

1- $\quad$ Considering that most stations belong to a specific political party, does a person's political affiliation affect their employment, their position or their progression in the job?

2- $\quad$ Considering that most stations belong to a specific religious group, does a person's religious belief affect their employment, their position or their progression in the job?

3- In Lebanon, it is said, it is about "who you know" and "what family you were born into." Can you comment on that in relation to the Lebanese television newsroom?

The Glass Ceiling Concept/Gender

1- $\quad$ Do you believe that women and men can occupy the same positions in a newsroom?

2- What are, in your opinion, the main obstacles that stand before women's career progression?

3- $\quad$ Are management opportunities at your present television station equal for both men and women?

4- $\quad$ Do you think women are well-represented or under-represented at the management level (editor-in-chief, executive producer,...)? Why yes or no?

5- $\quad$ Do you think we should have more women in leadership positions?

\section{Research Question 4 - Theme: Gender/Patriarchy/Coverage}

How does the patriarchal make-up of Lebanon affect the gender dynamic within the newsroom? Is the newsroom, like society, dominated by masculine norms? Are their male and female specific coverage areas and skills? Do age and appearance affect women more than men?

A- Coverage

1- What kinds of news do you cover? (asked to news reporters)

2- $\quad$ Are there news fields that are particular for women and others for men?

B- Gender/Patriarchy

1- $\quad$ Do you think that women receive less appreciation as professionals due to the traditional perception of the role they play in society? 
2- $\quad$ Do you believe that the religious dictates or beliefs that hinder women's progression?

C- $\quad$ Gender

1- To what age do you believe people can work in the newsroom?

2- Does the age bracket differ for men and women?

3- What is the age limit for women news anchors?

4- What is the age limit for men news anchors?

5- $\quad$ Are newsroom personnel scrutinized for their appearance?

6- Does appearance matter more for men or women?

\section{Research Question 5- Theme: Adaptation and Advancement Strategies}

What kind of strategies do women use in the Lebanese television newsroom? Do males and females use the same adaptation and advancement strategies?

Adaptation Strategies

1- $\quad$ Has the newsroom environment taught you to act in certain ways?

2- $\quad$ What ways you believe are effective for becoming successful in this environment?

3- Is there a specific attitude that men or women need to adopt?

4- Do adaptive measures differ between men and women?

5- $\quad$ Is there a specific dress code for the newsroom?

6- Does the dress code differ between men and women?

7- $\quad$ Do you believe there is an unspoken of rule of conduct or behaviour that governs the newsroom environment?

Old Boys' Club

1- Studies on the newsroom describe it as "an old boys" club" - do you agree?

2- What mainly hinders women's progression?

3- $\quad$ How do they avoid the main obstacles that hinder their progression?

4- $\quad$ Do they resist the newsroom environment or go along with it? And how do they do that?

5- $\quad$ Do men use the same strategies as women?

6- $\quad$ Do women have to present compromises to advance? If yes, then what kind of compromises?

7- $\quad$ Can men present the same compromises as women? Why?

8- Do women suffer from sexual advances in the newsroom? What kind of advances?

Are these advances common practice?

9- Why are women more present in the television newsroom than men? 


\section{Appendix D}

Television Stations

\begin{tabular}{|c|c|c|c|c|}
\hline Television Station & $\begin{array}{l}\text { Year } \\
\text { Established }\end{array}$ & Acronym & $\begin{array}{l}\text { Ownership/ } \\
\text { Chairman/ CEO }\end{array}$ & $\begin{array}{l}\text { Political } \\
\text { Affiliation }\end{array}$ \\
\hline Tele Liban & $\begin{array}{l}1959 \text { and } \\
1978\end{array}$ & $\mathrm{TL}$ & State Broadcaster & Non-political \\
\hline $\begin{array}{l}\text { Lebanese Broadcasting } \\
\text { Corporation } \\
\text { International }\end{array}$ & 1985 & LBCI & Pierre El Daher & Pro-Western \\
\hline Murr Television & 1991 & MTV & Gabriel El Murr & $\begin{array}{l}\text { Pro-Western - } \\
\text { Lebanese } \\
\text { Forces }\end{array}$ \\
\hline Orange Television & 2007 & OTV & $\begin{array}{l}\text { Free Patriotic } \\
\text { Movement } \\
(\mathrm{FPM})\end{array}$ & $\begin{array}{l}\text { Free Patriotic } \\
\text { Movement } \\
(\mathrm{FPM})\end{array}$ \\
\hline Al Jadeed & 1992 & & Tahseen Khayyat & $\begin{array}{l}\text { Leftist - Anti- } \\
\text { Govt. }\end{array}$ \\
\hline Future Television & 1993 & FTV & Harriri family & $\begin{array}{l}\text { Future } \\
\text { Political Party }\end{array}$ \\
\hline Al-Manar & 1991 & & Hezbollah & Hezbollah \\
\hline $\begin{array}{l}\text { National Broadcasting } \\
\text { Network }\end{array}$ & 1996 & $\mathrm{NBN}$ & $\begin{array}{l}\text { Al Amal Political } \\
\text { Party }\end{array}$ & $\begin{array}{l}\text { Al Amal } \\
\text { Political Party }\end{array}$ \\
\hline Tele Lumiere & 1991 & & Noursat & $\begin{array}{l}\text { Religious - } \\
\text { Christian }\end{array}$ \\
\hline
\end{tabular}

